THE UNIVERSITY OF MANITOBA

\title{
GRAIN BOUNDARY DEPENDENT CREEP BEHAVIOUR OF INCONEL 718
}

\section{WEIXING CHEN}

\begin{abstract}
A Dissertation Submitted to the Faculty of Graduate Studies in Partial Fulfillment of the Requirements of the Degree of
\end{abstract}

\section{DOCTOR OF PHILOSOPHY}

\author{
Metallurgical Science Laboratory \\ Department of Mechanical Engineering \\ Winnipeg, Manitoba
}

JANUARY, 1995 
National Library

of Canada

Acquisitions and

Bibliographic Services Branch

395 Wellington Street

Ottawa, Ontario

K1A ON4
Bibliothèque nationale

du Canada

Direction des acquisitions et

des services bibliographiques

395, rue Wellington

Ottawa (Ontario)

KIAON4
Your file volre refterence

Our file Notre reterence
THE AUTHOR HAS GRANTED AN IRREVOCABLE NON-EXCLUSIVE LICENCE ALLOWING THE NATIONAL LIBRARY OF CANADA TO REPRODUCE, LOAN, DISTRIBUTE OR SELL COPIES OF HIS/HER THESIS BY ANY MEANS AND IN ANY FORM OR FORMAT, MAKING THIS THESIS AVAILABLE TO INTERESTED PERSONS.
L'AUTEUR A ACCORDE UNE LICENCE IRREVOCABLE ET NON EXCLUSIVE PERMETTANT A LA BIBLIOTHEQUE NATIONALE DU CANADA DE REPRODUIRE, PRETER, DISTRIBUER OU VENDRE DES COPIES DE SA THESE DE QUELQUE MANIERE ET SOUS QUELQUE FORME QUE CE SOIT POUR METTRE DES EXEMPLAIRES DE CETTE THESE A LA DISPOSITION DES PERSONNE INTERESSEES.
THE AUTHOR RETAINS OWNERSHIP OF THE COPYRIGHT IN HIS/HER THESIS. NEITHER THE THESIS NOR SUBSTANTIAL EXTRACTS FROM IT MAY BE PRINTED OR OTHERWISE REPRODUCED WITHOUT HIS/HER PERMISSION.
L'AUTEUR CONSERVE LA PROPRIETE DU DROIT D'AUTEUR QUI PROTEGE SA THESE. NI LA THESE NI DES EXTRAITS SUBSTANTIELS DE CELLECI NE DOIVENT ETRE IMPRIMES OU AUTREMENT REPRODUITS SANS SON AUTORISATION.

ISBN $\quad 0-315-99101-1$

\section{Canadăa}


GRAIN BROUNDARY DEPENDENT CREEP BEHAVIOUR

OF INCONEL 718

BY

WEIXING CHEN

A Thesis submitted to the Faculty of Graduate Studies of the University of Manitoba in partial fulfillment of the requirements of the degree of

DOCTOR OF PHILOSOPHY

(C) 1995

Permission has been granted to the LIBRARY OF THE UNIVERSITY OF MANITOBA to lend or sell copies of this thesis, to the NATIONAL LIBRARY OF CANADA to microfilm this thesis and to lend or sell copies of the film, and LIBRARY MICROFILMS to publish an abstract of this thesis.

The author reserves other publication rights, and neither the thesis nor extensive extracts from it may be printed or other-wise reproduced without the author's written permission. 


\section{Acknowledgement}

I would like to express my heartfelt thanks to my advisor, Dr. M. C. Chaturvedi, for providing me with the opportunity and the financial support to study under his supervision and work on this project. I'm also grateful to him for his precious guidance, encouragement, patience and valuable help during the entire course of my study.

I would like to express my appreciation to Dr. J. R. Cahoon and Dr. N. Richards for their many helpful suggestions and interesting discussions. I would like to thank $\mathrm{Mr}$. John Van Dorp, Mr. Don Mardis and Mr. Roy Hartle for their dedicated technical assistance which make the experimental work a success. Thanks are due to the University of Manitoba for providing me a university graduate fellowship.

Last but not the least, I would like to express my gratefulness to my wife, Yan Xu, for her patience and endless support and encouragement, and to my parents who can always understand and support me. 


\section{ABSTRACT}

This dissertation reports a study on grain boundary dependent creep deformation behaviour of Inconel 718 in the region of power-law dislocation creep. It is proposed that grain boundaries may influence the creep deformation not only exciusively by grain boundary sliding, but also by an alternative mechanism yet to be determined. Existence of this new mechanism is justified by the fact that in the past many results have been explained unsatisfactorily on the basis of models of grain boundary sliding, and also that a few available results, although they are incomplete, are supportive of this concept.

The material used in this study was a wrought commercial precipitation strengthened nickel base alloy Inconel 718. This material was heat treated to produce two types of materials which were different only in the microstructures of their grain boundaries. The grain boundaries of one type were free of precipitates (material A) and those of the second type were decorated with $\delta$-phase particles (material B). Creep tests on specimens with these two microstructures were comparatively conducted at a temperature in the range of $600^{\circ} \mathrm{C}$ to $650^{\circ} \mathrm{C}$ and at constant applied stress in the range of $745 \mathrm{MPa}$ and $860 \mathrm{MPa}$. These creep tests provided a strong evidence of grain boundary dependent creep bahaviour which is distinguished the grain-material dependent creep behaviour in the following three major aspects: (1) It has a secondary creep rate that is independent of the strength of grain material, (2) It shows much stronger dependence of secondary creep rate on applied stress and effective stress as well, (3) It causes the back stress to be dependent on the applied stress and grain boundary microstructure (which includes the grain size and the amount of coverage of precipitates on grain boundaries).

The observed results have been also analyzed and it is proposed that creep deformation of this material involves a grain boundary dependent deformation mechanism that is different from the mechanism of grain boundary sliding. It is suggested that the elastic and plastic incompatibility around grain boundaries caused heterogeneity in the 
distribution of applied stress. This incompatibility is described by a variable $R$, which considers the strengthening state of the grain interior and of the grain boundaries. Partitioning of the applied stress in both regions is, then, quantitatively given by a factor which includes the effect of $\mathrm{R}$ and grain size. Based on these concepts, it is proposed that (1) the incompatibility in material with clean grain boundaries can be eliminated very soon after the stress is applied, and therefore, a uniform distribution of applied stress can be achieved. This may result in a creep behaviour which is dependent on the microstructures of grain interior; (2) In material B, however, the incompatibility can be intensified due to the high stress concentration around densely spaced particles on grain boundaries. This produces a heterogeneity in partitioning of the applied stress to the grain interior and the regions of grain boundaries. As a result, the creep deformation is observed to depend on grain boundary microstructure as well. Results reported in the literature can also be satisfactorily explained on the basis of the proposed mechanism. 


\section{TABLE OF CONTENTS}

\section{ACHNOWLEDGEMENTS}

ABSTRACT

ii

TABLE OF CONTENTS

iv

LIST OF FIGURES

ix

LIST OF TABLES

xvi

CHAPTER ONE INTRODUCTION

CHAPTER TWO LITERATURE REVIEW 4

2.1 INTRODUCTION 4

2.2 GRAIN MATERIAL - CONTROLLED DISLOCATION CREEP 8

2.2.1 Basic consideration $\quad 8$

$\begin{array}{lll}\text { 2.2.1.1 Creep dislocation in grain material } & 8\end{array}$

1. Dislocation velocity $\quad 8$

2. Dislocation climb 9

3. Dislocation density 10

2.2.1.2 General consideration of dislocation creep mechanism 10

1. Dislocation glide - controlled creep model 10

2. Recovery - controlled creep model 11

2.2.1.3 Temperature dependence of creep rate 13

1. Apparent activation energy of creep 13

2. Correlation of experiments determined activation energy 14

3. Relation between activation energy of creep and self-diffusion 15

$\begin{array}{ll}2.2 .1 .4 \text { Stress dependence } & 17\end{array}$

$\begin{array}{ll}\text { 2.2.2 Dislocation creep in pure metals } & 18\end{array}$

$\begin{array}{ll}\text { 2.2.2.1 Dislocation substructures } & 18\end{array}$

2.2.2.2 Temperature and stress dependence 20

1. Recovery - controlled dislocation glide creep model 22

2. Dislocation climb: Nabarro creep $\quad 29$

3. Creep controlled by dislocation glide 32 
2.2.2.3 Harper - Dorn creep $\quad 34$

1. High temperature H-D creep 34

2. Intermediate temperature H -D creep 37

2.2.3 Creep in solid solution alloys $\quad 40$

2.2.3.1 Introduction 40

2.2.3.2 Creep mechanisms 41

2.2.4 Creep in precipitation and dispersion strengthened alloys 45

2.2.4.1 Introduction 45

2.2.4.2 Origin of threshold stress 49

1. Local climb 49

2. General climb 51

3. Co-operative climb 53

\subsection{ROLE OF GRAIN BOUNDARY IN POWER-LAW DISLOCATION CREEP- GRAIN BOUNDARY SLIDING $\quad 60$}

$\begin{array}{ll}2.3 .1 \text { Introduction } & 60\end{array}$

2.3.2 Model of grain boundary sliding 63

2.3.2.1 Intrinsic sliding models 63

2.3.2.2 Extrinsic sliding models $\quad 65$

2.3.3 Contribution of boundary sliding to total creep deformation 70

2.3.4 Experimental results on grain boundary sliding $\quad 75$

2.3.4.1 Measurements of grain boundary sliding 75

2.3.4.2 Comparison with experimental results 77

1. Dependence on stress 77

2. Dependence on temperature $\quad 78$

3. Dependence of grain size $\quad 79$

\subsection{GRAIN BOUNDARY DEPENDENT CREEP BEHAVIOR - INITIATION} OF PRESENT STUDY

2.4.1 Variation of creep rate with grain size $\quad 81$

2.4.1.1 Creep rate is insensitive to grain size 81

2.4.1.2 U-shape dependence of creep rate on grain size 83

1. In fine grain region 83

2. In coarse grain region $\quad 85$ 
2.4.2 Dependence of creep behaviour on grain boundary microstructures 90

2.4.3 Grain boundary dependent creep behaviour 92

2.4.4 Proposal for grain boundary dependent creep study 93

CHAPTER THREE EXPERIMENTAL METHODS 95

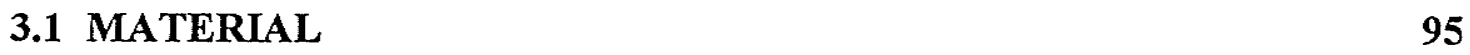

3.2 PREPARATION OF TENSILE AND CREEP SAMPLES 95

3.3 HEAT TREATMENT PROCEDURES 96

3.4 MICROSTRUCTURAL EXAMINATION

3.4.1 Observation of microstructure 97

3.4.2 Measurement of $\gamma^{\prime \prime}$ precipitate size 98

3.4.3 Measurements of grain boundary particle parameters 99

3.4.4 Measurement of grain size 99

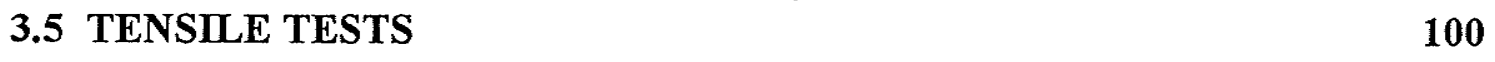

$\begin{array}{ll}\text { 3.6 CREEP TESTS } & 100\end{array}$

$\begin{array}{lll}\text { CHAPTER FOUR } & 102\end{array}$

4.1 MICROSTRUCTURAL CHARACTERIZATION OF INCONEL 718

4.1.1 Microstructureof Inconel 718 102

4.1.2 Microstructure used in this study 103

4.1.2.1 Grain boundary precipitation 103

$\begin{array}{ll}\text { 4.1.2.2 Precipitation within the grains } & 107\end{array}$

4.1.2.3 Variation of grain size with solid solution temperature 107 
4.3 Dependence of creep rate on applied stress 117

4.3.1 Material A

4.3.2 Material B

4.3.3 Effect of back stress

4.4 Dependence of creep rate on temperature

4.5 Effect of grain boundary particle density on creep behavior

4.5.1 Creep deformation

138

4.5.2 Rupture behaviour

4.6 Effect of grain size on creep behavior

4.6.1 Dependence of creep rate on grain size

\section{CHAPTER FIVE DISCUSSION}

5.1.1 Creep mechanism in Material A

5.1.2 Creep mechanism in Material B

5.2 Characterization of grain boundary sliding $\quad 164$

5.2.1 Grain boundary sliding process in material A and material B 164

5.2.2.1 Incubation time for grain boundary sliding 164

5.2.2.2 Incubation time of grain boundary sliding in present materials 168

5.2.2.3 Effect of incubation time on fracture behaviour $\quad 175$

5.2.2 Contribution of grain boundary sliding to total creep strain 179

5.3 Grain boundary dependent creep behavior $\quad 183$

$\begin{array}{ll}\text { 5.3.1 Theoretical basis } & 183\end{array}$

5.3.1.1 Basic consideration $\quad 184$

5.3.1.2 Quantitative description of heterogeneity of applied stress $\quad 188$

1. Nix and Ilshner's consideration 188

2. Partition of Applied stress between grain boundary and grain interior$\begin{array}{ll}\text { based on Hall-Petch relationship } & 190\end{array}$ 
3. Partition of applied stress between grain boundary and grain interiorbased on the deformation behavior of hard and soft region $\quad 194$

5.3.2 Correlation between proposed mechanism and experimental results $\quad 199$

5.3.2.1 On the creep rate dependence 199

1. In the material with clean grain boundaries 199

2. In the material with precipitates at grain boundaries 200

5.3.2.2 On the origin of back stress 210

1. The origin of the back stress due to the microstructure of grain interior

2. Grain boundary dependent back stress 211

5.4 Application to other situation-dependence of creep rate on grain size $\quad 217$

CHAPTER SIX CONCLUSIONS 232

REFERENCES 236 


\section{LIST OF FIGURES}

Fig. 2.1 Schematic representation of the strain/time curves when logarithmic behaviour is observed at low temperatures and when normal creep curves are displayed at temperature above $0 \sim 0.4 \mathrm{Tm}$.

Fig. 2.1a Example of a deformation map. Pure nickel, mean grain diameter $d=1 \mathrm{~mm}$. field A: dislocation glide without participation of recovery; field B: dislocation creep, dislocation core diffusion; field $\mathrm{C}$ : dislocation creep, lattice diffusion: field $\mathrm{D}$ and $\mathrm{E}$ : diffusion Nabarro-Herring and Coble creep respectively. The curves of constant strain rates are shown on the map[3].

Fig. 2.1b Example of deformation map wherein GBS mechanisms are taken into account[3a].

Fig. 2.3 Changes in total dislocation density $\rho_{t}$, free dislocation density $\rho$ and the density of dislocations associated in sub-boundaries, $\rho_{B}$, with the creep strain; alpha iron crept at $873 \mathrm{~K}$ and $75 \mathrm{MPa}[31]$.

Fig. 2.4 Illustration of establishment of creep mechanisms.

Fig. 2.5 Results of measurements of internal stress $\sigma_{i}$ in steady state creep assembled by Takeuchi and Argon[29].

Fig. 2.6 Nabarro model of creep. An arrangement of edge dislocations into the regular three-dimensional network[60]

Fig. 2.7 Schematic representation of stress dependence of creep rate showing Class II $\rightarrow$ Class I $\rightarrow$ Class II transition in solid solution alloys. Stress interval in which Newtonian (diffusional or Harper-Dorn) creep occurs is also shown (d means the grain size)[88]

Fig. 2.8 Schematic illustrations of dislocation configurations perpendicular to and in the glide planed for a) local climb; b) general climb; c) co-operative climb[91].

Fig. 2.9 Model of Lagneborg[106]. a) a relation between the back stress and the applied stress; b) corresponding applied stress dependence of creep rate. 
Fig. 2.10 Typical creep data for a)Nickel containing low volume fractions of incoherent oxide particles[110], and b) a nickel-base superalloy containing high volume fraction of coherent particles[111].after Mclean [91]

Fig. 2.11 Model of Mclean[91]: minimum flow resistance--or threshold stress for the three particle by-pass-mechanisms as a function of volume fraction of $\gamma^{\prime}$-phase particle fro various applied stresses using parameters relevant to directionally solidified IN 738LC alloy stressed parallel to $\langle 100\rangle$.

Fig. 2.12 Deformation in a polycrystal for a)Rachinger sliding and b) Lifshitz sliding in a material with a mesoscopic grain size and c) superplasticity in a material with a microscopic grain size; the tensile axis is vertical [118].

Fig. 2.13 An example of a triple point fold (A) formed in high-purity aluminum due to intergranular sliding on boundary B. Specimen deformed to 7.8 percent at $573 \mathrm{~K}$ under a stress of 3.5 MPa: grain size $=535 \mu \mathrm{m}$. The stress axis is vertical[126]

Fig. 2.14 Contours of normalized shear strain rate $\dot{\gamma}_{x y} / \dot{\gamma}_{A}$ during steady-state creep fro a grain obeying power law creep ( with exponents of 1.0, 4.4 and 8.8 ) surrounded by freely sliding boundaries. The fourth quadrant shows a typical mesh of elements[128].

Fig. 2.15 A typical stress - strain rate plot in dimensionless $\bar{\gamma} / G \eta_{B}{ }^{*}-\bar{\tau} / G$ coordinates, computed from the finite element model. The transition strain rate is adequately located by the intersection of the power-law creep curve for the grains $\dot{\gamma}=A(\bar{\tau} / G)^{n}$ with the flow law for the grain boundary, normalized to the grain size $\dot{\gamma}=\left(\delta_{B} / d\right)\left(\bar{\tau} / \eta_{B}\right)$ [128].

Fig. 2.16 Stress enhancement factor $f$ as a function of reciprocal stress exponent, $1 / n$ [139].

Fig. 2.17 a) A deformation mechanism map for pure aluminum of grain size $316 \mu \mathrm{m}$ and ledge $h=0.01 \mu \mathrm{m}$ showing the sub-fields of power-law creep in which GBS is extensive and in which it is negligible. $b$ ) in a) but for a ledge height $h=0.1 \mu \mathrm{m}$ (i.e., for a boundary viscosity which is 100 times greater)[128]

Fig. 2.18 Displacement vectors for a general sliding boundary[124]. 
Fig. 2.19 The grain size dependence of the secondary creep rate of polycrystalline copper at $20.68 \mathrm{MPa}$ and $769 \mathrm{~K}[158]$. o: sample deformed $50 \%$ and annealed for different times at $973 \mathrm{~K}, \Delta$ : samples deformed varying amounts before a fixed anneal at $973 \mathrm{~K}, \square$ : samples deformed $50 \%$ and annealed at temperatures in the range 1123 to $1323 \mathrm{~K}$.

Fig. 2.20 Dependence of secondary creep rate on grain size for an iron-base austenitic alloy steel at $704{ }^{\circ} \mathrm{C}[160]$.

Fig. 2.21 Variation of steady state creep rate $\dot{\varepsilon}_{s}$ with grain size at various stresses for 873 $\mathrm{K}[168]$.

Fig. 2.22 Plots of $\log \dot{\varepsilon}_{s} v \cdot d^{-1 / 2}$ at $873 \mathrm{~K}$ for different stresses (d is grain size ) [168].

Fig. 2.23 Existence of an optimal grain size for which the minimal creep rate $\dot{\varepsilon}_{s}$ is lowest [174].

Fig. 3.1 Dimension of creep and tensile specimens.

Fig. 4.1 TEM image showing clean grain boundaries in material A.

Fig. 4.2 SEM images showing precipitates at grain boundaries in material B after furnace cooling from solid solution treatment at $1020^{\circ} \mathrm{C}$ for 4 hours.

Fig. 4.3 Microstructures of the materials being partially solid solution treated after furnace-cooling. The partial solid solution temperature is a) $900{ }^{\circ} \mathrm{C}$, b) $925^{\circ} \mathrm{C}$, c) $975^{\circ} \mathrm{C}$, d) $1000^{\circ} \mathrm{C}$.

Fig. 4.4 The effect of partial solid solution temperature on the distribution parameters of $\delta$ precipitates at grain boundaries.

Fig. 4.5 TEM images showing precipitates of $\gamma^{\prime \prime}$ in material A (a) and material B (b).

Fig. 4.6 Variation of $\gamma^{\prime \prime}$-size with aging time at $725^{\circ} \mathrm{C}$.

Fig. 4.7a SEM images of precipitates of the $\delta$ phase at grain boundaries. The materials have been aged at $725^{\circ} \mathrm{C}$ for $25 \mathrm{~h}(\mathrm{a})$ and $50 \mathrm{~h}(\mathrm{~b})$.

Fig. 4.7b Dark field TEM images of $\gamma^{\prime \prime}$ of grain interiors. The materials have been aged at $725^{\circ} \mathrm{C}$ for $25 \mathrm{~h}$ (a) and $50 \mathrm{~h} \mathrm{(b).} \mathrm{In} \mathrm{(a)} d_{\gamma^{\prime \prime}}=17.3 \mathrm{~nm}$, in (b) $d_{\gamma^{\prime \prime}}=21.2 \mathrm{~nm}$.

Fig. 4.8 Variation of grain size with solid solution temperature. 
Fig. 4.9 Change of creep rate with creep strain for the materials with various sizes of $\gamma^{\prime \prime}$. The creep test was conducted at $770 \mathrm{MPa}$ and $625^{\circ} \mathrm{C}$.

Fig. 4.10 Dependence of steady state creep rate on the size of $\gamma^{\prime \prime}$.

Fig. 4.11a) Variation in creep rate with creep strain in material A tested at $600{ }^{\circ} \mathrm{C}$.

Fig. 4.11b) Variation in creep rate with creep strain in material A tested at $600^{\circ} \mathrm{C}$.

Fig. 4.12 Variation in creep rate with creep strain in material A tested at $625^{\circ} \mathrm{C}$.

Fig. 4.13 Dependence of creep rate on applied stress in material A and B.

Fig. 4.14a, b Creep rate versus creep time for material B tested at $600{ }^{\circ} \mathrm{C}$.

Fig. 4.14c Creep rate versus creep time for material B tested at $625^{\circ} \mathrm{C}$.

Fig. 4.14d Creep rate versus creep time for material B with a grain size of $175 \mu \mathrm{m}$.

Fig. 4.14e Creep rate versus creep strain for material B with a grain size of $175 \mu \mathrm{m}$

Fig. 4.15 Dependence of creep rate on applied stress obtained in material B tested at two temperature levels.

Fig. 4.16 Relationship between cumulative incubation time and remaining applied stress.

Fig. 4.17 Dependence of back stress on applied stresses at $625^{\circ} \mathrm{C}$.

Fig. 4.18 Dependence of minimum of steady state creep rate on effective stress.

Fig. 4.19 Determination of the value of apparent activation energy.

Fig. 4.20 Effect of temperature on back stress at the initial applied stress of $820 \mathrm{MPa}$.

Fig. 4.21 Determination of the values of effective activation energy.

Fig. 4.22 Creep rate versus creep strain for the material with different precipitate density at grain boundaries.

Fig. 4.23 Variation of steady state creep rate with the density of precipitates at grain boundaries.

Fig. 4.24 Relationship between remaining applied stress and cumulative time for the material with different grain size.

Fig. 4.25 Variation of back stress with the density of precipitates at grain boundaries 
Fig. 4.26 Creep curves obtained from the test at $625^{\circ} \mathrm{C}$ an $795 \mathrm{MPa}$ on the materials with various precipitate density at grain boundaries.

Fig. 4.27 Dependence of total creep strain and rupture time on precipitate density at grain boundaries.

Fig. 4.28 SEM fractographs of the materials solid solution treated at a) $900{ }^{\circ} \mathrm{C}$, b) 925 $\left.{ }^{\circ} \mathrm{C}, \mathrm{c}\right) 975^{\circ} \mathrm{C}$, d) $1020^{\circ} \mathrm{C}$ and creep tested at $625^{\circ} \mathrm{C}$ and $795 \mathrm{MPa}$.

Fig. 4.29 Wedge cracks at the triple points of grain boundaries are often observed in the material with clean grain boundaries (a), and with a partial solid solution temperature at $975^{\circ} \mathrm{C}(\mathrm{b})$ and higher. Void-formed cracks are mainly found in the material with a solid solution temperature at $925^{\circ} \mathrm{C}(\mathrm{c})$ and $900^{\circ} \mathrm{C}(\mathrm{d})$.

Fig. 4.30a Variation of creep rate with creep time for material A tested at $770 \mathrm{MPa}$ and $625^{\circ} \mathrm{C}$.

Fig. 4.30b Creep rate versus creep strain for material $A$ tested at $625^{\circ} \mathrm{C}$ and $770 \mathrm{MPa}$.

Fig. 4.31 Creep rate versus creep strain for material B with different grain size.

Fig. 4.32 Dependence of creep rate on grain size.

Fig. 4.33 Dependence of creep rate on applied stress for material B with various grain size.

Fig. 4.34 Dependence of back stress on grain size for both material A and B. The test was conducted at $625^{\circ} \mathrm{C}$, the initial applied stress is $770 \mathrm{MPa}$.

Fig. 4.35 Dependence of steady state creep rate on effective stress for material B at two levels of grain size.

Fig. 4.36 Dependence of steady state creep rate on grain size for material B at a given effective stress of $168 \mathrm{MPa}$.

Fig. 5.1 Schematic aging hardening curves illustration the particle size of the optimum high temperature creep resistance and the particle size in the material used in present studies. 
Fig. 5.2 Relaxation of shear stress along a sliding grain boundary between boundary particles by viscous sliding of the boundary [210].

Fig. 5.3 Microstructures of grain boundaries in material B. The material has been tested and interrupted at a) position $A, b$ ) position $B$, c) position $C$ as in Fig. 4.15.

Fig. 5.4 Size distribution of grain boundary precipitates in the material with a second solid solution treatment at $975^{\circ} \mathrm{C}$ for one hour.

Fig. 5.5 Schematic diagrams illustrating the dependence of creep time of creep strain on particle density at grain boundaries.

Fig. 5.6 SEM photos showing the microstructure on the intergranular surface of the material with a precipitate density at grain boundaries of $67 \%$ and $45 \%$, respectively.

Fig. 5.7 Dependence of creep rate in primary stage on creep time in the material with clean grain boundaries.

Fig. 5.8 Sequence of stages in polycrystalline deformation, starting with (a, B) localized plastic flow in the grain-boundary regions ( microyielding), forming a grain-boundary work-hardened layer ( $\mathrm{c}, \mathrm{d})$ that effectively reinforces the microstructure, and leading to $(e, f)$ macroyielding in which the bulk of the grains undergo plastic deformation[211].

Fig. 5.9 Intergranular substructures developing: a) at high strain rates and/or low temperatures; b) at high temperatures and/or small flow rates where recovery processes are important[170].

Fig. 5.10 A model of the internal stress due to elastic bending of sub-boundaries: $\tau_{i}^{B}$ is the internal stress field of sub-boundaries; because of $\tau_{i}^{B}$ the local stress $\tau-\tau_{i}^{B}$ is high at the sub-boundaries and low in the subgrain interior [215].

Fig. 5.11 variation of the local stress with distance from a sub-boundary for different creep strains; $\mathrm{Al}-11 \mathrm{Zn}$ solid solution alloy crept at $523 \mathrm{~K}$ and $8 \mathrm{MPa}$.

Fig. 5.12 Diagram showing a cubic grain with a thickness of $2 t$ is applied with a stress $\sigma_{a}$.

Fig. 5.13 Variation of yielding stress with $\gamma^{\prime \prime}$-disc diameter. 
Fig. 5.14 Dependence of steady state creep rate on modified stress $\sigma_{a o}{ }^{\prime}$, for material B with different grain size.

Fig. 5.15 Dependence of creep rate on grain size.

Fig. 5.16 Dependence of $1 / \sigma_{a}$ on $1 / \sqrt{d}$.

Fig. 5.17 Predicted variation in creep rate with grain size at two different levels of $d_{o}$. The stress exponent is assumed to be 5.0 .

Fig. 5.18 The predicted variation in creep rate with grain size at different values of stress exponent. The value of $d_{o}$ is assumed to be $1 \mu \mathrm{m}$.

Fig. 5.19 Dependence of creep rate on grain size ( Garafalo's work ) [160]

Fig. 5.20 Variation of stress exponent with grain size ( Garafalo's work) [160].

Fig. 5.21 Correlation between the predicted dependence of creep rate on grain size and experimental results.

Fig. 5.22 Relationship between the applied stress and the value of B.

Fig. 5.23 Relationship between the applied stress and the value of $d_{o}$. 


\section{LIST OF TABLE}

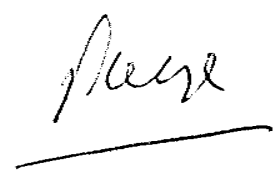

Table 2.1 The dependence of creep rate on applied stress

Table 2.2 Creep is controlled by recovery process

Table 2.3 Dislocation creep mechanisms in solid solution alloys

Table 2.4 Creep models for precipitate-strengthened alloys

Table 2.5 Definition of grain size ranges showing similar characteristics [114]

Table 2.6 Comparison of the stress exponent in polycrystals [126]

Table 2.7 A comparison of the activation energies for GBS [126]

Table 2.8 An unified explanation for grain boundary sliding

Table 2.9 Stress exponents and activation energies for steady state creep and calculated back stress values for specimens without and with grain boundary carbides [175]

Table 3.1 Chemical composition of Inconel 718 (wt. \%)

Table 3.2 Heat treatment schemes for Inconel 718

Table 3.3 Etchants used for Inconel 718 in this study

Table 4.1 Typical phases present in wrought Inconel 718

Table 4.2 Summary of apparent stress exponent for material A and B

Table 4.3 Experimentally determined values of activation energy of creep

Table 5.1 Characterization of grain boundary sliding in the material with grain boundary precipitates

Table 2.1 Variation in stress factor for grain material with $d_{o}$

Table 5.2 Variation of stress factor for grain boundaries with $d_{o}$

Table 5.3 Modification of applied stress by the stress factor given in Eqn. 5.33

Table 5.4 Parameters used for calculations 


\section{CHAPTER ONE INTRODUCTION}

In the power-law dislocation creep region, creep deformation is assumed to be caused by two sources (assuming. that macro defects are not introduced in the material).

These are, (1) deformation from the grain interior, and (2) deformation from the grain boundaries due to grain boundary sliding. The grain boundary sliding is considered to provide an extra contribution to the total creep strain, and is assumed not to influence the creep mechanism occurring in the grain interior. Therefore, is not normally included in the creep equation.

With the above considerations, one question can be asked; are there any other mechanisms through which creep behaviour in the power-law dislocation creep region can be influenced by grain boundaries? The answer to this question is, "yes" when a material is deformed at low temperatures. At these temperatures, grain boundaries are considered to provide an strengthening effect and the grain boundary dependent deformation behaviour is described by the well-known Hall-Petch relationship.

However, at a temperature higher than $0.5 \mathrm{Tm}$, the answer to this question is very controversial. First of all, it is generally believed that grain boundaries at this high temperature have a softening effect. Due to this belief, the deformation of grain boundaries is ignored except for grain boundary sliding. However, this commonly held belief is in fact not related to the question raised above, since the grain boundary strengthening is not because of inhibition of grain boundary sliding in the low temperature region. It is because of a mechanism that has nothing to do with grain boundary sliding but a mechanism that can provide resistance to the deformation of the grain interior. Therefore, the current consideration of a grain boundary as having a softening effect is due to the observation of grain boundary sliding., not due to the invalidity of the mechanism that operates at low temperatures. 
Secondly, the experimental results concerning the effect of grain boundaries on creep behaviour are very often contradictory to each other. For example, in one study, the creep rates were observed to be independent of grain size, but in another, they were found to be strongly dependent on grain size. In many cases attempts to explain the effect of grain boundaries on creep behaviour by the model of grain boundary sliding have been unsuccessful ( refer to Chapter Two). These unsuccessful attempts may, therefore, suggest a positive answer to the question raised at the beginning of this chapter; that is, do the grain boundaries influence creep behaviour through a mechanism which is different from the mechanism of grain boundary sliding. This question is often given an affirmative answer by the experimental results (see section 2.4.3)

The argument above provides the rationale of the existence of a grain boundary dependent creep mechanism which is not identical to the mechanism of grain boundary sliding. To understand this mechanism, however, research both on experimental and theoretical bases is required. This was the intention of the present investigation.

The study of grain boundary dependent creep can be carried out by using material with appropriate grain boundary microstructures. The microstructures of grain boundaries can be changed by micro alloying and by heat treatment. In this study, the heat treatment method has been used to produce materials with microstructures that are different only at the grain boundaries. That is, the strength of grain material is the same but that of the grain boundaries is different from one material to another. The two type of materials have been creep deformed and the influence of grain boundaries on the overall creep deformation has been studied.

In Chapter two of this dissertation, the relevant literature has been reviewed which is followed by a description of the scope of the research carried out in this study. Chapter three describes various research techniques used and the experimental results are provided in Chapter Four. The results are discussed in Chapter Five with reference to the currently held beliefs and available models. An attempt has also been made to point out their 
inadequacies and a new model has been suggested which can not only explain the results obtained in this study but results reported by other investigators as well. 


\section{CHAPTER TWO LITERATURE REVIEW}

\subsection{INTRODUCTION}

When a material is subjected to a static external load, individual atoms adjust their positions in such a way that the equilibrium between external forces and interatomic forces is maintained. Macroscopically, the adjustment of atomic position is manifested as deformation.

The deformation, which is the response of a material to applied stress, generally may have three components: elastic, anelastic and plastic. The elastic strain is time independent and reversible, its magnitude is a single valued function of the stress. The anelastic deformation, like elastic deformation is reversible, but in contrast to the elastic deformation, it is time dependent. Plastic deformation is irreversible and leads to a permanent change in the form of a body. Generally, it consists of time dependent and time independent components. The time dependent component of plastic deformation is designated as creep.

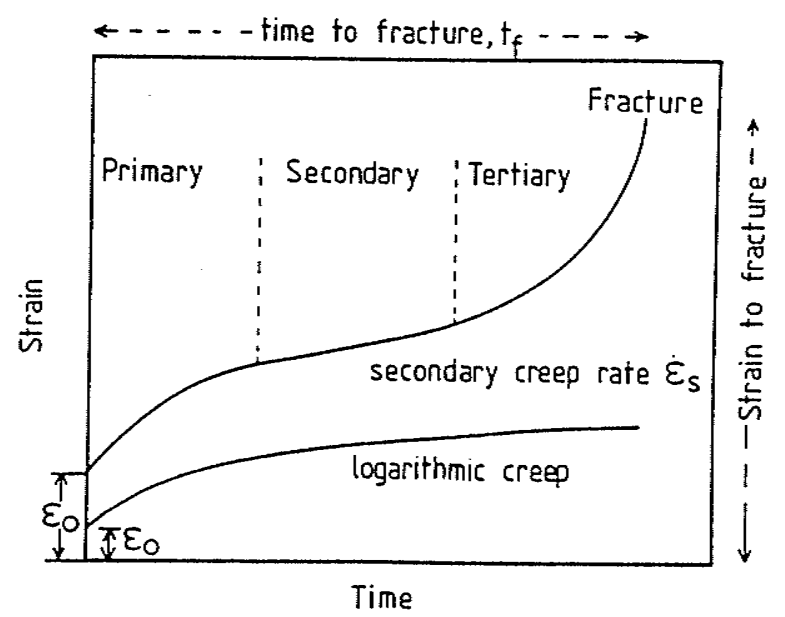

Fig. 2.1 Schematic representation of the strain/time curves when logarithmic behavior is observed at low temperatures and when normal creep curves are displayed at temperatures above $0 \sim 0 . f T_{m}$ 
The graphical representation of the time dependence of strain is known as the creep curve. This curve, shape of which is a function of stress and temperature, characterizes one or two stages of creep, and possibly the third stage, if the stress or temperature is high enough. When all three stages take place, the form of the creep curve is as illustrated in Fig. 2.1. The first stage during which, possibly after an instantaneous strain $\varepsilon_{o}$, the creep rate $\dot{\varepsilon}$ decreases with time is called the primary stage or transient creep (in Fig. 2.1). At low homologous temperatures, only this stage of creep is observed. The creep rate decreases with time and finally reaches a negligible value. In the second stage, which is also known as the steady-state or secondary creep, the creep rate is time invariant. This creep rate is designated as steady-state or secondary creep rate $\dot{\varepsilon}_{s}$. The steady-state creep takes place only at relatively high homologous temperatures, at which the recovery rate is sufficiently high to compensate the effects of deformation strengthening at any instant of time.

For several decades, considerable effort has been spent in describing the time dependence of creep strain, i.e., the creep curve, quantitatively. The approach to such a description was predominantly empirical during the period of $1930-60[1,2]$, however it has become phenomenological and physical during last 30 years. The description of creep curves, no matter which approach is used, may be useful from the point of view of the needs of engineering practice. However it is not very helpful in understanding the physical mechanism in terms of dislocation motion, which is the area of interest during the last three decades and is also the focus of the present research project.

During the plastic deformation of a polycrystalline materials, the total strain can consists of the following components

$$
\varepsilon=\varepsilon_{d g}+\varepsilon_{n}+\varepsilon_{g b}+\varepsilon_{d}+\varepsilon_{v}
$$


where $\varepsilon_{d g}, \varepsilon_{n}, \varepsilon_{g b}, \varepsilon_{d}$, and $\varepsilon_{v}$ are the strains caused by dislocation glide, non-conservative motion of dislocations, grain boundary sliding, stress directed diffusion of vacancies and intercrystalline void nucleation and growth, respectively.

The significant contribution of each component to the total strain depends on the temperature and the magnitude of applied stress. This can be demonstrated through deformation map as shown in Fig. 2.2a[3].

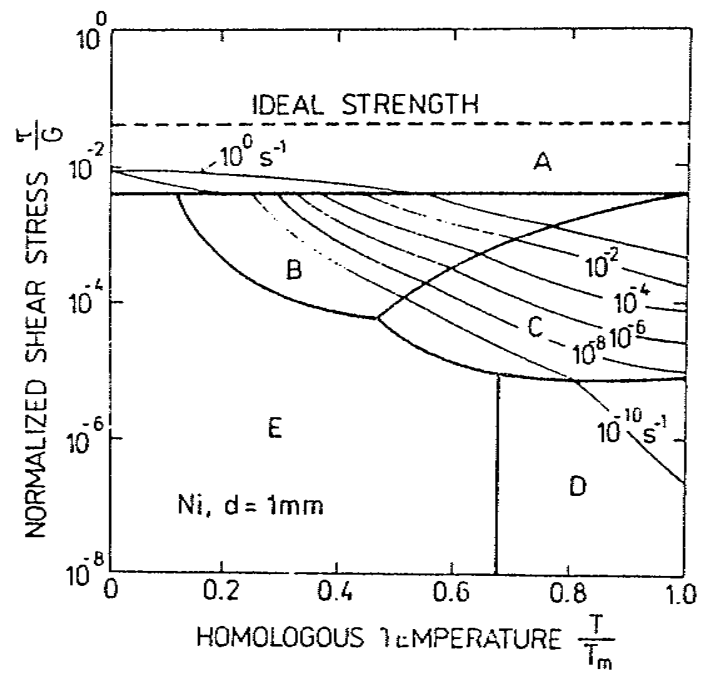

Fig. 2.2a Example of a deformation map. Pure nickel, mean grain diameter $d=I \mathrm{~mm}$. field A-dislocation glide without participation of recovery; Field B-dislocation creep, dislocation core diffusion: Field $C$-dislocation creep, lattice diffusion: Field $D$ and E- diffusion Nabarro-Herriing and Coble creep respectively. The curves of constant strain rates are shown on the map[3].

In region A dislocation glide is dominant and takes place at relatively low homologous temperatures and high strain rates. In this region the dislocation density increases which manifests itself by an increase in plastic strain with stress.

Regions $\mathrm{D}$ and $\mathrm{E}$ are diffusional creep regions. Diffusional creep takes place through stress-directed diffusional mass transport without any participation of lattice 
dislocations. This possibility was considered for the first time by Nabarro[4] in 1948 and

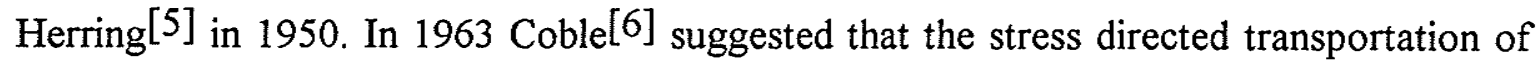
mass by diffusion need not take place via the crystal lattice as assumed by Nabarro and Herring, instead it can occur via grain boundaries (region E). The mechanism of diffusional creep has been well studied but will not be addressed in this literature review since it is not relevant to the research reported in this dissertation.

In dislocation creep region [ region $\mathrm{B}$ (dislocation core diffusion) and region $\mathrm{C}$ (lattice diffusion)], the deformation due to intercrystalline void nucleation and growth may play a significant role only when polycrystal integrity is damaged. Therefore, two factors which may have to be considered for the total deformation in dislocation creep region are (1) deformation in the grain material, (2) deformation in the grain boundaries.

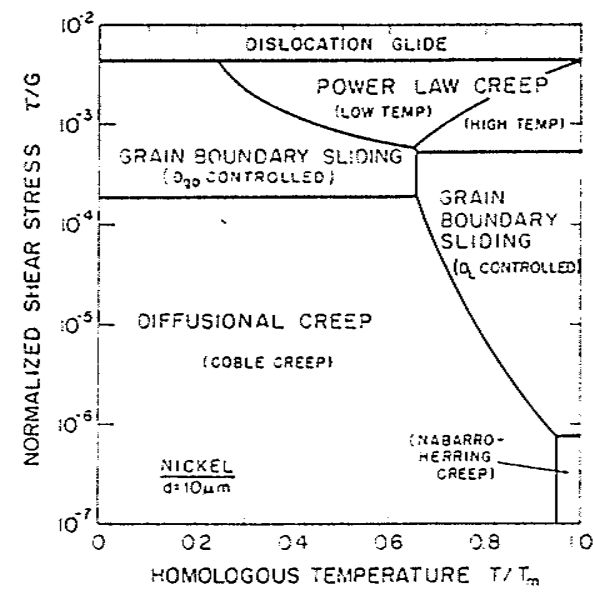

Fig. 2.2b Example of deformation map wherein GBS mechanisms are taken into account $[3 a]$.

It should be noted that grain boundary sliding is not considered an individual deformation mechanism in Fig. 2.2a since this mechanism would dominate only when superplastic deformation occurs, especially in the material with rather small grain size. However, if it does occur, grain boundary sliding may become an individual deformation 
mechanism and can be included in the deformation map as shown in Fig. 2.2b[3a]. Under normal power-law dislocation creep, grain boundary sliding is not significant, though it does have an influence on the total creep rate (refer to section 2.3).

\subsection{GRAIN MATERIAL-CONTROLLED DISLOCATION CREEP}

\subsubsection{BASIC CONSIDERATIONS}

\subsubsection{CREEP DISLOCATIONS IN GRAIN MATERIAL \\ 1. DISLOCATION VELOCITY}

In tensile testing, dislocations can overcome the local barrier on the slip plane without a significant assistance by thermal activation. In creep testing, however, the applied stress is constant and less than the level which can cause a dislocation to overcome the local barriers, therefore, thermal activation is needed to help a dislocation move from one stable configuration to another. When the barrier is a stress field $\left(\sigma_{i}\right)$ created by other dislocations, the effective stress $\sigma^{*}$ acting on the mobile dislocation will be reduced as shown in the following expression:

$$
\sigma^{*}=\sigma-\sigma_{i}
$$

where $\sigma$ is the macroscopically homogeneous external (applied) stress.

The velocity of dislocation in this thermally activated mode, $u^{*}$ can be defined as [7] 


$$
v^{*}=v_{o} \exp \left(\frac{-\Delta G}{k T}\right)
$$

where $\Delta G$ is the free activation enthalpy; the quantity $v_{o}$ can, in the first approximation, be interpreted as the maximum attainable dislocation glide velocity. The free activation enthalpy $\Delta G$ can be considered to consist of a part, $\Delta G_{o}$, which does not depend on effective stress, and a part which does depend on effective stress[8]. That is,

$$
\Delta G=\Delta G_{o}-b \int_{0}^{\sigma^{*}} A^{*} d \sigma^{*}
$$

where $b$ is the length of Burgers vector and $A^{*}$ is the activation area, which is defined by the following expression

$$
A^{*}=-\frac{1}{b}\left(\frac{\partial \Delta G}{\partial \sigma^{*}}\right)_{T}=\frac{k T}{b}\left(\frac{\partial \ln v^{*}}{\partial \sigma^{*}}\right)_{T}
$$

Therefore, $v^{*}$ can be expressed by the following expression,

$$
v^{*}=v_{o} \exp \left(\frac{-\Delta G}{k T}\right) \exp \left[\frac{b}{k T} \int_{0}^{\sigma^{*}} A^{*} d \sigma^{*}\right]
$$

\section{DISLOCATION CLIMB}

A dislocation can also climb over a physical barrier or only that part of a dislocation which hindered the motion of the entire dislocation may disappear. This can be done by the emission and or absorption of vacancies by the dislocation and /or by other long range source. By this consideration the velocity of a dislocation is given by[9]

$$
v_{c}=\frac{2 \pi D_{L} \Omega \sigma}{b k T \ln \left(R / r_{o}\right)}
$$


where $r_{o}$ is the dislocation core radius, $\mathrm{R}$ is the distance from the dislocation line on which the vacancy concentration reaches the thermal equilibrium value $C_{O}, D_{L}$ is the coefficient of lattice diffusion and $\Omega$ is the atomic volume.

Eqn. 2.7 has been modified by considering the factors that influence the value of $R[10,11]$. These include the effect of non-symmetrical distribution of vacancies round the dislocation, the geometrical patterns of vacancy diffusion, as well as the stacking fault energy

\section{DISLOCATION DENSITY}

Two different types of dislocations can be distinguished from each other during creep in terms of their influence on creep deformation. (1) Free dislocations: these are not associated with subboundaries and remain arranged in the matrix in a three-dimensional network during steady-state creep stage. (2) Mobile dislocations: these are potentially mobile free dislocations. Moving dislocations represent a fraction of mobile dislocations which are actually moving. The total dislocations is the sum of free dislocations and the dislocations associated with subboundaries.

\subsubsection{GENERAL CONSIDERATION OF DISLOCATION CREEP MECHANISMS}

Two groups of models of dislocation creep are often considered: dislocation glide controlled creep models and recovery-controlled creep models

\section{DISLOCATION GLIDE-CONTROLLED CREEP MODELS}

These models are based on the assumption that the recovery occurs so quickly that it does not limit the creep rate, and consequently the creep deformation is controlled by 
dislocation glide. Therefore, recovery is not considered. Under this assumption, the plastic strain rate of crystalline solids is described by the well-known Orowan equation $[12,13]$.

$$
\dot{\varepsilon}=\rho_{m} b v^{*}
$$

where $\rho_{m}$ is the mobile dislocation density, which is proportional to the density of free dislocations $\rho$. That is,

$$
\rho_{m}=K_{m} \rho
$$

where $K m$ is a constant. The free dislocation density is related to applied stress by the following expression[14]:

$$
\rho=\frac{1}{b^{2}}\left(\frac{\sigma}{G}\right)^{2}
$$

By combining Eqns. 2.8, 2.9 and 2.10, the creep rate can be expressed by the following equation.

$$
\dot{\varepsilon}=K_{o} \frac{2 \pi}{b^{2}} D_{L} \frac{G \Omega}{k T}\left(\frac{\sigma}{G}\right)^{3}
$$

where $K_{o}=K_{m} / \ln \left(R / r_{o}\right)$ is a dimensionless constant.

\section{RECOVERY-CONTROLLED CREEP MODELS}

These models are based on the assumption that creep is controlled by recovery, i.e. by a process which compensates to some extent the effects of deformation strengthening that results from an increase in dislocation density and the formation of various dislocation 
arrangements. In these models, generally, it is accepted that the steady state could not be established. That is, the recovery did not proceed quickly enough to ensure that the quantitative characteristics of dislocation structure are independent of time. These characteristics include the density of free dislocations $\rho$, the mean subgrain diameter $d_{s}$, the mean angle of misorientation of neighbouring subgrains $\Theta$ and the characteristics derived from $\rho, d_{s}$ and $\Theta$, i.e., the density of dislocations forming sub-boundaries $\rho_{B}$ and the total dislocation density $\rho_{t}$. Therefore, the models of recovery controlled creep involve recovery mechanisms.

To describe the rate of high temperature recovery controlled creep, Orowan expression (Eqn. 2.8) and the Bailey-Orowan expression[12, 15], described below, are frequently used:

$$
\dot{\varepsilon}=\frac{r}{h}
$$

Here $r$ is the rate of recovery and $h$ the coefficient of deformation strengthening.

The Bailey-Orowan equation has been found to be equivalent to Orowan equation in the following form $[16]$ :

$$
\dot{\varepsilon}=\rho_{m} b v_{c} \frac{L}{h_{c}}
$$

where $L$ is the glide distance along a path parallel to the glide plane, $h_{c}$ is the climb distance in a direction normal to the glide plane. From this expression the creep rate equation can be modified to:

$$
\dot{\varepsilon}=K_{o} \frac{2 \pi}{b^{2}} D_{L} \frac{L}{h_{c}} \frac{G \Omega}{k T}\left(\frac{\sigma}{G}\right)^{3}
$$


If the constant $K_{O}$ and the structure factor $L / h_{c}$ do not depend on stress, the creep rate is proportional to the third power of stress, which is in agreement with Weertman's analysis [17]. Thus, the usually observed stress dependence of steady state creep rate of pure metals and single phase alloys, behaving as Class II solids, can be explained only in that either the ratio of structural parameters $L / h_{c}$ or the constant $K m$ is a function of stress. The latter implies that the density of mobile dislocations, $\rho_{m}$, increases with stress more quickly than the free dislocation density, $\rho$.

\subsubsection{TEMPERATURE DEPENDENCE OF CREEP RATE}

\section{APPARENT ACTIVATION ENERGY OF CREEP}

Generally, the dependence of creep rate on temperature is described by the Arrhenius law

$$
\dot{\varepsilon}=\dot{\varepsilon}_{o} \exp \left[-\frac{Q_{c}}{k T}\right]
$$

where $Q_{c}$ is the activation energy of creep and $k$ is the Boltzman's constant. $\dot{\varepsilon}_{o}$ is the frequency factor and has the same dimension as the strain rate $\dot{\varepsilon}$.

Eqn. 2.15 reflects the fact that creep involves thermally activated process and thermally activated mechanisms operating on atomic scale. If one of these mechanisms dominates, and thus controls the creep rate, the activation energy of creep $Q_{\mathcal{C}}$ is identical to the activation energy of this particular mechanism, or is at least in an immediate relation to it. Therefore, $Q_{c}$ has a definite physical meaning.

Eqn. 2.15 can also be written as: 


$$
\begin{aligned}
& \text { or } Q_{c}=\left[\frac{\partial \ln \dot{\varepsilon}_{s}}{\partial-1 / k T)}\right]_{\sigma} \\
& \text { and } \ln \dot{\varepsilon}=\ln \dot{\varepsilon}_{o}-\frac{Q_{c}}{k T}
\end{aligned}
$$

From Eqn. 2.17, it follows that when $Q_{c}$ is not a function of temperature, the relationship between $\ln \dot{\varepsilon}$ and $l / T$ is linear and thus, the activation energy $Q_{c}$ is equal to the product of $k$ and the slope of $\ln \dot{\varepsilon}-1 / T$ plot. However, when two or more mechanisms with different activation energies contribute to the creep rate to a comparable extent the $\ln \dot{\varepsilon}-1 / T$ plot is no longer linear. In this case, the activation energy depends on temperature, and represents only a phenomenological quantity. However, this situation, if ever occurs, can usually be satisfactorily analyzed. From Eqns. 2.15 and 2.17, it follows that when $\dot{\varepsilon}_{o}=\dot{\varepsilon}_{o}(T)$, the activation energy

$$
Q_{C}=\Delta H_{C}+\left[\frac{\partial \ln \dot{\varepsilon}_{o}}{\partial-1 / k T)}\right]_{\sigma}
$$

where $\Delta H_{c}$ is the activation enthalpy of creep.

\section{CORRELATION OF EXPERIMENTS DETERMINED ACTIVATION}

\section{ENERGY}

From an analysis of extensive experimental data, it has been concluded that the frequency factor in Eqn. 2.15, $\dot{\varepsilon}_{o}$, can be expressed as [18] 


$$
\dot{\varepsilon}_{o}=A\left(\frac{\sigma}{E}\right)^{n}
$$

where $n$ in a constant, $A$ is a factor independent of both temperature and stress and $E$ is the Young's modulus.

From Eqns. 2.18 and 2.19, it follows that

$$
Q_{c}=-\Delta H_{c}-n k \frac{T^{2}}{E} \frac{d E}{d T}
$$

Generally $d E / d T<0$, so that $Q_{c}>\Delta H_{c}$. A theoretical analysis has led to the conclusion that the description of creep by the following equation

$$
\dot{\varepsilon}_{s}=A\left(\frac{\sigma}{G}\right)^{n-1} \frac{\Omega \sigma}{k T} \exp \left(-\frac{\Delta \mathrm{H}_{c}}{k T}\right)
$$

is physically more accurate[19]. In Eqn. 2.21, Ao is a constant, $G$ is the shear modulus and $\Omega$ is the atomic volume. From Eq. 21, the following expression for $Q_{c}$ is obtained.

$$
Q_{c}=\Delta H_{c}-(n-1) \frac{k T^{2}}{G} \frac{d G}{d T}+\frac{k T^{2}}{\Omega} \frac{d \Omega}{d T}
$$

\section{RELATIONSHIP BETWEEN ACTIVATION ENERGY OF CREEP AND}

\section{ACTIVATION ENTHALPY OF DIFFUSION}

Extensive experimental evidence is available to show that the activation energy of creep $Q_{\mathcal{C}}$, especially when corrected for the temperature dependence of elastic modulus, i.e., $\Delta H_{c}$ is equal or at least close to the activation enthalpy of lattice self-diffusion, $\Delta H_{L}$, at homologous temperature $T / T_{m}>\eta_{L}$. The quantity $\eta_{L}$ depends on the ratio $\sigma / E$ [19 23]. For a typical value of this ratio, e.g., $5 \times 10^{-4}, \eta_{L}=0.5$ for all metals with the exception of 
tin, for which $\eta_{L}=0.9[19]$. For homologous temperatures higher than 0.5, Eqns. 2.19 and 2.21 can be written in the form

$$
\frac{\dot{\varepsilon}_{s}}{D_{L}}=A^{\prime}\left(\frac{\sigma}{E}\right)^{n}
$$

or, more precisely, in the form

$$
\frac{\dot{\varepsilon}_{s}}{D_{L}}=A \frac{G \Omega}{b^{2} k T}\left(\frac{\sigma}{G}\right)^{n},
$$

where $A$ is a dimensionless constant and $D_{L}$ is the coefficient of lattice self-diffusion. In subsequent discussion, the quantity $\dot{\varepsilon}_{s} / D_{L}$ is called the steady-state creep rate normalized to diffusion coefficient or simply the normalized steady state creep rate. Similarly, the ratios $\sigma / G$ and $\sigma / E$ will be called applied stress normalized to the shear modulus and Young's modulus respectively, or simply normalized applied stress. Eqn. 2.24 is generally known as the Dorn creep equation.

When diffusion through dislocation core is involved, Sherby and collaborators [20 22] have applied a phenomenological relation of the following form:

$$
\dot{\varepsilon}_{s} \propto D_{e f f}=D_{L} f_{L}+D_{\text {cor }} f_{c o r} \text {, }
$$

where $D_{e f f}$ is the effective coefficient of diffusion, $D_{L}$ and $D_{c o r}$ are the coefficient of lattice self-diffusion and dislocation core diffusion, respectively, $f_{L}$ is the fraction of atoms taking part in lattice diffusion and $f_{c o r}$ is the fraction of atoms taking part in dislocation core diffusion. The fraction $f_{c o r}$ is proportional to the dislocation density which is a function of normalized stress $\sigma / E$. Sherby and Young[22] showed that $f_{\text {cor }} \approx 2 \times 10^{2}(\sigma / E)^{2}$. 


\subsubsection{STRESS DEPENDENCE}

The dependence of steady state creep rate on applied stress can be characterized by the parameter $m^{\prime}$ which describes the sensitivity of steady-state creep rate to applied stress. It is defined as

$$
m^{\prime}=\left(\frac{\partial \ln \dot{\varepsilon}_{s}}{\partial \ln \sigma}\right)_{T}
$$

The dependence of creep rate on applied stress varies with the range of applied stress. Such a dependence is summarized in Table 2.1 in which $m^{\prime}$ is replaced by $n$.

Table 2.1 The dependence of creep rate on applied stress

\begin{tabular}{|c|c|c|}
\hline STRESS RANGE & EQUATION & STRESS DEPENDENCE \\
\hline $\begin{array}{c}\text { Low and Medium } \\
\text { Stress }\end{array}$ & $\begin{array}{l}\dot{\varepsilon}=A \sigma^{n} \\
\dot{\varepsilon}=A\left(\frac{\sigma}{E}\right)^{n} \\
\dot{\varepsilon}=A\left(\frac{\sigma}{G}\right)^{n}\end{array}$ & $\begin{array}{l}n=5 \text { dislocation creep in pure metals } \\
n=3 \text { dislocation creep in Class I solids } \\
n=1 \text { diffusional creep in pure metals } \\
n>5 \text { dislocation creep in PS and ODS alloys } \\
\text { [Ref.24] }\end{array}$ \\
\hline High Stress & $\begin{array}{l}\dot{\varepsilon}=A^{\prime} \exp [B \sigma] \\
\dot{\varepsilon}=A^{\prime} \exp \left[B_{n} \frac{\sigma}{E}\right]\end{array}$ & $\begin{array}{l}A^{\prime}, A^{\prime} n, B, B n \text { are constants } \\
\text { [Ref. } 2,24,25]\end{array}$ \\
\hline $\begin{array}{c}\text { Entire Stress } \\
\text { Range } \\
\end{array}$ & $\begin{array}{l}\dot{\varepsilon}=A^{\prime \prime}\left(\sinh B^{\prime \prime} \sigma\right)^{n} \\
\dot{\varepsilon}=A_{o} \sigma^{n-1} \sinh B_{o} \sigma\end{array}$ & $\begin{array}{l}A=B^{\prime \prime n} A^{\prime \prime} \text { at low stress [Ref. 26] } \\
\left\{\begin{array}{l}A^{\prime}=A^{*} / 2 \\
B=n B^{*}\end{array} \text { at high stress [Ref. 27, 28] }\right.\end{array}$ \\
\hline
\end{tabular}




\subsubsection{DISLOCATION CREEP IN PURE METALS}

\subsubsection{DISLOCATION STRUCTURE}

The dislocation arrangements developed during Power-law creep, as identified by $\mathrm{X}$-ray techniques, etch-pitting studies and transmission electron microscopy, have been comprehensively reviewed by Takeuchi and Argon[29]. Although the precise dislocation configurations observed in pure metals vary with stress, strain, temperature and material parameters such as stacking fault energy, they have some general similarities in their characteristics and nature.

After the initial straining of the specimen on loading, the dislocation structure that forms closely resembles that produced by deformation at low temperatures. During creep of most metals, particularly those characterized by a high stacking fault energy, the relatively uniform dislocation arrangements observed initially are found to change gradually as a consequence of the formation of a subgrain structure. Their subgrains have regions of comparatively low dislocation density separated by low-angle tilt and twist subboundaries which often have a complex nature ${ }^{[30]}$. Early in the primary stage, a high density of subgrains form in some regions but not in others. As primary strain increases, this heterogeneous subgrain structure becomes more homogeneous and the average misorientation across the sub-boundaries increases. It then seems to remain constant at about 1 or $2^{\circ}$ or less throughout the secondary stage[29].

In pure metals, such as alpha iron, the density of free dislocations initially increases. It quickly reaches a maximum value and then decreases slowly to a value corresponding to the steady-state at a given applied stress and temperature as shown in Fig. $2.3[31]$. From this figure, it can be seen that the density of dislocations forming subboundaries, $\rho_{B}$, increases during primary creep and the total dislocation density $\rho_{t}=\rho+\rho_{B}$ increases similarly. The free dislocation density represents only a small fraction 
of the total dislocation density. The density of dislocations associated with sub-boundaries is an order of magnitude higher than the free dislocation density.

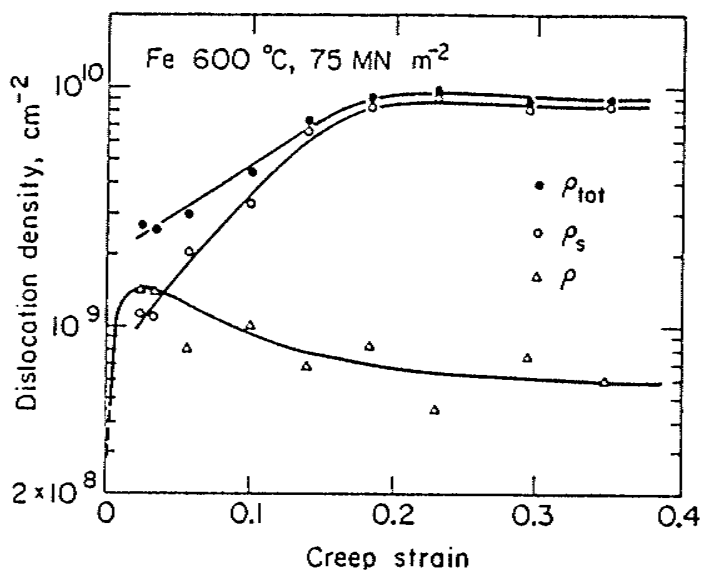

Fig. 2.3 Changes in total dislocation density $\rho_{t}$, free dislocation density $\rho$ and the density of dislocations associated in sub-boundaries, $\rho_{B}$, with the creep strain; alpha iron crept at $873 \mathrm{~K}$ and $75 \mathrm{MPa}[31]$.

The quantitative characteristic of dislocation structure are described in terms of total dislocation density $\rho_{t}$, density of free dislocation $\rho$, mean subgrain diameter $d_{S}$, mean subgrain misorientation angle $\Theta$, density of dislocations forming sub-boundaries $\rho_{B}$ and density of free dislocation $\rho$. The dependence of $\rho$ on applied stress $\sigma$ can be described by the following expression[14]:

$$
\rho=K_{G}\left(\frac{\sigma}{G b}\right)^{p}
$$

where $K_{G}$ is a constant, the value of which ranges from 1.0 to 6.5. $p$ is an exponent which is in the range of 1 to 2 ; in theoretical considerations $p$ is usually accepted to be equal to 2. 
The density of sub-boundary-forming dislocations $\rho_{B}$, is expressed as follows $[31]$ :

$$
\rho_{B}=\frac{3 \Theta}{b d_{s}}
$$

where $d_{S}$, is the mean subgrain diameter, $\Theta$ is the mean subgrain misorientation expressed as $\Theta=b / h$. Here $h$ is the mean distance between dislocations in sub-boundaries .

The mean subgrain diameter $d_{s}$ is found to be ${ }^{[14]}$

$$
\frac{d_{s}}{b}=K_{d} \frac{G}{\sigma}
$$

where $K_{d} \approx 10.5[14]$, by combining Eqns. 2.29 and 2.30 ,

$$
\rho_{B}=K_{B} \frac{\Theta}{b^{2}} \frac{\sigma}{G}
$$

Since during steady state creep the ratio $\rho_{B} / \rho_{t}$ remains constant, the total dislocation density $\rho_{t}$ is proportional to the free dislocation density, $\rho$. Therefore, the subgrain diameter, $d_{s}$, can be expressed by the following:

$$
d_{s}=K \rho^{-1 / 2}
$$

where $K$ is a constant.

\subsubsection{TEMPERATURE AND STRESS DEPENDENCE OF CREEP RATE}

Intensive experimental investigations suggest that when homologous temperatures at which creep occurs are sufficiently high for lattice diffusion to dominate dislocation core diffusion, the apparent creep activation energy is equal to the activation energy of 
lattice self-diffusion, and the creep rate depends on applied stress with an exponent of 5 . At lower homologous temperatures, where dislocation core diffusion dominates over lattice diffusion, a stronger dependence of creep rate on applied stress is often observed.

With few exceptions, various models of creep assume that the creep strain is a result of dislocation glide and non-conservative motion of dislocations. These models are

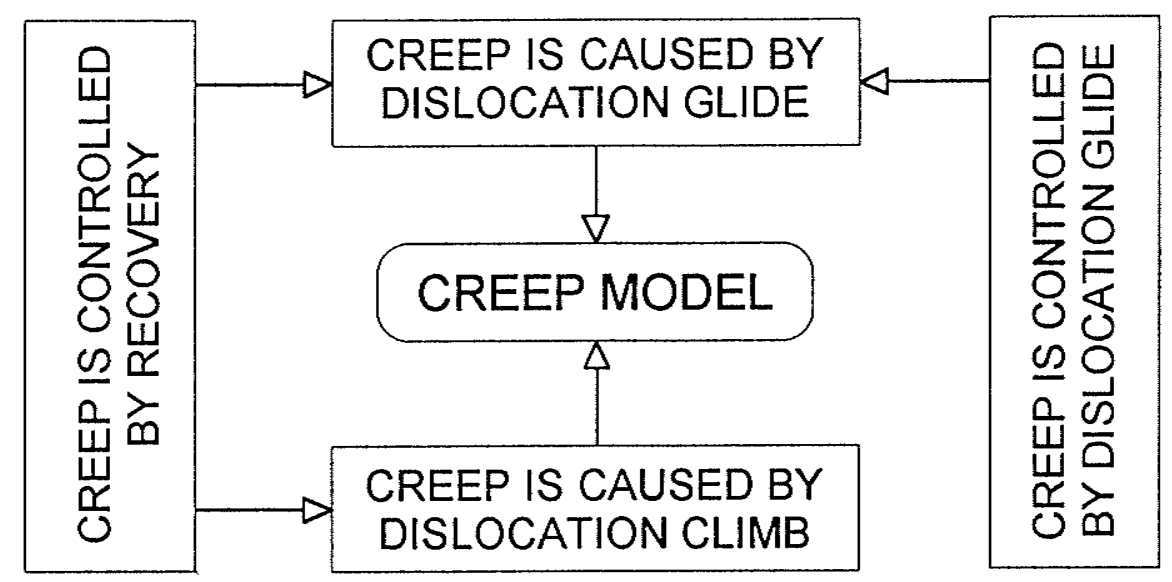

Fig. 2.4 Illustration of establishment of creep mechanisms

illustrated in Fig.2.4. These models are based on two separate assumptions. The first type of models assume that creep strain is a result of dislocation glide and that nonconservative motion of dislocations contributes to the overall creep strain to a negligible extent. These models, also known as models of "Glide Creep", can be essentially divided into two groups. Models of the first group start from an idea that the process that controls creep rate is recovery which consists of climb and annihilation of edge dislocations. Models of the second group are based on the assumption that dislocation glide is the creep rate controlling process. These models assume that the creep strain is a result of dislocation climb, also known as models of dislocation "climb creep", and ignore any contribution of dislocation glide to the creep strain. In the following section, a brief review 
of only those models of dislocation creep will be given which have contributed to the development of ideas on dislocation creep mechanisms significantly.

\section{RECOVERY CONTROLLED DISLOCATION GLIDE CREEP MODEL}

a) Weertman's Earlier Models [32, 27]: As shown in Table 2.2, Weertman's models predict not only the usually observed temperature dependence but also the frequently observed stress dependence of steady state creep rate. Nevertheless, numerous objections were raised against it. The more noteworthy of them are the following:

i). the assumed dislocation configuration is unstable $[33,34]$

ii). dislocation pile-ups were not observed in crept specimens

iii). the assumption of a fixed and stress independent permanent density of dislocation sources has never been supported experimentally.

Generally, the dependence of creep rate on the 4.5 th power of stress is reached due to an ad-hoc assumption of independence of dislocation source density of stress. However, if the assumption is ignored, the Weertman's model would predict a third power dependence of creep rate on stress.

b) Models Involving the Role of Sub-boundaries : If dislocations forming the subboundaries act as sources and sinks for vacancies, then Nabarro-Herring diffusion creep occurs, the rate of which is given by

$$
\frac{\dot{\varepsilon}}{D_{L}}=B_{N H} \frac{G \Omega}{d_{s}^{2} k T} \frac{\sigma}{G}
$$

where $B_{N H}$ is a constant and $d_{S}$ is the mean subgrain diameter. Considering the dependence of $d_{s}$ on stress, the creep rate with above equation is given by

$$
\frac{\dot{\varepsilon}}{D_{L}}=B_{o} \frac{G b}{k T}\left(\frac{\sigma}{G}\right)^{3}
$$


Table 2.2 CREEP IS CONTROLLED BY RECOVERY PROCESS

\begin{tabular}{|c|c|c|}
\hline MODEL & EQUATION & ASSUMPTION \\
\hline $\begin{array}{l}\text { Weertman's } \\
\text { Model }[32,27]\end{array}$ & $\dot{\varepsilon}=A \frac{D_{L}}{b^{3.5} M^{0.5}} \frac{G b^{3}}{k T}\left(\frac{\sigma}{G}\right)^{4.5}$ & $\begin{array}{l}\text { Dislocation pile-ups, a fixed and stress } \\
\text { independent permanent density of } \\
\text { dislocation sources }\end{array}$ \\
\hline \multirow{5}{*}{$\begin{array}{l}\text { Models Involving } \\
\text { the Role of Sub- } \\
\text { boundaries }\end{array}$} & $\dot{\varepsilon}=A D_{L} \frac{G \Omega}{b^{2} k T}\left(\frac{\sigma}{G}\right)^{3}$ & Ivanov and Yanushkevich [35] \\
\hline & $\dot{\varepsilon}=A_{B} \frac{a}{b^{3}} D_{L} \frac{G \Omega}{k T}\left(\frac{\sigma}{G}\right)^{4}$ & $\begin{array}{l}\text { Finite subboundary thickness a. } \\
\text { Blum[36] }\end{array}$ \\
\hline & $\frac{\dot{\varepsilon}}{D_{L}}=A_{a T} \frac{G \Omega}{b^{2} k T}\left(\frac{\gamma_{F}}{G b}\right)\left(\frac{\sigma-\sigma_{i}}{G}\right)^{3}$ & Argon and Takeuchi[ ${ }^{[37]}$ \\
\hline & $\frac{\dot{\varepsilon}}{D_{L}}=A_{W S} \frac{G \Omega}{b^{2} k T}\left(\frac{\sigma}{G}\right)^{5}$ & Weertman $[38]$ \\
\hline & $\frac{\dot{\varepsilon}}{D_{L}}=A_{W 5} \frac{G \Omega}{b^{2} k T}\left(\frac{d}{b}\right)^{p}\left(\frac{\sigma}{G}\right)^{7}$ & Ref. $47 \sim 49$ \\
\hline \multirow[t]{2}{*}{$\begin{array}{l}\text { Dislocation } \\
\text { Network Models }\end{array}$} & $\frac{\dot{\varepsilon}}{D_{L}}=\frac{8 \pi^{3}}{b^{2}} \frac{G \Omega}{k T}\left(\frac{\sigma}{G}\right)^{3}$ & $\begin{array}{l}\text { Coefficient is independent of applied } \\
\text { stress }\end{array}$ \\
\hline & $\dot{\varepsilon} \propto\left(\frac{\sigma}{G}\right)^{4}$ & $\begin{array}{l}\text { When deformation strengthening } \\
\text { coefficient depends on the reciprocal } \\
\text { of stress }\end{array}$ \\
\hline
\end{tabular}

The model described by Eqn. 2.34 was presented by Ivanov and Yanushkevich[35]. Eqn. 2.34 was also derived in a simple way by Weertman. These two assumed that subboundaries have a "zero "thickness. Blum[36] modified Ivanov and Yanushkevich's analysis by making an ad-hoc assumption of a finite sub-boundary thickness. Consequently, the creep rate is described by the following equation 


$$
\frac{\dot{\varepsilon}}{D_{L}}=A_{B} \frac{a}{b^{3}} \frac{G \Omega}{k T}\left(\frac{\sigma}{G}\right)^{4}
$$

The relation $\frac{\dot{\varepsilon}}{D_{L}} \propto\left(\frac{\sigma}{G}\right)^{3}$ is commonly accepted as a natural third power law of high temperature creep. An explanation of the discrepancy between the "natural" power law creep exponent for pure metals, $n=3$, and the creep exponent usually observed experimentally, $n>3$, has not yet been provided:

Argon and Takeuchi Model[37]: Argon and Takeuchi derived the "natural " creep relation of the form:

$$
\frac{\dot{\varepsilon}_{s}}{D_{L}}=A_{A T} \frac{G \Omega}{b^{2} k T}\left(\frac{\gamma_{F}}{G b}\right)^{3}\left(\frac{\sigma}{G}\right)^{3}
$$

which, with the exception of the factor $\left(\frac{\gamma_{F}}{G b}\right)^{3}$, has an identical form to that derived by Weertman $\left(\dot{\gamma}_{F}\right.$ is the stacking fault energy). Argon and Takeuchi assumed that the dependence of creep rate on the third power of stress is a consequence of the internal stress not being taken into account and thus replaced the applied stress $\sigma$ by the effective stress $\sigma^{*}=\sigma-\sigma_{i}$. Consequently, the creep rate is expressed as

$$
\frac{\dot{\varepsilon}_{s}}{D_{L}}=A_{A T} \frac{G \Omega}{b^{2} k T}\left(\frac{\gamma_{F}}{G b}\right)^{3}\left(\frac{\sigma-\sigma_{i}}{G}\right)^{3}
$$

Further, the authors developed a theory of internal stress, $\sigma_{i}$, assuming that this stress is exclusively due to sub-boundary bow-out caused by the applied stress. Based on this assumption, they obtained the following expression for $\sigma_{i}$ 


$$
\sigma_{i}=\alpha K_{d} G \Theta \frac{1-v}{\pi}\left(\frac{\sigma}{K G \Theta}\right)^{2 / 3}
$$

where the constant $\alpha=0.317, \Theta$ is the mean misorientation angle of a sub-boundary and $K_{d}$ is the proportionality constant in Eqn. 2.30. They used strain transient dip test technique to study eight pure metals and solid solution alloys that exhibit Class II creep behaviour and in which subgrain structure develops during creep deformation ( Fig. $2.5)^{[29] . ~ T h i s ~ c o n c l u s i o n ~ w a s ~ s u p p o r t e d ~ b y ~ t h e ~ r e s u l t s ~ o f ~ O r l o v a[39] . ~}$

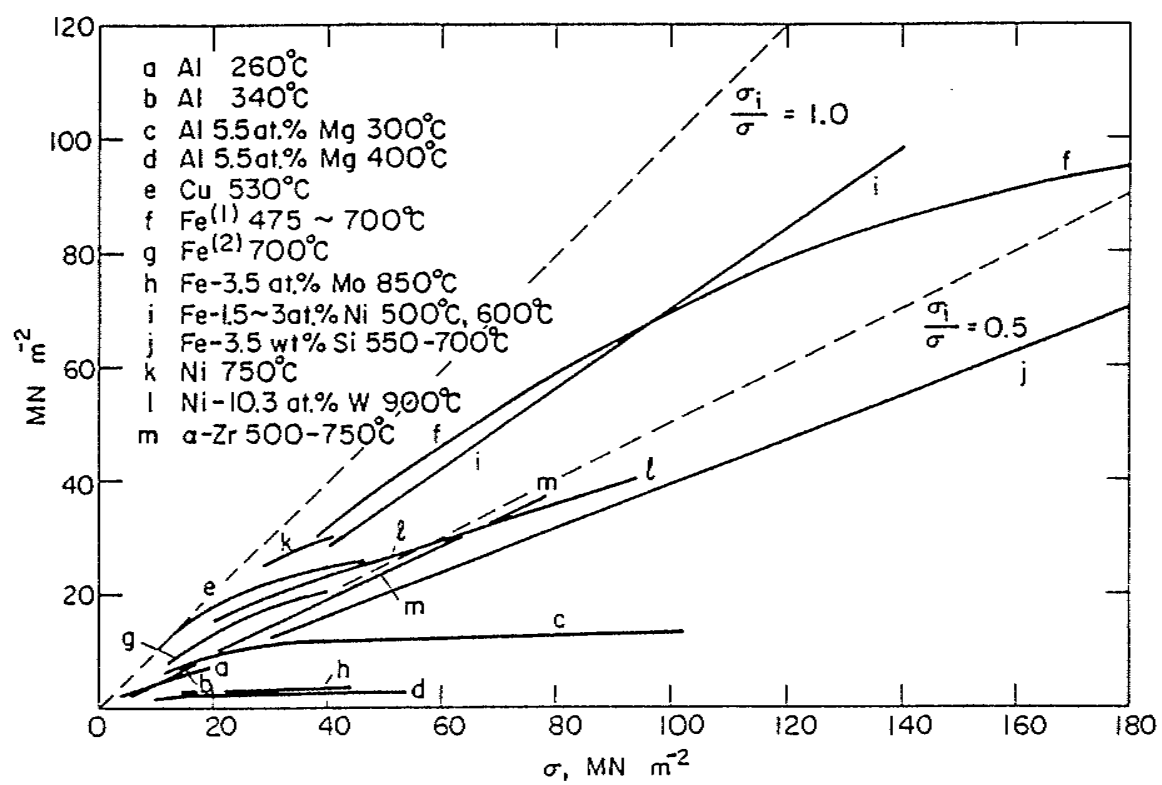

Fig. 2.5 Results of measurements of internal stress oi in steady-state creep assembled by Takeuchi and Argon[29]

Weertman's Model[38]: On the basis of recent high voltage TEM observations by Caillard and Martin on the behavior of dislocation networks in high temperature creep [40 42], Weertman developed a dislocation creep model in which $\dot{\varepsilon}$ and $\sigma$ are related by the following expression: 


$$
\frac{\dot{\varepsilon}}{D_{L}}=A_{W 5} \frac{G \Omega}{b^{2} k T}\left(\frac{\sigma}{G}\right)^{5}
$$

where $A_{W}$ is approximately equal to $1 \times 10^{9}$ for pure $\mathrm{BCC}$ and high stacking fault energy FCC metals if the power exponent is set to be equal to 5 .

The natural 5 th power arises in this theory because the screw dislocation segments move a distance which is proportional to the applied stress rather than a distance which is inversely proportional to the applied stress. The edge dislocation segments move a distance which is inversely proportional to the applied stress. Most of the edge dislocation segment annihilation occurs not through climb but through a cross slip process of screw dislocation segments as suggested by the Caillard-Martin observations [40 42]. However, the rate controlling process remains the climb of edge dislocations. Consequently the activation energy of high temperature creep is that of self diffusion. According to this theory, for high temperature creep in the intermediate temperature range the natural stress exponent is 7 and the activation energy is that of pipe diffusion.

Robinson and Sherby's Model[47]: The majority of theories proposed to describe the creep process neither include subgrain size as an important variable nor utilize the subgrain boundaries in the formulation of a rate equation. The reasons for relegating subgrains to an incidental role in the creep process are based on evidence obtained in the 1950s. This evidence indicated that a true substructural steady state in which dislocation density, subgrain size and subgrain misorientation were constant did not exist[43]. However, later studies on aluminum show that subgrain size, misorientation and shape remain essentially constant up to strains of $3.7[44]$. This constancy of subgrain size and misorientation has been reconfirmed using transmission electron microscopy $[45,46]$.

An attempt to incorporate subgrain size in a strain rate description of the creep process was made by Robinson and Sherby[47]. After analyzing all of the creep data 
available on polycrystalline tungsten, they proposed an empirical equation to describe the steady state creep strain rate which included subgrain size as an important parameter. Later, Young et al.[48], using subgrain size data available in the literature combined with results from high temperature constant strain rate tests for high purity aluminum, obtained results which were similar to those found in the earlier study on tungsten. In 1977, Sherby et al.[49] reanalyzed the data available in the literature for several materials and proposed a creep rate equation of the form

$$
\dot{\varepsilon}_{i}=S\left(\frac{D}{b^{2}}\right)\left(\frac{\lambda}{b}\right)^{p}\left(\frac{\sigma}{E}\right)^{N}
$$

where $\dot{\varepsilon}_{i}$ is instantaneous strain rate, $S=$ structure dependent constant, $D=$ effective diffusion coefficient, $\lambda=$ subgrain size.

For a constant value of $\lambda$, a stress exponent of 8 is obtained. Under steady state conditions, $\lambda$ varies as $\sigma^{-1}$, hence the stress exponent is 5 , as is commonly observed. Ferreira and Stang[50] confirmed the form of this relationship, but found that a stress exponent of 7 and a subgrain size exponent of 2 were more appropriate. The constant dislocation structure creep was also analyzed based on the thermodynamics of dislocation glide in subgrain interior controlled by over-coming of obstacles[51 53].

c) Dislocation Network: The first model of creep based on experimental evidence that free dislocations are arranged into a three dimensional network and on the idea that the deformation strengthening results by the network refinement and the recovery on the network coarsening, which is dependent on diffusion, was proposed by McLean $[54]$ in 1968 . The decrease in mean mesh size $\lambda$ leads to an increase in dislocation density, while the growth of the mean mesh size results in a decrease. The role of recovery is in an occasional thermally activated release of a dislocation network link. Based on this the recovery rate is given by $[55]$ : 


$$
r=-\frac{\partial \sigma}{\partial t}=\frac{4 \pi^{2} D_{L} b}{G K T}
$$

and coefficient of deformation strengthening, $h$, by $[56]$ :

$$
h=\frac{\partial \sigma}{\partial \varepsilon}=\frac{G}{2 \pi}
$$

Substituting Eqn. 2.41 and 2.42 into Bailey-Orowan equation (Eqn. 2.12), the creep rate is given by $[57]$ :

$$
\frac{\varepsilon}{D_{L}}=\frac{8 \pi^{3}}{b^{2}} \frac{G \Omega}{K T}\left(\frac{\sigma}{G}\right)^{3}
$$

Thus, the above simple analysis also gives a stress exponent of 3 for the creep rate.

This analysis assumes an independence of $h$ on $\sigma$, which is actually not observed. However, by considering the usually observed dependence of deformation strengthening coefficient $h$ on the reciprocal of stress, Lagneborg[58] obtained the following relationship

$$
\varepsilon \propto\left(\frac{\sigma}{G}\right)^{4}
$$

The network of dislocation is not stationary, but is in a dynamic equilibrium as newly created dislocation line is continuously being annihilated by climb. Thus, at any time, the link in the network can be considered in various stages of multiplication or coarsening process. Based on this, Burton[59] proposed a dislocation network theory which gives the creep rate by : 


$$
\frac{\dot{\varepsilon}_{s}}{D_{L}}=A_{B} \frac{G b}{k T}\left(\frac{\sigma}{G}\right)^{3}
$$

Therefore, it can be concluded that dislocation network models of creep controlled by lattice diffusion also yield a value of 3 for the stress exponent of the creep rate.

\section{DISLOCATION CLIMB CREEP : NABARRO CREEP}

All the models of dislocation (power law) creep discussed so far assume that the creep strain results essentially from dislocation glide, though the creep rate is controlled by recovery dependent on dislocation climb occurring through lattice diffusion. In contrast, in Nabarro creep, the creep strain results exclusively from non-conservative dislocation motion, i.e. dislocation climb.

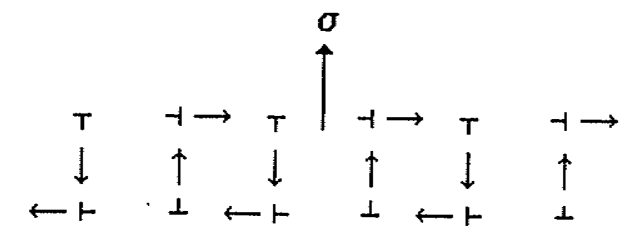

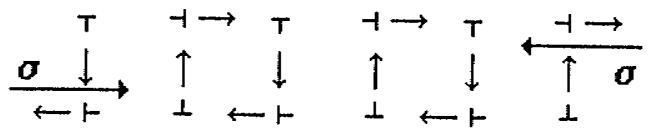

$$
\begin{aligned}
& \begin{array}{rccccc}
r & \dashv \rightarrow & T & -1 \rightarrow & T & \dashv \rightarrow \\
\downarrow & \uparrow & \downarrow & \uparrow & \downarrow & \uparrow \\
\leftarrow-1 & \perp & \leftarrow & \perp & \leftarrow & 1 \\
& & & & &
\end{array}
\end{aligned}
$$

Fig. 2.6 Nabarro model of creep. An arrangement of edge dislocations into the regular three-dimensional network [60].

This model was established for a case where the interdislocation spacing in subboundaries can be comparable to the subgrain diameter. The dislocations are arranged into three dimensional networks as shown in Fig. 2.6.. In this figure, the directions of dislocation climb are shown by the arrows 
A detailed model of this type of dislocation climb creep was presented by Nabarro [60] in 1967. Nabarro considered individual links of the network to operate as Bardeen-Herring dislocation sources. That is, while absorbing or emitting vacancies they bow which causes their length in unit volume to increase. That is, their dislocation density increases. An increase in dislocation density is compensated by the annihilation of dislocations of opposite signs which meet during climb. In the steady state, the dislocation density remains constant and the mean link length also does not change.

Nabarro's analysis led to the equation[60],

$$
\frac{\dot{\varepsilon}}{D_{L}}=A_{N} \frac{G \Omega}{b^{2} k T}\left(\frac{\sigma}{G}\right)^{3} \ln \left(\frac{4 G}{\pi \sigma}\right)^{-1}
$$

The value of the logarithmic term changes with stress very slightly, so that the creep rate practically varies with the third power of stress.

In 1968, Weertman[11] rederived the equation for Nabarro creep rate using Orowan equation since the deformation is caused by dislocation climb, $L=\lambda=d s$. If it is accepted that all the dislocations are mobile, the resulting equation for creep rate can be written as follows

$$
\frac{\dot{\varepsilon}}{D_{L}}=A_{w} \frac{G \Omega}{b^{2} k T}\left(\frac{\sigma}{G}\right)^{3}
$$

As to the form, Eqn. 2.47 is identical to Eqn. 2.46, and except for the logarithmic factor, it is also identical to the original Nabarro Eqn. 2.46. It should be noted that the creep rate expressed by Eqn. 2.46 and 2.47 does not depend on the dimension of dislocation network, $\lambda$. Thus, Nabarro creep controlled by lattice diffusion also obeys the third power law. 
Besides the model of creep described above, Nabarro[60] developed another model of climb creep, assuming that edge dislocations are arranged into a regular three dimensional network and the dislocation core diffusion, instead of the lattice diffusion, controls the creep rate. The climb velocity controlled by core diffusion is given by [60]:

$$
v_{c c}=K_{c} \frac{b}{\lambda^{2}} D_{c} \frac{\sigma G}{k T}
$$

where $K_{\mathcal{C}}$ is a constant, $D_{\mathcal{C}}$ the coefficient of dislocation core diffusion and $\lambda$ is the mean spacing of dislocations between which the exchange of vacancies takes place, i.e., the mean mesh size of dislocation network. Since the dislocation density given by Eqn. 2.28 is proportional to $1 / \lambda^{2}$ and the creep rate is given by Eqn. 2.8 in which $v_{c c}$ is substituted for $v^{*}$, the following equation for creep rate is obtained

$$
\frac{\dot{\varepsilon}}{D_{c}}=A_{c} \frac{G \Omega}{b^{2} k T}\left(\frac{\sigma}{G}\right)^{s}
$$

Eqn. 2.49 is, with respect to the stress dependence of creep rate, similar to the equation originally suggested by Nabarro[60] and the creep rate varies as the fifth power of stress.

However, generally both lattice diffusion and dislocation core diffusion take places simultaneously in Nabarro creep. The creep rate is thus equal to the sum of the rates expressed by Eqn. 2.41 and 2.49 , i.e.,

$$
\dot{\varepsilon}=A_{N}^{c}\left[D_{L}+A_{N}^{\prime}\left(\frac{\sigma}{G}\right)^{2} D_{c}\right]\left(\frac{\sigma}{G}\right)^{3} \frac{G \Omega}{b^{2} k T}
$$

From this equation it follows that the effective coefficient of diffusion is 


$$
D_{e f f}=D_{L}+A_{N}^{\prime}\left(\frac{\sigma}{G}\right)^{2} D_{c}
$$

In the previous section, Weertman's "cell model" of creep controlled by lattice diffusion, which leads to a " natural " fifth power law, was discussed. At intermediate homologous temperatures, where dislocation core diffusion is more likely to occur than lattice diffusion to control dislocation climb, the stress exponent in the creep rate equation is increased and creep rate is described by the seventh power equation.

$$
\frac{\dot{\varepsilon}}{D_{c}}=A_{w 7} \frac{G \Omega}{b^{2} k T}\left(\frac{\sigma}{G}\right)^{7}
$$

The constant $A_{W 7}$ is approximately equal to $9.3 \times 10^{-3} A_{W 5}$. Weertman believes that this equation represents a " natural " seventh power law for creep controlled by dislocation core diffusion[38].

\section{CREEP CONTROLLED BY DISLOCATION GLIDE}

As an alternative to recovery dependent on dislocation climb, dislocation glide dependent on diffusion must be considered as a creep rate controlling process. The most acceptable and, consequently, most widely discussed model of creep controlled by dislocation glide dependent on diffusion is the model of non-conservative motion of jogs on screw dislocation. A possibility that the creep rate is controlled by the glide of screw dislocations with jogs was first considered by Mott $[61]$ in 1954 and later by Raymond and Dorn[62], Barrett and Nix [28] and other authors [63]. Hirsch and Warrington developed a theory of flow stress at high temperatures starting from the same ideas as Mott [61]. In the following paragraphs, the analysis performed by Barrett and Nix will be briefly described.

Barrett and Nix $[28]$ assumed that the non-conservative motion of jogs on screw dislocations can be related to both the emission and absorption of vacancies and that any 
screw segment contains either vacancy emitting or vacancy absorbing jogs. The vacancy motion emitted by a jog causes a vacancy supersaturation, while the absorption of vacancy during the motion of a jog causes a vacancy under saturation in the vicinity of the jog. Their detailed analysis has resulted in the creep rate being given by $[28]$ :

$$
\frac{\dot{\varepsilon}}{D_{L}}=4 \pi \beta l_{i} \frac{b^{2}}{a^{3}} \frac{G b}{k T}\left(\frac{\sigma}{G}\right)^{3}
$$

where $\beta$ is the number of atoms in the unit cell., $a$ the lattice parameter, $l_{i}$ the distance between jogs. 


\subsubsection{HARPER-DORN CREEP}

High temperature creep at very low normalized stresses sometimes shows features that are characteristic of diffusional creep (Newtonian behaviour, i.e., linear stress dependence of creep rate). At the same time, it also has the features which are in contradiction with the concept that creep occurs by stress directed diffusion of vacancies, which are emitted and absorbed by grain boundaries. That is, creep rate is independent of the mean grain diameter. Creep of this type is known as Harper-Dorn (H-D) creep, as Harper and Dorn[64] were first to observe it in aluminum in 1957.

Until recently, H-D creep has been thought to take place at homologous temperatures higher than about 0.95 , normalized stresses $\sigma / G$ lower than about $5 \times 10^{-6}$ and in materials with mean grain diameters larger than about $500 \mu \mathrm{m}$. However, in the past decade it has been shown that H-D creep can also take place at much lower homologous temperatures.

\section{HIGH TEMPERATURE H-D CREEP}

The primary characteristics of H-D creep at very high homologous temperatures and low stresses can be summarized as follows [65].

- The stress exponent is equal to 1 .

- The creep rate is independent of grain size and similar creep rates are observed both in polycrystals and single crystals.

- The activation energy for creep is equal to the activation enthalpy for lattice diffusion.

- The creep curves show a distinct primary stage which is followed by the steady state stage.

- the dislocation density is low, i.e., of the order of $\sim 5 \times 10^{7} \mathrm{~m}^{-2}$, and is independent of stress. 
- There is a random and reasonably uniform distribution of dislocations in specimens crept to the steady state.

- Very similar results are obtained on pure metals and solid solution alloys. There is no experimental evidence to suggest a variation in creep behaviour with solute concentration.

The H-D creep rate can be expressed by the following phenomenological equation[65]

$$
\frac{\dot{\varepsilon}}{D_{L}}=A_{H D} \frac{G b}{k T}\left(\frac{\sigma}{G}\right)
$$

Several models of "high" temperature H-D creep have been proposed.

a). Earlier models: In the earlier work of Dorn and co-workers $[64,66], H-D$ creep was attributed to the motion of jogged screw dislocations and the associated production of vacancies, using the concept developed by Mott[61]. According to Mohamed $[68,70]$ and Yavari's[ $[65]$ analysis this mechanism is not appropriate to be H-D creep for two reasons: (a) it requires a predominance of screw dislocations which contradicts experimental results [67], and (b) it requires an unrealistically small mean spacing between jogs $(<b)$.

b). Barrett's model: Barrett, Muehleisen and Nix ${ }^{69]}$ proposed a model based on the following assumptions: (1) the dislocation multiplication occurs by climb, while the creep strain results from dislocation glide; (2) the dislocation glide velocity $v_{g}=v_{o} \sigma$, where $v_{0} \propto D_{L}$; (3) the mean subgrain diameter is given by Eqn. 2.30 , just as it is in recovery (power-law) creep; (4) the dislocation-source density does not depend on stress; 
and (5) the annihilation and / or immobilization of dislocations occur exclusively in subboundaries. From this model, the following expression has been derived.

$$
\rho=\rho_{o} \frac{d_{o}}{v_{o}} \frac{D_{L} b}{G k L},
$$

where $\rho_{o}$ is the length of dislocation sources per unit volume and $d_{o}=d_{s} \sigma$ is a constant. Thus, the dislocation density does not depend on stress, which is in agreement with experimental results. The creep rate is described by the Orowan equation so that it can be expressed as

$$
\dot{\varepsilon}=\rho_{o} d_{o} \frac{D_{L} b^{2}}{k T}\left(\frac{\sigma}{G}\right)
$$

c). Mohamed, Murty and Morris[70] considered the possibility of H-D creep control led by the climb of jogged edge dislocations. For this process Hirth and Lothe derived the following equation for the steady-state strain rate.

$$
\frac{\dot{\varepsilon}}{D_{L}}=A^{o} \frac{\rho b^{3}}{l_{j}} \frac{G b}{k T}\left(\frac{\sigma}{G}\right)
$$

where $l_{j}$ is the mean jog spacing on the edge dislocation. Thermal jog spacing is of the order of $(\mathrm{b} / 10) \exp \left[U_{j} / k T\right]$, where $U_{j}$ is the energy of jog formation.

This model was later discussed in detail by Langdon and Yavari[67]. They suggested that an array of dislocations containing a very high jog density would exhibit vacancy saturation. When dislocation jogs become saturated with vacancies, the dislocation velocity may be controlled by diffusion of vacancies to or from the dislocation 
line. This mechanism was first considered by Friedel[71]. Following Hirth and Lothe[63], the steady state creep rate is given by,

$$
\frac{\dot{\varepsilon}}{D_{L}}=A^{s} \frac{\rho b^{2}}{\ln \left(\rho^{1 / 2} b\right)^{-1}} \frac{G b}{k T}\left(\frac{\sigma}{G}\right)
$$

where $A^{s}$ is a constant. Langdon and Yavari[67] showed that there are numerous points of agreement between requirements of this model and extensive experimental observation.

\section{INTERMEDIATE TEMPERATURES}

The main features of $\mathrm{H}-\mathrm{D}$ creep occurring at intermediate temperature are as follows $[72]$

- Well defined steady state creep rate is observed.

- Depending on conditions, the creep rate may be controlled either by lattice diffusion or by dislocation core diffusion.

- Creep can occur at dislocation densities several orders of magnitude higher $\left(\sim 10^{12} \mathrm{~m}^{-2}\right)$ than the upper limiting dislocation densities allowing H-D creep to occur at homologous temperatures close to 0.95 .

- The subgrain formation has not been observed even at grain diameters considerably larger than those resulting from Eqn. 2.30 with $K=10$. The dislocations are arranged into irregular three-dimensional network. The density of dislocations does not depend on stress.

- A threshold stress has been observed for steady-state creep which does not depend on the grain size[73 75]

- Creep occurs for grain sizes considerably smaller than at high temperatures. For example, the lower limiting grain size $\mathrm{d} \cong 195 \mu \mathrm{m}$ was found for alpha iron[ $[74]$. 
- A transient creep occurs, however, transient strains are relatively small and the duration of transient stage is relatively short $[75,76]$.

The "intermediate" temperature H-D creep rate can be generally described by the equation[73],

$$
\frac{\dot{\varepsilon}}{D}=A_{H D} \frac{G b}{k T}\left(\frac{\sigma-\sigma_{O}}{G}\right)
$$

where $A_{H D}$ is a constant; $D$ is a proper diffusion coefficient and $\sigma_{o}$ is the threshold stress.

The effect of dislocation core diffusion can be incorporated by setting the effective diffusion coefficient $D_{e f f}$ for $D$ in Eqn. 2.59. It is known that $D_{e f f}=f_{L} D_{L}+f_{C} D_{C}$, where $f_{L}$ and $f_{C}$ are the fraction of atoms participating in lattice diffusion and dislocation core diffusion, respectively. The value $f_{L} \approx 1$ and

$$
f_{C}=a_{c} \rho
$$

where $a_{c}$ is the area around the dislocation core participating in core diffusion. Then, substitution of Eqn. 2.25 and 2.60 into Eqn. 2.59 leads to the following general equation for H-D creep

$$
\dot{\varepsilon}=A_{H D}\left(D_{L}+a_{c} \rho D_{C}\right) \frac{G b}{k T}\left(\frac{\sigma}{G}-\frac{\sigma_{o}}{G}\right)
$$

Novotny, Fiala and Cadek $[75,77]$ suggested that the H-D creep rate in alpha iron and alpha zirconium at intermediate temperatures is controlled by jog dragging. That is, by a non-conservative motion of jogs on screw dislocations which is dependent on dislocation core diffusion and suggested that the creep rate can be expressed by, 


$$
\frac{\dot{\varepsilon}_{s}}{D_{C}}=K_{o} \rho_{s} l_{j} b \frac{G b}{k T}\left(\frac{\sigma}{G}-\frac{\sigma_{o}}{G}\right)
$$

where $K_{o}$ is a dimensionless constant, $\rho_{s}$ is the screw dislocation density and $l_{j}$ is the mean spacing between jogs on crew dislocations. 


\subsubsection{CREEP IN SOLID SOLUTION ALLOYS}

\subsubsection{INTRODUCTION}

The addition of solute B in solvent A may improve creep resistance by:

(i) a modification of stacking fault energy

(ii) the elastic interaction (Cottrell) of atoms with dislocations

(iii) the chemical interaction (Suzuki) of solute atoms with the stacking faults

(iv) an interaction of short range order with dislocations-Fisher interactions

A less important role may be played by Mott-Nabarro strengthening ( individual atoms of a solute represent local obstacles to glide), a modification of diffusion coefficient ( diffusion effects), a modification of elastic modulus and a modification of PeierlsNabarro stress.

Solid solution alloys may exhibit different creep behaviour: Class I ( Alloy type ), the value of $n$ is typically equal to 3 . Class II (Metal type), to which the pure metals belong, $n$ is typically equal to 5 . A solid solution alloy can behave as a Class I solid in one region of external conditions, while it can behave as a Class II solid in another.

Besides the difference in values of stress exponent $n$, other characteristic differences in Class I alloys have been noted[78]:

- No instantaneous plastic strain takes place after the application of stress and inverse primary creep occurs;

- If the applied stress $\sigma$ is reduced by $\Delta \sigma$ in steady state creep region, the creep rate measured immediately after the stress reduction is higher than the steady-state creep rate corresponding to the reduced stress $\sigma-\Delta \sigma$;

- The steady-state creep rate does not depend on, or only slightly depends on, the stacking fault energy;

- The dislocation substructure (cell or subgrain structure) does not form to any significant extent during creep; 
- Dislocations are generally only slightly curved, they are homogeneously distributed and the tendency for network formation is slight;

- Dislocations are predominantly of the edge type.

\subsubsection{CREEP MECHANISMS-CREEP CONTROLLED BY VISCOUS DISLOCATION GLIDE}

The main models for viscous dislocation glide-controlled creep is listed in Table 2.3. The Weertman's theory [79] was the first one of the kind. The theory is considered to be general in the sense that it does not assume a specific type of interaction of solute atoms with dislocations, however, it assumes specific dislocation arrangements which is neither consistent with the homogeneous dislocation distribution generally observed, nor with the fact that the dislocations are mostly of edge orientation.

Friedel[ $[71]$ assumed that the atmosphere around a dislocation is not saturated. Therefore, his theory is valid for very dilute solid solutions only, and thus, is not general enough.

Takeuchi and Argon's theory[78] does not rely on assumptions of either Weertman[79] or Friedel[71], and is based on the concept that both the dislocation glide and climb are influenced by the atmospheres around dislocations. Takeuchi and Argon[78] showed that their theory is in good agreement with the experimental results on Class II of solids, but the creep behaviour of Class I solids cannot be explained satisfactorily.

The criterion for Class I creep behaviour has been derived by Mohamed and Langdon $[80]$, which can be written in the form:

$$
\frac{B_{o}}{1-v}\left(\frac{\sigma}{G}\right)^{2}\left(\frac{G b^{3}}{k T}\right)^{2}\left(\frac{\gamma_{F}}{G b}\right)^{3} \frac{D_{L}}{D_{s}} \epsilon_{a}^{2} C_{o}>1
$$

where $B_{o}$ is a constant and has been experimentally determined to be $6.4 \times 10^{-10}$. 
TABLE 2.3 DISLOCATION CREEP MECHANISMS IN SOLID SOLUTION ALLOYS

\begin{tabular}{|c|c|c|}
\hline INVESTIGATORS & MODELS & CONDITIONS \\
\hline Weertman[ $[79]$ & $\dot{\varepsilon}=\frac{2 \pi(1-v) k T D_{s}}{G b^{5} \epsilon_{a}^{2} C}\left(\frac{\sigma}{G}\right)^{3}$ & $\begin{array}{l}\epsilon_{a}=\left(r-r_{o}\right) / r_{o}, \text { is the misfit } \\
\text { parameter. } r, r_{o} \text { is radii of solute and } \\
\text { solvent atoms respectively. }\end{array}$ \\
\hline Friedel[71] & $\dot{\varepsilon} \cong \frac{\pi(1-v) G b}{2 k T} D_{S}\left(\frac{\sigma}{G}\right)^{3}$ & $\begin{array}{l}D s \text { is the diffusion coefficient of the } \\
\text { solute }\end{array}$ \\
\hline $\begin{array}{l}\text { Tackeuchi \& } \\
\text { Argon }[78]\end{array}$ & $\begin{array}{l}\frac{\dot{\varepsilon}_{s} k T}{D G b}=A\left(\frac{\sigma}{G}\right)^{3} \\
A=\frac{1}{8 C_{o} \epsilon_{a}^{2}}\left(\frac{k T}{G b^{3}}\right)^{2}\end{array}$ & $\begin{array}{l}C=C_{o} \exp \left[\left|W_{M}\right| / k T\right] \text { is the solute } \\
\text { concentration in the atmosphere. } W_{M} \\
\text { is the solute atom-dislocation } \\
\text { interaction energy. }\end{array}$ \\
\hline
\end{tabular}

When the applied stress is increased to a critical value of $\sigma_{c}$, following the criterion represented by Eqn. 2.63, the stress exponent changes from a value close to 5 to a value close to 3 . However, when the stress increases further, the stress exponent increases again at another critical stress $\sigma_{c}^{\prime}>\sigma_{c}$ from $\mathrm{n} \approx 3$ to $\mathrm{n}>3$. The transition of Class I to Class II behaviour at higher stress levels has been observed by many authors $[81 \sim 89]$ and can be considered to be well established at the present

Three possible causes of the breakdown of Class I creep behaviour at high stress levels have been critically considered by Yavari and Langdon[88]

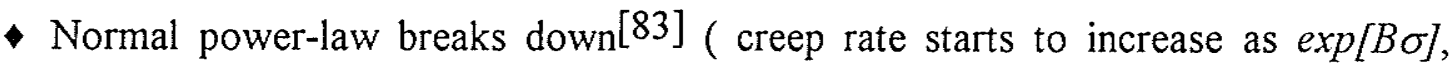
where $B$ is a constant). 
- Transition to a region of viscous glide controlled by dislocation core diffusion, so that deviation from $n \approx 3$ to $n \approx 3+2$ is analogous to the transition from lattice diffusion to dislocation-core diffusion controlled glide creep or climb creep.

- Breakaway of the dislocations from their solute atmospheres $[86,87]$ in a manner first suggested by Friedel[71].

The critical stress $\sigma_{c F}$ for the transition from Class I to Class II creep behaviour was derived by Friedel to be

$$
\sigma_{c F}=\frac{W_{M}^{2} C_{o}}{5 b^{2} k T}
$$

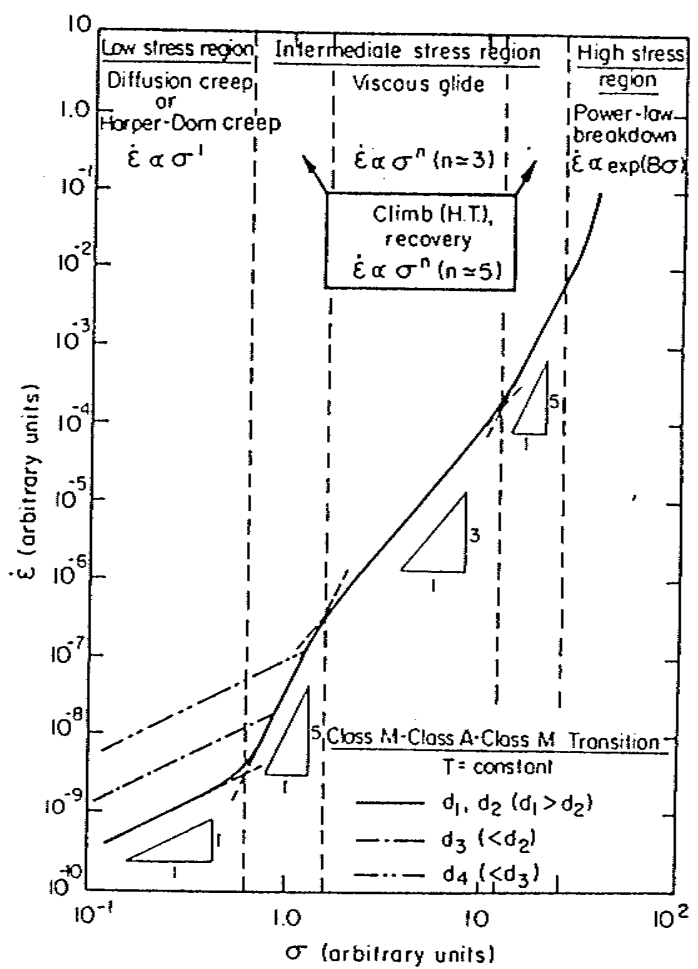

Fig. 2.7 Schematic representation of stress dependence of creep rate showing Class II $\rightarrow$ Class I $\rightarrow$ Class II transition in solid solution alloys. Stress interval in which Newtonian (diffusional or Harper-Dorn) creep occurs is also shown (d means the grain size)[88]. 
The possibility of a Class II $\rightarrow$ Class I $\rightarrow$ Class II transition occurring when the stress is increased is shown schematically in Fig. 2.7 on a logarithmic plot of creep rate versus stress [88]. This three-stage behaviour is well suggested by the results of experiments conducted over a wide range of stresses on a single solid solution alloy (e.g.[89]). Combining Eqn. 2.63 with 2.64 , it can be concluded that Class I creep behavior with $n \approx 3$ occurs within a range of normalized stresses which may be restricted to the range described by:

$$
\psi\left(\frac{1}{C_{o}}\right)^{\frac{1}{2}} \frac{k T}{G b^{3}}\left(\frac{D_{S}}{D_{L}}\right)^{\frac{1}{2}}\left(\frac{G b}{\gamma_{F}}\right)^{\frac{3}{2}} \frac{1}{\epsilon_{A}}<\frac{\sigma_{c F}}{G}<\frac{W_{M}^{2} C_{o}}{5 G b^{2} k T}
$$

where the constant $\psi=\left[B_{0} /(1-v)\right]^{-\frac{1}{2}}$. 


\subsubsection{CREEP IN PRECIPITATION AND DISPERSION STRENGTHENED ALLOYS}

\subsubsection{INTRODUCTION}

The high temperature strength of many engineering alloys is due to the dispersion of second phase particles in the material. The mechanisms by which deformation can occur in such particle strengthened alloys have been the subject of many studies which are largely based on the mechanism proposed by Brown and Ham[90]. In these studies, it has been envisaged that the mobile dislocations are arrested or slowed down at the particles and that extensive deformation cannot occur unless a minimum, or threshold, stress is applied that allows the dislocations to escape from the pinning particles by one of the four possible mechanisms which have, in general, different threshold stress, viz.[91],

a) particle shearing either by fracture of incoherent particles or by the glide of dislocation pairs through coherent particles

b) bowing between particles (Orowan bowing) where the matrix dislocation is extended in the glide plane between particles by the applied stress to the extent that the dislocation is released, leaving loops around the particles.

c) climb around particles where segments of the dislocation can extend in a direction normal to the glide plane by diffusional processes in order to avoid the particles

d) Drag of particles where the dislocation continues to glide at a rate constrained by the diffusional movement of the pinning particles

Processes a) and b) have very small temperature dependence (i.e. are athermal) and, although various modifications have been proposed to deal with them, for example, elastic anisotropy [92], the general form of the Brown-Ham treatment of the deformation 
process has been widely accepted. The threshold stress for Orowan bowing mechanism is given by $[90]$ :

$$
\tau_{O B}=\frac{G b}{2 \pi \lambda} \ln \left(\frac{\lambda}{r_{o}}\right)
$$

and threshold stress for the cutting of coherent particles with a long range ordered structure is given by $[90]$

$$
\tau_{p c}=\frac{\gamma_{A}}{2 b}\left[\left(\frac{4 \gamma_{A} a f}{\pi \Gamma}\right)^{1 / 2}-f\right]
$$

In both these equations, $\lambda$ is the interparticle spacing, $r_{O}$ the dislocation core radius $\left(r_{o}=\right.$ b), $\gamma_{A}$ the antiphase boundary energy, $\Gamma=\frac{1}{2} G b^{1 / 2}$ the dislocation line energy [93], $f$ is the particle volume fraction and $a$ the particle dimension.

Processes c) and d) involve diffusional mass transfer and will be intrinsically slower than the other process or processes. Consequently if either mechanism a) and b) can occur it will control the deformation process. There have only been a few isolated observations of particle dragging which will not be considered further here since it apparently contributes little to creep deformation. However, dislocation climb around particles can be dominant when the athermal processes are inhibited. (i.e. at lower stresses leading to slow strain rates)

The first model of creep in precipitate-strengthened (PS) and dispersion strengthened (DS) alloys due to dislocation climb around particles was proposed by Ansell and Weertmen in 1959[94]. Though these models have lost much of their original significance, it seems useful to outline them briefly in Table 2.4 . 
TABLE 2.4 CREEP MODELS FOR PRECIPITATE-STRENGTHENED ALLOYS

\begin{tabular}{|c|l|l|}
\hline $\begin{array}{c}\text { STRESS } \\
\text { RANGE }\end{array}$ & MODEL[94] & ASSUMPTION \\
\hline$\frac{G b}{L}<\sigma<\frac{G b}{\lambda}$ & $\frac{\dot{\varepsilon}}{D_{l}}=\pi^{2}\left(\frac{b}{h}\right)^{2} \frac{G b}{k T} \frac{\sigma}{\ln \left(R / r_{o}\right)}$ & $\begin{array}{l}\text { Creep rate controlling process is associated } \\
\text { with dislocation climb around particles }\end{array}$ \\
\hline$\sigma>\frac{G b}{\lambda}$ & $\frac{\dot{\varepsilon}}{D_{l}}=2 \pi\left(\frac{\lambda}{b}\right)^{2} \frac{G b}{k T}\left(\frac{\sigma}{G}\right)^{4}$ & $\begin{array}{l}\text { Dislocation passed the particles by Orowan } \\
\text { looping. The rate controlling process is the } \\
\text { climb of dislocation loop left around the } \\
\text { particle. }\end{array}$ \\
\hline
\end{tabular}

$L:$ the maximum radius of a dislocation loop generated by Frank-Read sources

$\lambda$ : the interparticles spacing, $h$ the mean path which a dislocation has to pass by climb.

Both models in Table 2.4 do not explain the frequently observed much stronger dependence of creep rate on stress. These models also require the apparent activation energy for creep to be close to the activation enthalpy for lattice self-diffusion, while the observed values for the apparent energy are frequently much higher. The models described above are not able to account for either the very high values of the stress sensitivity parameter or the unrealistically high values of the apparent activation energy for creep, $Q_{c}$, frequently observed for creep in particle strengthened alloys. It was proposed that these high values of $\mathrm{m}^{\prime}$ and $Q c$ can be rationalized by the current concepts of creep by expressing the creep rate which is in terms of the difference of the applied stress $\sigma$ and the back stress $\sigma_{B},\left(\sigma-\sigma_{B}\right)$, instead of in terms of the applied stress alone. In this analysis the back stress is associated with the particle by-pass mechanism. Then, provided that the 
creep is lattice diffusion controlled, the creep rate can be described by the phenomenological equation

$$
\frac{\dot{\varepsilon}}{D_{L}}=A \frac{G b}{k T}\left(\frac{\sigma-\sigma_{B}}{G}\right)^{n}
$$

where $A$ and $\mathrm{n}$ are constants. The initial approaches along these lines were made by Wickers and Greenfield[95] and by Lagneborg[96] in 1968, but the concept has been much developed by Wilshire and collaborators[97 100] and by other authors[101 103]. Thus, it has been shown $[98,99,104]$ that incorporation of the temperature dependence of $\sigma_{B}$ allows the remaining temperature dependence of creep to be described by the lattice diffusion in the matrix by Eqn. 2.68. This implies that creep processes in particle strengthened alloys are closely related to those in single phase systems. To the stress exponent, a value of 4 , following the Lagneborg's [96] theory, has been assigned.

From Eqn. 2.68 and those defining the apparent activation energy for creep $Q_{c}$ (Eqn. 2.16) and the stress sensitivity parameter $\mathrm{m}^{\prime}$ (Eqn.2.27), it follows that,

$$
Q_{c}=\Delta H_{L}-k T^{2}\left[(n-1) \frac{1}{G} \frac{d G}{d T}+\frac{n}{\sigma-\sigma_{B}}\left(\frac{\partial \sigma_{B}}{\partial T}\right)_{\sigma}\right]
$$

and

$$
m^{\prime}=\frac{n \sigma}{\sigma-\sigma_{B}}\left[1-\left(\frac{\partial \sigma_{B}}{\partial \sigma}\right)_{T}\right]
$$

From Eqn. 2.70, it follows that $m^{\prime}=n$ when the back stress does not depend on applied stress, i.e., $\partial \sigma_{B} / \partial \sigma=0$, the parameter $m^{\prime}$ is 


$$
m^{\prime}=\frac{n \sigma}{\sigma-\sigma_{B}}
$$

and since $n$ is constant, it approaches infinity with applied stress approaching the back stress $\sigma_{B}$. In this case $\sigma_{B}$ represents a true threshold stress below which creep as described by Eqn. 2.68 does not occur. The parameter $m^{\prime}$ decreases with increasing applied stress and approaches the value of the exponent $n$ at applied stresses much above the back threshold stress.

\subsubsection{THE ORIGIN OF THRESHOLD STRESS WHEN CLIMB OF DISLOCATIONS AROUND PARTICLES IS THE RATE CONTROLLING PROCESS}

The climb of dislocation around particles was proposed to proceed by three basic mechanisms (Fig. 2.8) :

1. LOCAL CLIMB $[90,91,106]$

This is illustrated in Fig. 2.8a), where the dislocation segment between the particles remains in the glide plane and the remainder assumes profiles of the particles surface as it climbs. The threshold stress is the stress that is required to create the new length of dislocation generated during climb. This analysis only considers the effect of the shear stress in the glide plane neglecting the contribution of the normal component of applied stress to the climbing segment of dislocation. This is equivalent to assuming that particle separation is much greater than the particle diameter. That is, there is a low volume fraction of particles so that the climb force on the dislocation segment of the particle due to the shear stress is amplified. Then, the threshold stress for local climb is given by the expression 


$$
\tau_{l c}=\tau_{O B} / \sqrt{2}
$$

Lagneborg $[106]$ first pointed out that during local climb the sharp transition from the dislocation segment in the glide plane to that climbing the particle will be unstable. $\mathrm{He}$ showed that relaxation of the dislocation requires a larger segment to climb. Moreover, the length of new segment of dislocation created in climbing over the obstacles depends on the curvature of the gliding segment(i.e. applied stress). This results in a back stress resisting the climb/glide sequence that is proportional to the applied stress rather than an absolute threshold stress of the climb by-pass process.

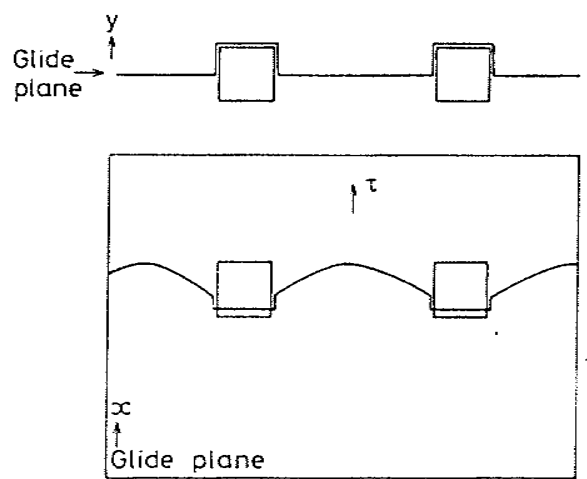

(a) Local climb

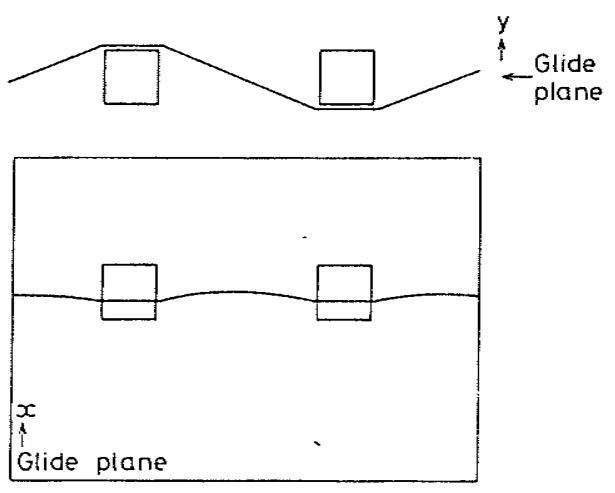

(b) General climb

a)

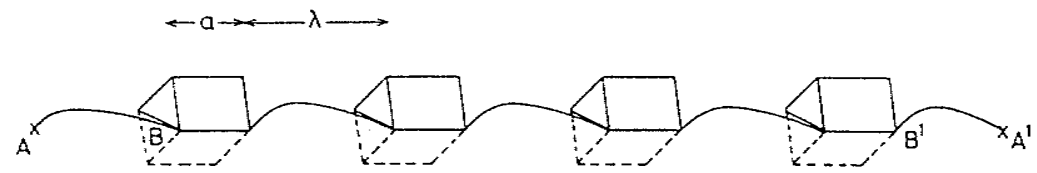

b)

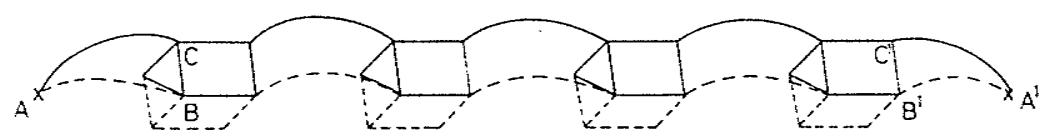

(c) Co-operative climb

Fig. 2.8 Schematic illustrations of dislocation configurations perpendicular to and in the glide plane for a) local climb; b) general climb; c) co-operative climb[91]. 

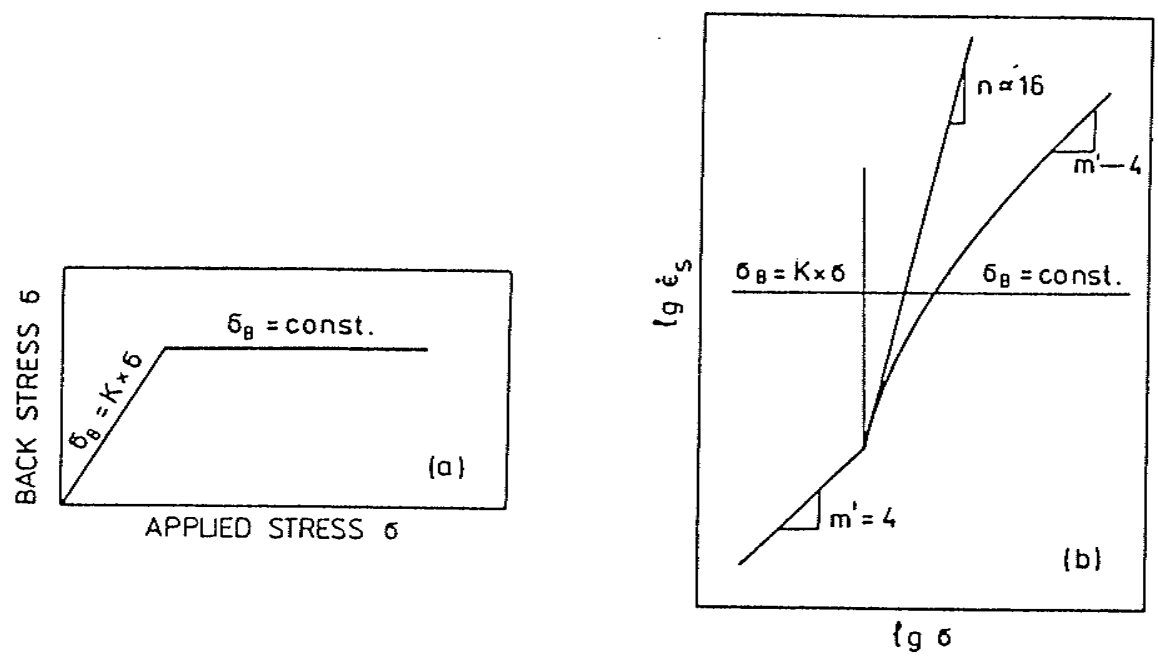

Fig. 2.9 Model of Lagneborg[106]. a) a relation between the back stress and the applied stress; b) corresponding applied stress dependence of creep rate.

At applied stresses lower than the Orowan threshold stress, the back-stress is given by,

$$
\sigma_{B}=K \sigma
$$

where the constant $K=0.7$. From Eqn. 2.71 , it follows that at applied stresses lower than $\sigma_{O B}$ the parameter $m^{\prime}=n$; for applied stresses higher than $\sigma_{O B}, m^{\prime}=16$ for $n=4$. With increasing stress the parameter $m^{\prime}$ decreases, and at applied stresses much higher than $\sigma_{O B}$ its value approaches the value of exponent $n$. This dependence of creep rate on applied stress is shown schematically in Fig. 2.9.

\section{GENERAL CLIMB}

As illustrated in Fig. 2.8b, general climb can occur with a smaller increase in dislocation length when all of the dislocation climbs out of the glide plane. This leads to a 
smaller threshold stress, or rather a range of threshold stresses depending on the effective mean spacing of obstacles which varies with the stress level.

Then,

$$
\begin{aligned}
& \tau_{G C}=\tau_{O B} f^{1 / 2} / 2^{1 / 4} \text { for high stress } \\
& \tau_{G C}=\tau_{O B} f^{3 / 2} / 5^{5 / 4} \text { for low stress }
\end{aligned}
$$

It is argued that general climb will occur many orders of magnitude more slowly than local climb since it involves considerably more diffusional mass transport. This will certainly be true in the low volume fraction approximation. However, for $\mathrm{f} \geq 12.5 \%$ the kinetics of the two processes should be largely equivalent.

These concepts have been very successful in accounting for the creep behaviour of alloys strengthened by low volume fraction of stable oxide particles. Measurements on single crystals of both $\mathrm{Cu}-\mathrm{SiO} 2$ (reviewed by Shewfelt and Brown[105]) and $(\mathrm{Ni}, \mathrm{Cr}$ )ThO2 (Nix and co-workers) $[107,108]$ show clear evidence of a threshold stress for creep at about $\sqrt{1 / 2} \tau_{O B}$. Associated with this is a very rapid increase in creep rate with applied stresses greater than $\sqrt{1 / 2} \tau_{O B}$ which declines to the stress sensitivity associated with the matrix as indicated in Fig. 2.10a $[110]$. The threshold stress measured experimentally has been associated with the local climb mechanism[109]; and although general climb is predicted to have a lower threshold stress, the strain rates produced are thought to be too low to be detected by the creep tests performed. This type of behaviour is not, however, observed in nickel-base superalloys that are reinforced by high volume fractions of coherent precipitate particles. On the contrary, there is an increase rather than a decrease in the value of stress sensitivity with an increase in applied stress as indicated in Fig.2.10b)[111]. 


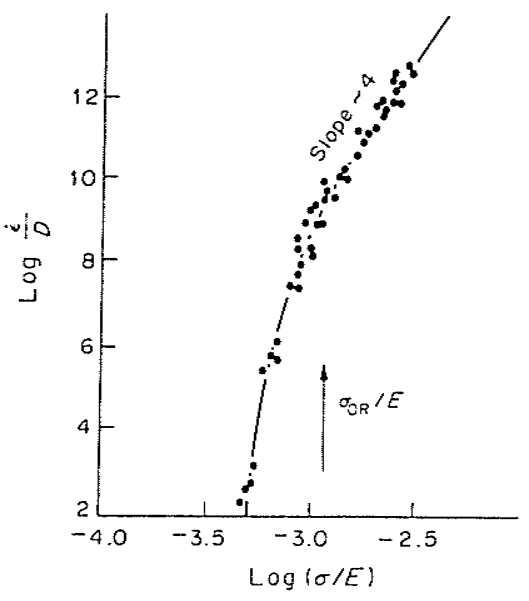

a)

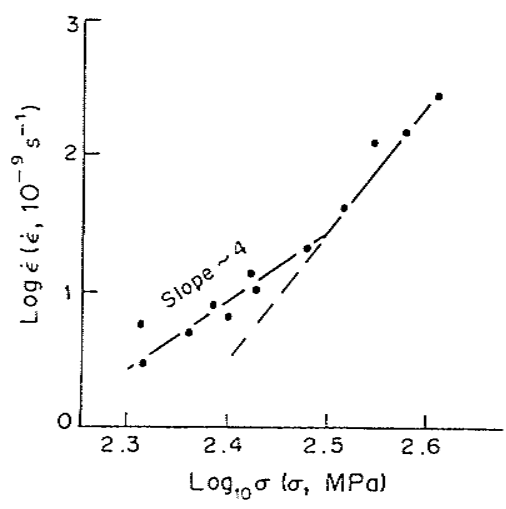

b)

Fig. 2.10 Typical creep data for a) Nickel containing low volume fractions of incoherent oxide particles [110], and b) a nickel-base superalloy containing high volume fraction of coherent particles[111].( after Mclean [91])

\section{GENERAL COOPERATIVE CLIMB [112]:}

Evans and Knowles proposed a process of general cooperative climb during creep deformation. They assumed that dislocations are arranged into a three-dimensional dislocation network and the nodes of this network are spatially fixed. At stresses higher than the Orowan bowing stress $\sigma_{O B}$, the lengths of dislocation links are shorter than the mean inter particle spacing $\lambda$ while at stresses $\sigma<\sigma_{O B}$ they are longer than this spacing. For $\sigma<\sigma_{O B}$ the situation is similar to that shown in Fig. 2.8c. The climb-by-passing of the particles which do not join at the nodes of the dislocation network will not be associated with creation of a new length of dislocation, i.e., dislocations climb in a cooperative manner around groups of particles. There is an energy advantage in allowing such a climb rather then climbing around each individual particle. The back stress then results exclusively due to an increment in length of the link between the nodes and the 
neighboring particles ( segments $\mathrm{AB}$ and $\mathrm{B}^{\prime} \mathrm{A}^{\prime}$ in Fig. 2.8c). Evans and Knowles[112] showed that under this assumption, the back stress is expressed by

$$
\sigma_{B}=\frac{8 \Gamma a}{3 b \lambda}\left[a^{2}+\left(\frac{\lambda}{4}\right)^{2}\right]^{-1 / 2}
$$

provided that $\sigma b \lambda / 8 \Gamma<1$. In En. $2.75, \Gamma=\frac{1}{2} G b^{2}$ is the dislocation line energy, $a$ and $\lambda$ are line dimensions given in Fig. 2.8c. Thus the back stress does not depend on applied stress and, consequently, represents a true threshold stress; $\sigma_{B} \equiv \sigma_{G C}$. The $\sigma_{G C} / \sigma_{O B}$ ratio depends strongly on the parameters of dispersion, i.e., on ratio $a / \lambda$. If value of this ratio approaches unity, which would be the case for regularly packed cube-shaped particles, $\sigma_{G C} / \sigma_{O B}$ approaches 0.75 . This analysis is most likely to be appropriate for high particle volume fraction alloys where the kinetics of general and local climb-converge.

Mclean[91] criticized the Evans-Knowles' analysis on the grounds that:

- It only considers the climb force generated by the shear stress and does not include the normal Peach-Koehler climb force component, and

- The work done in moving the dislocation link is only calculated over the part that changes length (segments $A B$ and $B^{\prime} A^{\prime}$ in Fig. 2.8c) rather than over the entire length that it climbs.

As the particle volume fraction increases, the climb force due to the normal component of the applied stress becomes relatively more important. This is taken into account in Mclean's formulation[91] of the model of general cooperative climb around particles. Conceptually, Mclean's[91] analysis is similar to that of Evans and Knowles[112].

Mclean $[91]$ considered the link of a three-dimensional dislocation network initially situated in a glide plane that intersects cube-shaped particles and pinned at the nodal points $A$ and $A^{\prime}$ (Fig. 2.8c). The climb force due to the normal component of the applied 
stress acts over the entire dislocation link and is biased in one direction. Consequently, cooperative general climb can occur over a group of particles as shown in Fig. 2.8c, while creating small new dislocation length than if climb is general.

The climb of a link of length $L$ over a particle involves displacement $\delta y$ (climb) normal to the glide plane and $\delta x$ (glide) in the glide plane. The energy change involved in these displacements is given by:

$$
\delta E=\Gamma \delta L-\tau b L \delta x-\sigma_{n} v L \delta y
$$

where $\sigma_{n}$ is the applied stress component normal to the glide plane. Although the whole dislocation link climbs, the only new length of dislocation created in climbing a height $y$ is at the ends of the link adjacent to the nodes $\mathrm{A}$ and $\mathrm{A}^{\prime}$. Then the increase in dislocation link length is $\delta L=2(A C-A B)$, which was shown by Evans and Knowles[112] to be expressed by:

$$
\delta L=2\left\{\left[y^{2}+\left(\frac{2 \Gamma}{\tau b} \sin ^{-1} \frac{\imath b \lambda}{2 \Gamma}\right)^{2}\right]^{-\frac{1}{2}}-\frac{2 \Gamma}{\not b} \sin ^{-1} \frac{\not b \lambda}{4 \Gamma}\right\}
$$

The effective force $\mathrm{F}$ acting on the dislocation is given by

$$
F=-\frac{d E}{d y}
$$

Combining Eqns. 2.76 and $2.77,2.78$, the following expression for the effective force is obtained, 


$$
F=-2 \Gamma y\left[y^{2}+\left(\frac{2 \Gamma}{\tau b} \sin ^{-1} \frac{\tau b \lambda}{2 \Gamma}\right)^{2}\right]^{-\frac{1}{2}}+\left(\sigma_{n}+\tau \frac{d x}{d y}\right) b L
$$

Dislocation will climb around the particles if $F>0$ for all values of $y \geq a / 2$. The threshold in this situation may be given by the condition $F=0$ under which climb is just possible.

Now, it is necessary to specify the link length $L$. In the absence of particles the network link length is given by the Orowan flow condition $L=\alpha G b / \sigma_{a}$, where $\alpha$ is a constant and $\sigma_{a}$ is the applied stress. In the presence of dispersed particles, part of the applied stress, $\sigma_{B}$, is required to extend the dislocations in order to for it climb over the particles and the difference is available for deformation of the matrix. Consequently,

$$
L=\frac{\alpha G b}{\sigma_{a}-\sigma_{B}}
$$

It is also necessary to establish the relative values of $\sigma_{n}$ and $\tau$. This is determined by the orientation of the applied stress relative to the glide plane. Thus the tensile stress $\sigma$ applied at an angle $\Theta$ to the normal to the glide plane has the following shear $(\tau)$ and normal $\left(\sigma_{n}\right)$ component in that plane

$$
\tau=\sigma \sin \Theta \cos \Theta ; \quad \sigma_{n}=\sigma \sin ^{2} \Theta
$$

Substituting Eqns. 2.80 and $2.80 \mathrm{a}$ into Eqn. 2.79 the back stress $\sigma_{B}$ is obtained by assigning a value of zero to $F$ and solving the resulting equation analytically. This is possible only when $\sigma \sin \Theta \cos \Theta<G b / \lambda$. Then,

$$
\frac{\sigma_{B}}{\sigma_{a}}=\left[1+\alpha\left(\sin ^{2} \Theta+\sin \Theta \cos \Theta \frac{d x}{d y}\right)\left(1+\frac{\lambda}{a^{2}}\right)^{1 / 2}\right]^{-1} .
$$


For constant volume fraction of particles, $f$, the ratio $\lambda / a$ is independent of particle size and is given by:

$$
\frac{\lambda}{a} \approx f^{-1 / 3}-1
$$

Thus,

$$
\frac{\sigma_{B}}{\sigma_{a}}=\left\{1+\alpha\left(\sin ^{2} \Theta+\sin \Theta \cos \Theta \frac{d x}{d y}\right)\left[1+\left(f^{-1 / 3}-1\right)^{2}\right]^{1 / 2}\right\}^{-1}
$$

Consequently, the back stress or resistance to flow, $\sigma_{B}$, by a glide/climb by-pass mechanism is proportional to the applied stress and is independent of the parameters of dispersion, i.e., a and $\lambda$, in contrast to the model of Evans and Knowles[112]. Climb-bypass of the particles is possible until $\sigma \sin \Theta \cos \Theta \geq G b / \lambda$ and this is the condition for looping of dislocations between particles by the Orowan mechanism. More precise results can be obtained by solving Eqn. 2.79 numerically[91].

In Fig. $2.11^{[91]}$ the minimum flow resistance or threshold stress for the three particle by-pass mechanisms(Orowan bowing, particle cutting and cooperative general climb) as a function of volume fraction of $\gamma^{\prime}$-phase particles in directionally solidified IN738LC nickel-base alloy for various applied stresses is shown. The applied stress is parallel to the $\left\langle 100>\right.$ direction, and the values of $G, b, a, \Theta, a, \gamma_{A}$ and $d x / d y$ are shown in the figure caption. It can be seen that at an applied stress of $300 \mathrm{MPa}$, for instance, the true threshold stress associated with Orowan bowing increases up to $f \cong 0.4$, when the condition for glide/climb by-pass mechanism if fulfilled. The flow resistance decreases abruptly to about $120 \mathrm{MPa}$ and then increases slightly with increasing value of $f$ up to $f \cong$ 0.8 , when the condition for the particle cutting mechanism is fulfilled and the flow resistance is consequently given by the true threshold for this mechanism. There is a 
discontinuous fall in flow resistance on changing from either Orowan bowing or cutting to climb-by-pass mechanism. In practice, however, there are a range of particle sizes and spacing which would lead to a coexistence of deformation mechanisms in the transition regions and this will smooth out the discontinuous changes.

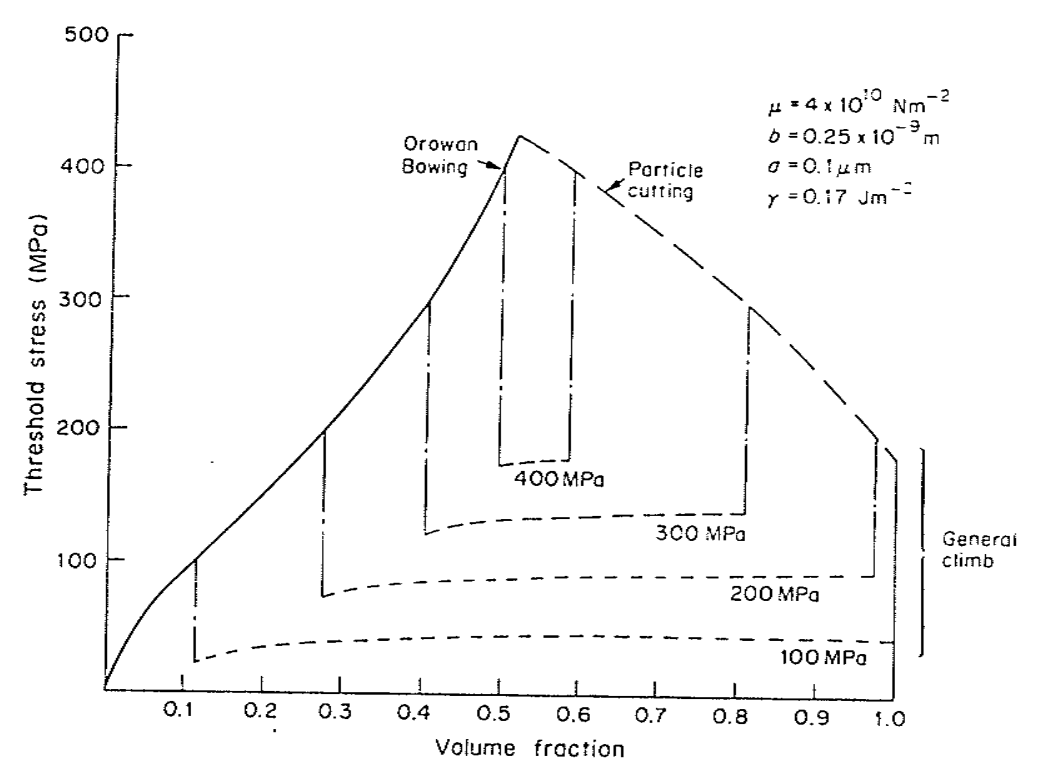

Fig. 2.11 Model of Mclean[91]: minimum flow resistance - or threshold stress for the three particle by-pass-mechanisms as a function of volume fraction of $\gamma^{\prime}$-phase particle for various applied stresses using parameters relevant to directionally solidified IN $738 L$ C alloy stressed parallel to $<100>$.

It should be noted that the implications of Mclean model[91] are quite different from those of the conceptually similar model of Evans and Knowles[112], but are qualitatively similar to the implications of the Lagneborg[106] model based on quite different assumptions. The main difference between the Mclean and Lagneborg models lies in the constants of proportionality between $\sigma_{B}$ and $\sigma$ which are $\sim 0.4$ and $\sim 0.7$, respectively. 
Mclean's model[ $[91]$ is based on an assumption of regularly spaced particles. It is argued that in many alloys with high volume fraction of strengthening phase, the particles are not randomly distributed but are regularly packed. For example, the ordered $\gamma^{\prime}$-phase in nickel-based superalloys is often in the form of cube-shaped particles arranged in an uniform array. Such a configuration leads to an extensive layers of matrix, along which long straight dislocation segments can climb without statistical modulations considered by Shewfelt and Brown[105], and Arzt and Ashby[113]. For high volume fractions of particles, the small inter-particle spacing relative to the size of the particles introduces constraints in both their orientation and distribution, and leads to large free paths along the matrix layers. Consequently, the configuration shown schematically in Fig. $2.8 \mathrm{c}$ is probably quite relevant. 


\subsection{ROLE OF GRAIN BOUNDARIES IN POWER-LAW DISLOCATION CREEP—GRAIN BOUNDARY SLIDING}

\subsubsection{INTRODUCTION}

It is generally recognized that the grain boundaries may play significant role in the creep deformation depending on the grain size of the material. This is presented in Table 2.5 , as recently suggested by Langdon[114].

\section{TABLE 2.5. DEFINITIONS OF GRAIN SIZE RANGES SHOWING SIMILAR CHARACTERISTICS[114]}

\begin{tabular}{|c|c|c|c|}
\hline $\begin{array}{l}\text { Grain size } \\
\text { range }\end{array}$ & Material condition & $\begin{array}{l}\text { Major characteristics of } \\
\text { flow }\end{array}$ & $\begin{array}{l}\text { Role of GBs in high } \\
\text { temperature deformation }\end{array}$ \\
\hline Macroscopic & $\begin{array}{l}\text { All single crystals. and very } \\
\text { large grained polycrystals } \\
\text { (typically }>1000 \mu \mathrm{m} \text { ) }\end{array}$ & Intragranular dislocation slip & No significant role \\
\hline Mesoscopic & $\begin{array}{l}\text { Medium grained polycrystals } \\
\text { (typically } 10-1000 \mu \mathrm{m} \text { ) }\end{array}$ & $\begin{array}{l}\text { Subgrains formed in high } \\
\text { temperature deformation, } \\
\text { core/mantle behavior }(d>\lambda)\end{array}$ & $\begin{array}{l}\text { Minor role in low (e.g. grain } \\
\text { boundary sliding in creep), } \\
\text { possible major role in fracture }\end{array}$ \\
\hline Microscopic & $\begin{array}{l}\text { very small grained polycrystals } \\
\text { (typically } 0.01-10 \mu \mathrm{m} \text { ) }\end{array}$ & $\begin{array}{l}\text { No subgrains formed, mantle } \\
\text { behavior only }(d<\lambda)\end{array}$ & $\begin{array}{l}\text { Major role in flow and } \\
\text { fracture (e.g. Superplasticity) }\end{array}$ \\
\hline Nanoscopic & $\begin{array}{l}\text { nanocrystalline materials } \\
\text { (typically }<0.01 \mu \mathrm{m} \text { ) }\end{array}$ & $\begin{array}{l}\text { Flow associated with boundary } \\
\text { processes, volume fraction of } \\
\text { grain boundaries }>30 \%\end{array}$ & $\begin{array}{l}\text { Grain boundaries account for } \\
\text { essentially all deformation }\end{array}$ \\
\hline
\end{tabular}


The macroscopic grain sizes are of little interest since they play only a minor role in creep deformation. Nanoscopic grain sizes represent an area where the current data are incomplete or even conflicting. Therefore, this section will only examine flow and fracture within the mesoscopic and microscopic grain size ranges.

In the power-law dislocation creep region, grain boundaries deform by sliding along each other due to shear stress along the plane of the grain boundaries. Grain boundary sliding may take place in a polycrystalline material either as a flow mechanism occurring independently of diffusion creep or as a natural consequence of the process of diffusion creep. Cannon[115] named these two mechanisms Rachinger sliding and Lifshitz sliding because of early evaluations of these two processes by Rachinger $[116]$ and Lifshitz [117], respectively.

The distinction between Rachinger sliding and Lifshitz sliding may be described by referring to Fig.2.12 where four hexagonal grains are deformed to different macroscopic strain for (a) Rachinger sliding, (b) Lifshitz sliding, respectively. The applied stress in Fig.2.12 acts in a vertical direction[118]

Rachinger sliding without diffusion creep is illustrated in Fig.2.12(a) and this may be accompanied by four different processes: (1) intragranular slip throughout adjacent grains (as in grain A), (2) localized slip adjacent to the boundaries (as in grain B), (3) the formation of triple point folds (as in grain C) or (4) the opening up of wedge cracks at the triple points (as in grain D at the junction of grains $\mathrm{A}$ and $\mathrm{B}$ ). The marker line in Fig.2.12(a) lies parallel to the stress axis and it shows sharp offsets at the boundaries due to the occurrence of grain boundary sliding. As noted by Cannon[115], Rachinger sliding provides additional strain by attempting to rearrange the grains so as to increase their numbers along the tensile axis. 


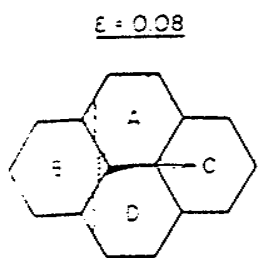

(o)

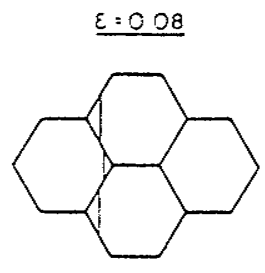

(b)

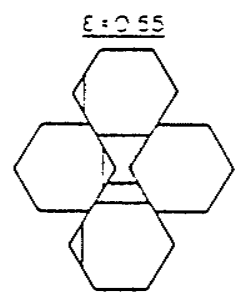

(c)

Fig. 2.12 Deformation in a polycrystal for a) Rachinger sliding and b) Lifshitz sliding in a material with a mesoscopic grain size and c) superplasticity in a material with a microscopic grain size; the tensile axis is vertical[118].

Lifsitz sliding is illustrated in Fig.2.12(b) and it refers to the situation where the individual grains become elongated through Nabarro-Herring [4,5] or Coble[6] diffusion creep. As the grains close up to maintain coherency, sharp offsets are produced in any marker lines at the points where they cross grain boundaries. It is important to note that the appearance of these offsets is similar to those produced by Rachinger sliding, but their origin is different because they represent only the accommodation of the change in grain shape due to diffusion creep and, in the limit, there is no increase in the number of grains lying along the tensile axis.

Considerable attention has been devoted to determining and evaluating the ratecontrolling mechanisms during steady-state flow. From experimental investigations, combined with theoretical consideration, it has been established that the steady-state creep rate, $\dot{\varepsilon}$, may be generally represented by an equation of the form[114]

$$
\dot{\varepsilon}=\frac{A D G b}{k T}\left(\frac{b}{d}\right)^{p}\left(\frac{\sigma}{G}\right)^{n}
$$


where $D$ is the diffusion coefficient, $A$ is a dimensionless constant, and $p$ and $n$ are constants which represent the exponents of the inverse grain size and the stress, respectively

\subsubsection{MODEL OF GRAIN BOUNDARY SLIDING}

The theories of Lifshitz and Rachinger divide grain boundary sliding into two distinct types. The first type is designed to predict the intrinsic rate of sliding of a grain boundary in which there is no hindrance from triple points and neighboring grains. In principle, this type of theory is applicable only to smooth, planar boundaries in bicrystal specimens. The second type considers accommodation of the sliding process also, and thus it applies to polycrystalline materials. These two types, termed intrinsic and extrinsic sliding models, are considered separately.

\subsubsection{INTRINSIC SLIDING MODELS}

The first detailed attempts to derive relationships for the intrinsic velocity of grain boundary sliding, $v_{s}$, were performed by Ashby and co-workers[119 121]. By assuming that the grain boundary slides in a Newtonian viscous manner and that the ledges or other irregularities on the surface of the boundary are of no more than atomic height, it was shown that $v_{s}$ may be expressed as $[121]$ :

$$
v_{s}=\frac{8 \delta D_{g b} G b}{k T}\left(\frac{\tau}{G}\right)^{1.0}
$$

Where $\delta$ is the width of the grain boundary, $D g b$ is the coefficient of grain boundary diffusion, and $\tau$ is the shear stress acting in the plane of the boundary. However, if there are ledges in the boundary plane of height $h$, Eqn. 2.67 is replaced by [119]: 


$$
\nu_{S}=\frac{8 \delta D_{g_{b}} G b}{k T}\left(\frac{b}{h}\right)^{2.0}\left(\frac{\tau}{G}\right)^{1.0}
$$

Eqn. 2.68 assumes that matter is transported between the ledges by grain boundary diffusion, and thus it refers to Lifshitz sliding. However, this type of flow is adequately modeled for polycrystalline materials by the theories of Nabarro-Herring [4, 5] and Coble[6] for diffusion creep, and it does not, in general, lead to cavity formation. In practice, it is more important to obtain a relationship for Rachinger sliding since this may lead to intergranular failure. It is anticipated that models for Rachinger sliding will be based on dislocation movement rather than vacancy flow, and two models for intrinsic sliding are now available.

Gates[123] developed a mechanism in which sliding arises due to the movement of structural or intrinsic grain boundary dislocation, and it was assumed that sliding was due to a combination of glide and climb processes. For the situation where the steps in the grain boundary are effective obstacles to dislocation motion, it was shown that

$$
v_{s}=\frac{\beta \delta D G b}{k T}\left(\frac{\tau}{G}\right)^{1.0}
$$

where $D$ is the appropriate diffusion coefficient and $\beta$ is defined as

$$
\beta= \pm\left(\frac{\psi \Omega^{2 / 3}}{x}\right) \frac{(1+\tan \alpha \cot \gamma)}{\tan \alpha \cot \gamma}
$$

where $\psi$ is the inverse of the spacing of the moving dislocations in the network, $\Omega$ is the atomic volume, $x$ is the length of the diffusion path (assumed to be equal to $10 b_{g b}$, where $b_{g b}$ is the Burgers vector of a grain boundary dislocation), and $\alpha$ and $\gamma$ are angles relating the grain boundary to the rotation axis. Although the diffusion coefficient was not defined 
explicitly in this model, it would probably be equivalent to the value for grain boundary diffusion.

In a later model, Pond et al[ $[124]$ considered that sliding arose from the movement of grain boundary dislocations in the boundary plane by a climb process. Then the shear strain rate in the plane of the boundary due to sliding, $\dot{\gamma}_{g b s}$, is given by

$$
\dot{\gamma}_{g b s}=\left(\frac{2 b_{g b}^{3} c_{j} \rho_{g b}}{\psi \xi}\right)\left(\frac{D_{g b} G b_{g b}}{k T}\right)\left(\frac{\tau}{G}\right)^{1.0}
$$

where $c_{j}$ is the jog concentration, $\rho_{g b}$ is the density of moving grain boundary dislocations, $\psi$ is a factor relating $b_{g b}$ to the distance a grain boundary dislocation climbs for each atom added $(1 \leq \psi \leq 10)$, and $\zeta$ is a constant relating the orientation of $b_{g b}$ to the grain boundary plane (typically, $\zeta=0.5$ ).

The important result contained in these models is that the sliding process is intrinsically Newtonian viscous in character, so that $n=1.0$, both for the mechanism based on vacancy flow(Eqns. 2.67 and 2.68) and for the two mechanisms based on dislocation climb (Eqs. 2.69 and 2.70). In practice, however, experiments on polycrystals generally show $n>1$. Pond et al[124] have suggested that this may be due to a stress dependence of $c_{j}$ or $\rho_{g b}$ in Eqn. 2.70 .

\subsubsection{EXTRINSIC SLIDING MODELS}

The preceding models are appropriate for planar boundaries in bicrystals, but they are not directly applicable to polycrystalline materials where it is necessary to consider the role of accommodation of stress ( or strain ) at the triple points also.

If sliding occurs by the climb and glide of dislocations in a zone adjacent to the grain boundary, the rate of sliding is governed by the rate of climb since this is the slower process. Furthermore, Langdon[125] has suggested that, if the sliding is accommodated 
not by an intragranular flow mechanism but by the opening of grain boundary cracks and cavities, then the strain rate due to sliding in a polycrystalline material, $\dot{\varepsilon}_{g b s}$, is given by

$$
\dot{\varepsilon}_{g b s}=\frac{A_{1} D_{l} G b}{k T}\left(\frac{b}{d}\right)^{1.0}\left(\frac{\sigma}{G}\right)^{2.0}
$$

where $D_{l}$ is the coefficient of lattice self diffusion, and $A l$ is a constant close to unity. This model therefore predicts a stress exponent of 2.0 , and activation energy equal to that of lattice self-diffusion, and an inverse linear dependence on grain size.

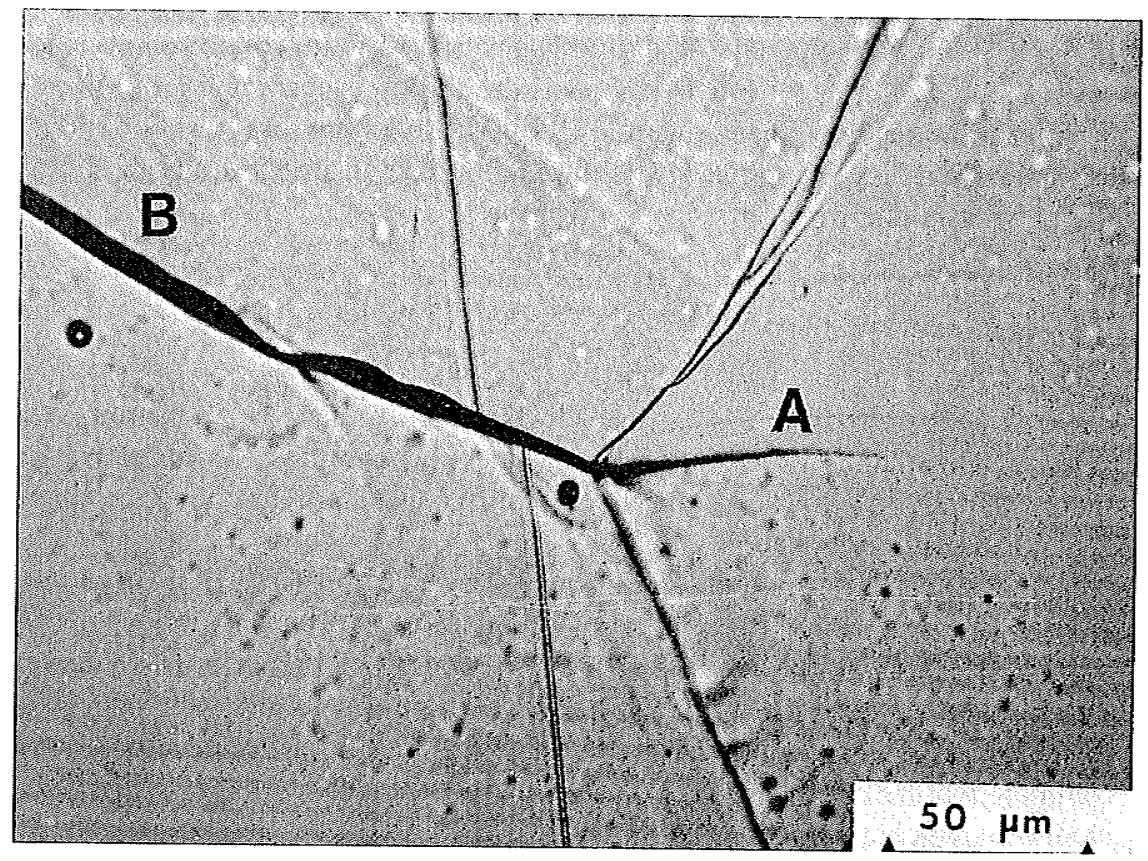

Fig. 2.13 An example of a triple point fold (A) formed in high-purity aluminum due to intergranlar sliding on boundary B. Specimen deformed to 7.8 percent at $573 \mathrm{~K}$ under a stress of 3.5 MPa: grain size $=535 \mu \mathrm{m}$. The stress axis is vertical $[126]$.

In polycrystalline materials deforming with extensive grain boundary sliding, an important experimental observation is the formation of intragranular folds at the triple 
points. An example of this type of folding is shown in Fig.2.13 for high-purity aluminum, where the fold A was formed by intergranular, sliding on the boundary labeled B. Triple point folds are a common feature in high-temperature creep. Gifkins [127] developed a model in which the formation of folds accommodated the sliding process. This model leads to rate of sliding which is given by,

$$
\dot{\varepsilon}_{g b s}=\left(\frac{2 F y \lambda A_{2}}{b^{2}}\right) \frac{D_{l} G b}{k T}\left(\frac{b}{d}\right)^{2.0}\left(\frac{\sigma}{G}\right)^{4.5}
$$

where $F$ is a stress concentration factor due to the action of sliding at the triple point, $y$ is the width of the triple point fold, $\lambda$ is the subgrain size, and $A_{2}$ is the value of the constant in the standard rate equation for lattice creep by dislocation climb. In the earlier theory of climb at the head of dislocation pile-ups [27], $A_{2}$ is given by $3^{0.5} \pi^{2} / 8 b^{1.5} M^{0.5}$, where $M$ is the number of active dislocation sources per unit volume. In the later theory based on climb at multiples[11], $A 2$ is equal to $1 / \beta^{\prime} \pi^{0.5} b^{1.5} M^{0.5}$, where $\beta^{\prime} \approx 6$.

In practice, the subgrain size is inversely related to stress through the following expression[126]

$$
\lambda=\Lambda\left(\frac{\sigma}{G}\right)^{-1}
$$

where $A$ is a constant. Thus Eqn. 2.72 is equivalent to

$$
\varepsilon_{g b s}=\left(\frac{2 \Lambda F y A_{2}}{b}\right)\left(\frac{D_{1} G b}{k T}\right)\left(\frac{b}{d}\right)^{2.0}\left(\frac{\sigma}{G}\right)^{3.5}
$$

This model therefore gives a stress exponent of 3.5 , an activation energy equal to the value for lattice self-diffusion, and an inverse grain size exponent of 2.0 . 
Crossman and Ashby[128] extended the relationship for intrinsic grain boundary sliding(Eqn. 2.68) to a polycrystalline matrix in which sliding is accommodated by plastic flow within the grains. They developed the deformation contour ( Fig. 2.14) within a grain when grain boundaries can slide freely, and found that as creep in the grains becomes more non-linear ( $n=4.4,8.8$ ) slip becomes increasingly concentrated into a band (the often observed intragranular folds at the triple points), across the horizontal mid-plane of the grains where the strain rate is more than twice $\bar{\gamma}_{A}$, and large parts of the grain deform at rates which are much less than $\bar{\gamma}_{A}$. Their resultant sliding rate is given by

$$
\dot{\varepsilon}_{g b s}=\left(\frac{8 \delta}{3 b}\right)\left(\frac{D_{g b} G b}{k T}\right)\left(\frac{b}{h}\right)^{2.0}\left(\frac{b}{d}\right)^{1.0}\left(\frac{\sigma}{G}\right)^{1.0}
$$

Thus, this model predicts a stress exponent of 1.0 , an activation energy equal to the value for grain boundary diffusion, and an inverse grain size exponent of 1.0 .

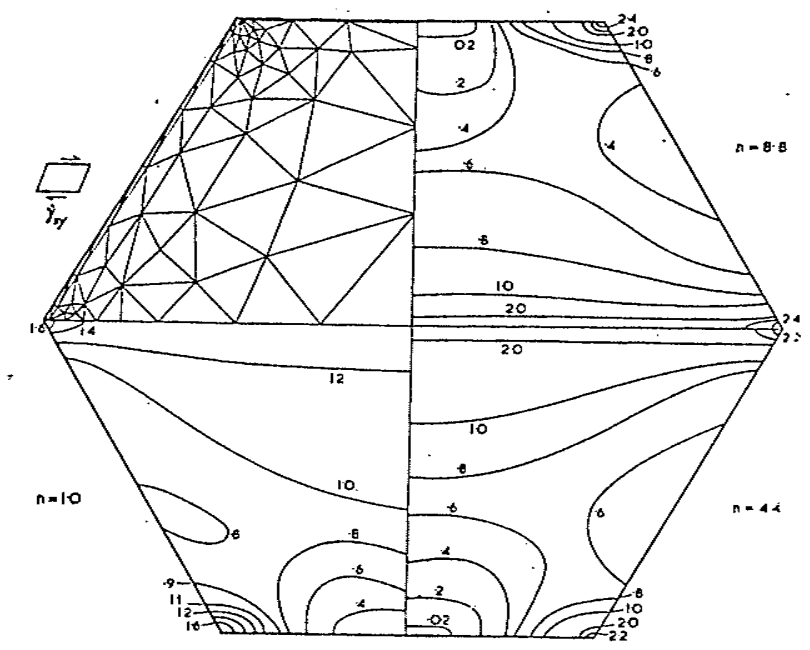

Fig. 2.14 Contours of normalized shear stain rate $\dot{\gamma}_{x y} / \dot{\gamma}_{A}$ during steady-state creep for a grain obeying power law creep (with exponents of 1.0, 4.4 and 8.8) surrounded by freely sliding boundaries. The fourth quadrant shows a typical mesh of elements[128]. 
An alternative analysis by Speight $[129]$ is also available in which it is assumed that coherency is preserved at the grain boundaries. Gifkins $[130]$ has pointed out that there are difficulties in applying this model to the experimental data, and it also appears that the analysis represents a special limiting case[131]. Accordingly, this model will not be included in the present discussion.

Finally, it should be noted that several theories are available for grain boundary sliding under superplastic conditions where the grain sizes are extremely small[132 134]. These theories are not generally applicable to normal polycrystalline materials deforming under high-temperature creep conditions, and they are therefore excluded from this review.

Howell and Dunlop[135] have observed experimentally that the main obstacles to the motion of grain boundary dislocations are particles situated on grain boundaries and triple junctions. These obstacles contribute to a threshold stress for grain boundary sliding. The authors have assumed that the rate at which grain boundary dislocations can surmount such obstacles is the major factor influencing the grain boundary sliding rate, i.e., the rate of accommodation of flow in grains is sufficiently rapid for the grain boundary sliding to be the rate controlling process. Under this assumption, they proposed the following equation for strain rate due to grain boundary sliding:

$$
\dot{\varepsilon}_{g b s}=A_{o} D_{B} \delta_{B}\left(\frac{G b}{k T}\right)\left(\frac{b}{d}\right)^{2}\left(\frac{\sigma-\sigma_{o}}{G}\right)^{n}
$$

where $n=2$ and the threshold stress

$$
\sigma_{o}=\sigma_{f}+\sigma_{p}+\Delta \sigma_{T J}
$$


$\sigma_{f}$ is a friction stress for the movement of grain boundary dislocations $[136,137], \sigma_{p}$ is the contribution due to particles situated on grain boundaries and $\Delta \sigma_{T J}$ is the contribution due to dislocation pile-ups at triple points (this is likely to be significant for small grain sizes). A value of 2 for the stress exponent $\mathrm{n}$ has been on an ad-hoc basis following Ball and Hutchison[138]. However, this value of $\mathrm{n}$ is not supported by experimental data.

\section{3. 3 CONTRIBUTION OF GRAIN BOUNDARY SLIDING TO TOTAL CREEP DEFORMATION}

Using finite element calculations, Crossman and Ashby[128] have studied the contribution of grain boundary sliding to total creep rate. If boundaries do not slide, the polycrystals deform uniformly following the creep law for the interior of a single grain.

$$
\overline{\dot{\gamma}}=A\left(\frac{\bar{\tau}_{A}}{G}\right)^{n}, \quad(\text { no } G B S)
$$

where $\bar{\gamma}$ is average strain rate, $\bar{\tau}$.is the average applied shear stress and $A$ and $n$ are constants. If, instead, grain boundaries slide freely, the flow field and stress field become non-uniform but the polycrystal again deforms according to power law with the same power $\mathrm{n}$ as before, and strain rate is given by $[128]$,

$$
\bar{\gamma}=A\left(f \frac{\bar{\tau}_{A}}{G}\right)^{n}, \quad(\text { free } G B S)
$$

where the stress enhancement factor, $f$, describes the acceleration of creep caused by freely sliding boundaries. The stress enhancement factor $f$ and the strain rate enhancement factor $f^{n}$ are independent of grain size.

Eqns. 2.78 and 2.79 are limiting cases, the first for high strain rates, the second for low strain rates. The transition from the latter to the former limiting case arises when grain 
boundary sliding can no longer occur fast enough to contribute significantly to the total strain rate. If a stress $\bar{\tau}$ is applied to the polycrystal, the stress in the sliding grain boundary can never exceed $\bar{\tau}$; thus the maximum contribution of GBS to the total strain rate is,

$$
\dot{\gamma}_{g b} \cdot \frac{\dot{\mu}}{d}=\frac{\delta_{B} \bar{\tau}}{d \eta_{B}}
$$

where the grain boundary viscosity $\eta_{B}$ is equal to $k T / 8 b D_{B}$. For convenience the authors $[128]$ have defined a normalized grain boundary viscosity

$$
\eta_{B}^{*}=\frac{d}{\delta_{B}} \eta_{B}
$$

so that

$$
\gamma_{g b}^{*}=\frac{\bar{\tau}}{\eta_{B}^{*}}
$$

Then, when the transition occurs this strain rate is equal to that caused by uniform creep described by Eqn.. 2.78, thus giving,

$$
\frac{\bar{\tau}_{T}}{G}=\left(\frac{G}{A \eta_{B}^{*}}\right)^{1 /(n-1)}
$$

or

$$
\dot{\gamma}_{T}=\left[\frac{1}{A}\left(\frac{G}{\dot{\eta_{B}}}\right)^{n}\right]^{1 /(n-1)}
$$


where $\bar{\tau}_{T}$ is the transition stress and $\dot{\gamma}_{T}$ is the transition strain rate. The transition strain rate varies with mean grain diameter as $d^{-n(n-1)}$. For a typical value of $n=5, \dot{\gamma}_{T}$ varies with grain diameter as $1 / d^{5 / 4}$.

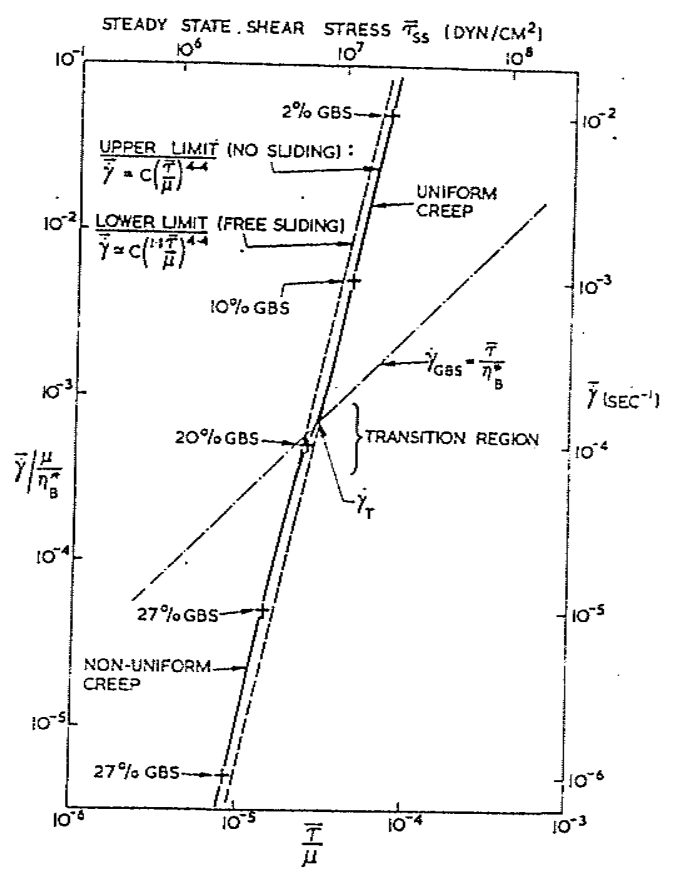

Fig. 2.15 A typical stress - strain rate plot in dimensionless $\bar{\gamma} / G \eta_{B}^{*}-\bar{\tau} / G$ coordinates, computed from the finite element model. The transition strain rate is adequately located by the intersection of the power-low creep curve for the grains $\dot{\gamma}=A(\bar{\tau} / G)^{n}$ with the flow low for the grain boundary, normalized to the grain size $\dot{\gamma}=\left(\delta_{B} / d\right)\left(\bar{\tau} / \eta_{B}\right)[128]$.

This simple approximation has been supported by computations using the finite element model[128]. The results of these computations in dimensionless coordinates $\bar{\gamma} / G \eta_{B}^{*}-\bar{\tau} / G$ are shown in Fig.2.15. The transition from non uniform to uniform flow is centered about the intersection of plot based on the grain boundary sliding Eqn. 2.80 with the plot based on creep Eqn. 2.78. This transition strain rate, given by Eqn. 2.84, is considered a logical normalizing parameter. The relative contribution of GBS $\chi=\gamma_{g b} / \bar{\gamma}_{A}$ depends not on the absolute value $\dot{\gamma}_{T}$, but on whether it is greater or less than $\dot{\gamma}_{A}$. The transition takes place in less than one decade of strain rate and the enhancement of strain 
rate due to GBS is not large. In Fig. $2.15, f_{n}=1.5$ for $n=4.4$. According to other authors $[131,139]$ the strain rate enhancement should be larger, ranging from 4 to 7.5 if the stress exponent $n=5[140]$. the best estimate of Crossman and Ashby is 2.2 for $n=$ 4.4 .

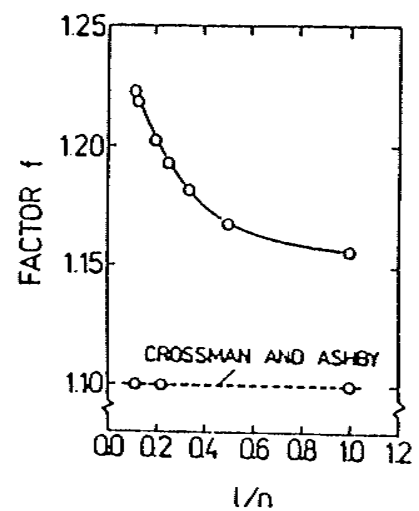

Fig. 2.16 Stress enhancement factor $f$ as a function of reciprocal stress exponent, $1 / n[139]$.

The problem of the effect of GBS on steady state creep in polycrystals was later analyzed by Chen and Argon and Ghahremani[139]. More accurate computations, using the finite element method led to the dependence of the stress enhancement factor $f$ on the reciprocal of stress exponent, 1/n, shown in Fig. 2.16. In this figure, the results of Crossman and Ashby are also shown for comparison.

The above results of Crossman and Ashby[128] have been displayed as fields on deformation mechanism maps. For aluminum, these maps are shown in Fig.2.17. In constructing the maps the ledge controlled viscosity

$$
\eta_{B}=\frac{k T}{8 b D_{B}}\left(\frac{h}{b}\right)^{2}
$$


was used with ledge heights of $0.01 \mu \mathrm{m}$. The boundary between the fields "no GBS" and "GBS" is given by Eqs. 2.83 and 2.84. From these maps, the effect of reducing ledge height $h$ and thus, of reducing the grain boundary viscosity can be determined. It is found that a reduction in the value of $h$ expands the field of non-uniform creep at the expense of uniform creep.

Grain boundary precipitation would have the reverse effect. By raising the grain boundary viscosity it would shrink the field in which sliding is important, and reduce the creep rate by the factor $f^{n}$.

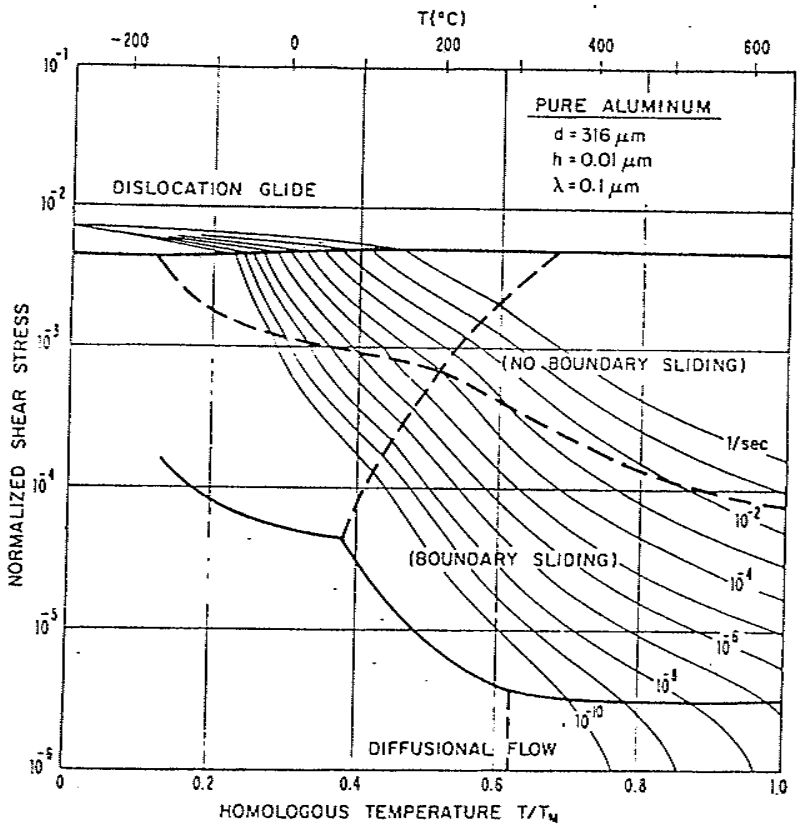

(a)

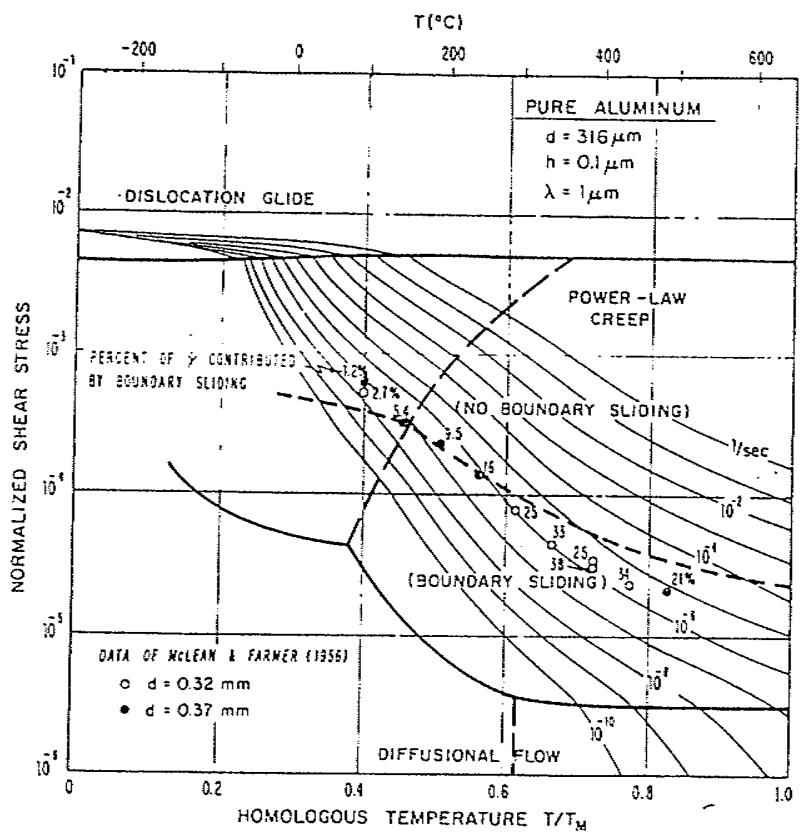

(b)

Fig. 2.17 a) A deformation mechanism map for pure aluminum of grain size 316 um and ledge $h=0.01$ am showing the sub-fields of power-low creep in which GBS is extensive and in which it is negligible. b) in a) but for a ledge height $h=0.1 \mu \mathrm{m}$ (i.e., for a boundary viscosity which is 100 times grater ) [128]. 


\subsubsection{EXPERIMENTAL RESULTS ON GRAIN BOUNDARY SLIDING}

\subsubsection{MEASUREMENTS OF GRAIN BOUNDARY SLIDING}

It is usual to separate total creep strain into two components

$$
\varepsilon_{\text {tot }}=\varepsilon_{g}+\varepsilon_{g b s}
$$

Attention is then focused on the ratio $\xi=\varepsilon_{g b s} / \varepsilon_{t o t}$ and its variation with testing and microstructural conditions.

The most obvious way of determining $\varepsilon_{g b s}$ is to measure $\varepsilon_{g b s}$ and $\varepsilon_{g}$ separately after creep and obtain $\varepsilon_{g b s}$ by subtraction through Eqn. 2.86. $\varepsilon_{\text {tot }}$ can be obtained from the creep curves and several techniques are available for the determination of $\varepsilon_{g}$.

Two methods are based on the changes in grain shape which occur during creep and can be applied equally well to the surface and interior of the specimen. The method described by Rachinger $[116]$ measures the average number of grain boundary intersection per unit length along lines parallel to and perpendicular to the stress axis before and after creep. The grain strain is given by

$$
\varepsilon_{g}=\left[\frac{N_{T}^{\prime} N_{L}}{N_{T} N_{L}^{\prime}}\right]^{2 / 3}-1
$$

where $N_{L}$ and $N_{L}^{\prime}$ are the number of intersections on a line parallel to the stress axis before and after creep, respectively. Similarly $N_{T}$ and $N^{\prime} T$ are number of intersections measured on a line transverse to the applied stress.

The confidence limits on the values of $\varepsilon_{g}$ are often large due to initial scatter in grain size and it has been proposed that a better accuracy can be obtained[114] by measuring, for a large number of individual grains, the maximum grain dimensions parallel 
to and at right angles to the stress direction before and after creep. A calculation of $\varepsilon_{g}$ follows from Eqn.. 2.87 when various intercept counts are replaced by the reciprocals of the average maximum grain dimensions in the appropriate direction.

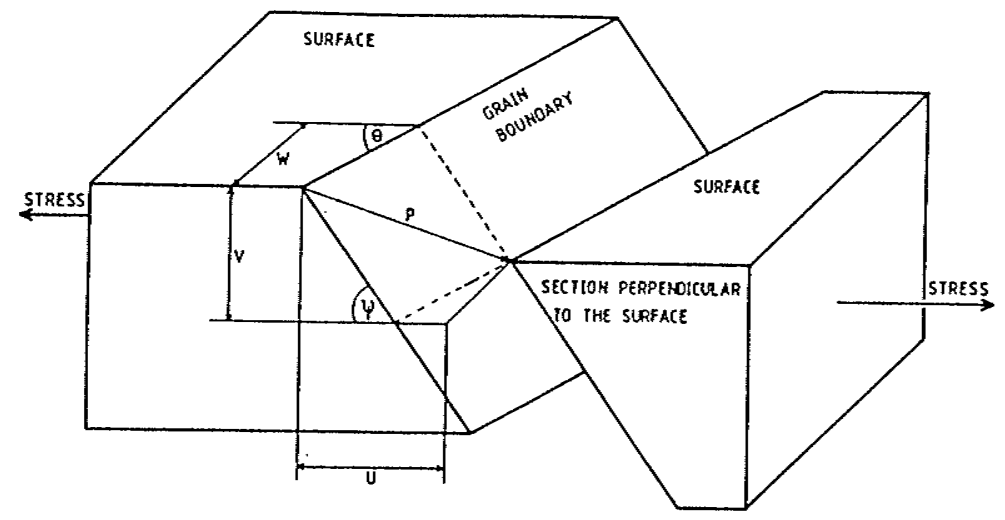

Fig. 2.18 Displacement vectors for a general sliding boundary[142].

An alternative general technique for grain boundary sliding measurements relates $\varepsilon_{g b s}$ directly to the average displacement between adjacent grains [142]. Fig. 2.18 shows the general displacement at a grain boundary which intersects the surface of a specimen. The overall displacement vector $p$, can be resolved into three mutually perpendicular components $u, v, w$, where $u$ is parallel to the uniaxial stress axis and $v$ is normal to the specimen surface. From this figure, it is seen that,

$$
u=\frac{v}{\tan \varphi}+\frac{w}{\tan \theta}
$$

For a line inscribed parallel to the stress axis prior to deformation, the average value of $u$ along the line is directly related to $\varepsilon_{g b s}$ by,

$$
\varepsilon_{g b s}=N_{L} \bar{u}
$$


In view of the Eqn. 2.88 and considering that $\theta$ and $\varphi$ (see Fig. 2.18) are not physically distinguishable in the interior of the specimen, then

$$
\varepsilon_{g b s}=2 N_{L}\left[\frac{\bar{w}}{\tan \theta}\right]
$$

The determination of $\bar{u}$ is often made difficult by grain boundary migration. This is also true for surface measurements of $\bar{w}$.

The simplest displacement parameter which can be measured with precision is $\bar{v}$ since it can be determined by interference techniques. The translation of $\bar{v}$ into $\varepsilon_{g b s}$ is not straightforward and relationships of the kind

$$
\varepsilon_{g b s}=K N v
$$

have been employed . Here $N$ and $\bar{v}$ must be determined from a random sample of grain boundaries and $\mathrm{K}$ is a constant.

\subsubsection{COMPARISON WITH EXPERIMENTAL RESULTS}

\section{DEPENDENCE ON STRESS}

Several attempts have been made to analyze the experimental data to determine directly the value of $n_{g b s}$. The results for polycrystalline materials are summarized in Table 2.6. A review of the data in Table 2.6 shows a large variation between the different sets of experiments. In all cases the results consistently show $n_{g b s}<n$. There is no support from the experiments on polycrystalline materials for $n_{g b s} \approx 1$, thereby tending to exclude the model represented by Eqn. 2.75. in which Newtonian viscous sliding is suggested to be 
accommodated by intragranular plastic flow. Furthermore, the results indicate $n_{g b s}>2$, thus casting some doubt on the climb-glide model given in Eqn. 2.71.

TABLE 2.6 A COMPARISON OF THE STRESS EXPONENT POLYCRYSTALS[126]

\begin{tabular}{llll}
\hline MATERIAL & $n$ & $n_{g b s}$ & REFERENCE \\
\hline & & & \\
Al-0.5Mg-0.5Si & $n-n_{g b s}=3.9$ & & Sklenicka et al[143] \\
$\mathrm{Cu}-30 \mathrm{Zn}$ & 5.1 & 3.3 & Saxl et al[144] \\
$\mathrm{Mg}-0.8 \mathrm{Al}$ & 5.2 & 2.4 & Langdon[145] \\
$\mathrm{Ni}$ & 3.8 & 2.3 & Rozenberg[146] \\
Low-carbon steel & 5.6 & 4.7 & Horton[147] \\
316 stainless steel & $6.0 \pm 0.2$ & $3.8 \pm 0.2$ & Horton[147] \\
Pure Al & 4.5 & 3.3 & Langdon[114] \\
\hline
\end{tabular}

\section{DEPENDENCE ON TEMPERATURE.}

Many experiments have been conducted to determine the activation energy for sliding, and the results are summarized in Table 2.7. For each material, the temperature range of test is indicated as a fraction of $T_{m}$, and the results are given as the approximate value of the ratio $Q_{g b s} / Q_{l}$. A value of $Q_{g b s} / Q_{l} \approx 1$ indicates that sliding is controlled by lattice diffusion, whereas a value of $Q_{g b s} / Q_{l} \approx 0.6$ tends to suggest control by grain boundary diffusion since, for most metals, $Q_{g b}=0.6 Q_{l}$ where $Q_{g b}$ is the activation energy for grain boundary diffusion. Thus an average value of $Q_{g b s} / Q_{l}$ close to 1 supports the inclusion of $D_{l}$ in the expression for $\dot{\varepsilon}_{g b s}$ (Eqns. 2.71 and 2.74), whereas an average value close to 0.6 supports the inclusion of $D_{g b}$ in the grain boundary sliding relationship 
(Eqn.2.75). In practice, although most, but not all, of the values of $Q_{g b s} / Q_{l}$ lie in the range from 0.6 to 1.0 .

TABLE 2.7 A COMPARISON OF THE ACTIVATION ENERGIES FOR GBS[126]

\begin{tabular}{llll}
\hline MATERIAL & T/Tm & $\sim Q_{g s s} / Q_{i}$ & REFERENCE \\
\hline Al & & & \\
& $0.6 \sim 0.7$ & 0.5 & Rozenbeerg \\
Cu-10Zn & & & Epshtein[148] \\
Cu-30Zn & $0.6 \sim 0.7$ & 0.6 & Saxl et al[149] \\
Ni & $0.6 \sim 0.7$ & 0.6 & Sklenicka et al[150] \\
& $0.5 \sim 0.6$ & 1.0 & Rozenberg[146 \\
Low-carbon steel & $0.5 \sim 0.6$ & $0.8 \sim 1.0$ & Ciha et al[151] \\
316 stainless steel & $0.6 \sim 0.7$ & 0.7 & Gates $[152]$ \\
Pure Al & $0.6 \sim 0.8$ & 1.0 & Langdon[114] \\
\hline
\end{tabular}

\section{DEPENDENCE ON GRAIN SIZE}

Since grain boundary sliding depends on the presence of grain boundaries, the value of $p$ is non-zero in Eqn. 2.66. However, it is difficult to determine the value of $p$ experimentally, because it is not sufficient to make a direct comparison of grain boundary sliding measurements taken at the same total strain, $\varepsilon$, for a series of different specimens of different grain size materials tested under the same conditions of stress and temperature. The reason is because a material having a smaller grain size will contain a larger number of grain boundaries and thus, at a fixed total strain, there are more grain boundaries each 
contributing a smaller offset. This problem was not appreciated in some of studies on grain size dependence $[153,154]$ of grain boundary sliding.

Langdon has applied an analytical procedure which avoids this problem, in the creep study of a Mg.-0.8Al alloy[145, 155] and $\mathrm{MgO}[156]$. His investigations give values for the inverse grain size exponent for sliding, $p_{g b s}$, to be 1.0 and 1.4, respectively. Thus these values of $p_{g b s}$ tend to support the dependence of $\dot{\varepsilon}_{g b s}$ on grain size represented by Eqns. 2.71 and 2.75 .

Very recently, Langdon has given a unified explanations of the behaviour of grain boundary sliding, which is summarized in Table 2.8[157].

TABLE 2.8 AN UNIFIED EXPLANATION FOR GRAIN BOUNDARY SLIDING

\begin{tabular}{|c|c|c|}
\hline GRAIN SIZE & EQUATION & \\
\hline Large grain size & $\dot{\varepsilon}_{g b s}=\frac{A_{g b s} D_{l} G b}{k T}\left(\frac{b}{d}\right)^{1}\left(\frac{\sigma}{G}\right)^{3}$ & $D_{l}$ :coefficient for lattice self-diffusion \\
\hline $\begin{array}{l}\qquad(\mathrm{d}>\lambda) \\
\text { Small grain size } \\
(\mathrm{d}<\lambda)\end{array}$ & $\dot{\varepsilon}_{s p}=\frac{A_{s p} D_{g b} G b}{k T}\left(\frac{b}{d}\right)^{2.0}\left(\frac{\sigma}{G}\right)^{2.0}$ & $\begin{array}{l}D_{g b}: \text { coefficient for GB diffusion } \\
\lambda: \text { subgrain size } \\
\text { Agbs, Asp: Dimensionless constant }\end{array}$ \\
\hline
\end{tabular}




\subsection{GRAIN BOUNDARY DEPENDENT CREEP BEHAVIOUR - INITIATION OF PRESENT STUDY}

A grain boundary is considered to be a softening influence in the region of powerlaw dislocation creep. The result of the softening influence is the grain boundary sliding, which has been discussed in detail in the previous section. However, one question can be

raised, are there any other mechanisms through which the creep rate or creep strain can be influenced by the presence of grain boundaries. The answer to the question is very controversial. On the one hand, it is generally assumed that creep rate is insensitive to grain size. On the other hand, many experimental results show clear evidence that creep rates are significantly influenced by grain size in a way that is not identical to grain boundary sliding. These controversies can be better visualized if the effect of grain boundary on creep behaviour is examined.

\subsubsection{VARIATION OF CREEP RATE WITH GRAIN SIZE}

The effect of grain size on creep rate in the power-law dislocation creep can be classified into the following two groups

\subsubsection{CREEP RATE IS INSENSITIVE TO GRAIN SIZE}

Often creep rate has been observed to be independent of grain size. A typical example of this type of behaviour, shown in Fig. 2.19, was reported by Barrett, Lytton and Sherby [158]. They investigated the creep of copper under two sets of conditions: a) random crystallographic orientation of grains and $b$ ) well developed cubic texture. The results showed that for random crystallographic orientation of grains, the creep rate, measured at a given mean grain diameter, does not depend on the mode of treatment producing this grain diameter. Also, when the mean grain diameter is greater than $100 \mu \mathrm{m}$, it does not influence the creep rate, but with mean grain diameter decreasing below $100 \mu$ 
$\mathrm{m}$, the steady-state creep rate increases slightly. Similar results were also reported by other investigators[159]. Hence it is not likely that the rate of dislocation creep depends on mean grain diameter. An increase in steady-state creep rate with decreasing mean grain diameter in the range below $100 \mu \mathrm{m}$ was explained on the basis of contribution of grain boundary sliding. The insensitivity of creep rate to grain size in the coarse grain region was related to the constant substructures developed in grain interiors. It has been assumed that dislocation substructure controls the creep rate, and since subgrain size is an inverse function of applied stress, the creep rate will remain the same at a given applied stress as grain size is increased.

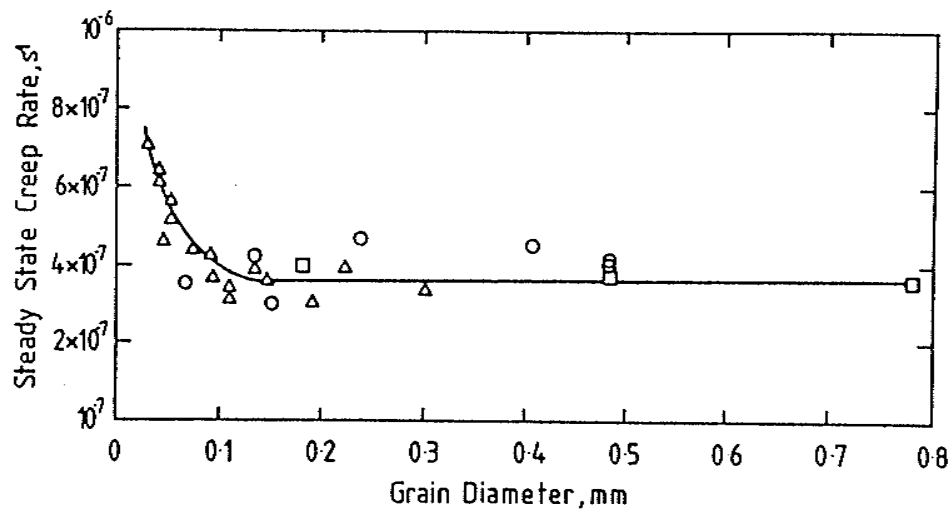

Fig. 2.19 The grain size dependence of the secondary creep rate of polycrystalline copper at $20.68 \mathrm{MPa}$ and $769 \mathrm{~K}[158]$.

o Samples deformed $50 \%$ and annealed for different times at $973 \mathrm{~K}$.

$\triangle$ Samples deformed varying amounts before a fixed anneal at $973 \mathrm{~K}$.

$\square$ Samples deformed $50 \%$ and annealed at temperatures in the range 1123 to $1323 \mathrm{~K}$. 


\subsubsection{U-SHAPE DEPENDENCE OF CREEP RATE ON GRAIN SIZE.}

In several investigations the creep rate is found to decrease and then increase with an increase in grain size. Fig. 2.20 shows a typical U-shape dependence of creep rate on grain size, which was reported by Garofalo et al[160]. The curve shows a negative dependence of creep rate on grain size in fine grain region, and positive dependence in coarse grain region. In the former region, the creep rate varies with grain size in the form of $d^{-p}$, where $\mathrm{p}$ is about 2 . The $\mathrm{U}$-shape dependence of creep rate on grain size were explained by dividing the curve into the fine grain and coarser grain region, respectively.

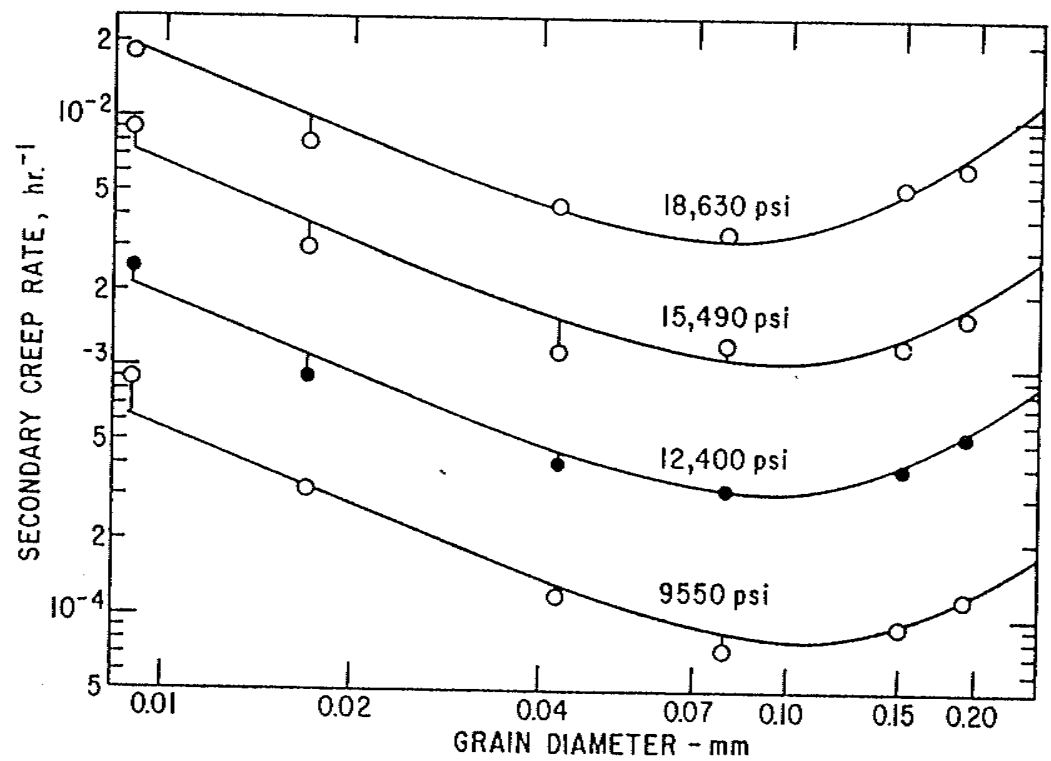

Fig. 2.20 Dependence of secondary creep rate on grain size for an iron-base austenitic alloy steel at $704^{\circ} \mathrm{C}[160]$

\section{FINE GRAIN REGION:}

Coble creep model: This model[161] was proposed mainly because the dependence of creep rate on grain size is similar to that found in Coble creep [6]. Further researches $[162]$ have shown that this idea is not valid because the stress-exponent , $n$, in 
this region is around 5 , which is much higher than that defined in Coble creep ${ }^{[6]}$ where $\mathrm{n}$ is found to be as low as 1 .

Dislocation pipe-diffusion model: $\quad$ This model[ $[163]$ is based on the idea that dislocation pipe-diffusion can increase the stress exponent by up to an extra order of 2. Since pipe-diffusion creep usually takes place at the temperature below $0.4 \mathrm{Tm}$, this model is also a not realistic one.

Grain boundary sliding model: Models of this type were established by considering the effect of grain boundary sliding of the following form.

$$
\left(\frac{\dot{\varepsilon}_{s} k T}{D G b}\right)_{g b s}=A_{g b s}\left(\frac{b}{d}\right)^{2}\left(\frac{\sigma_{a}}{G}\right)^{2}
$$

where $A_{g b s}$ is a constant, $d$ is grain size. Although Eqn. 2.92 explains the relationship between creep rate and grain size, the predicted stress exponent is still much lower than what is experimentally observed.

In order to explain the results shown in Fig. 2.20, Fang[164] et al have recently proposed a model using the grain boundary sliding mechanism suggested by Gifkins[165] based on the climb-controlled triple-point fold formation. They showed that in the region where the steady state creep rate increases with decreasing mean grain diameter $d$, the following expression is valid.

$$
\left(\frac{\dot{\varepsilon}_{s} k T}{D G b}\right)_{g b s}=A_{g b s}\left(\frac{b}{d}\right)^{2}\left(\frac{\sigma_{a}}{G}\right)^{n-1}
$$

Here, $A_{g b s}$ is a constant and $n=5.5$ is the stress exponent for steady state creep rate in the region of mean grain diameter where $\dot{\varepsilon}_{s}$ does not depend on $d$. As the mean grain diameter decrease further until it becomes equal to the mean subgrain diameter $d_{S}$, the stress and grain size dependencies of the steady state creep rate is given by [164]: 


$$
\left(\frac{\dot{\varepsilon}_{s} k T}{D G b}\right)_{g b s}=A_{g b s}{ }^{\prime}\left(\frac{b}{d}\right)\left(\frac{\sigma_{a}}{G}\right)^{n}, d \leq d_{s}
$$

where, again, $A_{g b s}{ }^{\prime}$ is a constant. The transition from Eqns. 2.93 to 2.94 should occur at very small grain diameters. The critical mean grain diameter below which Eqn. 2.93 becomes important will decrease with increasing applied stress.

Although the author found that Eqn. 2.93 fits the experimental results satisfactorily, contradictions still exist in several aspects. First of all, experimental results do not support the idea that stress exponent in fine grain region is an order of one unit less than that observed in coarse grain region. Secondly, the model predicts that the creep rate in the coarse grain region does not depend on the grain size. This does not agree with the experimental results in which creep rate was found to increase with an increase in grain size.

\section{IN THE COARSE GRAIN REGION}

Lagneborg[166], suggested that, the observed increase in $\dot{\varepsilon}_{s}$ with increasing grain size was probably the result of premature cracking which led to an early tertiary stage and thus an apparent enhancement of secondary creep rate. Langdon[167] also corroborated this view, based on the results of compressive creep tests in which $\dot{\varepsilon}_{s}$ was found to be independent of grain size in large grained materials. However, this suggestion has been criticized by Mannan and Rodriguez [168] who observed a strong increase in creep rate with grain size even at low stresses at which the premature cracking is unlikely to occur ( Fig. 2.21). This indicates that the positive dependence of creep rate on grain size is true.

Garofalo et al[160] explained the rising creep rate with grain size on the premise that, at high temperatures, grain boundaries are a steady source of dislocations and therefore grain size influences the mobile dislocation density. Barrett et al[169] have questioned the validity of this assumption on the basis of their experimental results where 
the density of dislocations within the subgrains was found to be unaffected by variation in grain size.

Mclean provided another explanation which is based on the strain-hardeningrecovery theory of creep, and uses the idea that, at high temperatures, fast grain boundary transport large dislocation meshes in and near grain boundaries which spread relatively quickly into the grain interior. By including the grain size dependent strain hardening along with grain size dependent recovery, the U-type curves observed for the variation of creep rate with grain size can be explained.

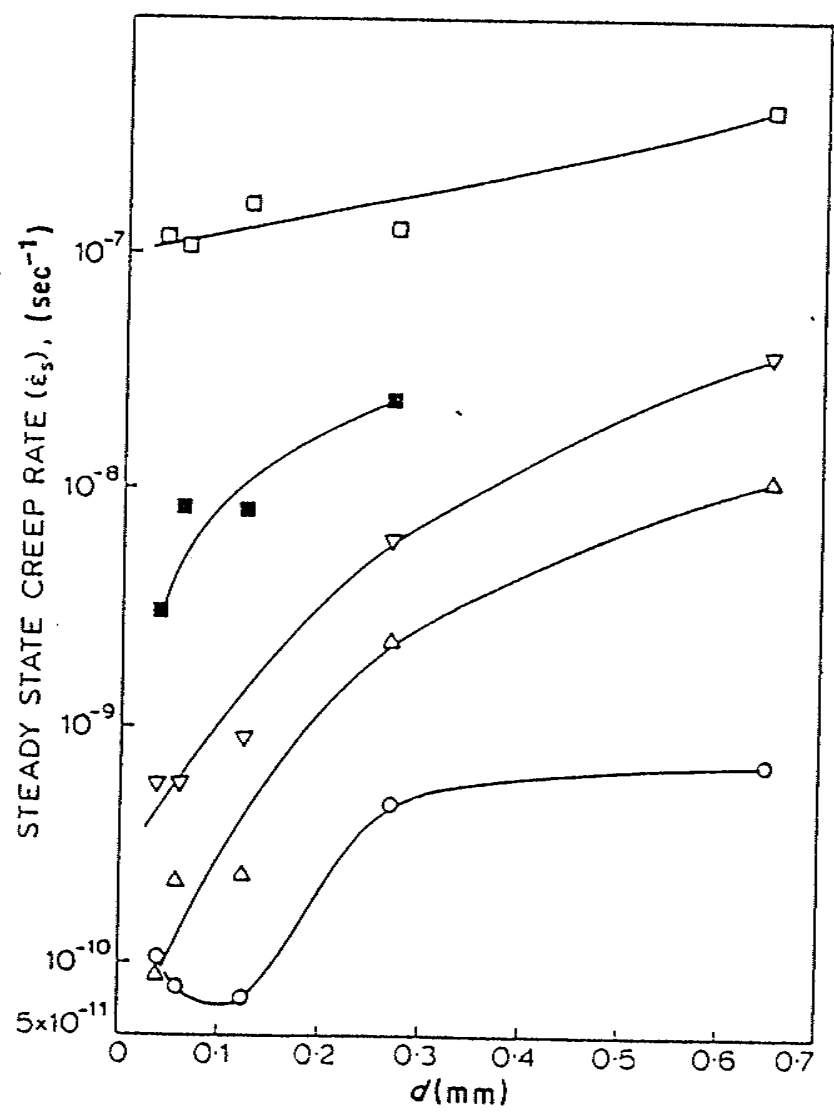

Fig. 2.21 Variation of steady state creep rate $\dot{\varepsilon}_{s}$ with grain size at various stresses for $873 K[168]$. 
Armstrong $[171]$ has developed a model to describe grain size effects on creep rate by incorporating the Hall-Petch relationship in the thermally activated flow model for deformation rates. He assumes that the single crystal flow stress $\sigma_{o \varepsilon}$ is the sum of single crystal athermal or internal stress $\sigma_{i}$, i.e.

$$
\sigma_{o \varepsilon}=\sigma_{i}+\sigma_{e}
$$

Substituting Eqn. 2.95 into the Hall-Petch relationship

$$
\sigma_{\varepsilon}=\sigma_{o \varepsilon}+K_{\delta} d^{-1 / 2}
$$

where $\sigma_{\varepsilon}$ is the flow stress at a given strain $\varepsilon$, and $\sigma_{o \varepsilon}$ and $K_{\varepsilon}$ are experimental constants known as the Hall-Petch intercept and the Hall-Petch slope, respectively. The grain size dependence of effective stress $\sigma_{\varepsilon}$ is found to be

$$
\sigma_{e}=\sigma_{\varepsilon}-\sigma_{i}-K_{\delta} d^{-1 / 2}
$$

Substituting of Eqn. 2.97 into the classical thermally activated flow model gives

$$
\dot{\varepsilon}_{s}=A^{\prime} \exp \left[-\frac{Q}{R T}+\frac{V^{*}}{m^{\prime} R T}\left(\sigma_{\varepsilon}-\sigma_{\dot{i}}-K_{\delta} d^{-1 / 2}\right)\right]
$$

where $Q$ is the magnitude of the rate limiting energy barrier in the deformation process, $V^{*}$ the activation volume, $A^{\prime}$ is a structure dependent constant, and $m^{\prime}$ is an orientation correction factor, while $R T$ has its usual meaning.

Based on Eqn. 2.98, the plots of $\log \dot{\varepsilon}_{s}$ versus $d^{-1 / 2}$ for the results presented in Fig. 2.21 are shown in Fig. 2.22. Even though the creep rate decreases as the grain size is 
decreased, the curvature is opposite to that predicted on the basis of Eqn. 2.98. The observed positive second derivative in Fig. 2.22 is consistent with earlier observations on other materials $[172,173]$ and implies that the role or grain boundaries cannot be described by simply incorporating the Hall-Petch relationship into the classical thermally activated flow model which is used to describe deformation rates.

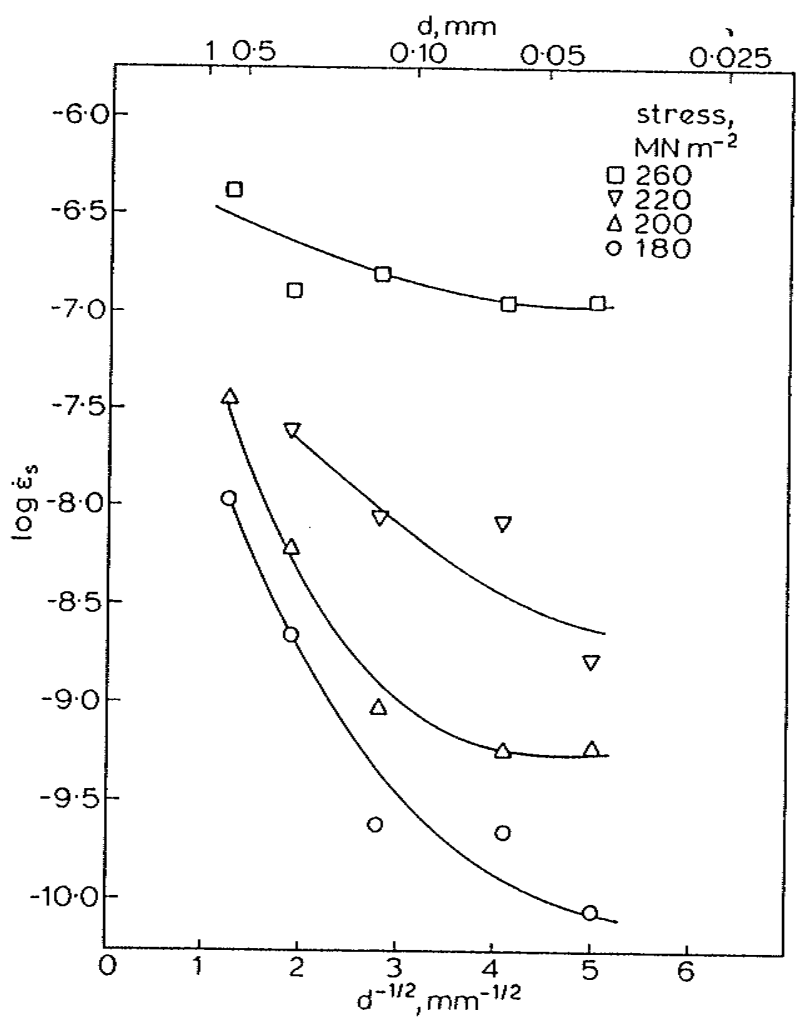

Fig. 2.22 Plots of $\log \dot{\varepsilon}_{s} v . d^{-1 / 2}$ at $873 \mathrm{~K}$ for different stresses (d is grain size) [168]. 


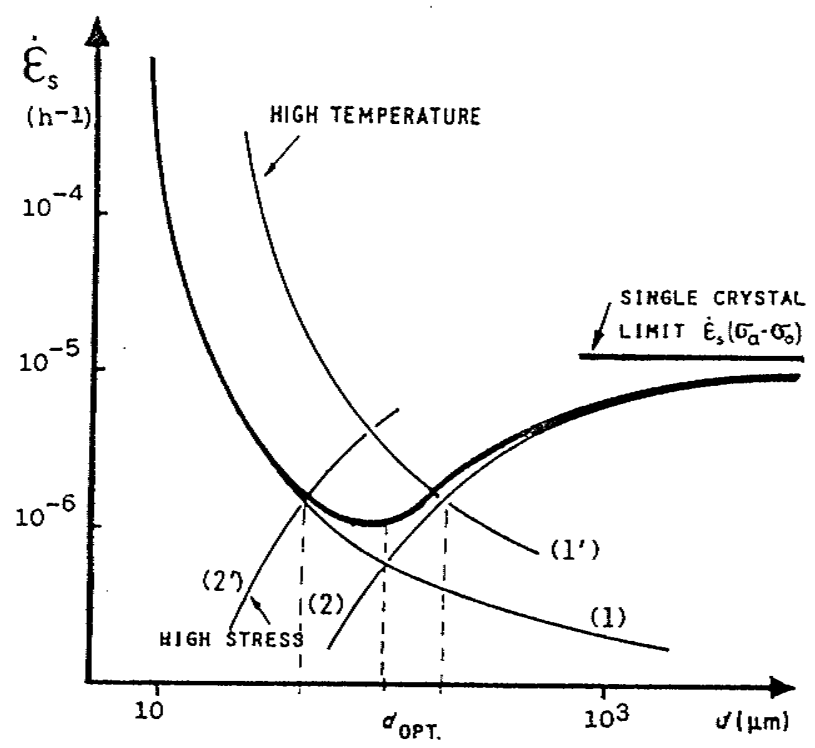

Fig. 2.23 Existence of an optimal grain size for which the minimal creep rate $\dot{\varepsilon}_{s}$ is lowest [174].

In a recent review paper, Lasalmonie and Strudel[174] gave a comprehensive explanation for the dependence of creep rate on grain size. They suggested the following expression:

$$
\dot{\varepsilon}_{s}=10^{7} D \frac{G b}{k T}\left(\frac{b}{d}\right)^{2}\left(\frac{\sigma_{a}}{G}\right)^{2}+10^{6} D \frac{G b}{k T}\left(\frac{\sigma_{e}}{G}\right)^{4.5}
$$

where $D$ is the diffusion coefficient at temperature $T, k$ is the Boltzmann's constant, $\sigma_{e}=\sigma_{a}-\sigma_{i}$ is the effective stress experienced by the dislocation and $\sigma_{i}$ the internal stress inside the material. The first term of Eqn. 2.99 describes the contribution of grain boundary sliding to the steady state creep rate, the second term of Eqn. 2.99 describes that of the dislocation creep. In order to include the grain size effects in the coarse grain region, it is suggested to consider 


$$
\sigma_{e}=\sigma_{a}-\sigma_{o}-k^{\prime} d^{-1 / 2}
$$

where $\sigma_{o}$ is associated with microstructural hardening,

By setting $\partial \dot{\varepsilon}_{s} / \partial d=0$, an optimum grain size of

$$
d_{o p t}=4\left[\frac{G(b)^{1 / 2}}{K}\right]^{2 / 3}\left(\frac{\sigma_{a}}{\sigma_{e}}\right)^{4 / 3}\left(\frac{G b}{\sigma_{e}}\right)
$$

can be obtained from Eqn. 2.99. The curve of Eqn. 2.99 is schematically shown in Fig. 2.23 .

Eqn. 2.99 also uses the grain boundary sliding model to explain the negative dependence of creep rate with grain size. This treatment, as stated above, contradicts the experimental results that the stress exponent in small grain region is always much higher than $2[160]$. In addition, simply incorporating the Hall-Petch relationship into the creep equation is also found to be inappropriate in explaining the positive dependence of creep rate on grain size observed in the coarser grain region[168].

\subsubsection{DEPENDENCE OF CREEP BEHAVIOUR ON GRAIN BOUNDARY MICROSTRUCTURES}

It is generally assumed that in the power-law dislocation creep, the creep deformation is controlled by the microstructures of grain interior. Grain boundaries may make contribution to total creep strain only by grain boundary siding. The change in microstructures at grain boundaries, then could influence the creep rate through the change in the rate of grain boundary sliding. As reviewed in section 2.3 , the change of 
sliding rate should not affect the creep mechanism which is always believed to be controlled by the microstructures of grain interiors. However, these beliefs can be questioned by the consideration of a few available results as described next.

Furillo, Davidson and Tien[175] have investigated the effect of grain boundary carbides on the creep and back stress of a Nimonic 115 superalloy, with a high ( about $40 \%$ ) volume fraction of $\gamma^{\prime}$ precipitates. By controlling heat treatment procedures, they produced microstructures that have the same precipitation conditions within grains. As shown in Table 2.9 , it was found that the true creep activation energies remain fairly constant for the both microstructural conditions, and are about equal to the activation energies determined from the creep of the polycrystalline nickel base superalloys. This suggests that in the either case creep is controlled by the thermally activated process involving vacancies. Concerning the large difference in the apparent stress exponent, they suggested that creep of the material without grain boundary carbides may be controlled by grain boundary sliding. For the material with grain boundary carbides, the stress exponent is much higher than that obtained for the material without grain boundary carbides. This is an indication of change in the creep mechanism.

Table 2.9 Stress exponents and activation energies for steady state creep and calculated back stress values for specimens without and with grain boundary carbides [175]

\begin{tabular}{lccccc}
\hline Microstructures & $n_{a}$ & $Q_{a}$ & $Q_{o}$ & $\left.\sigma_{b}\right|_{a t n_{o}=2}$ & $\left.\sigma_{b}\right|_{a r n_{o}=4}$ \\
& & $\left(\mathrm{~kJ} \mathrm{~mol}^{-1}\right)$ & $\left(\mathrm{kJ} \mathrm{mol}^{-1}\right)$ & $(\mathrm{MPa})$ & $(\mathrm{MPa})$ \\
\hline Without GB carbides & 2.18 & $334.4 \pm 104.1$ & 324.8 & 44.8 & \\
With GB carbides & 14.58 & $390.3 \pm 81.0$ & 297.4 & 467.0 & 394.5 \\
\hline
\end{tabular}
where $n_{a}$ is the apparent stress exponent, $Q_{a}$ is the apparent creep activation energy, $Q_{0}$ is the true creep activation energy, $\left.\sigma_{b}\right|_{a t n_{o}=2}$ is back stress value based on $n_{o}=2$, and $\left.\sigma_{b}\right|_{\text {at } n_{o}=4}$ is back stress value based on $n_{o}=4$ 
Zhang and Chen $[159,176 \sim 177]$ studied the effect of grain boundary strengthening on the creep of $\mathrm{Fe}-15 \mathrm{Cr}-25 \mathrm{Ni}$ alloys. By changing carbon content of the alloys and controlling heat treatment procedures, microstructures were obtained that were either purely single phase polycrystalline or single phase polycrystalline with only carbides at the grain boundaries. It was found that creep rate is insensitive to grain size for single phase material, which implies that grain boundary sliding has not occurred. However the creep rate was observed to increase with grain size ( $\dot{\varepsilon}_{s} \propto d^{0.4}$ at $850^{\circ} \mathrm{C}$ ) for the material with carbides at grain boundaries. The stress exponent for the two materials was also different, and was observed to be 5 for the former and around 7 for the latter.

Another evidence which supports the fact that creep bebaviour is grain boundary dependent was obtained by Maruyama, Wananabe and Oikava[178]. They found that with the addition of a very smail amount of aluminum in a zinc bi-crystal, creep rate can be reduced by one order of magnitude and the creep behaviour was also found to be altered by the addition of aluminum. They concluded that the grain boundary strengthening is as important as the other strengthening mechanisms available in the power-law creep regime.

\subsubsection{GRAIN BOUNDARY DEPENDENT CREEP BEHAVIOUR}

The following can be concluded from the analysis presented in the previous section:

(i) The creep rate in some cases is insensitive to grain size, however, is strongly dependent on grain size in many cases. The negative dependence of creep rate on grain size in fine grain region seems to be related to the mechanism of grain boundary sliding through various ways. This, however, seems to contradict the experimental observations in one aspect or another.

(ii) There are no doubts about the existence of positive dependence of creep rate on grain size. The Hall-Petch relationship has been simply incorporated to the creep 
equation for the explanation of the positive dependence of creep rate on grain size. This treatment has been found to be inappropriate.

(iii) The creep behaviour in terms of stress exponent has been also found to be a function of grain boundary microstructures. This indicates that grain boundary microstructures might be as important as the microstructures of grain interiors in controlling the creep deformation process.

Therefore, answer to the question posed at the beginning of the section is in affirmative. That is, grain boundaries can influence the creep rate by a mechanism which is different from grain boundary sliding. Due consideration to this might not have been given in the past because of the minor influence of non-grain boundary sliding mechanism observed in a few cases that were investigated and this aspect was generally ignored.

\subsubsection{THE SCOPE OF THE PRESENT RESEARCH}

The well developed commercial Inconel 718 was used in this investigation to study the grain boundary dependence of creep behaviour. This alloy has been extensively studied[179 189] and the effect of heat treatment on microsturctures is generally understood. The relationship between microstucture and mechanical properties have been also studied extensively[180 181,190 191]. The effect of grain boundary strengthening on mechanical properties is a subject that has been receiving increasing attention in recent years. However, the grain boundary-related creep behaviour has not received much

attention[182 182a]. In addition, most studies in this direction have been conducted mostly for the improvement of mechanical properties through some modified heat treatment procedures. Such modified heat treatments have changed the microstructures at grain boundaries as well as within the grain interior. As a result, it is not possible to ascertain if the resulting improvement in mechanical properties is due to the change in grain boundary microstructures or in the microstructures of grain interior. Therefore, this study was initiated to study the grain boundary dependence of creep in Inconel 718 by producing 
two types of materials one with precipitates of $\delta-\mathrm{Ni} 3 \mathrm{Nb}$ at the grain boundaries and another without. Having obtained the microstructures at grain boundaries, all the specimens were given an aging heat treatment at a temperature which is proven to be low enough so that it does not cause any changes in the microstructures of grain boundaries. By this heat treatment, specimens with the following microstructures were prepared:

- Specimens with identical microstructures at grain boundaries but with varied microstructures, and hence, strength in the grain material.

- Specimens with identical strength in grain materials but with various precipitate density at grain boundaries

- Specimens with identical microstructures except for the grain size Creep tests on these specimens were conducted at temperatures ranging from $600^{\circ} \mathrm{C}$ to $650^{\circ} \mathrm{C}$ and at an applied stress ranging from $745 \mathrm{MPa}$ to $860 \mathrm{MPa}$. Back stresses of certain specimens were also determined. With these tests, the following major results on the two type of materials were obtained

- The dependence of creep rate on the strength of grain material

- The dependence of creep rate on applied stress and test temperature

- Variation in creep behaviour with the precipitate density at grain boundaries

- Effect of grain size on creep behaviour

- The dependence of back stress on (i) applied stress, (ii) temperature, (iii) precipitate density at grain boundaries, and (iv) grain size.

By analyzing the results obtained, mechanisms relevant to the deformation of grain boundaries have been suggested. 


\section{CHAPTER THREE EXPERIMENTAL METHODS}

\subsection{MATERIAL}

The material used in this study was wrought commercial Inconel 718 which was provided by Bristol Aerospace Lt. Canada. The nominal chemical composition ( wt. \%) as well as the actual chemical composition of the material is listed in Table 3.1.

Table 3.1 Chemical composition of Inconel 718 (wt.\%)

\begin{tabular}{ccc}
\hline Elements & Actual composition (wt.\%) & $\begin{array}{c}\text { Nominal composition } \\
\text { (wt.\%) }\end{array}$ \\
\hline $\mathrm{C}$ & 0.03 & 0.03 \\
$\mathrm{Fe}$ & 19.2 & 19.0 \\
$\mathrm{Ni}$ & 52.37 & $\mathrm{Bal}$. \\
$\mathrm{Cr}$ & 18.24 & 18.0 \\
$\mathrm{Al}$ & 0.52 & 0.5 \\
$\mathrm{Ti}$ & 0.97 & 1.0 \\
$\mathrm{Mo}$ & 3.07 & 3.0 \\
$\mathrm{Nb}+\mathrm{Ta}$ & 4.98 & 5.0 \\
$\mathrm{Mn}$ & 0.007 & $/$ \\
$\mathrm{S}$ & 0.007 & $/$ \\
$\mathrm{Si}$ & 0.3 & $/$ \\
$\mathrm{Cu}$ & 0.04 & $/$ \\
\hline
\end{tabular}

\subsection{PREPARATION OF TENSILE AND CREEP SAMPLES}

A $2.54 \mathrm{~mm}$ thick sheet of the alloy was cold-rolled to a thickness of about $1.4 \mathrm{~mm}$ before it was machined into flat creep and tensile samples which have a gauge dimension of $1.3 \mathrm{~mm} \times 5.3 \mathrm{~mm} \times 2.54 \mathrm{~mm}$, as shown in Fig. 3.1 The machining of the sample was carried out by a numerically controlled universal milling machine. 


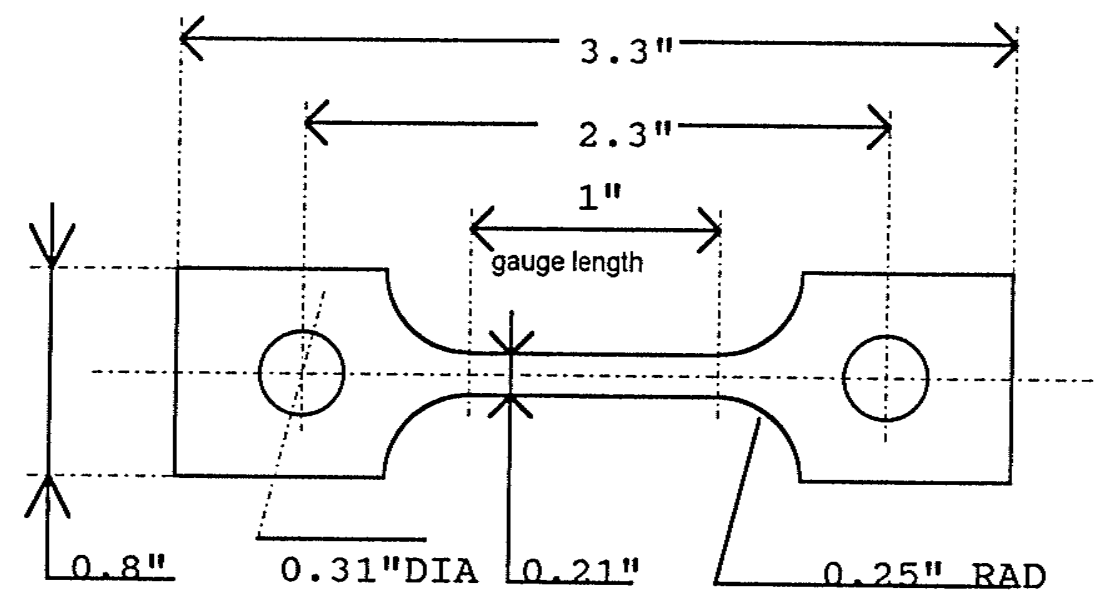

Fig. 3.1 Dimension of creep and tensile specimens

Before the tensile or creep testing, all the samples were grounded on sandpaper from the coarse to fine up to 600 grades, to remove all the defects and oxidized layer from the surface.

\subsection{HEAT TREATMENT PROCEDURES}

The tensile and creep samples were heat-treated in accordance with the scheme illustrated in Table 3.2. In order to obtain a microstructure with grain boundaries free from precipitates, the samples were solid solution treated at a temperature above $1020^{\circ} \mathrm{C}$ for 4 hours, and then air-cooled to room temperature. The material after such a heat treatment was designated as material A. The second type of material, designated as material $\mathrm{B}$, was given the same solid solution treatment, but was furnace-cooled instead at a cooling rate of $50^{\circ} \mathrm{C} /$ hour to $725^{\circ} \mathrm{C}$. The furnace cooling, as reported by other investigators $[180,182$, $190]$, can introduce small precipitates of $\delta$-phase at grain boundaries, and the coarse precipitates of $\gamma^{\prime \prime}+\gamma^{\prime}$ within the grains. The subsequent solid solution treatment at a temperature ranging from $900^{\circ} \mathrm{C} \sim 1000^{\circ} \mathrm{C}$ for the material was designed to dissolve the 
coarse $\gamma^{\prime \prime}+\gamma^{\prime}$ particles, but maintain the $\delta$-phase particles at grain boundaries. As a result of these two solid solution treatments, the intragranular microstructure of material B and material A were identical, however, the grain boundaries of material A were free of precipitates and those of material B had $\delta$-precipitates on them.

Table 3.2 Heat treatment schemes for Inconel 718

\begin{tabular}{|l|l|l|}
\hline Material & \multicolumn{1}{|c|}{ Solid solution treatment } & Aging heat treatment \\
\hline Material A & $1020^{\circ} \mathrm{C} \sim 1100^{\circ} \mathrm{C} \times 4$ hour with air-cooling & $725^{\circ} \mathrm{C}$ for various time \\
\hline Material B & $\begin{array}{l}1020^{\circ} \mathrm{C} \sim 1100^{\circ} \mathrm{C} \times 4 \text { hour with furnace-cooling } \\
\text { at } 50^{\circ} \mathrm{C} / \text { hour to } 725^{\circ} \mathrm{C} \\
900^{\circ} \mathrm{C} \sim 1000^{\circ} \mathrm{C} \times 1 \text { hour with air-cooling }\end{array}$ & $725^{\circ} \mathrm{C}$ for various time \\
\hline
\end{tabular}

After the solid solution treatment, both materials were given the same aging treatment at $725^{\circ} \mathrm{C}$ for various lengths of time to produce strengthening precipitates in the grain interior. This aging treatment did not cause any change in the grain boundary microstructure of both the materials, since $\delta$-phase starts to precipitate at a temperature much higher than $725^{\circ} \mathrm{C}$. Therefore, the heat treatment used in this study produced two types of microstructure, both of which differs from each other only in the microstructure at grain boundaries.

\subsection{MICROSTRUCTURAL EXAMINATION}

\subsubsection{OBSERVATION OF MICROSTRUCTURE}

Microstructures before and after the creep tests were examined by optical microscope and a JEOL 840 Analytical Scanning Electron Microscope. Both materials 
were etched differently to reveal different aspects of their microstructures. Various of etchants used in this study are listed in Table 3.3.

Table 3.3 Etchants used for Inconel 718 in this study

\begin{tabular}{|l|l|}
\hline \multicolumn{1}{|c|}{ Etchant used } & \multicolumn{1}{|c|}{ Comments } \\
\hline $\mathrm{H}_{3} \mathrm{PO} 4(12 \mathrm{ml})+\mathrm{HNO}_{3}(40 \mathrm{ml})+\mathrm{H}_{2} \mathrm{SO}_{4}(48 \mathrm{ml})$ & Observation of precipitates \\
Electrical etching at $5-6$ volts for 10 seconds & \\
\hline $\mathrm{HCL}(30 \mathrm{ml})+\mathrm{HNO}_{3}(10 \mathrm{ml})+$ Ethylene Glycol$(20 \mathrm{ml})$ & Observation of grain boundaries \\
Immersing and swabbing & \\
\hline
\end{tabular}

\subsubsection{MEASUREMENTS OF $\gamma^{\prime \prime}$ PRECIPITATE SIZE}

The $\gamma^{\prime \prime}$ precipitates are disc shaped in Inconel 718, Therefore, their size was determined by measuring the diameter of discs by transmission electron microscope. To make TEM thin foils, thin slices were cut from the heat treated or the crept specimens. The thin slices were first grounded on sandpaper to 600 grade, then further thinned by electopolishing $3 \mathrm{~mm}$ diameter discs in a a jet electropolishing unit using $15 \%$ perchloric acid, $85 \%$ methanol electrolyte at a temperature of $223-233 \mathrm{~K}$ and a current of $85-100$ ma. The thin foils were examined in JEOL 2000FX Analytical TEM/STEM.

Due to the presence of large coherent strains around the $\gamma^{\prime \prime}$ and $\gamma^{\prime}$ particles, individual precipitates could only be observed in dark field micrographs obtained by using their superlattice reflections. Furthermore, the $\gamma^{\prime \prime}$ particles in Inconel 718 grow coherently into discs on $\{100\}$ plane of the FCC matrix with the $\mathrm{c}$ axis of the $\gamma^{\prime \prime}$ phase being perpendicular to the discs. The $\gamma^{\prime}$ phase also forms coherently on the $\{100\}$ planes of FCC matrix. Therefore, the dark field image of $\gamma^{\prime \prime}$ and $\gamma^{\prime}$ were obtained with the specimen in the $\{100\}$ orientation. The images obtained were enlarged, and then processed on an image 
analyzer to determine the size of $\gamma^{\prime \prime}$. At least 5 images, each containing more than 50 particles, were analyzed.

\subsubsection{MEASUREMENTS OF PRECIPITATE PARAMETERS FOR $\delta$ PHASE PARTICLES AT GRAIN BOUNDARIES.}

The size and number of $\delta-\mathrm{Ni} 3 \mathrm{Nb}$ precipitates at the grain boundaries were determined from the binary images created in a scanning electron microscope using secondary electrons. This analysis was carried out on the entire grain boundaries of several grains. The total length of the grain boundaries analyzed was also measured on the SEM micrographes. The average line density of precipitates at grain boundaries were calculated by the number and the average size of precipitates on a given length of grain boundary. More than a thousand particles on grain boundaries of at least 5 grains were scanned on each material.

\subsubsection{MEASUREMENT OF GRAIN SIZE}

The grain size was measured by the line intercept methods. The sample to be examined was placed on the graduated stage of an optical microscope. At the beginning of the measurement, the sample was moved to such a position where a grain boundary was at the cross marked in the eyepiece of the microscope. Then the number of intercepts of grain boundary with the cross was counted as the stage of the microscope was moved. The grain size was obtained by dividing the total length traversed by the stage by the number of intercepts $(-1)$. By this method the whole surface of the specimen could be examined. Therefore, each line can cover a large number of grains. In addition, at least five directions were scanned for each material. 


\subsection{TENSILE TESTS}

Tensile testing was conducted at creep testing temperatures at a constant strain rate of $1.0 \times 10^{-4} S^{-1}$ on both materials $\mathrm{A}$ and $\mathrm{B}$. The test temperature was controlled within $\pm 3^{\circ} \mathrm{C}$ by a three-zone furnace filled with argon and monitored by a thermocouple attached to the gauge section of the specimens.

\subsection{CREEP TESTS}

The tensile creep tests were carried out in three T48 Avery-Denison constant stress creep machines. The testing temperature was controlled within $\pm 2^{\circ} \mathrm{C}$ by a threezone furnace. The furnace was adjusted to have a constant temperature zone of a length longer than that of the gauge section of the specimen, and the temperature along the zone was also maintained to within $\pm 2^{\circ} \mathrm{C}$. The test temperature was always monitored by thermocouples attached directly to the gauge section of the specimen.

The creep deformation was measured by LVDT with extensometer attached to the specimen grips inside the argon-filled chamber, and was recorded on a strip chart recorder. The creep strain was calculated by assuming that all of the measured displacement was due to homogeneous deformation of the gauge length of the sample. In subsequent analysis, the creep deformation was presented in the form of creep rate versus creep strain or creep time. The creep rate at a given moment was calculated by determining the change in deformation strain within a short interval of time.

The back stress or threshold stress was determined by the Wilshire technique or the consecutive stress reduction method[191 195]. When the creep test reached the secondary creep stage the applied stress was reduced by a small amount, $\Delta \sigma_{1}$, typically $0.05 \sigma_{a}$. This stress reduction resulted in an elastic contraction of the specimen, which was followed by an incubation period of zero creep rate. Creep then recommenced with a slower creep rate at the reduced stress level. As soon as a new steady state creep rate was reached a second small stress reduction, $\Delta \sigma_{2}$, was made and so on. The duration of 
successive incubation periods $\left(\Delta t_{1}, \Delta t_{2} \cdots \cdots\right)$ was recorded for each consecutive small stress reduction $\left(\Delta \sigma_{1}, \Delta \sigma_{2}, \cdots \cdots\right)$. Eventually, the incubation period became very long. In order to determine $\sigma_{b}$, the data were plotted as cumulative incubation time, $\Sigma \Delta t$, against the remaining stress on a linear scale. The back stress or threshold stress, $\sigma_{b}$, was taken to be the asymptotic value of the remaining stress when the cumulative incubation time approached infinity. 


\section{CHAPTER FOUR RESULTS}

\subsection{MICROSTRUCTURAL CHARACTERIZATION OF INCONEL 718}

\subsubsection{MICROSTRUCTURE OF INCONEL 718}

Inconel 718 is a precipitate-strengthened nickel base alloy. This alloy is widely used as hot end parts for gas engines, such as turbine blades, discs and vanes. Typical phases present in the as received material are listed in Table 4.1. The (Nb, Ti)C-carbides, that form during solidification, have a volume fraction of about $1 \%$, and have been found to be very stable up to $1200^{\circ} \mathrm{C}[184]$. The ordered disc shaped $\mathrm{BCT} \gamma^{\prime \prime}-\mathrm{Ni} 3(\mathrm{Nb}, \mathrm{Fe})$ particles are the main strengthening phase in the material $[196,197]$. The FCC $\gamma^{\prime}-\mathrm{Ni}_{3}(\mathrm{Al}$, $\mathrm{Ti}, \mathrm{Nb}$ ) particles provide only a minor contribution to strength (10-20\%). In the peak aged condition, the total volume fraction of the $\gamma^{\prime \prime}+\gamma^{\prime}$-precipitates is $17 \%$ and the ratio of the volume fraction of $\gamma^{\prime \prime}$ to $\gamma^{\prime}$ is between $2.5 \sim 4.0[198]$. Because of these reasons, only $\gamma^{\prime \prime}$ precipitates are often considered wherever precipitate-strengthening is involved (which is also the case in the present study). Finally, $\delta-\mathrm{Ni}_{3} \mathrm{Nb}$ phase can precipitate directly in the matrix or can form by the transformation of $\gamma^{\prime \prime}$-precipitates. They can also form at the grain boundaries under appropriate heat treatment conditions.

Table 4.1 Typical phases present in wrought Inconel 718

\begin{tabular}{cclcc}
\hline Phases & Structure & Shape & Temperature & Area \\
\hline$(\mathrm{Nb}, \mathrm{Ti}) \mathrm{C}$ & $\mathrm{FCC}$ & Block-like & $\mathrm{T}_{\mathrm{m}}$ & Whole matrix \\
\hline$\gamma^{\prime \prime}-\mathrm{Ni} 3(\mathrm{Nb}, \mathrm{Al}, \mathrm{Ti})$ & $\mathrm{BCT}$ & Disc-shaped & $900 \sim 730^{\circ} \mathrm{C}$ & Grain interiors \\
\hline$\gamma^{\prime}-\mathrm{Ni}_{3}(\mathrm{Al}, \mathrm{Nb}, \mathrm{Ti})$ & Ordered FCC & Spherical & $820 \sim 720^{\circ} \mathrm{C}$ & Grain interiors \\
\hline$\delta-\mathrm{Ni} 3 \mathrm{Nb}$ & Orthorhombic & Needle-like & $1010 \sim 820^{\circ} \mathrm{C}$ & $\begin{array}{c}\text { Grain boundaries } \\
\text { and interiors }\end{array}$ \\
\hline
\end{tabular}




\subsubsection{MICROSTRUCTURE USED IN THIS STUDY}

\subsubsection{GRAIN BOUNDARY PRECIPITATION}

In order to produce different microstructures at grain boundaries, the material was heat treated according to the scheme listed in Table 3.2. Fig. 4.1 is a TEM image of material A showing clean grain boundaries obtained by air cooling from solid solution treatment at $1020^{\circ} \mathrm{C}$ for 4 hour. Material B was furnace-cooled from the solid solution heat treatment temperature of $1020^{\circ} \mathrm{C}$, which produced coarse precipitates of $\gamma^{\prime \prime}+\gamma^{\prime}$ phases in the grain interiors as well as smaller particles of $\delta$ - phase at grain boundaries (Fig. 4.2)[180]. These $\delta$ phase particles at grain boundaries have been extensively characterized by many investigators $[179,180,185]$, and therefore, their characterization will not be repeated here. Material B was given a second solid solution treatment at a lower temperature in the range of $900^{\circ} \mathrm{C} \sim 1000^{\circ} \mathrm{C}$ for one hour. This second solid solution treatment was designed to dissolve the coarse $\gamma^{\prime \prime}+\gamma^{\prime}$ precipitates within grain interiors which were introduced during the furnace cooling, and maintain the $\delta$ phase precipitates at grain boundaries without undergoing excessive coarsening. As shown in Fig. 4.3a, the second solid solution heat treatment at a temperature below $925^{\circ} \mathrm{C}$ was not successful in achieving this. However, as seen in Fig. 4.3b-d when the temperature was $925^{\circ} \mathrm{C}$ or above, the specimens were free of all the intragranular precipitates and the $\delta$ precipitates at grain boundaries had grown slightly as compared to those obtained before the second solid solution treatment.

The size and the amount of $\delta$ particles were influenced by the second solid solution temperature. The quantitative analysis of these grain boundary particles was conducted by SEM. The results are presented in Fig. 4.4, where the average diameter and the line density of the precipitates at grain boundaries have been plotted against the second solid solution treatment temperature. It is seen that, the average diameter of $\delta$ particles varies 


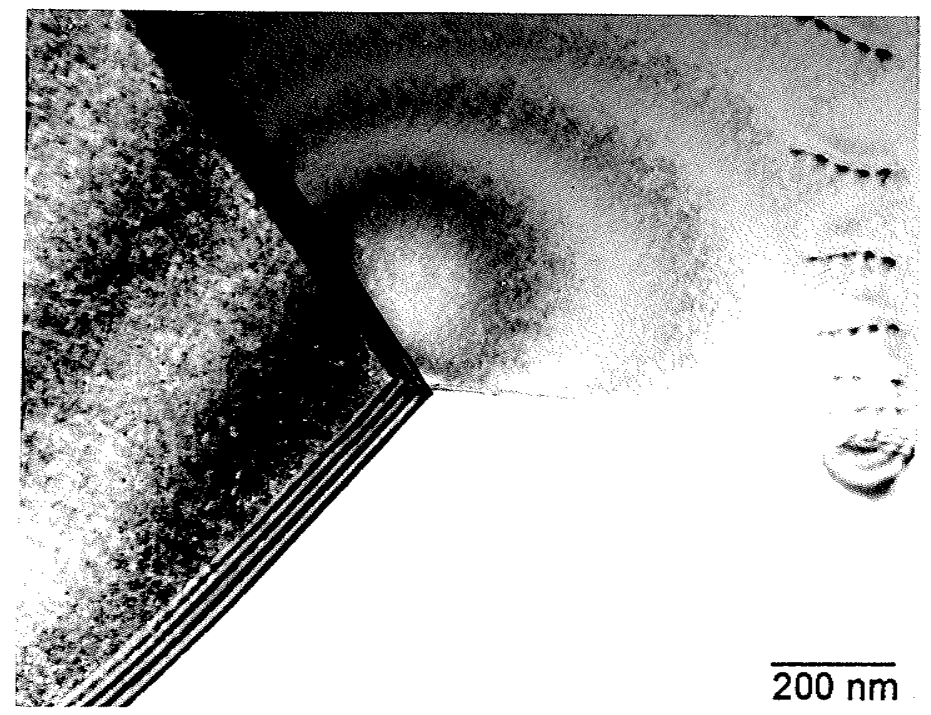

Fig. 4.1 TEM image showing clean grain boundaries in material $A$.

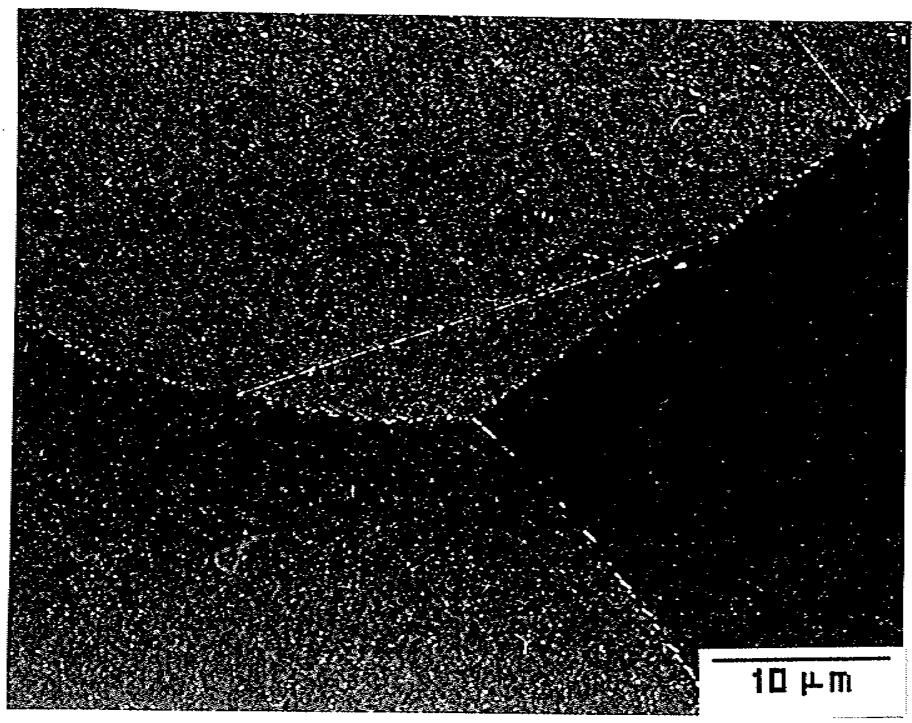

Fig. 4.2 SEM image showing precipitates at grain boundaries in material $\mathrm{B}$ after furnace cooling from solid solution treatment at $1020^{\circ} \mathrm{C}$ for 4 hour. 


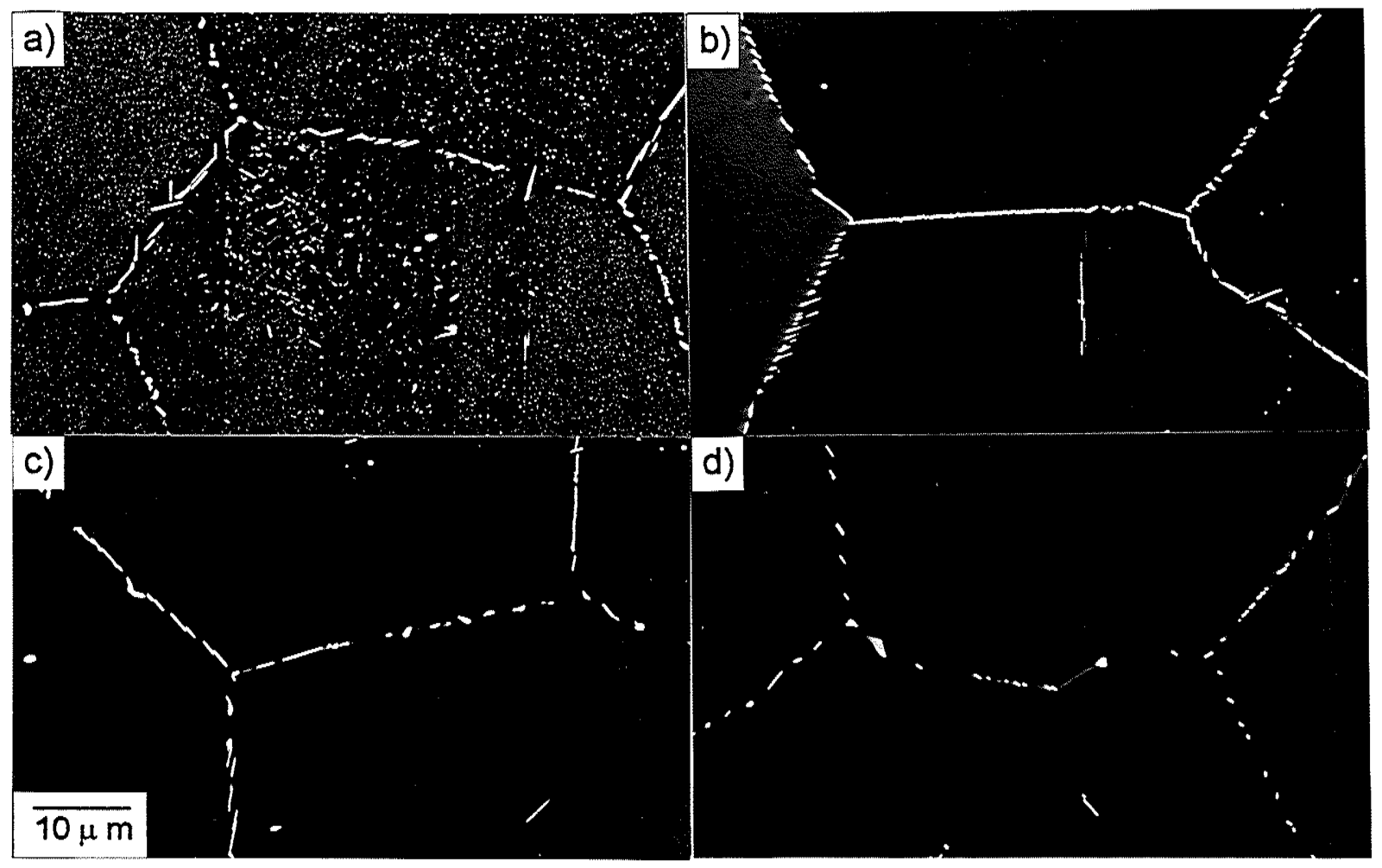

Fig. 4.3 Microstructures of the materials being partially solid solution treated after furnace cooling. The partial solid solution temperature is a) $900^{\circ} \mathrm{C}$, b) $925^{\circ} \mathrm{C}$, c) $975^{\circ} \mathrm{C}$, d) $1000^{\circ} \mathrm{C}$ 


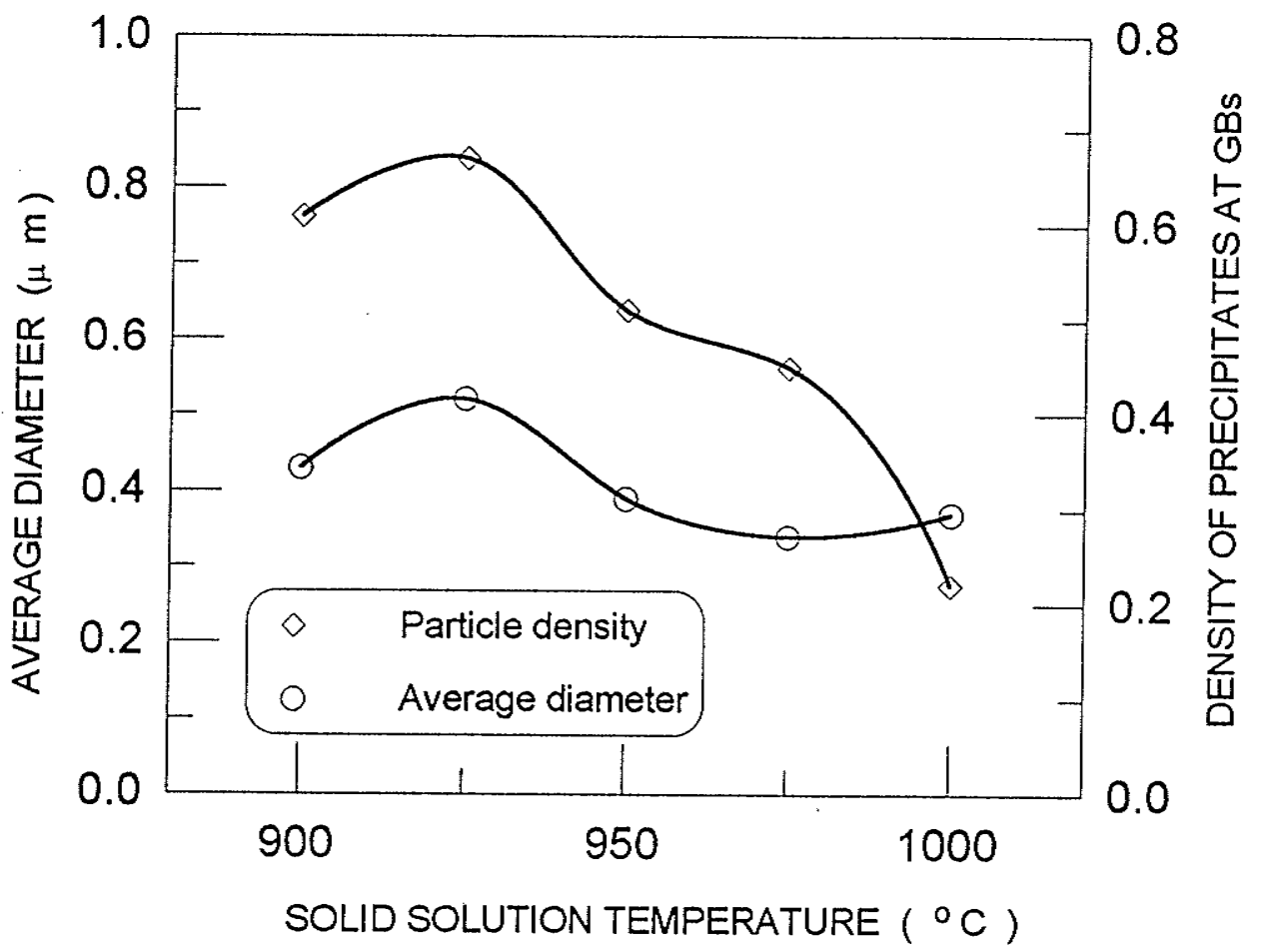

Fig. 4.4 The effect of partial solid solution temperature on the distribution parameters of $\delta$ precipitates at grain boundaries. 
from $0.52 \mu \mathrm{m}$ at $925^{\circ} \mathrm{C}$ to $0.34 \mu \mathrm{m}$ at $975^{\circ} \mathrm{C}$ and the average density varies from $67 \%$ at $925^{\circ} \mathrm{C}$ to $20 \%$ at $1000^{\circ} \mathrm{C}$.

\subsubsection{PRECIPITATION WITHIN THE GRAINS}

After the two solid solution treatments, both material A and material B had single $\gamma$ phase grain interiors, although their microstructures at grain boundaries were different, i.e. material A had clean grain boundaries while material B had $\delta$ phase precipitates at grain boundaries. Both the materiais were given a subsequent aging treatment at $725^{\circ} \mathrm{C}$ for different lengths of time to obtain various sizes of strengthening precipitates within the grains. Fig. 4.5 compares the size of $\gamma^{\prime \prime}$ precipitates in grain interiors of both the materials aged at $725^{\circ} \mathrm{C}$ for 25 hour. It is seen that the size of $\gamma^{\prime \prime}$ in material A is nearly the same as that observed in material B. The diameter of the discs $\gamma^{\prime \prime}$ discs was measured. Its variation with aging time is given in Fig. 4.6.

The formation of $\delta$ phase at grain boundaries occurs in the temperature range of 810 to $1010^{\circ} \mathrm{C}$. Therefore, it is certain that the aging at $725^{\circ} \mathrm{C}$ will not change the grain boundary microstructure of either of the two materials. This is verified by the microstructures shown in Figs.4.7a) and b), in which the size of $\delta$ phase at grain boundaries in both the materials is seen to be identical (Fig. 4.7a), although both of them were aged at $725^{\circ} \mathrm{C}$ for different lengths of time ( Fig. 4.7b).

\subsubsection{VARIATION OF GRAIN SIZE WITH SOLID SOLUTION TEMPERATURE}

In order to obtain different grain sizes, material $\mathrm{A}$ and material $\mathrm{B}$ were solid solution treated for 4 hours at different temperatures above $1020^{\circ} \mathrm{C}$. Fig. 4.8 shows the variation in grain size with solid solution temperature. It is seen that the second solid solution treatment did not change the grain size of material B. This is because i) grain 


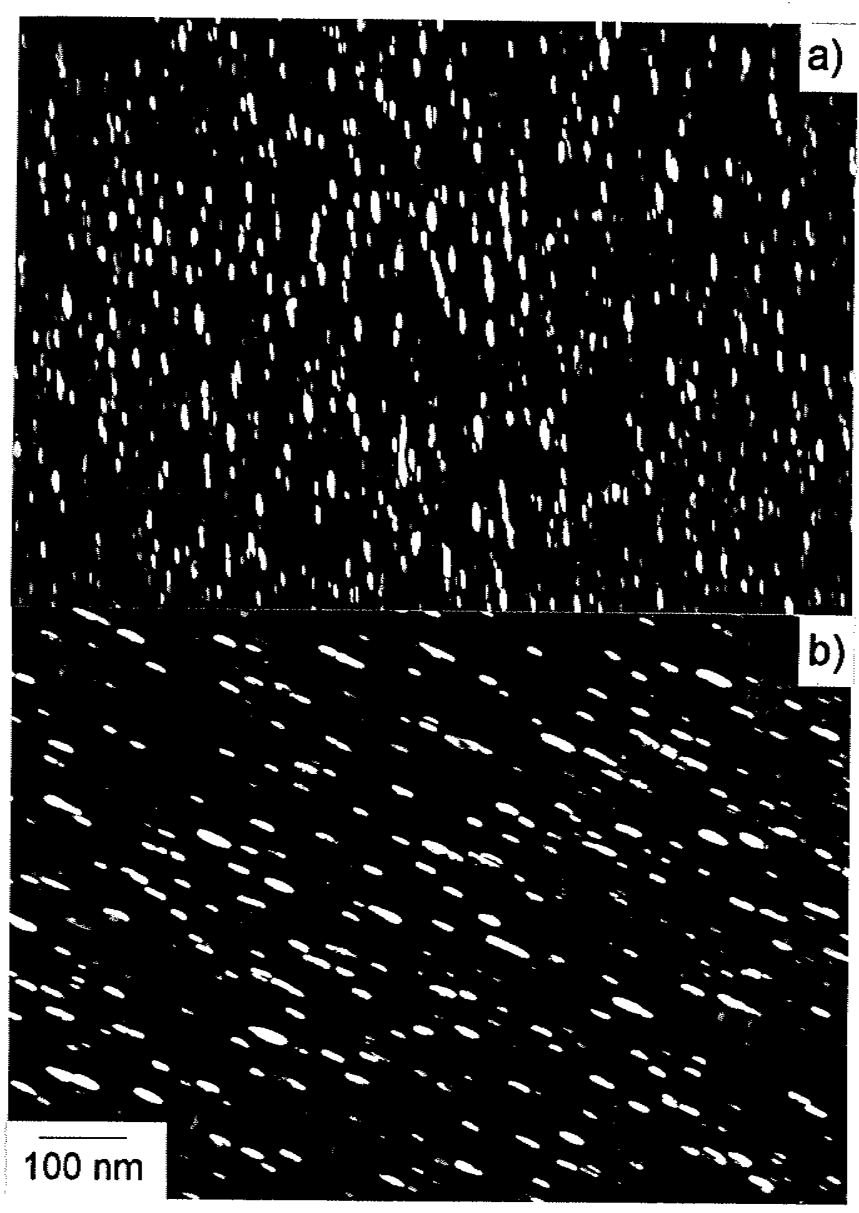

Fig. 4.5 TEM images showing precipitates of $\gamma$ " in material A (a) and material $B(b)$. 


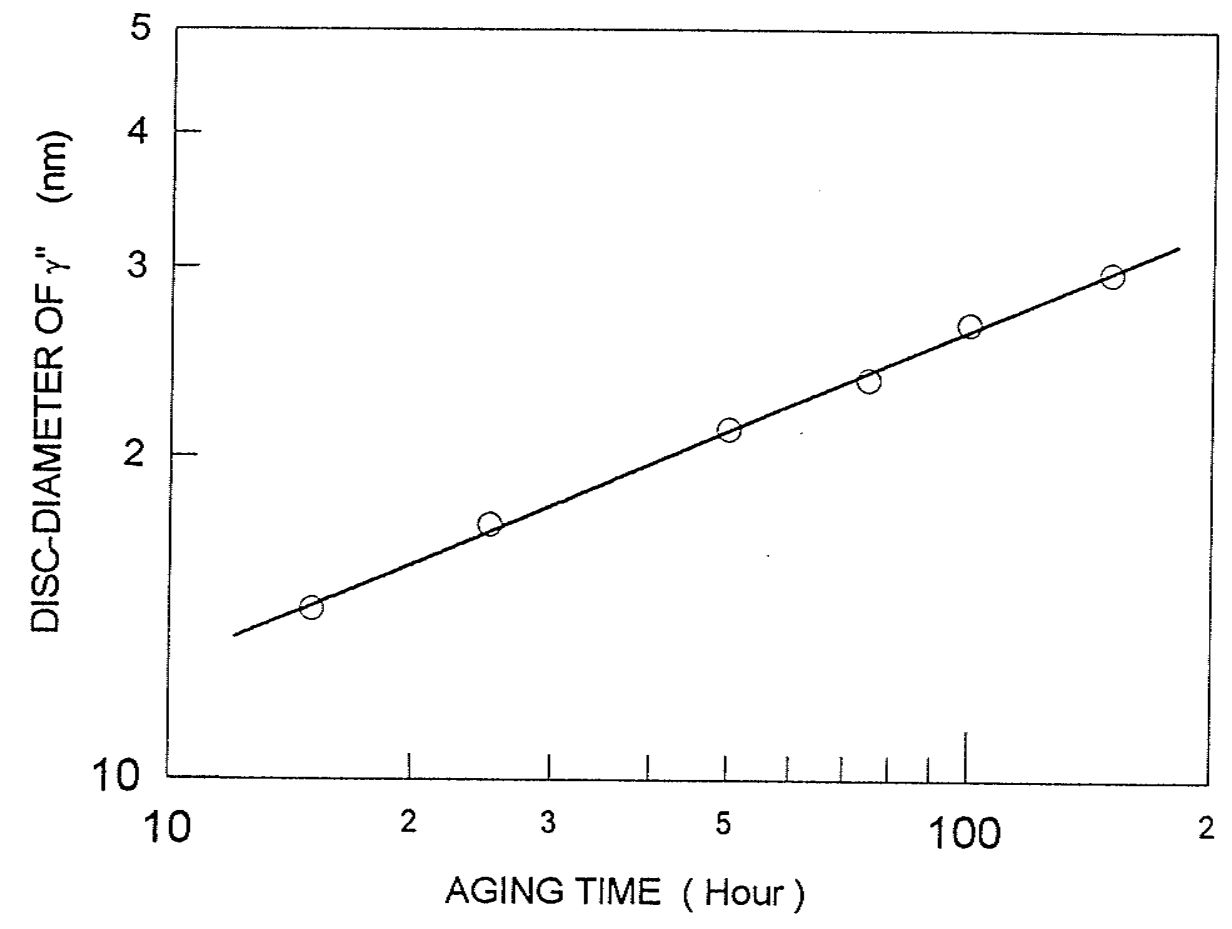

Fig. 4.6 Variation of $\gamma$ " - size with aging time at $725^{\circ} \mathrm{C}$ 


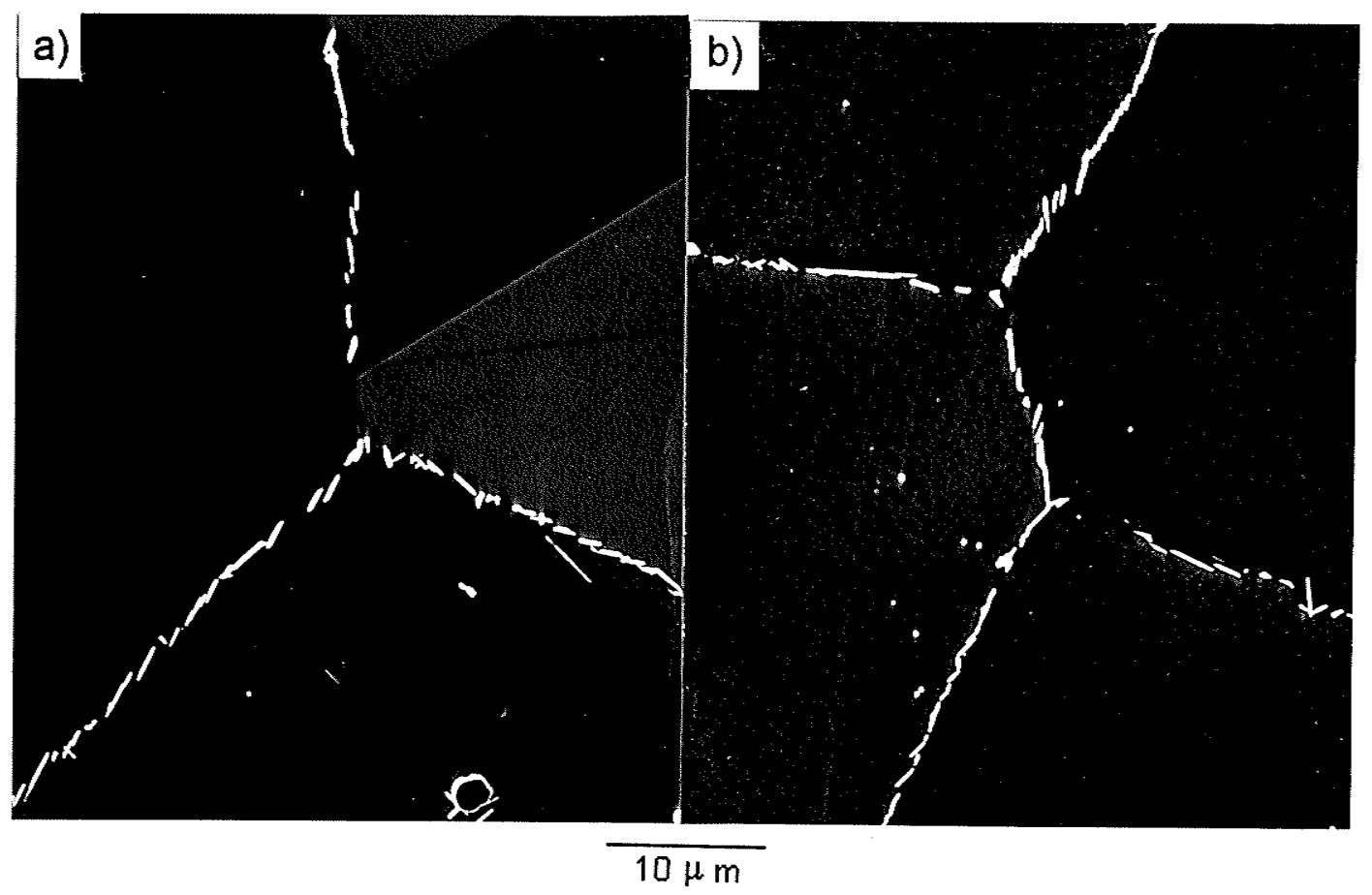

Fig. 4.7a SEM images of precipitates of the $\delta$ phase at grain boundaries. The materials have been aged at $725^{\circ} \mathrm{C}$ for $25 \mathrm{~h}$ (a) and 50 (b). 


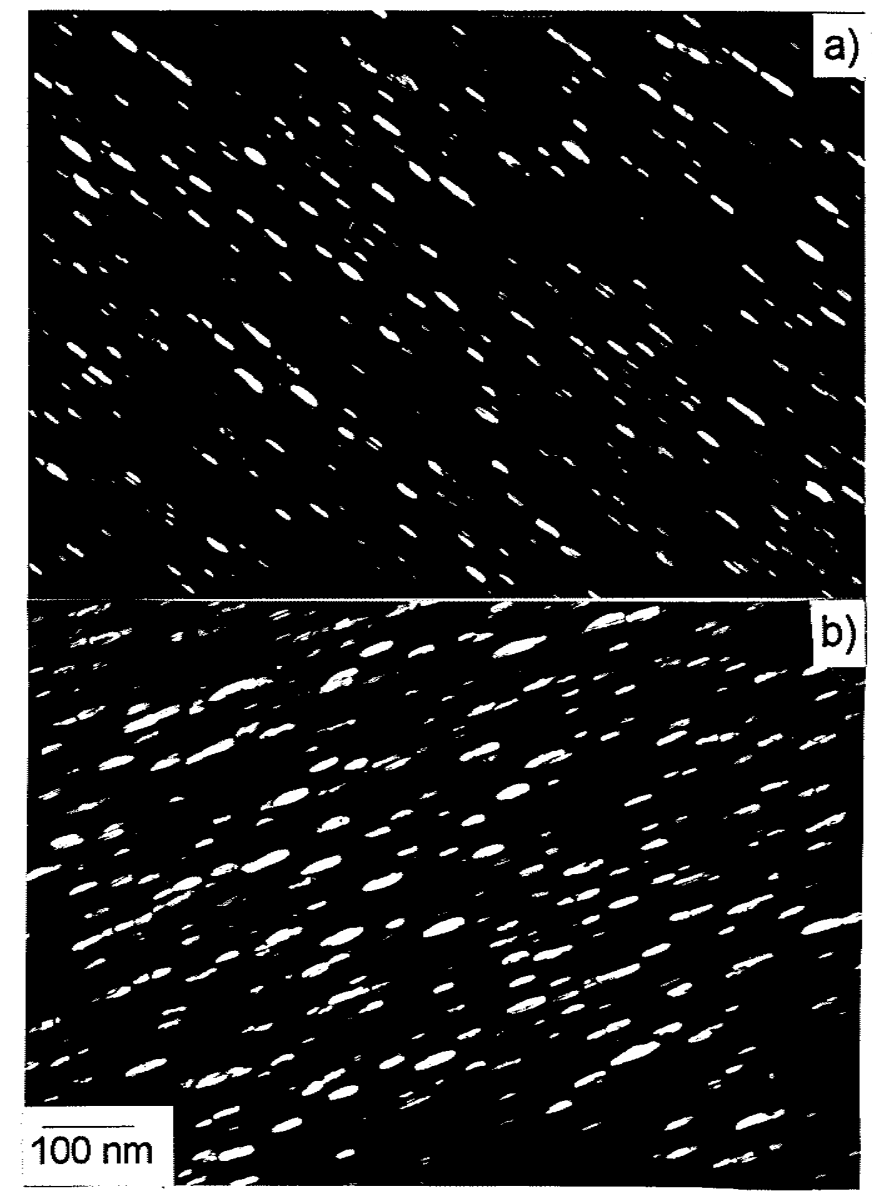

Fig. 4.7b) Dark field TEM images of $\gamma^{\prime \prime}$ of grain interiors. The materials have been aged at $725{ }^{\circ} \mathrm{C}$ for $25 \mathrm{~h} \mathrm{(a)} \mathrm{and} 50 \mathrm{~h}$ (b). In (a) $d_{\gamma^{\prime \prime}}=17.3 \mathrm{~nm}$, in (b) $d_{\gamma^{\prime \prime}}=21.2 \mathrm{~nm}$ 


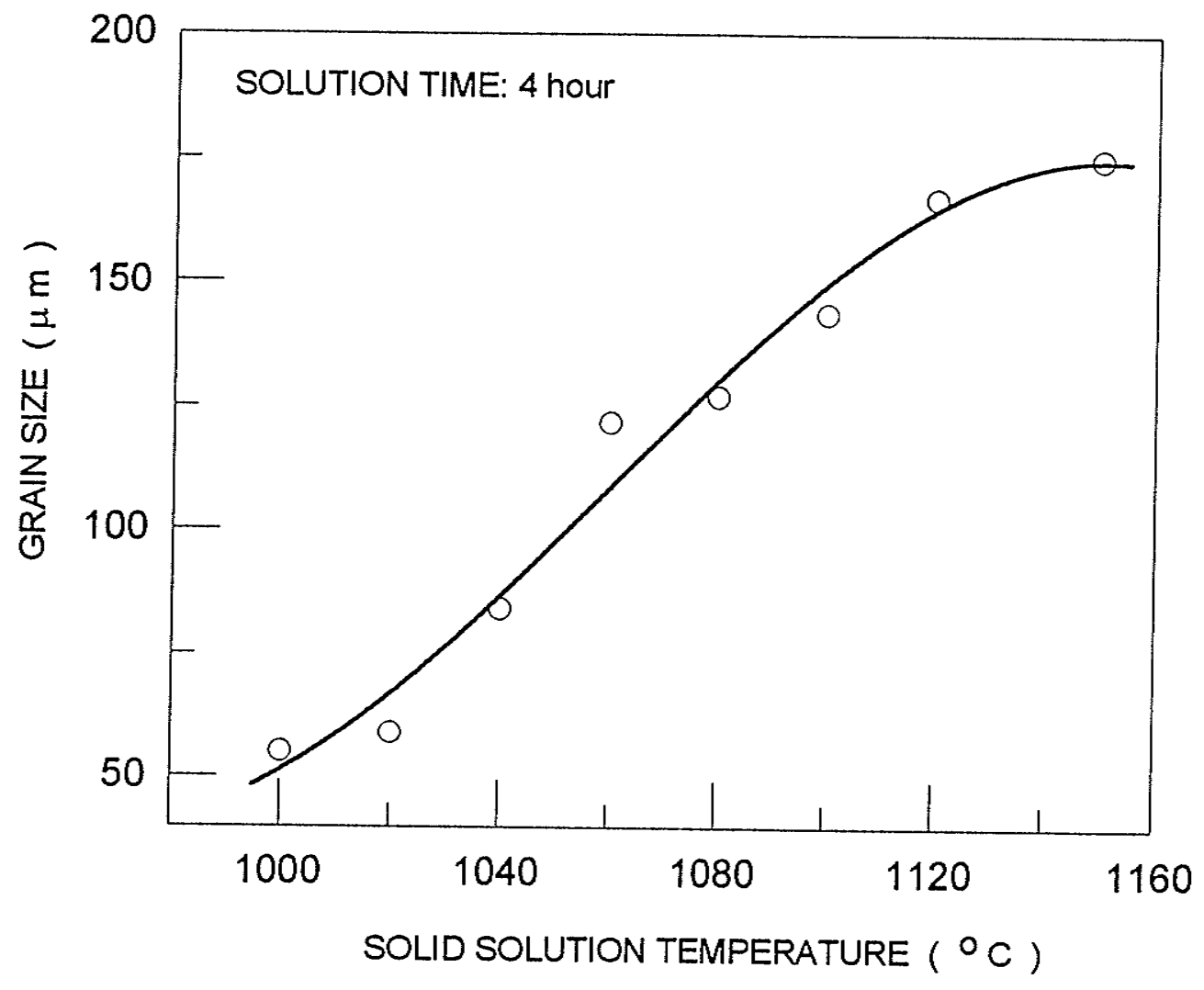

Fig. 4.8 Variation of grain size with solid solution temperature. 
growth in both the materials starts at $1020^{\circ} \mathrm{C}$; ii) the pre-precipitated $\delta$ phase particles at grain boundaries prevent grain growth.

\subsection{DEPENDENCE OF CREEP RATE ON THE STRENGTH OF GRAIN MATERIAL}

The dependence of creep rate on the strength of grain material was determined for both material A and material B. Various levels of strength within the grain material of both materials $\mathrm{A}$ and $\mathrm{B}$ were achieved by aging them at $725^{\circ} \mathrm{C}$ for different lengths of time. Since the precipitation of $\delta$ phase in Inconel 718 occurs in the temperature range of $820 \sim$ $1010^{\circ} \mathrm{C}$, the subsequent aging at $725^{\circ} \mathrm{C}$ did not cause any change in the size of precipitates at grain boundaries in material $\mathrm{B}$, and also did not produce any grain boundary $\delta$ precipitates in material $A$. This is shown in Figs. 4.7 a and $4.7 \mathrm{~b}$ which are the SEM micrographs of a specimen which are aged for 25 and 50 hours at $725^{\circ} \mathrm{C}$ after the second solid solution treatment at $925^{\circ} \mathrm{C}$ The dark field TEM micrographs of these two specimen are shown in Fig. 4.7 a and 4.7 b, where the average diameter of $\gamma^{\prime \prime}$ discs was found to be $17.3 \mathrm{~nm}$ and $21.2 \mathrm{~nm}$, respectively. Therefore, it is concluded that the heat treatment used in this study above produces material that has the same size of $\delta$ phase precipitates at grain boundaries and different sizes of $\gamma^{\prime \prime}$ phase precipitates depending upon the length of aging at $725^{\circ} \mathrm{C}$. The average grain size of the material remained constant at $59 \mu \mathrm{m}$.

The variation in creep rate with creep strain for various specimens contains $\gamma^{\prime \prime}$ precipitate discs of different diameter is shown in Fig. 4.9. For a clearer presentation of results, that is, without undue overlapping of curves, this figure is divided into two halves. All the seven curves show the occurrence of a steady state creep rate with increasing creep strain. The value of steady state creep rate, $\varepsilon_{\mathrm{S}}$, for the specimen with the smallest and the largest $\gamma^{\prime \prime}$ precipitate particles in them is greater than the value observed in other specimens in which the size of $\gamma^{\prime \prime}$ precipitates had a value in between the two extremes. 


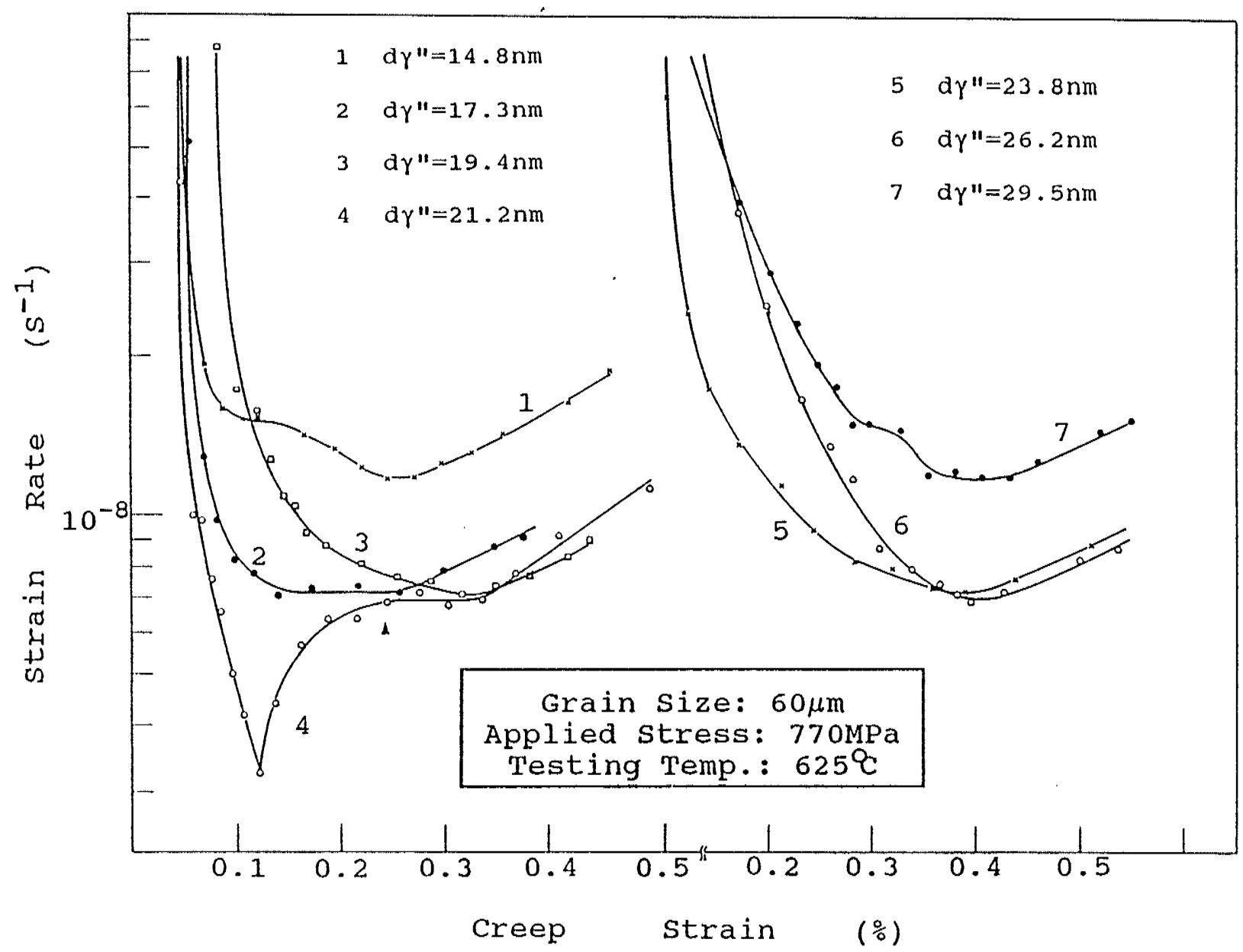

Fig. 4.9 Change of creep rate with creep strain for the materials with various size of $\gamma$ " The creep test was conducted at $770 \mathrm{MPa}$ and $625^{\circ} \mathrm{C}$ 
The steady state creep rate, $\dot{\varepsilon}_{s}$, is also observed to be the same as the minimum creep rate, $\dot{\varepsilon}_{m}$, with the exception of specimen 4 , where average diameter of the $\gamma^{\prime \prime}$ discs is 21.4 $\mathrm{nm}$. The value of the minimum creep rate in this specimen is significantly smaller than the steady state creep rate. The validity of the existence of this sharp minimum was established by duplicate tests. It should be noted that specimens with $17.3 \mathrm{~nm}$ and $21.2 \mathrm{~nm}$ diameter $\gamma$ " precipitates exhibit a significant steady state creep region and in the specimen with 21.2 $\mathrm{nm} \gamma^{\prime \prime}$ the sharp minimum in creep rate occurred before the steady state stage was reached. In Fig. 4.10, the values of steady state creep rate observed in various specimens are plotted against average diameter of $\gamma^{\prime \prime}$ discs in them. It is seen that the value of steady state creep rate acquires a constant value when the average diameter of the $\gamma^{\prime \prime}$ discs reaches $17.3 \mathrm{~nm}$ and increases again when it is $26.2 \mathrm{~nm}$.

The creep behaviour of specimens with clean grain boundaries under the test conditions similar to those used in this study has been characterized by Han and Chaturvedi $[199,200]$ as power-law dislocation creep with a true stress exponent of about 5. The dependence of steady state creep rate on the size of $\gamma^{\prime \prime}$ in specimens tested at $625^{\circ} \mathrm{C}$ and $765 \mathrm{MPa}$, as reported by Han and Chaturvedi ${ }^{[200]}$, is included in Fig. 4.10. It can be seen that the creep rate of the material with clean grain boundaries is strongly dependent upon the size of $\gamma^{\prime \prime}$ precipitates. Such a dependence of steady state creep rate on the precipitate particle size has been observed in the applied stress range of $620-815$ $\mathrm{MPa}$ and also reported in Cu-Co alloys by Threadgill and Wilshire [201]. However, the results of this study show that the presence of about $0.5 \mu \mathrm{m}$ size $\delta$ precipitates at the grain boundaries makes the minimum creep rate, $\varepsilon_{\mathrm{m}}$, independent of the $\gamma^{\prime \prime}$ precipitate size over a certain size range. That is to say, that the values of the steady state creep rate are independent of the strength of the grain material unlike that is generally believed for creep in the power-law dislocation creep region. It should also be noted that the values of steady state creep rate in the material with $\delta$ precipitates at the grain boundaries are significantly higher than those observed in the material with clean grain boundaries. 


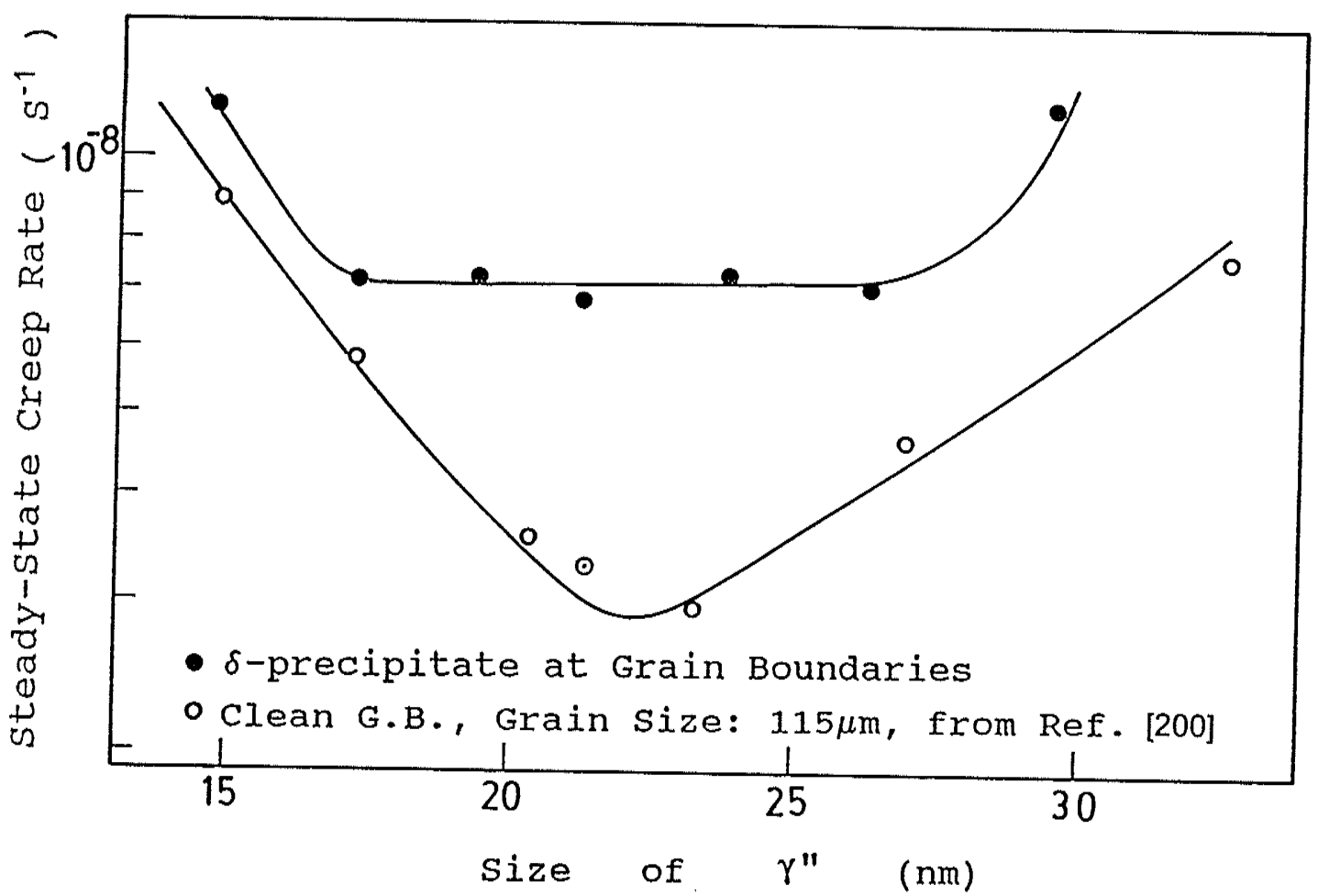

Fig. 4.10 Dependence of steady state creep rate on the size of $\gamma$ " 


\subsection{DEPENDENCE OF CREEP RATE ON APPLIED STRESS}

The results presented in the previous section clearly show the existence of a creep behaviour that is independent of the strength of grain material when the material has precipitates at grain boundaries. In order to understand the mechanisms that may cause such an unusual behaviour, stress and temperature dependence of creep deformation were conducted. All the specimens used in these tests were given the same aging treatment of 25 hours at $725^{\circ} \mathrm{C}$ to obtain an identical strengthening state for grain interior. This aging treatment produced a discs of $\gamma^{\prime \prime}$ precipitates of average diameter of $17.3 \mathrm{~nm}$ and $16.5 \mathrm{~nm}$ for material B and material A, respectively. This size of $\gamma^{\prime \prime}$ precipitates in material B is in the range within which the material displays a steady state or minimum creep rate which is

independent of the size of $\gamma^{\prime \prime}$. The creep tests were conducted in the temperature range of $600^{\circ} \mathrm{C} \sim 650^{\circ} \mathrm{C}$ and in the stress range of $745 \mathrm{MPa} \sim 860 \mathrm{MPa}$.

\subsubsection{MATERIAL A}

The plots of creep rate versus creep time (or creep strain) for material A tested at temperatures of $600^{\circ} \mathrm{C}$ and $625^{\circ} \mathrm{C}$ and at various stress levels are shown in Figs. 4.11(a, b) and Fig. 4.12 , respectively.

The creep curves for the specimens tested at $600^{\circ} \mathrm{C}$ are quite complex. These curves consist of either a point of minimum creep rate followed by a stage with a constant creep rate (in the high stress region ) (Fig.4.11a) or two stages of steady state of creep rate ( in the low stress region) (Fig 4.11b). Detailed studies, not included in this dissertation and to be published elsewhere, have shown that this unusual creep behaviour is a combination of Portevin-le-Chatelier effect and a normal creep deformation. It has been suggested that the Portevin-le-Chatelier effect is responsible for the occurrence of a minimum creep rate (in high stress region) and the first steady state creep rate stage (in 


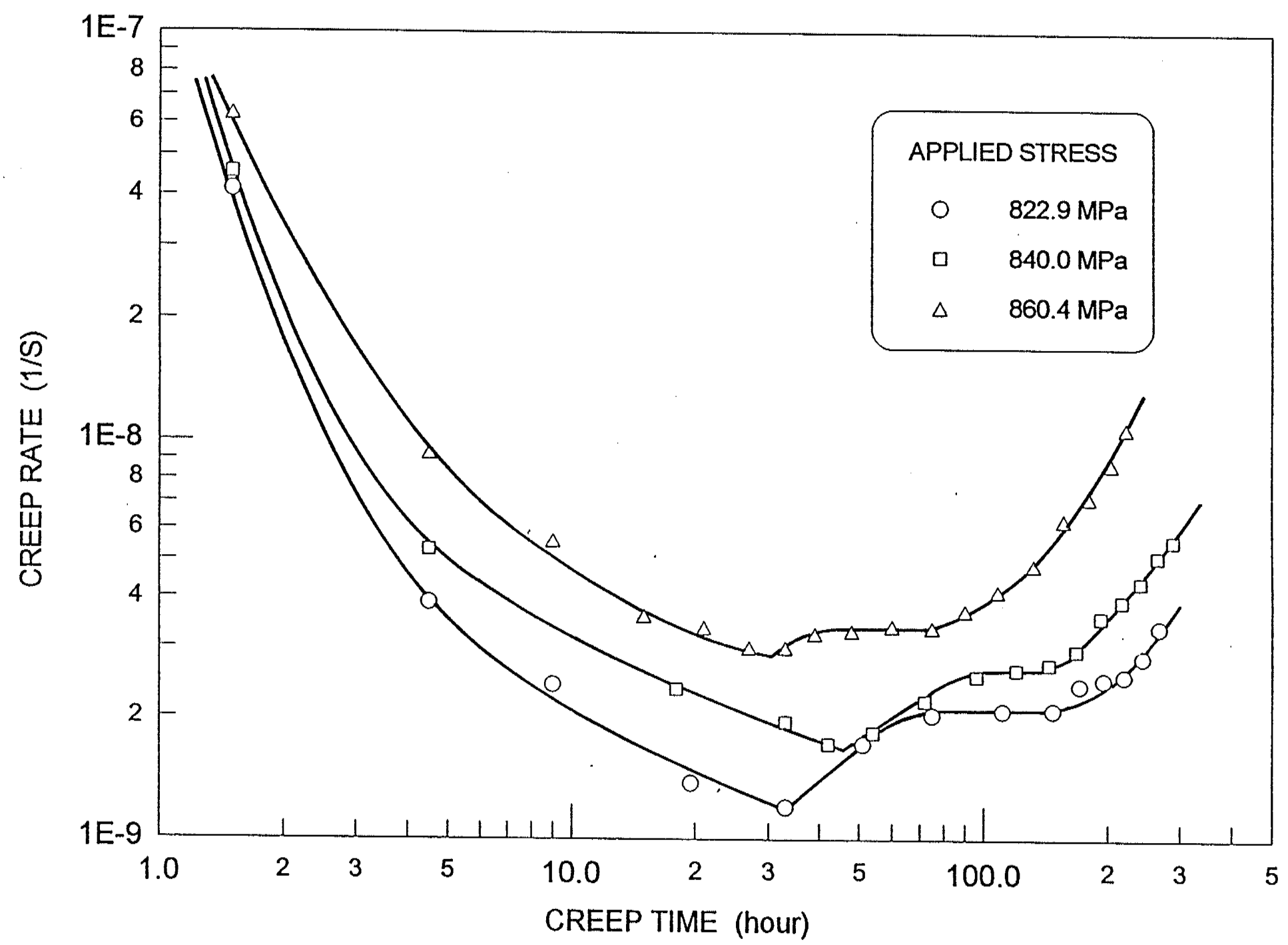

Fig. 4.11a Creep rate versus creep time for material A tested at $600^{\circ} \mathrm{C}$ 


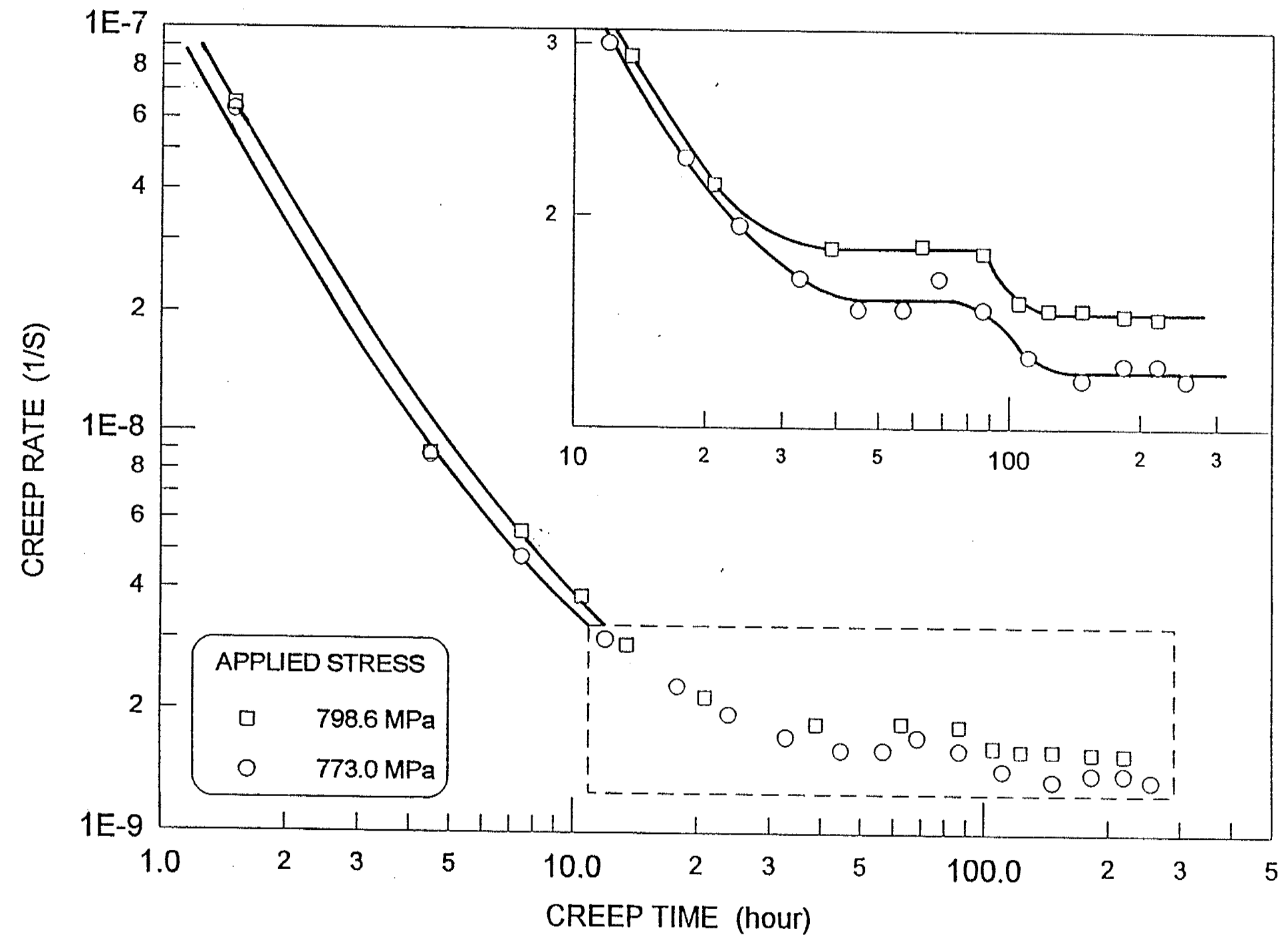

Fig. $4.11 \mathrm{~b}$ Creep rate versus creep time for material A tested at $600^{\circ} \mathrm{C}$ 


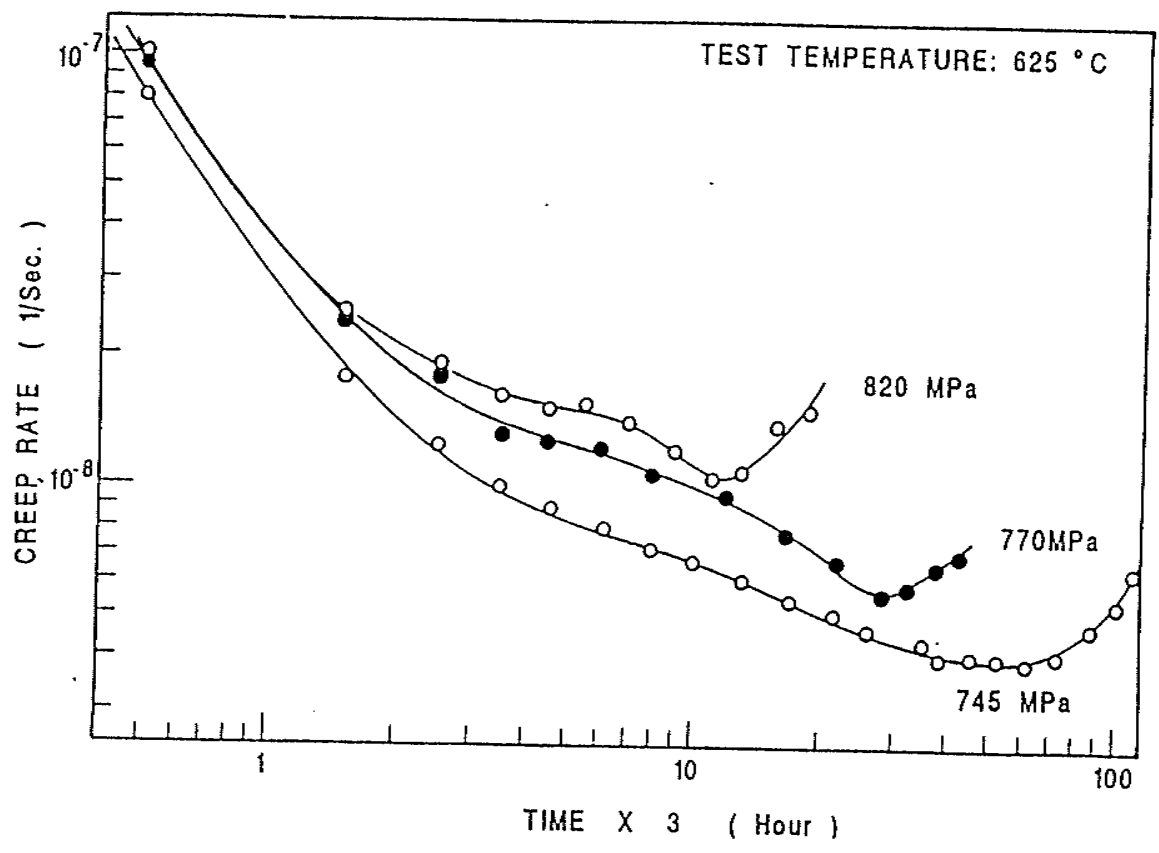

Fig. 4.12 Creep rate verrsus creep time for material A with a grain size of $59 \mu \mathrm{m}$ 
low stress region ). However, it gradually disappeared towards the second steady state stage. Therefore, it is believed the final steady state creep rate represents the creep resistance of material without the influence of Portevin-La-Chatelier effect.

In contrast to the results at $600^{\circ} \mathrm{C}$, the characteristics of creep curves ( Fig. 4.12) obtained at $625^{\circ} \mathrm{C}$ seem to be normal. They have a prolonged primary stage with a rapidly decreasing creep rate, a minimum creep rate which is followed by tertiary stage that leads to the final fracture of the sample.

The minimum creep rate at $625^{\circ} \mathrm{C}$ and the final steady state creep rate at $600^{\circ} \mathrm{C}$ have been plotted against applied stress in Fig. 4.13. It is seen that the stress dependence of creep rate at $600^{\circ} \mathrm{C}$ varies with applied stress. In the higher stress region, the stress exponent is about 11 . This value is nearly the same as the stress exponent obtained when the material was tested at $625^{\circ} \mathrm{C}$. As the applied stress is decreased, the stress exponent at $600^{\circ} \mathrm{C}$ is observed to decrease to a value of about 5.0.

\subsubsection{MATERIAL B}

The plots of creep rate versus creep time (or creep strain) for material B are shown in Fig. 4.14a, b, c, d, e. These creep curves are quite different from the creep curves observed for the material with clean grain boundaries. In the material with clean grain boundaries the creep rate decreases rapidly with creep strain (or time) until a minimum point is reached, it then accelerates towards the final fracture of the material. In the material with precipitates at grain boundaries, creep rate is observed to decrease to a stage with a well defined constant creep rate. Besides that, a significant difference between the creep curves of material A and Material B also appears in the primary stage. In the primary stage of material A, creep rate is significantly influenced by applied stress only when creep is approaching the minimum creep rate. In contrast to this, the strong dependence of creep rate on applied stress in material B starts at the very beginning of creep deformation. Such a difference in creep rate during the primary stage on applied 


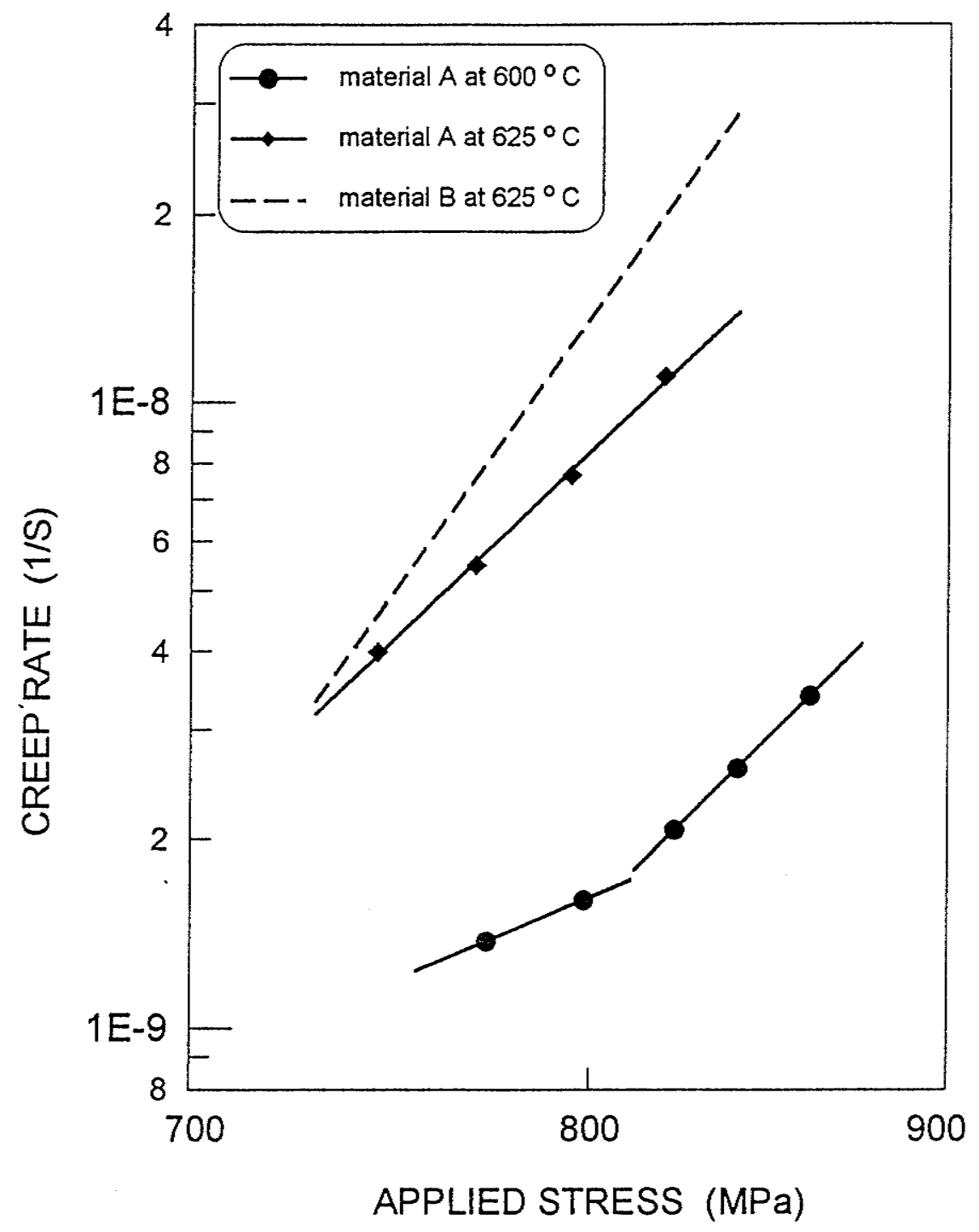

Fig. 4.13 Dependence of creep rate on applied stress in material $A$ and material $B$ 


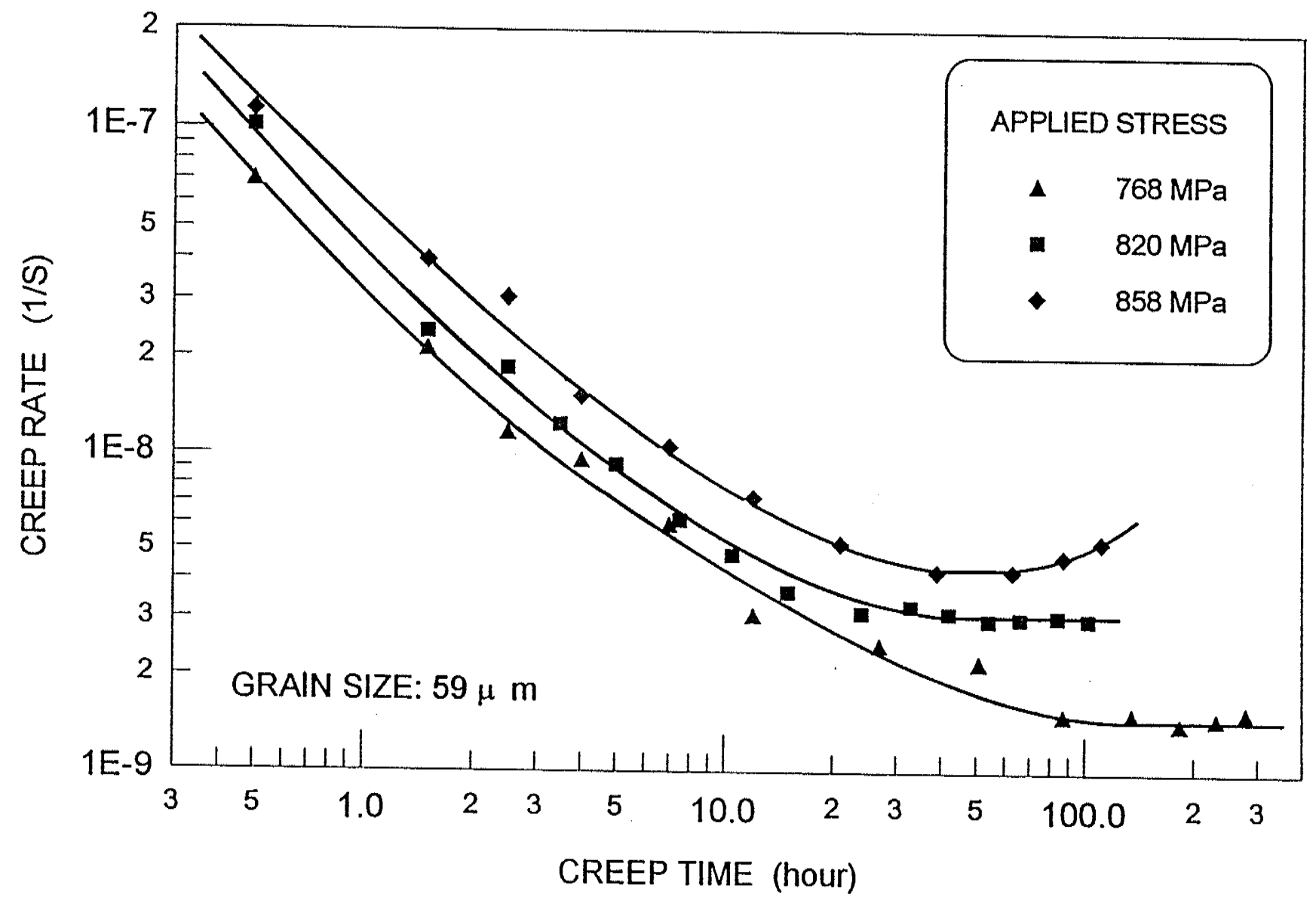

Fig. 4.14a Creep rate versus creep time for material B tested at $600^{\circ} \mathrm{C}$ 


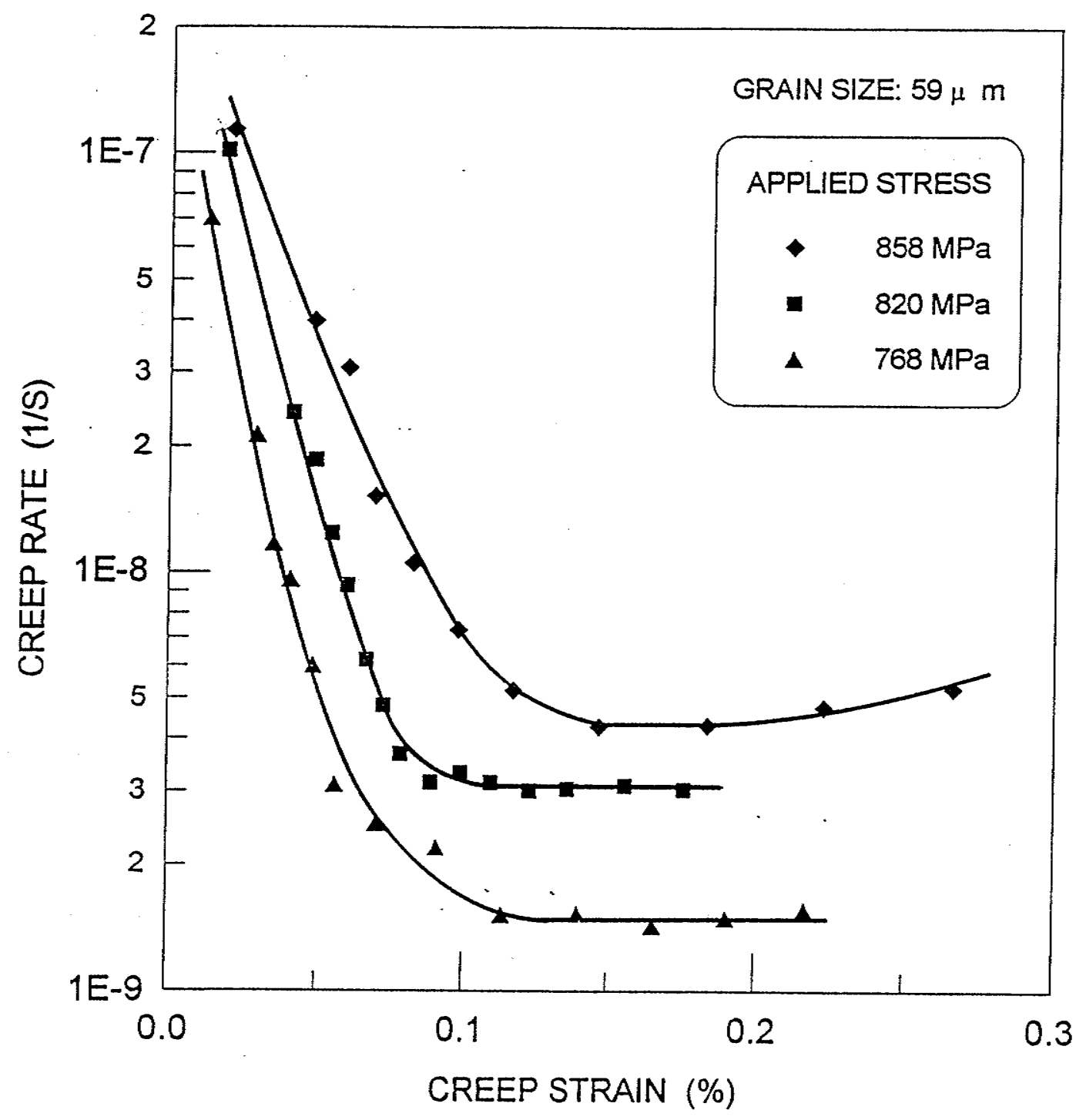

Fig. 4.14b

Creep rate versus creep strain for material $B$ tested at $600^{\circ} \mathrm{C}$ 


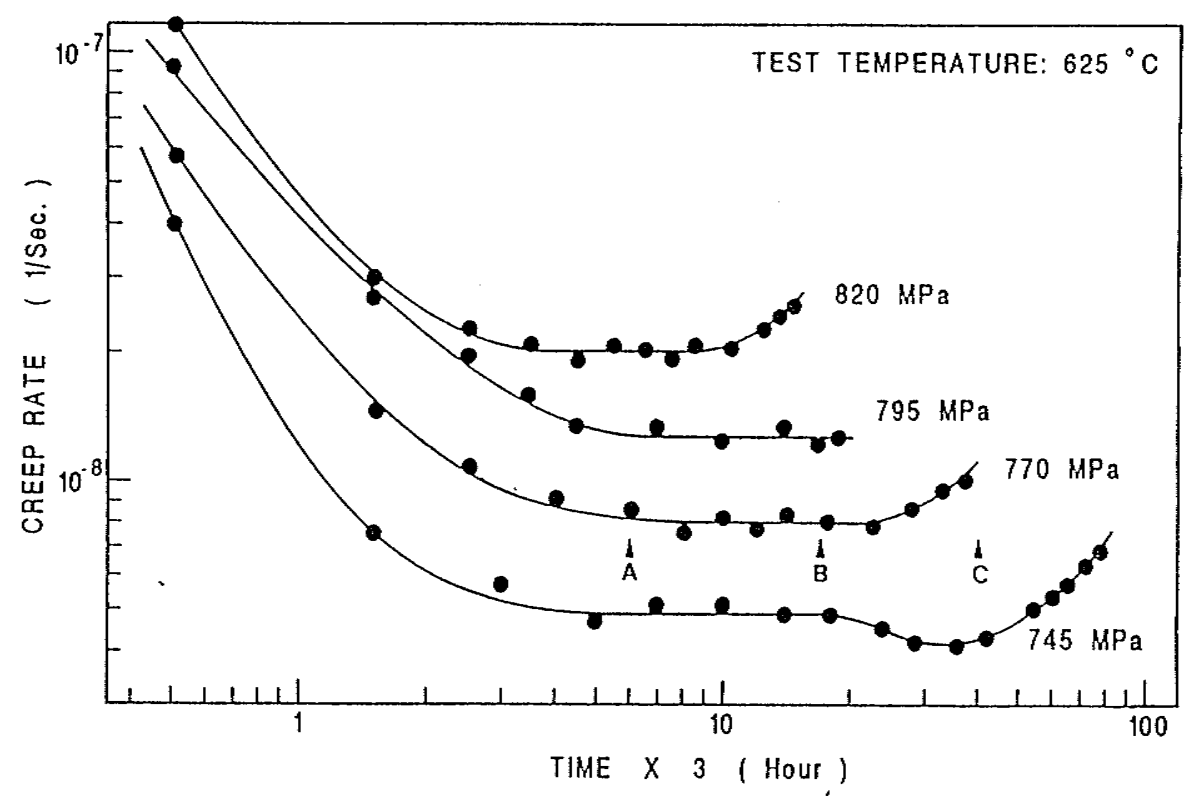

Fig. 4.14c Creep rate verrsus creep time for material $B$ with a grain size of $59 \mu \mathrm{m}$ 


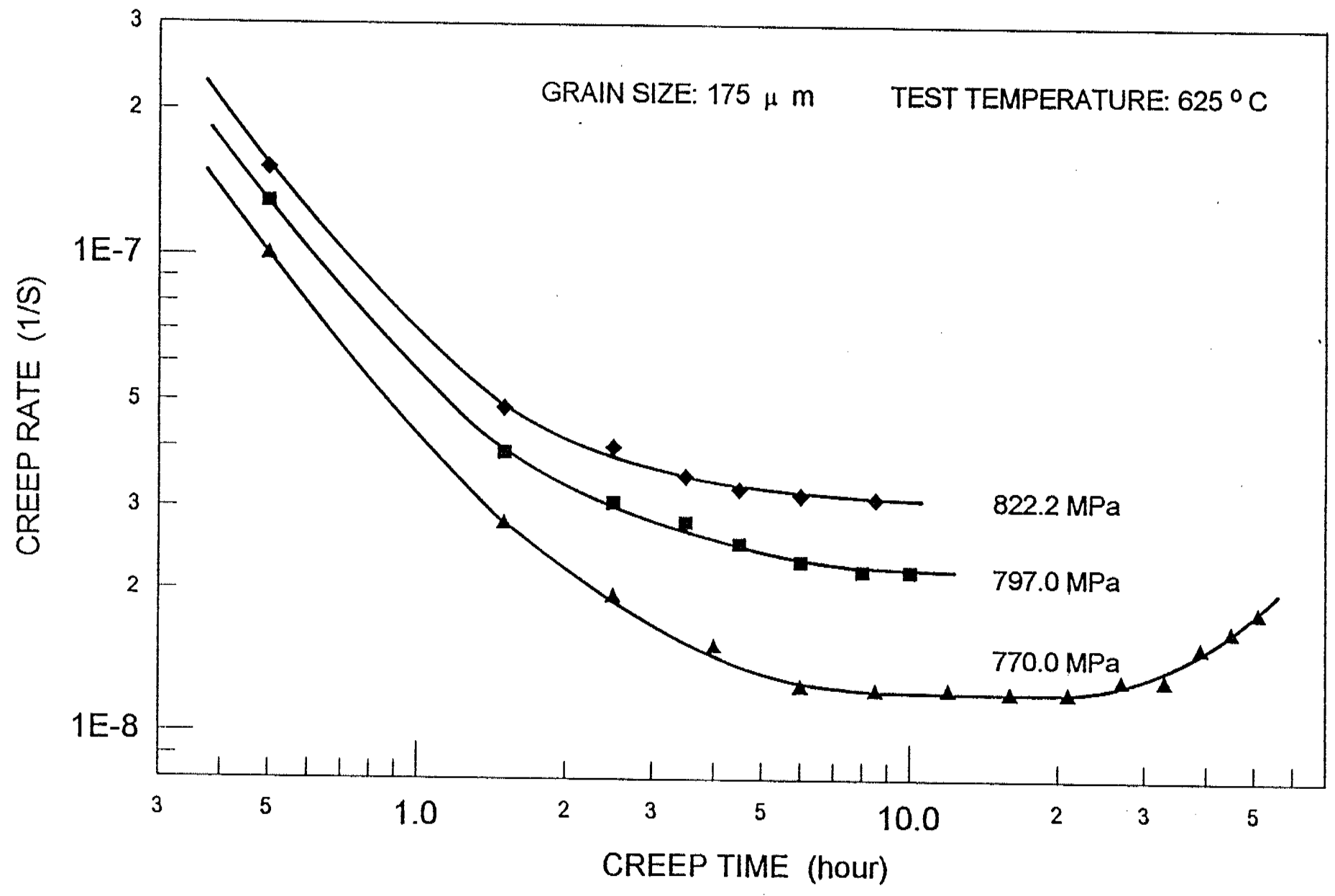

Fig. 4.14d Creep rate versus creep time for material B with a grain size of $175 \mu \mathrm{m}$ 


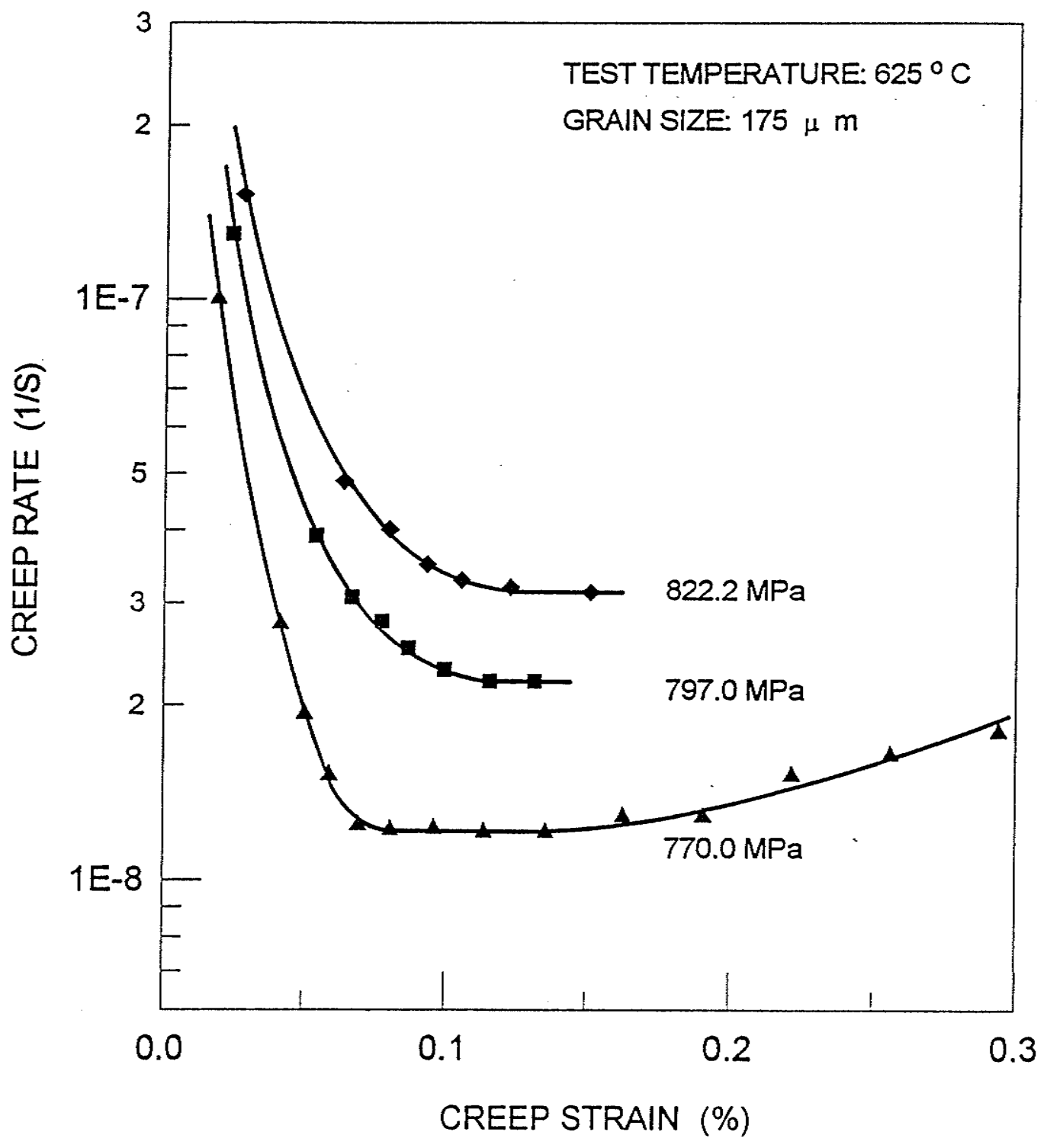

Fig. 4.14e Creep rate versus creep strain for material B with a grain size of $175 \mu \mathrm{m}$. 
stress does not seem to be significant in the plot of creep rate versus creep time, however, becomes very profound in the plots of creep rate against creep strain (Fig. $4.14 \mathrm{~b}$ and e).

The stress dependence of steady state creep rate for material B at two temperature levels is plotted in Fig. 4.15. The stress exponent for material B, varies with temperature. The variation in steady state creep rate with applied stress at $600^{\circ} \mathrm{C}$ and $625^{\circ} \mathrm{C}$ for material B with a grain size of $59 \mu \mathrm{m}$ are also presented by a dotted line in Fig. 4.13. The values of stress exponent for both materials A and B are listed in Table 4.2.

Table 4.2 Summary of apparent stress exponent for materials $A$ and $B$

\begin{tabular}{c|cc}
\hline Material & $600^{\circ} \mathrm{C}$ & $625^{\circ} \mathrm{C}$ \\
\hline A & $\begin{array}{c}11.0 \text { (At high stress ) } \\
4.8 \quad \text { (at low stress) }\end{array}$ & 10.9 \\
B & 10.8 & 13.0 \\
\hline
\end{tabular}

\subsubsection{EFFECT OF BACK STRESS}

The high values of stress exponent observed in the present study are similar to those observed in many other two-phase materials [142]. In these materials creep deformation occurs under the influence of an effective stress, which is given by. $\left(\sigma_{a}-\sigma_{b}\right)$. In this expression, $\sigma_{a}$ is the applied stress and $\sigma_{b}$ is the back stress. The consecutive stress reduction method [191 195] was employed to determine the back stress for both the materials during creep testing. An incubation period after about $5 \%$ stress reduction was observed in both the materials. Fig. 4.16 shows some examples of the relationship between the cumulative incubation time and residual applied stress for both the materials tested at $625^{\circ} \mathrm{C}$ and at the initial applied stress of $820 \mathrm{MPa}$ and $770 \mathrm{MPa}$.

The values of back stresses obtained experimentally are plotted against the initial stress in Fig.4.17. It can be noted that the value of Back stress for material $\mathrm{A}$ is not influenced significantly by the values of initial applied stress. This observation is similar to 


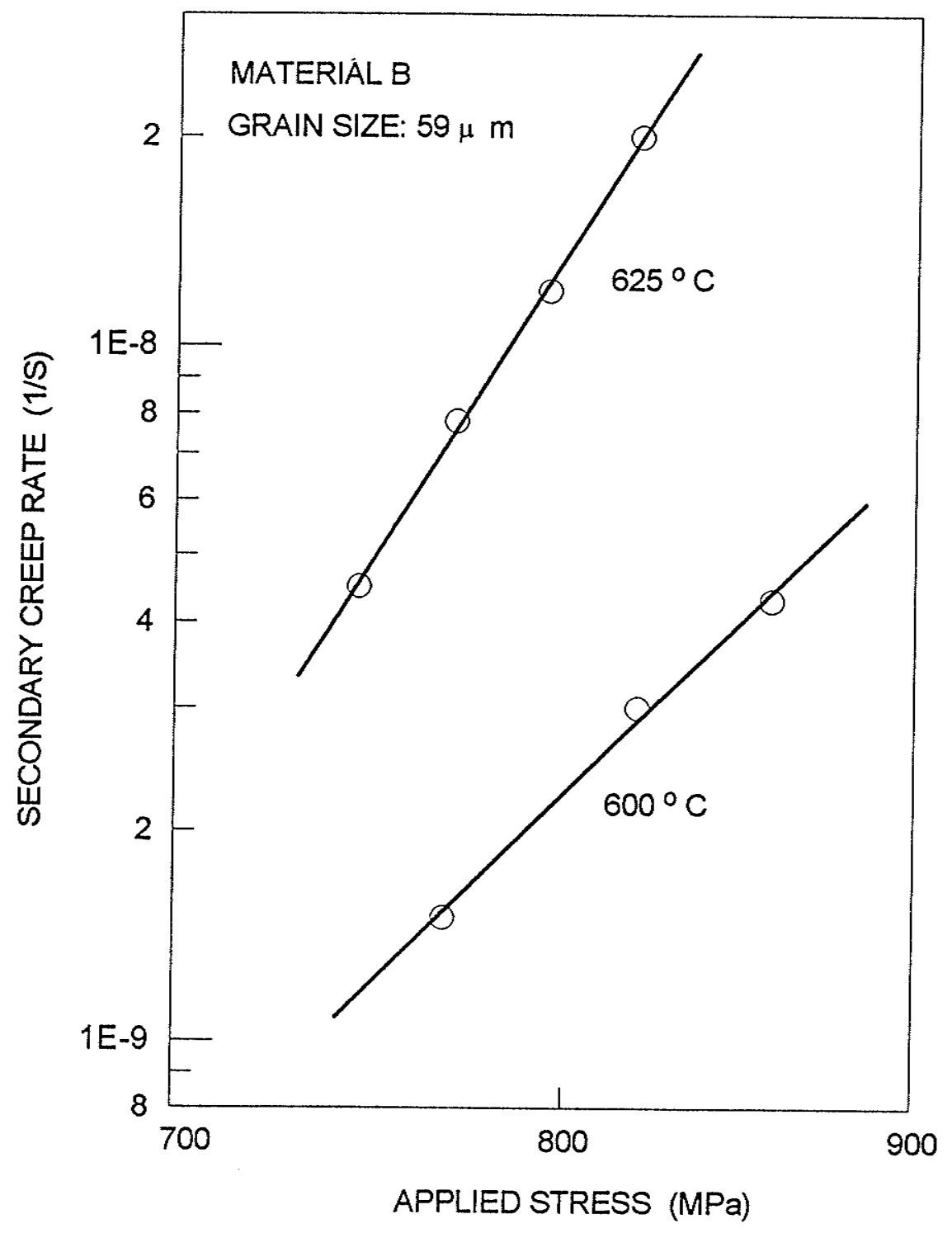

Fig. 4.15 Dependence of creep rate on applied stress obtained in material $B$ tested at two temperature levels. 


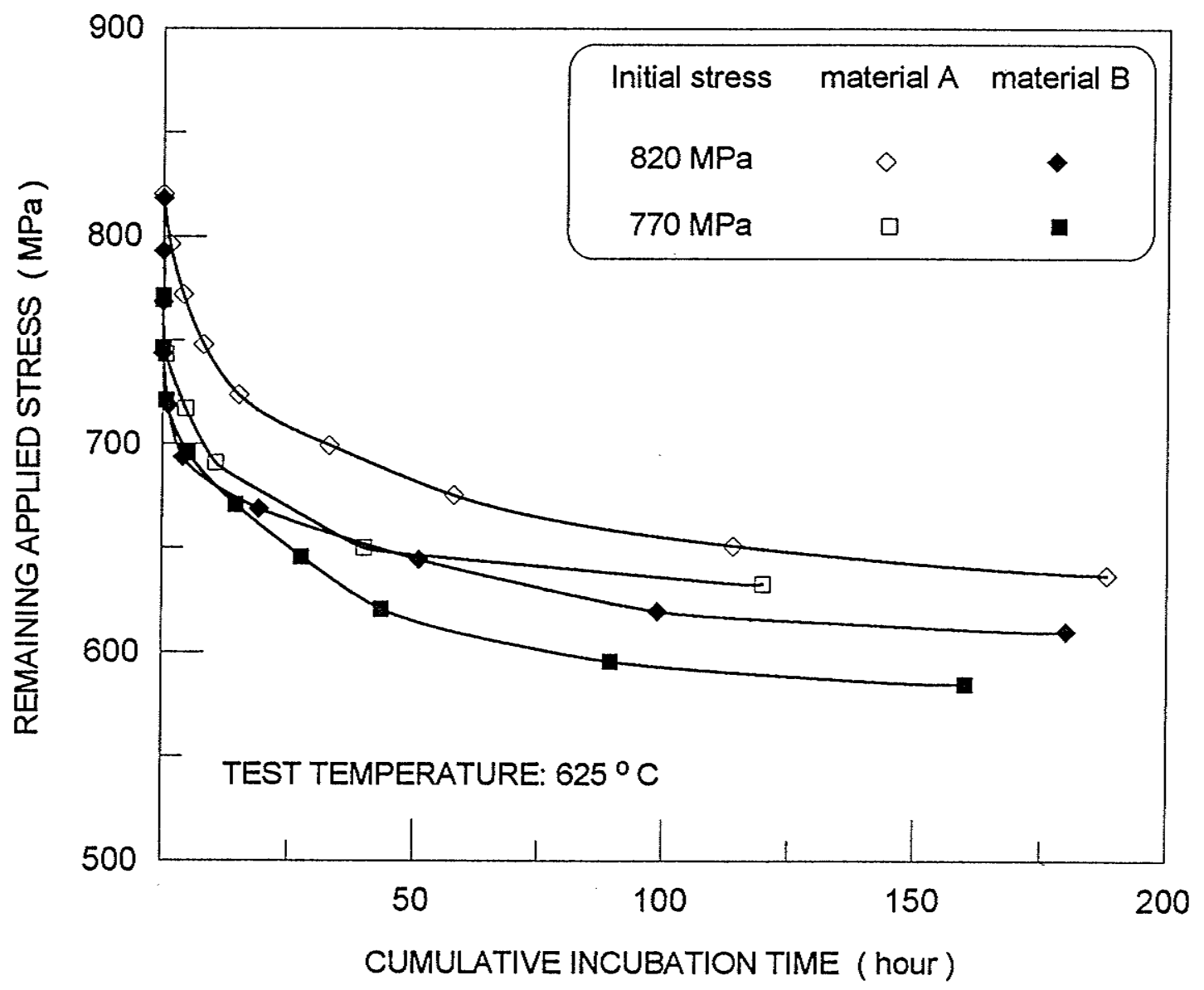

Fig. 4.16 Relationship between cumulative incubation time and remaining applied stress. 


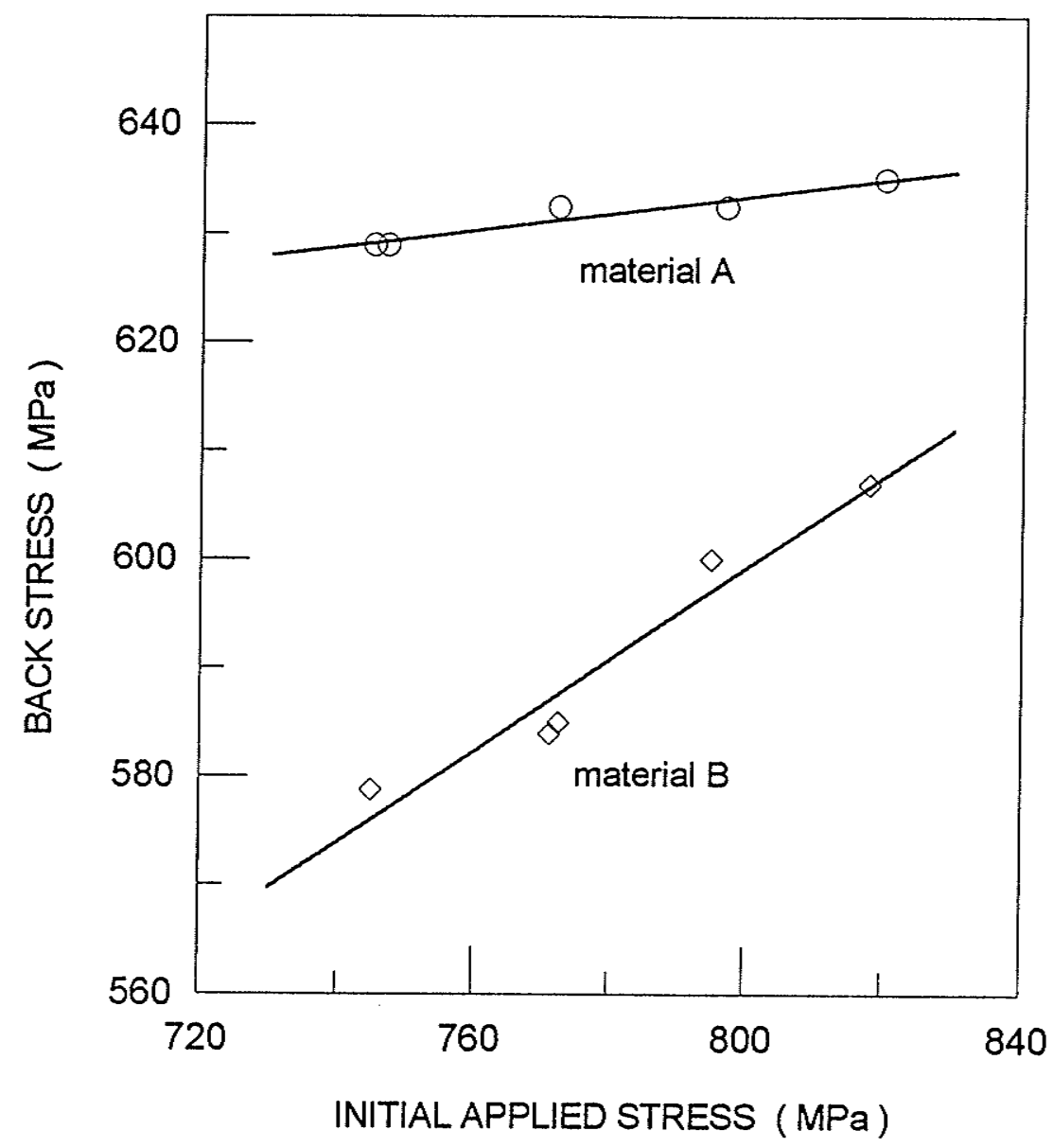

Fig. 4.17 Dependence of back stress on applied stress at $625^{\circ} \mathrm{C}$ 
the results reported earlier $[199,202]$ on Inconel 718 which had a clean grain boundaries but with an average $\gamma^{\prime \prime}$ disc diameter of $26.9 \mathrm{~nm}$. However, the value of back stress for material B is observed to increase with an increase in applied stress.

The effective creep stress, which is obtained by subtracting the back stress from the applied stress is plotted against minimum creep rate for material A and against steadystate creep rate for material B in Fig. 4.18. The values of effective stress exponent of creep rate were calculated from these plots. The value of $n_{e}$ for material $\mathrm{A}$ was found to be 3.0 This is similar to the values normally observed in two-phase materials which undergo creep deformation by dislocation power law mechanism. The value of $n_{e}$ in material $\mathrm{B}$ was found to be 6.8 . This would also suggest that the creep mechanism operating in material B is different than that operating in material A.

\subsection{DEPENDENCE OF CREEP RATE ON TEMPERATURE}

The activation energy for the creep deformation process is a reflection of the mechanism of creep deformation. Therefore, the activation energies were measured for both the materials.

The creep strain rate, $\dot{\varepsilon}_{s}$, applied stress $\sigma_{a}$, testing temperature T, and apparent activation energy, $Q_{a}$, are related by the following creep rate equation:

$$
\dot{\varepsilon}_{s}=A\left(\frac{\sigma_{a}}{G}\right)^{n_{a}}\left(\frac{G b}{k T}\right) \exp \left(-\frac{Q_{a}}{k T}\right)
$$

where $n_{a}$ is the apparent stress exponent, $\mathrm{G}$ is the shear modules, $\mathrm{b}$ is the Burger's vector, $\mathrm{k}$ is the Boltzmann constant and $\mathrm{A}$ is a material constant.

The apparent activation energy, $Q_{a}$, can be obtained from the slope of the plot of $\ln \left(\dot{\varepsilon}_{s} T / G\right)\left(G / \sigma_{a}\right)^{n_{a}}$ vs. $1 / \mathrm{T}$. Therefore, both the materials A and B were tested at $600^{\circ} \mathrm{C}$, $625^{\circ} \mathrm{C}$ and $650^{\circ} \mathrm{C}$ at an applied stress of $820 \mathrm{MPa}$. The $\ln \left(\dot{\varepsilon}_{s} T / G\right)\left(G / \sigma_{a}\right)^{n_{a}}$ vs. 1/T plots 


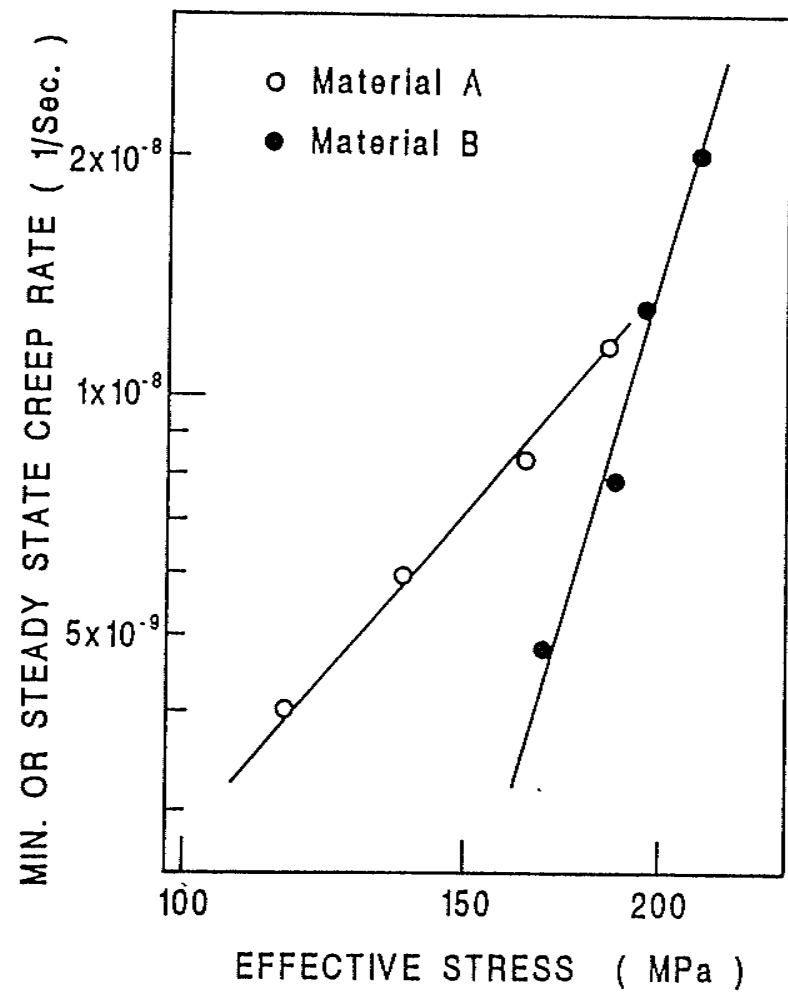

Fig. 4.18 Dependence of minimum or steady state creep rate on effective stress. 


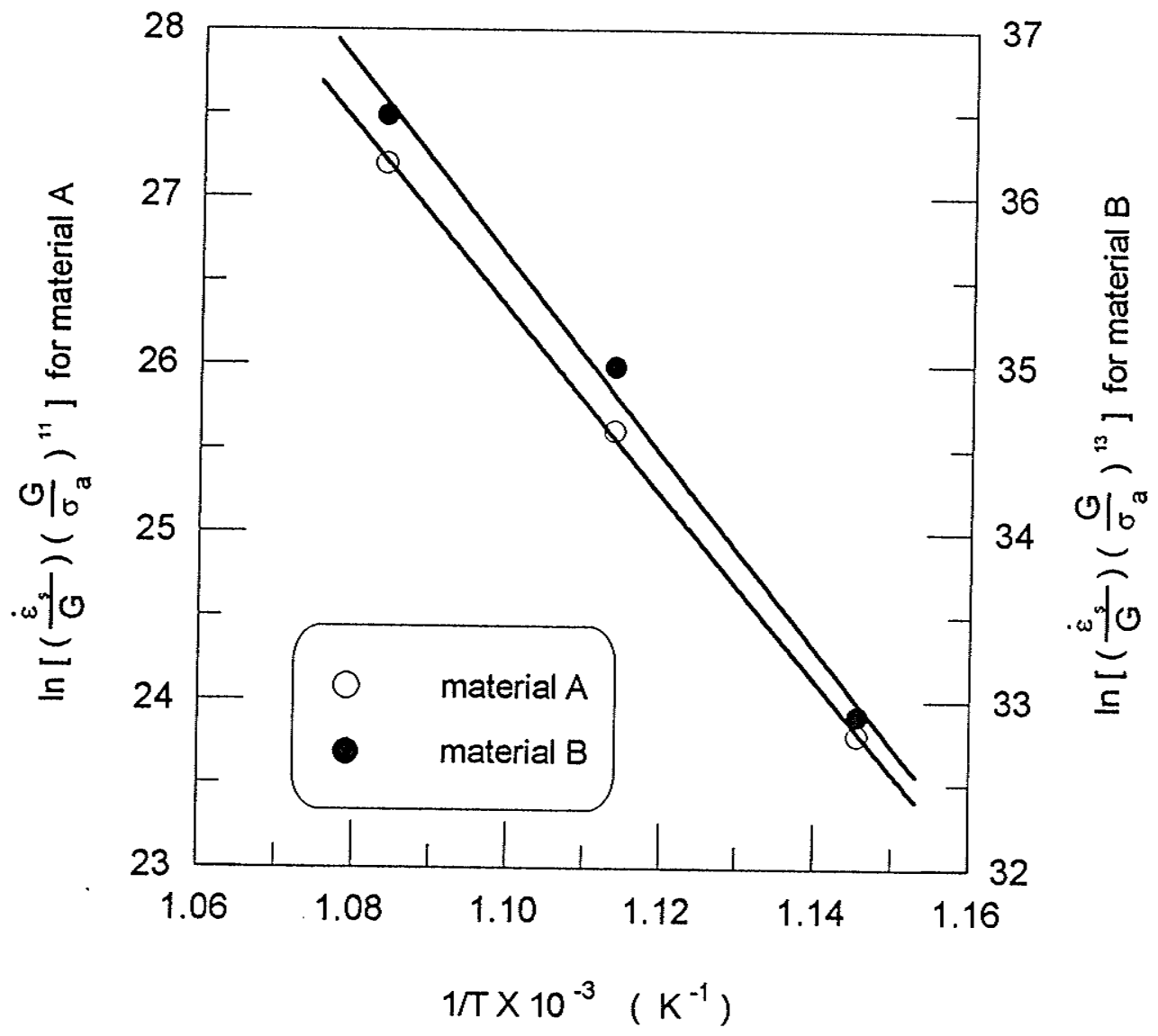

Fig. 4.19 Determination of the values of apparent activation energy 


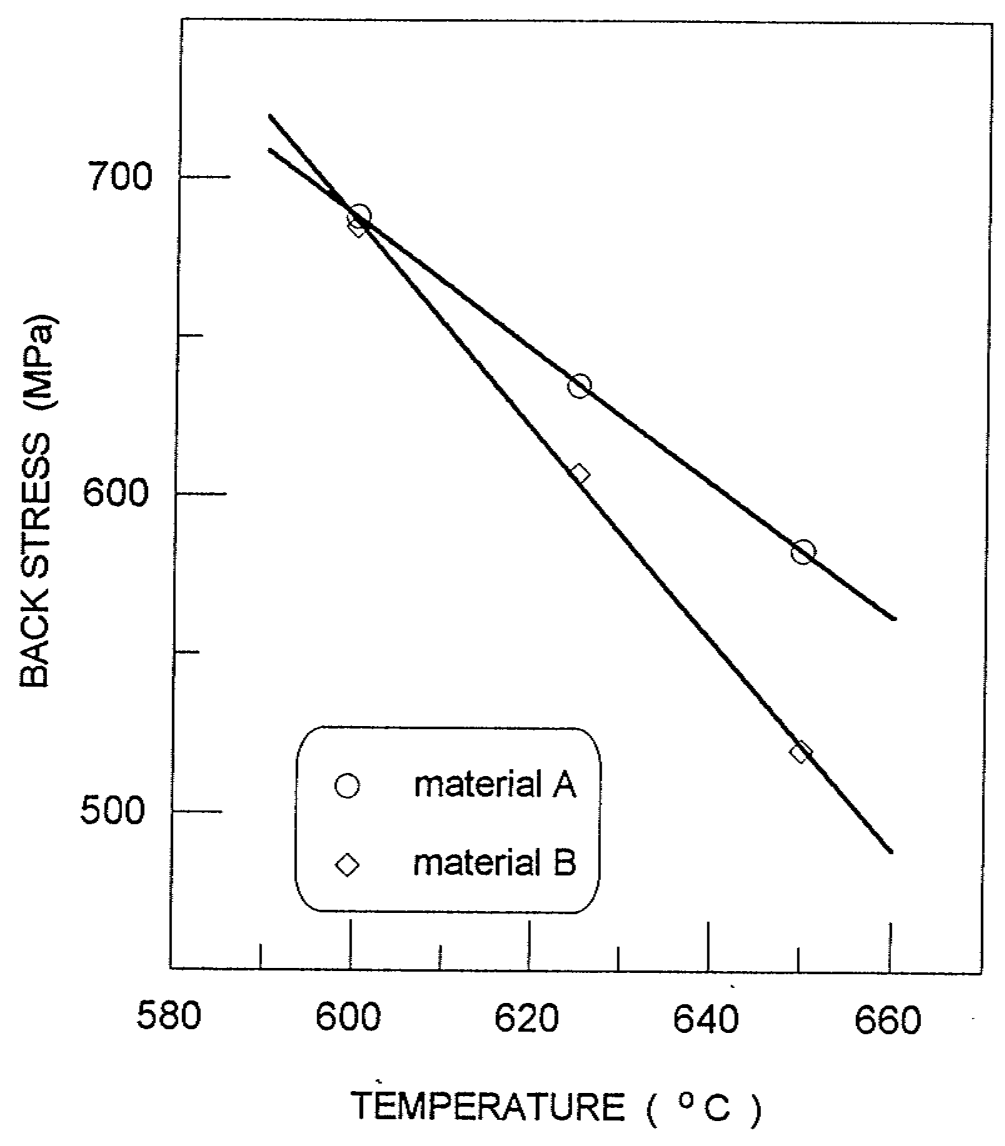

Fig. 4.20 Effect of temperature on back stress at the initial applied stress of $820 \mathrm{MPa}$. 


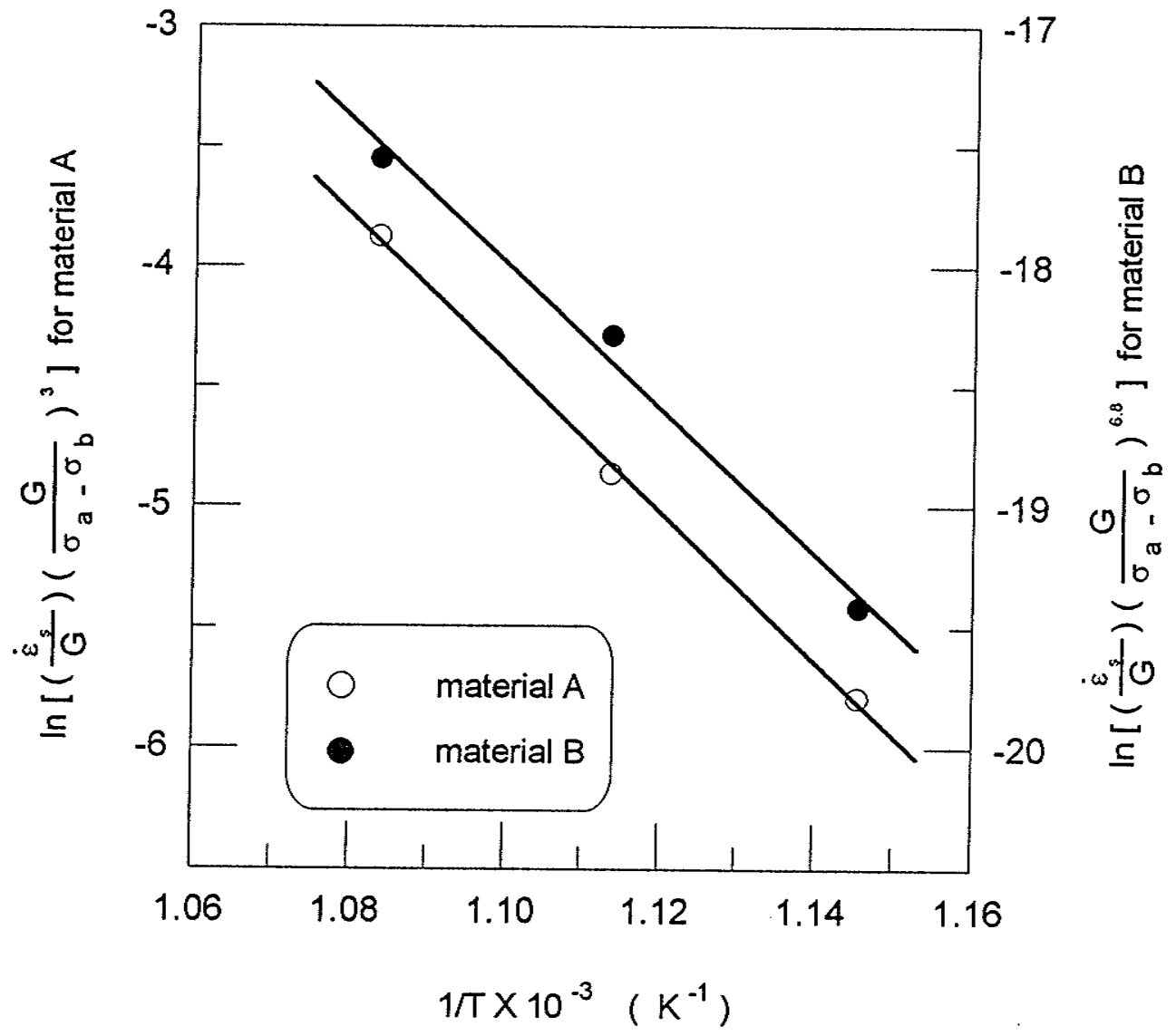

Fig. 4.21 Determination of the values of effective activation energy 
are shown in Fig. 4.19. The calculated values of apparent activation energy, $Q_{a}$, are listed in Table 4.3. It is seen that these values $\left(450-475 \mathrm{kj} \mathrm{mol}^{-1}\right)$ are much higher than those observed for self-diffusion or for the creep process in pure nickel and $\mathrm{Ni}-\mathrm{Cr}$ solid solution $\left(265-295 \mathrm{kj} \mathrm{mol}^{-1}\right)[107,193,203]$. However, Eq. 4.1 does not consider the influence of back stress on the creep rate and the activation energy. Therefore, the creep rate equation is modified as follows by replacing $\sigma_{a}$ by $\left(\left(\sigma_{a}-\sigma_{b}\right)\right.$ [195].

$$
\dot{\varepsilon}_{s}=A\left(\frac{\sigma_{a}-\sigma_{b}}{G}\right)^{n_{a}}\left(\frac{G b}{k T}\right) \exp \left(-\frac{Q_{e}}{R T}\right)
$$

From this expression, the effective activation energies, $Q_{e}$, can be determined from the slope of $\ln \left(\dot{\varepsilon}_{s} T / G\right)\left[G /\left(\sigma_{a}-\sigma_{b}\right)\right]^{n_{c}}$ vs. $1 / T$.

Table 4.3 Experimentally determined values of activation energy of creep

\begin{tabular}{|c|c|c|}
\hline Material & $Q_{a} k \mathrm{~mol}^{-1}$ & $Q_{e} k^{J} \mathrm{~mol}^{-1}$ \\
\hline Material A & 452.7 & 248.1 \\
\hline Material B & 473.6 & 250.8 \\
\hline Pure Ni and Ni-Cr alloys & $265-295$ & (Ref. $[107,193,203])$ \\
\hline
\end{tabular}

The back stress of Inconel 718 with clean grain boundaries has been observed to decrease with an increase in temperature $[199,202]$. This was confirmed in the present study. The back stress for both the materials, with clean grain boundaries and with $\delta$ precipitates on the grain boundaries, was observed to decrease with an increase in deformation temperature, as shown in Fig.4.20. The $\ln \left(\dot{\varepsilon}_{s} T / G\right)\left[G /\left(\sigma_{a}-\sigma_{b}\right)\right]^{n_{c}} v s .1 / T$ plots, using temperature corrected values of back stress, are shown in Fig. 4.21. From these plots, the values of effective activation energy were determined to be 248.1 and 
$250.8 \mathrm{~kJ}$ mol-1 for material A and Material B, respectively, and are listed in Table 4.3. These values are in a reasonable agreement with the activation energies observed for selfdiffusion and for creep deformation of pure nickel and Ni-Cr solid solution alloys (256$295 \mathrm{~kJ}$ mol-1) $[107,193,203]$. They suggest that the creep deformation process in both the materials is thermally activated and involves vacancy migration [94, 199, 202].

\subsection{EFFECT OF GRAIN BOUNDARY PRECIPITATE DENSITY ON CREEP BEHAVIOUR}

The results presented in previous section suggest that the back stress is influenced by the introduction of precipitates at grain boundaries. Therefore, it is necessary to determine if the back stress is also dependent on the precipitates at grain boundaries. To obtain different coverage of precipitates at grain boundaries, material B was given different second solution treatments at temperatures ranging from $900^{\circ} \mathrm{C}$ to $1000^{\circ} \mathrm{C}$. The results of this heat treatment were described in detail in section 4.1.2. The creep tests on these materials were conducted at $625^{\circ} \mathrm{C}$ at an applied stress of $795 \mathrm{MPa}$. The results of these tests are described next.

\subsubsection{CREEP DEFORMATION}

Some of the typical creep curves for specimens with different grain boundary precipitate density are shown in Fig. 4.22. The steady state creep rate or the minimum creep rate for all the specimens tested were plotted against the density of precipitates at grain boundaries. This plot is shown in Fig. 4.23. The main features of the curves shown in Figs. 4.22 and 4.23 can be summarized as follows:

(1). There is a well defined steady state stage in materials with a grain boundary precipitate density of $45 \%, 51 \%$ and $61 \%$. In contrast to this, creep curve of the material with a lower density of precipitates at grain boundaries $(22 \%)$ does not exhibit a steady 


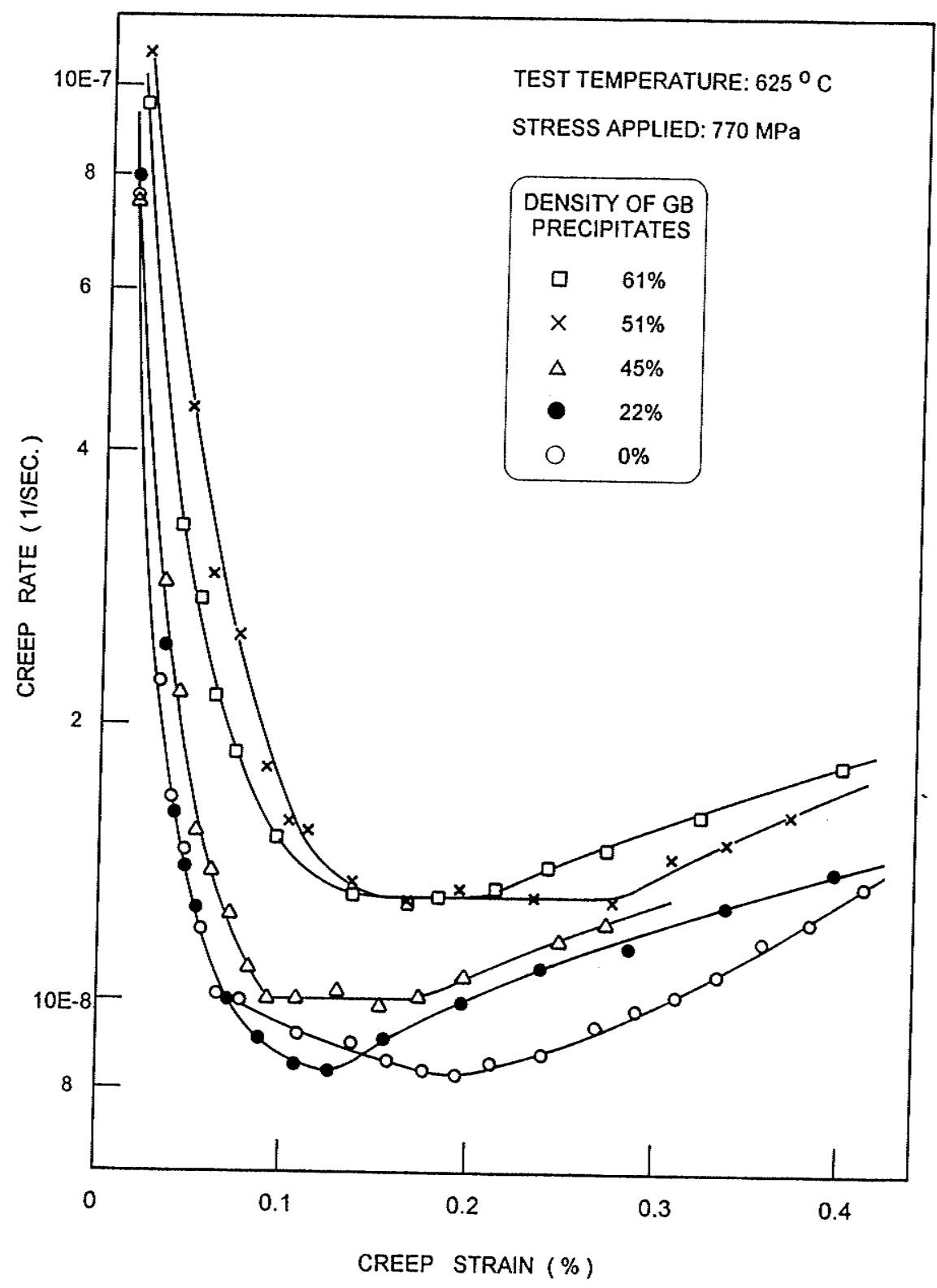

Fig. 4.22 Creep rate versus creep strain for the materials with different precipitate density at grain boundaries. 


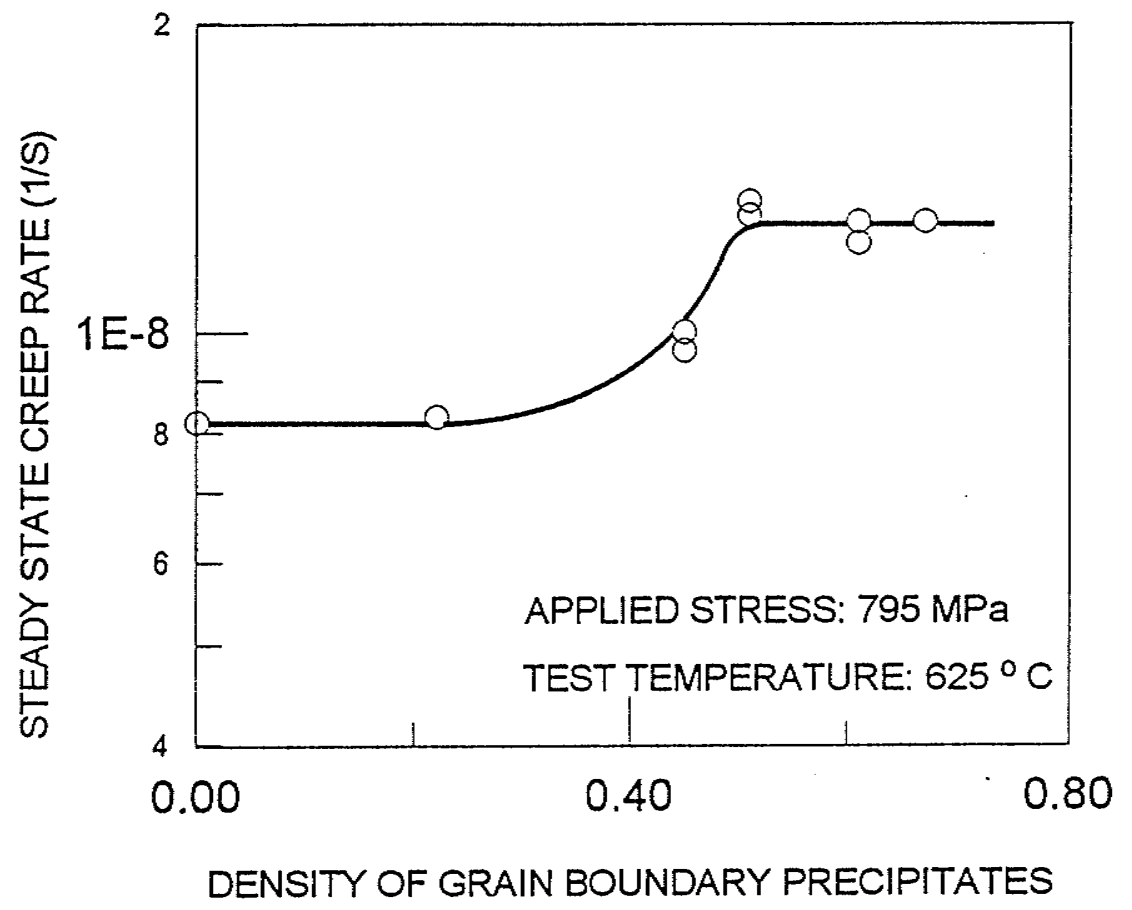

Fig. 4.23 Variation of steady state creep rate with the density of precipitates at grain boundaries 
state stage. This observation is similar to that observed in creep curve of the material with clean grain boundaries.

(2) The steady state creep rate does not change when the material has a higher density of precipitates at grain boundaries, and the minimum creep rate in the material with a lower density of precipitates at grain boundaries (22\%) is identical to that of the material without any precipitates at grain boundaries.

The back stress of the materials with various levels of coverage of grain boundaries by precipitates was also determined. The typical plots of remaining applied stress versus cumulative time are presented in Fig. 4.24. The dependence of back stress on the density or grain boundary precipitates at the same initial applied stress is demonstrated in Fig.4.25. This curve can be divided into three regions. In the region with a very high or a very low density of precipitates at grain boundaries, the back stress is not influenced by the presence of grain boundary precipitates. However, in the region with an intermediate density of precipitates at grain boundaries, the back stress is strongly dependent on the density of precipitates at grain boundaries. In this region, with a decrease in precipitate density at grain boundaries, the back stress decreases from a constant value of back stress in the high density region, and then increases to another constant value constant in the low density region. In addition to this, some other features should also be noted: (1) the value of back stress in region III is lower than that observed in region I. (2) the back stress in region II is lower than in both regions I and III. All of these features contradict the generally held belief that back stress is a reflection of the creep resistance of grain material and not likely to be influenced by the precipitates at grain boundaries.

\subsubsection{RUPTURE BEHAVIOUR}

Besides the creep deformation behaviour, the rupture behaviour of the material should be also influenced by the change in the precipitate density at grain boundaries. This 


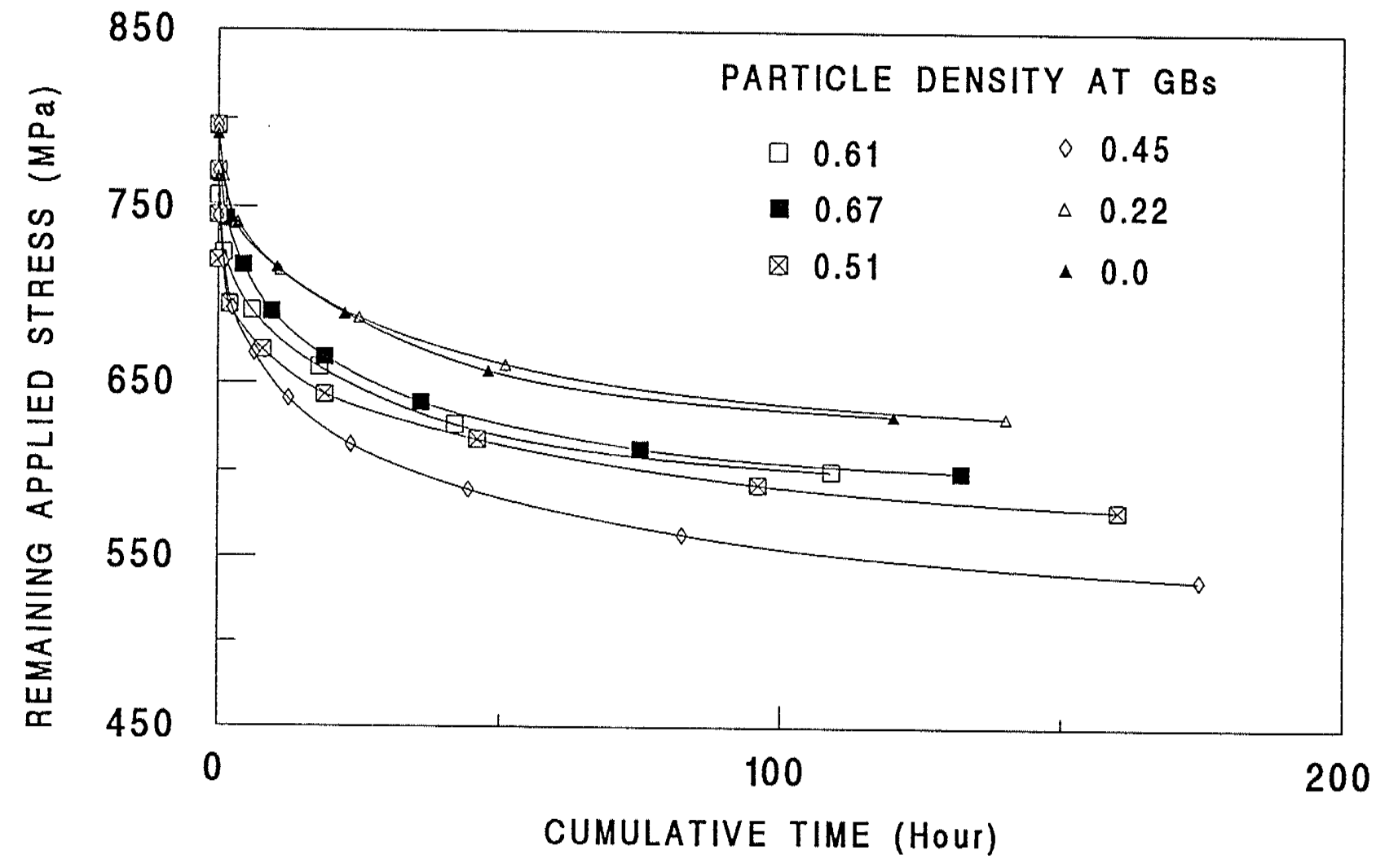

Fig. 4.24 Relationship between remaining applied stress and cumulative time for the material with various particle density at grain boundaries. The initial applied stress is $795 \mathrm{MPa}$ and test temperature is $652^{\circ} \mathrm{C}$. 


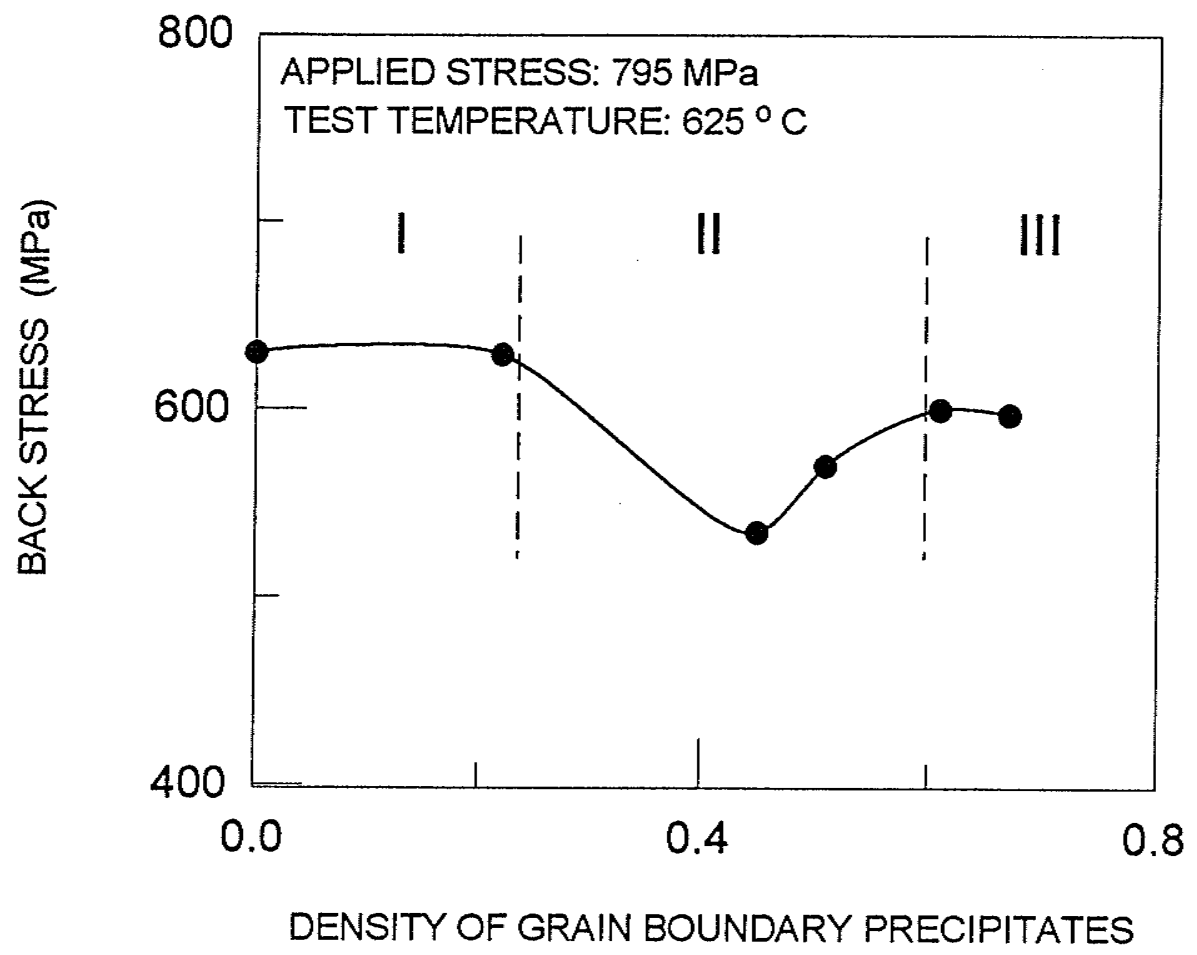

Fig. 4.25 Variation of back stress with the density of precipitates at grain boundaries. 


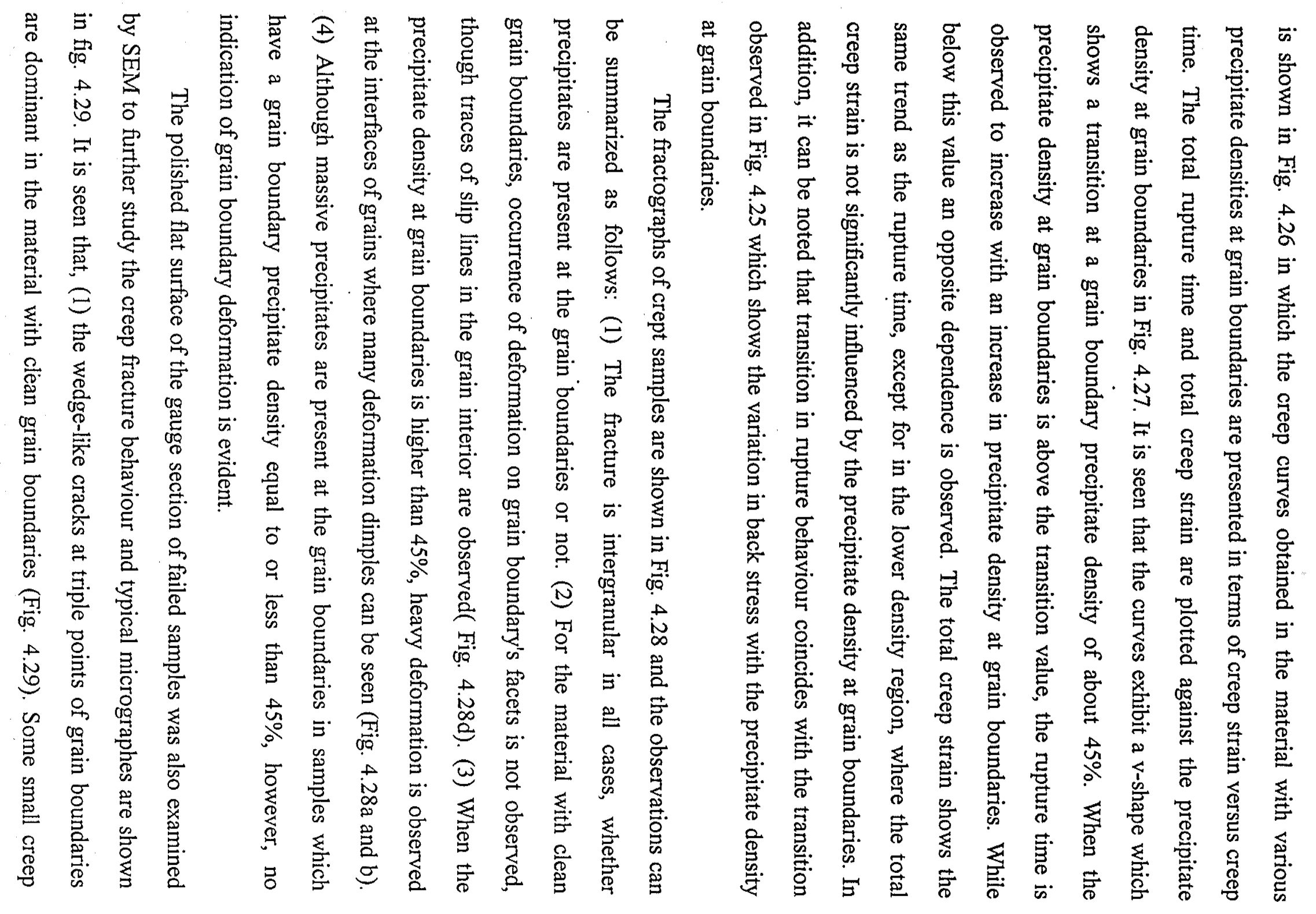




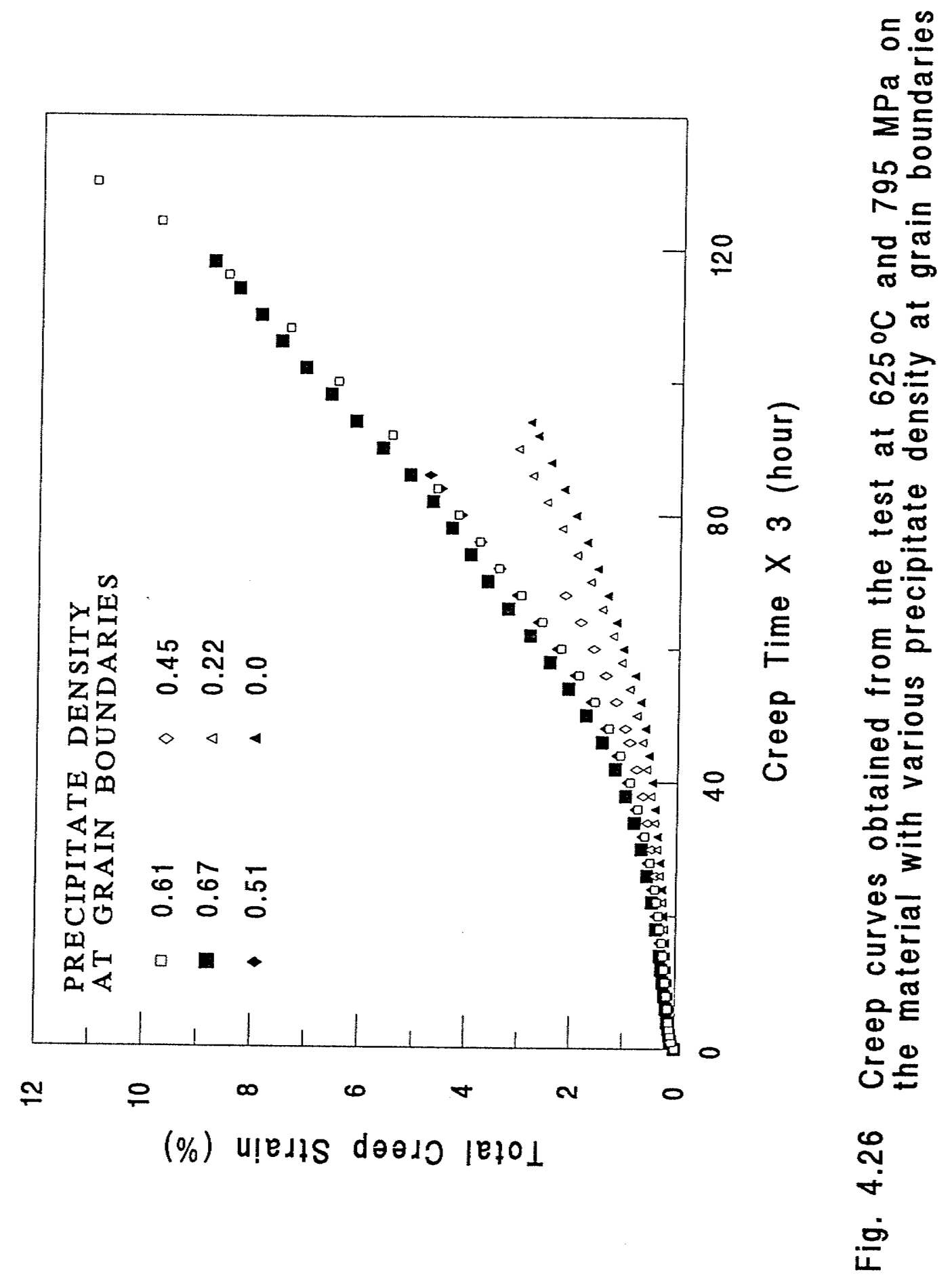




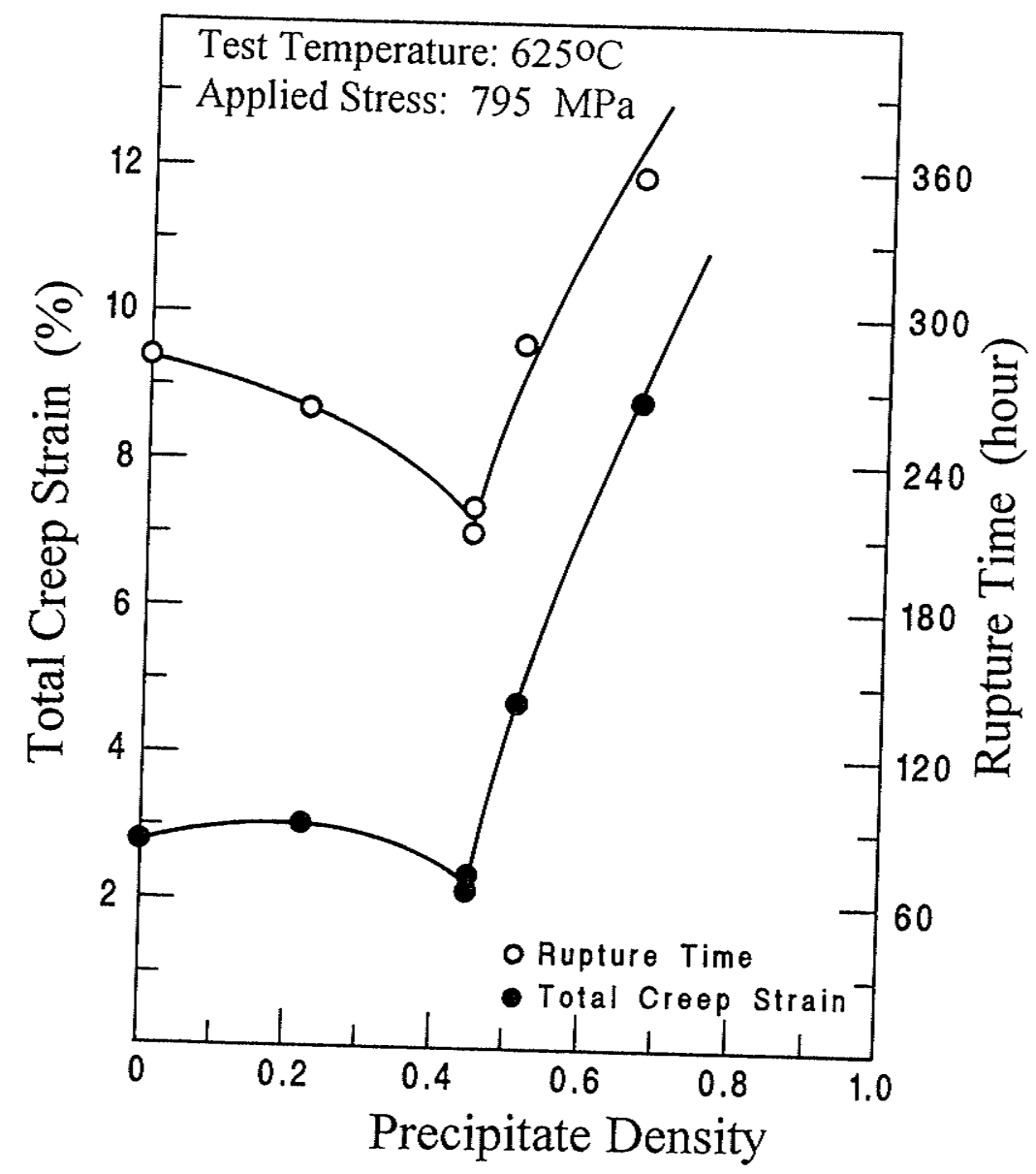

Fig. 4.27 Dependence of total creep strain and rupture time on precipitate density at grain boundaries. 


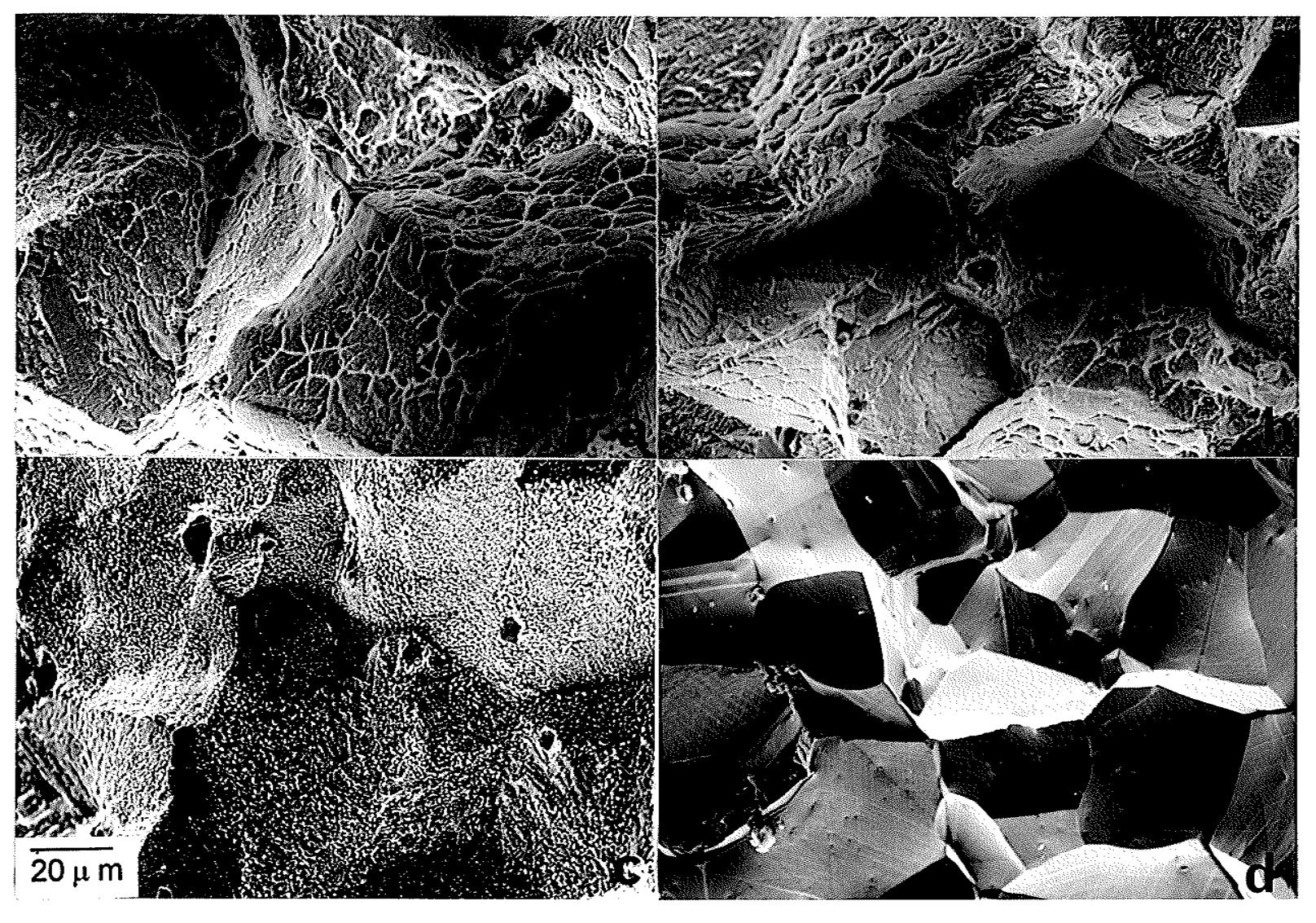

Fig. 4.28 SEM fractographs of the materials solid solution treated at a) $9000^{\circ} \mathrm{C}$, b) $925^{\circ} \mathrm{C}$, c) $975^{\circ} \mathrm{C}$, d) $1020^{\circ} \mathrm{C}$ and creep tested at $625^{\circ} \mathrm{C}$ and $795 \mathrm{MPa}$. 


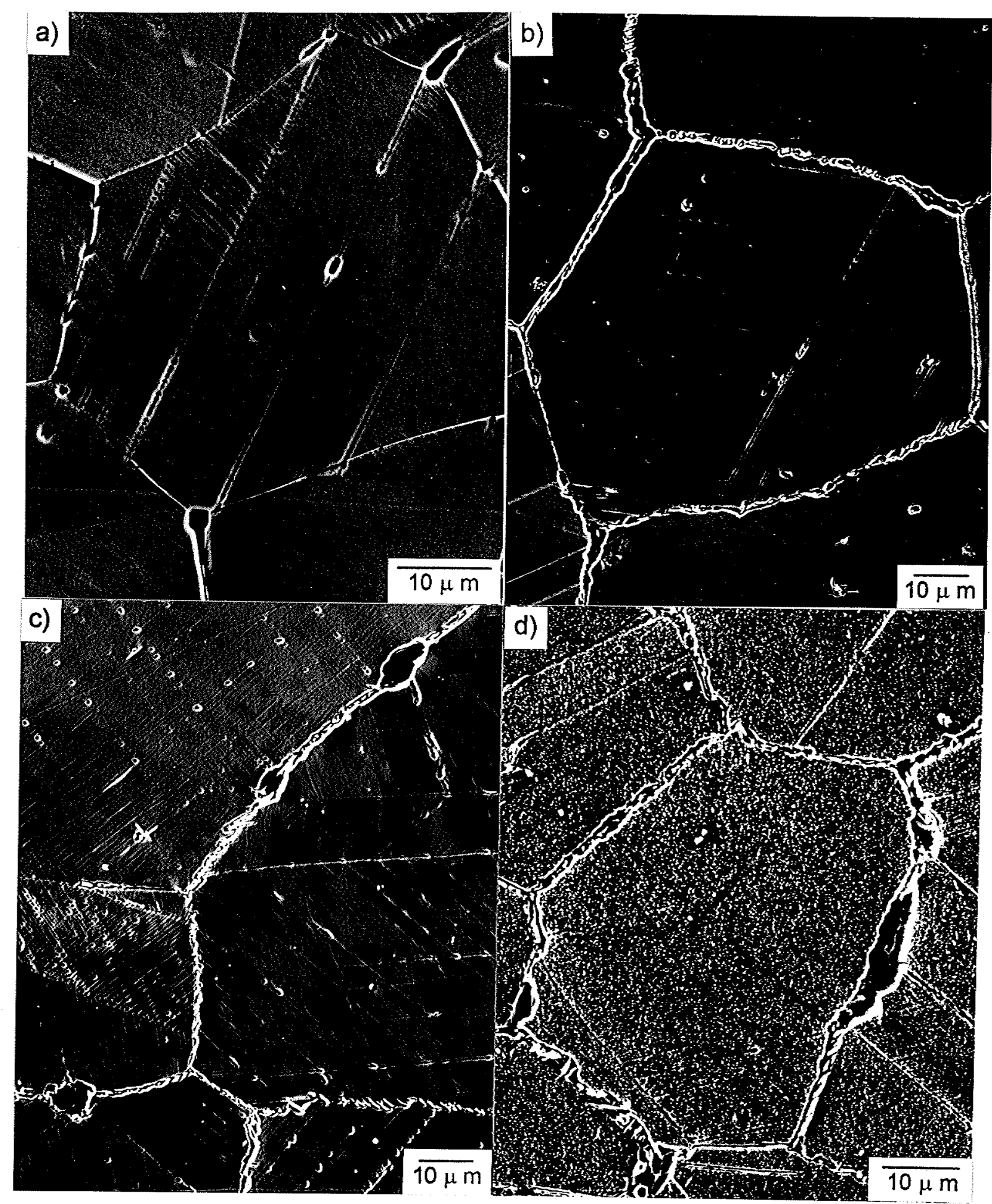

Fig. 4.29 Wedge cracks at the triple points of grain boundaries are often observed in the material with clean grain boundaries (a), and with a partial solid solution temperature at $975^{\circ} \mathrm{C}$ (b) and higher. Void-formed cracks are mainly found in the material with a solid solution temperature at $925^{\circ} \mathrm{C}(\mathrm{c})$ and $900^{\circ} \mathrm{C}(\mathrm{d})$. 
voids on regular grain boundaries are also observed, though they are often associated with intersection site of slip lines and twins and grain boundaries; (2) the wedge cracks at triple points might initiate the fracture in the material with low density of precipitates at grain boundaries. The wedge cracks are seldom observed in materials with high density of precipitates at grain boundaries, instead creep cracks are often found on normal grain boundaries.

\subsection{EFFECT OF GRAIN SIZE ON CREEP BEHAVIORS}

\subsubsection{DEPENDENCE OF CREEP RATE ON GRAIN SIZE}

Material $\mathrm{A}$ and $\mathrm{B}$ with various grain sizes were also tested at a temperature of $625^{\circ} \mathrm{C}$ and at different levels of applied stress. The variation in grain size was achieved by changing the solid solution temperature. In order to maintain an identical grain boundary microstructure (except grain size), all the specimens of material B were given the same subsequent heat treatment. That is, furnace-cooling at a rate of $50^{\circ} \mathrm{C} / \mathrm{h}$ from the solution treatment temperature to $725^{\circ} \mathrm{C}$ and second solid solution treatment at $925^{\circ} \mathrm{C}$ for 1 hour ( which produced a grain boundary precipitate density of about $67 \%$ ). For all the specimens of material A, air cooling was used, which produced clean grain boundaries in the material. All the samples of material $\mathrm{A}$ and $\mathrm{B}$ were given an aging treatment at $725^{\circ} \mathrm{C}$ for 25 hours to strengthen the grain interior.

The typical creep rate-creep time curves for specimens of material A and B with various grain sizes are given in Fig. 4.30 and 4.31 , respectively. Three major difference can be observed between material A and material B:

(1) The creep curves of material A show a decelerating primary stage and accelerating tertiary stage with a minimum in creep rate between the two stages; in the creep curves of material $B$, a well defined steady state stage between the primary and tertiary stages is observed. 
(2) In the primary stage, the creep rate is not influenced by the variation in grain size of material B, however, a decrease in creep rate with an increase in grain size is observed in material A

(3) The dependence of minimum creep rate or steady state creep rate on grain size is shown in Fig. 4.32. The minimum creep rate observed in material $\mathrm{A}$ is almost independent of grain size. In contrast to this, the steady state creep rate in material $B$ increases with an increase in grain size and the exponent is calculated to be 0.40 .

The dependence of creep rate on applied stress at various level of grain size in material B is shown in Fig. 4.33. It is seen that the stress exponent for material B appears to be constant at different leveis of grain size.

\subsubsection{BACK STRESS}

Back stress is generally believed to be an indication of creep resistance of grain material, and therefore, is not expected to be influenced by the presence of precipitates at grain boundaries (refer to section 2.2.4). This hypothesis is found to be true for the material with clean grain boundaries. To test this hypothesis, the back stress of both the materials with and without precipitates, but with different grain sizes was determined. As shown in Fig. 4.34, the back stress for material A is constant at various grain size levels. However, for the material B, the back stress increases with an increase in grain size, and the effective stress, in turn, would decrease with an increase in grain size..

Fig. 4.35 shows the dependence of steady state creep rate on effective stress for material B with a grain size of $59 \mu \mathrm{m}$ and $175 \mu \mathrm{m}$, respectively. The stress exponent obtained for material with $\mathrm{d}=175 \mu \mathrm{m}$ is about 6.5 , which is very close to the value obtained for material B with a grain size of $59 \mu \mathrm{m}$. The dependence of steady state creep rate on grain size at a given effective stress is shown in Fig. 4.36. It is observed that the steady state creep rate varies with $d^{2.5}$. 


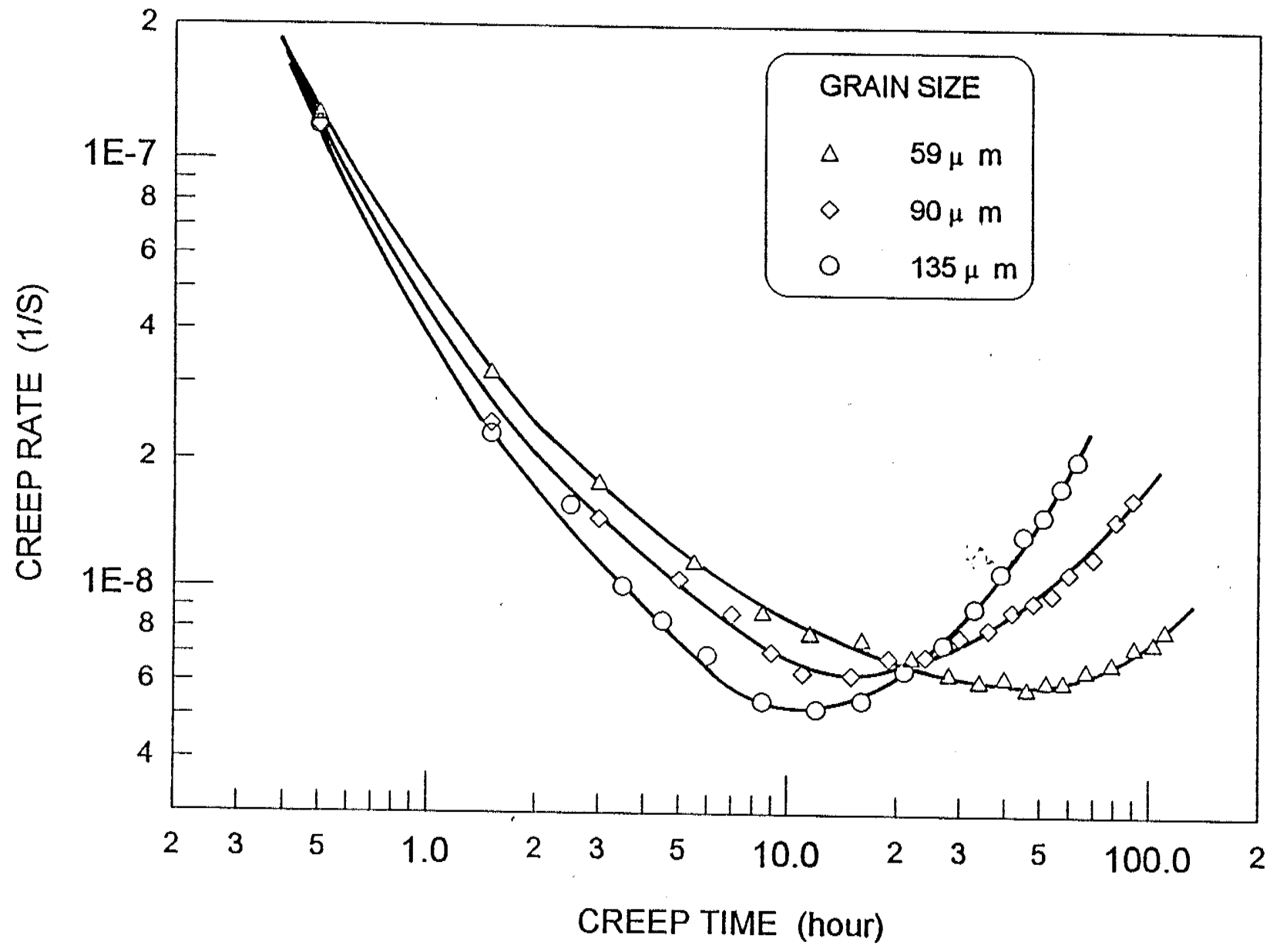

Fig. 4.30a Creep rate versus creep time for material A tested at $770 \mathrm{MPa}$ and $625^{\circ} \mathrm{C}$ 


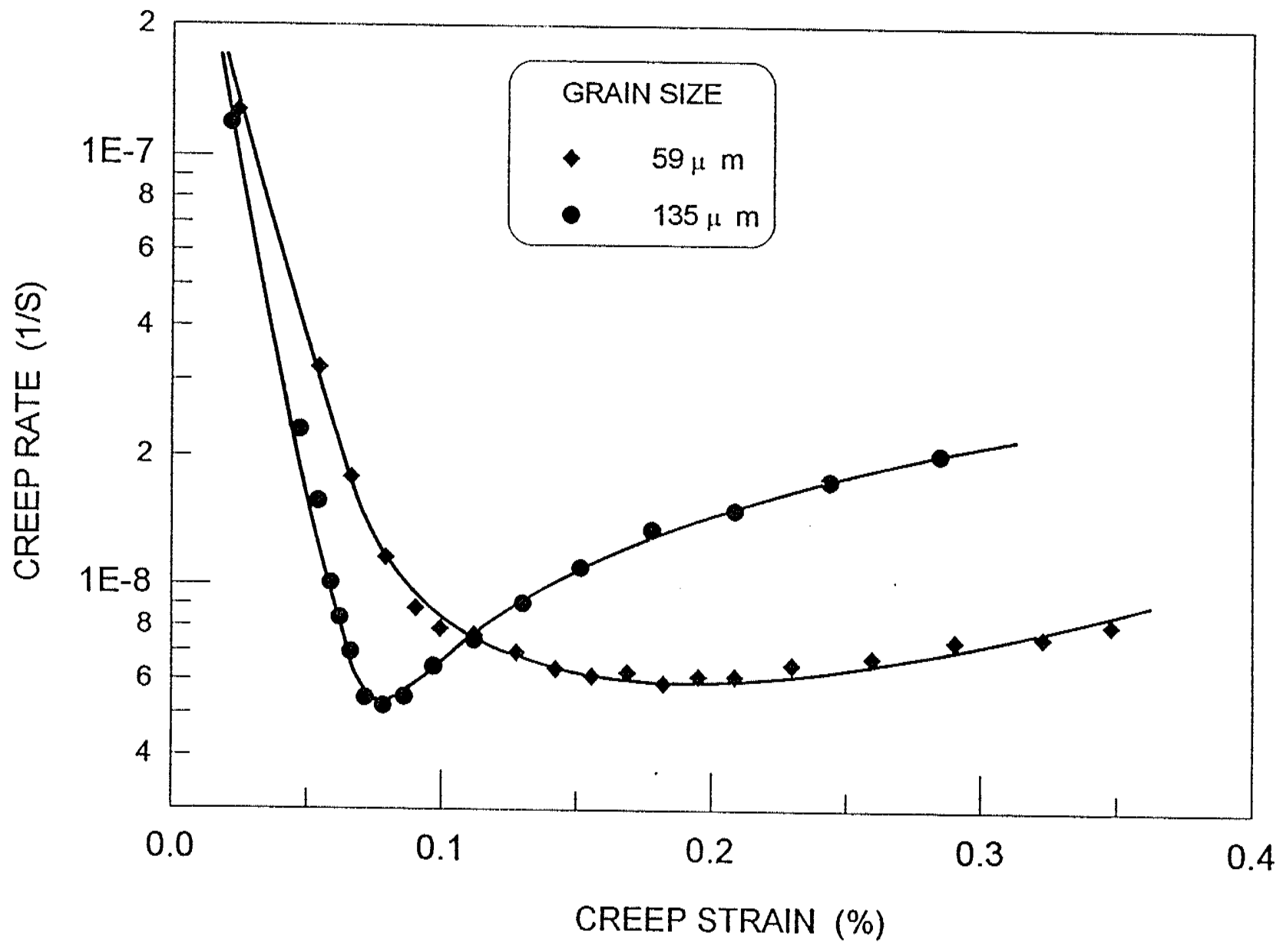

Fig. 4.30b Creep rate versus creep strain for material A tested at $770 \mathrm{MPa}$ and $625^{\circ} \mathrm{C}$ 


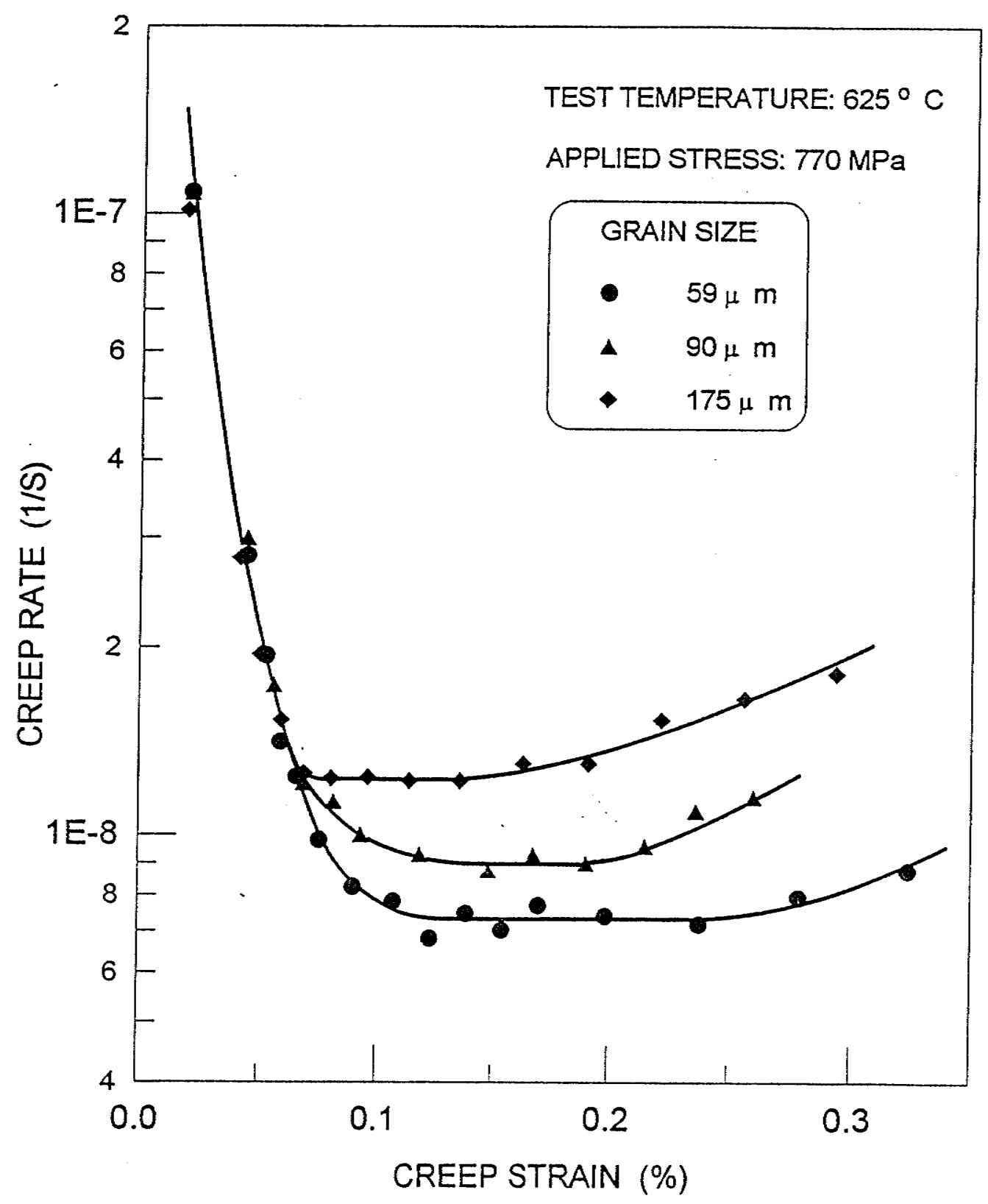

Fig. 4.31 Creep rate versus creep strain for material B with different grain size. 


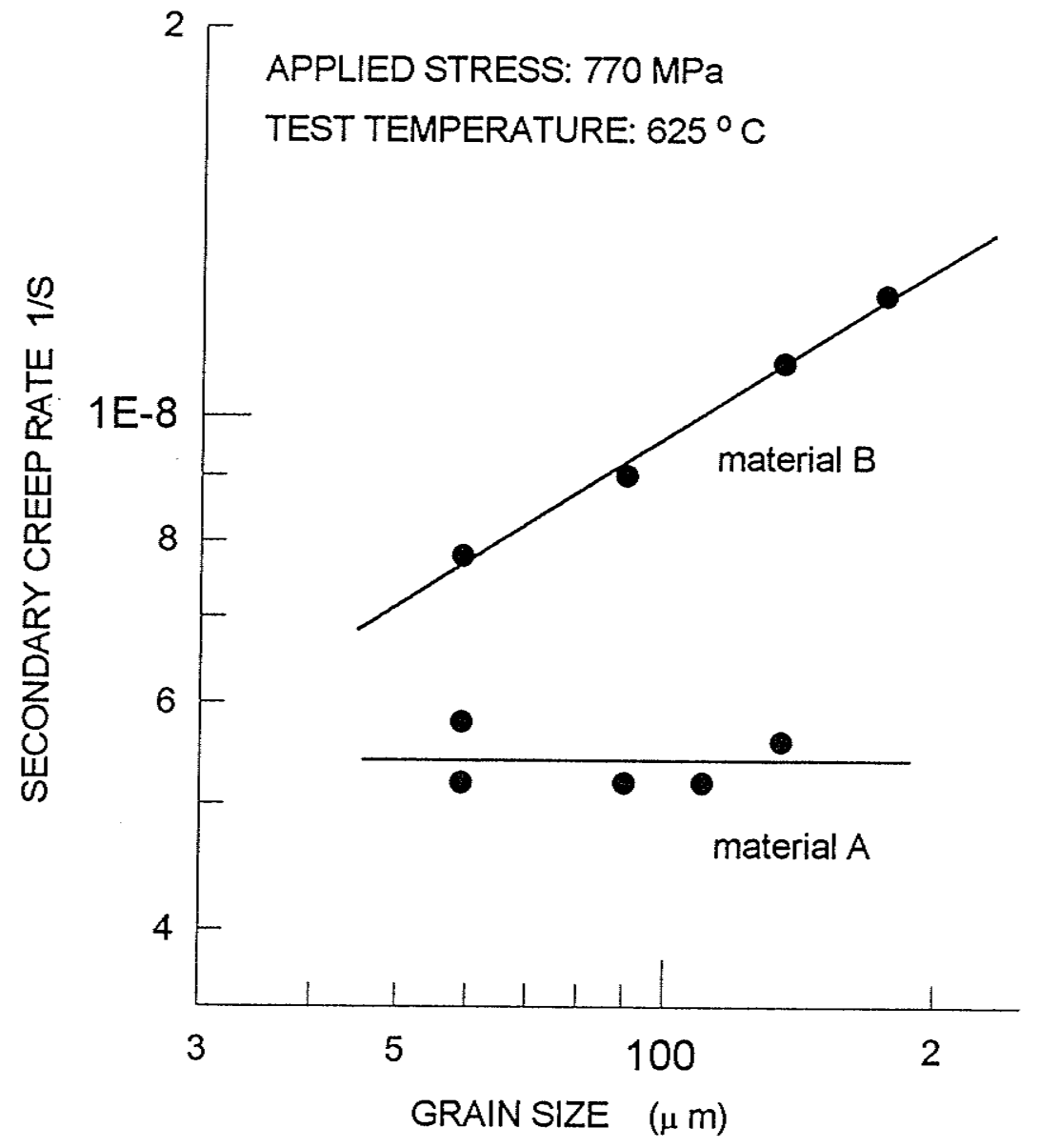

Fig. 4.32 Dependence of creep rate on grain size 


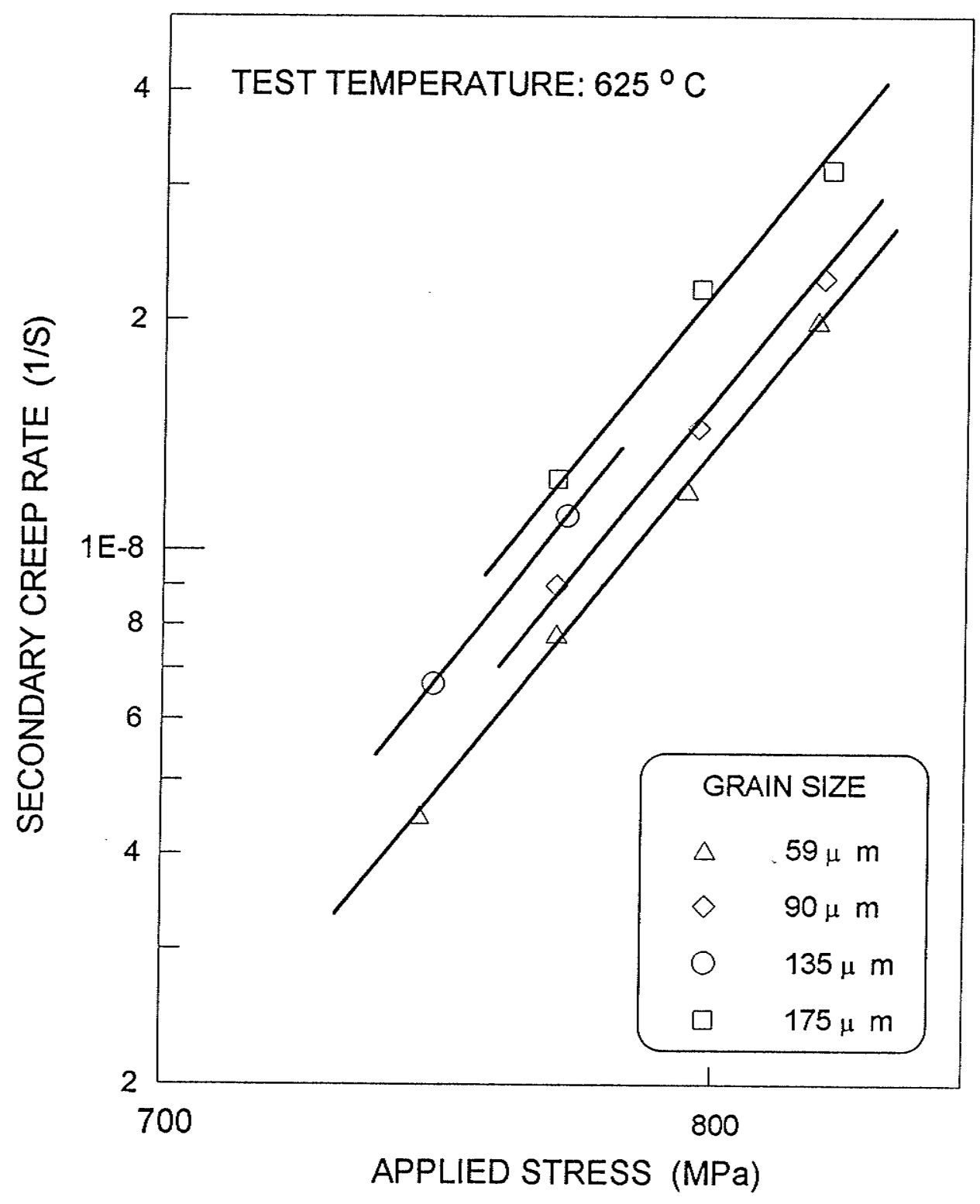

Fig. 4.33 Dependence of creep rate on applied stress for material $\mathrm{B}$ with various grain size. 


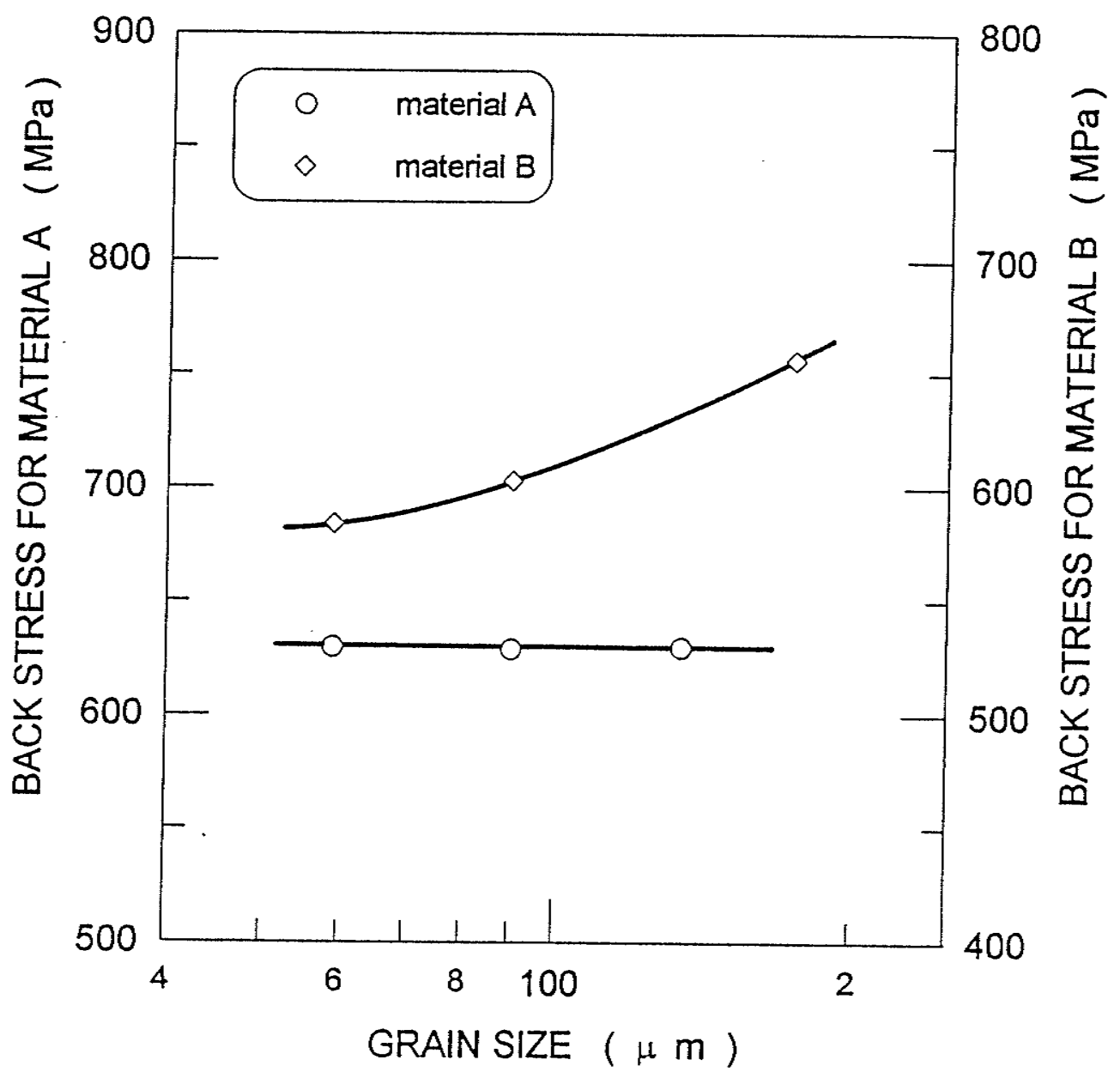

Fig. 4.34 Dependence of back stress on grain size for material A and $\mathrm{B}$. The test was conducted at $625^{\circ} \mathrm{C}$, the initial applied stress is $770 \mathrm{MPa}$. 


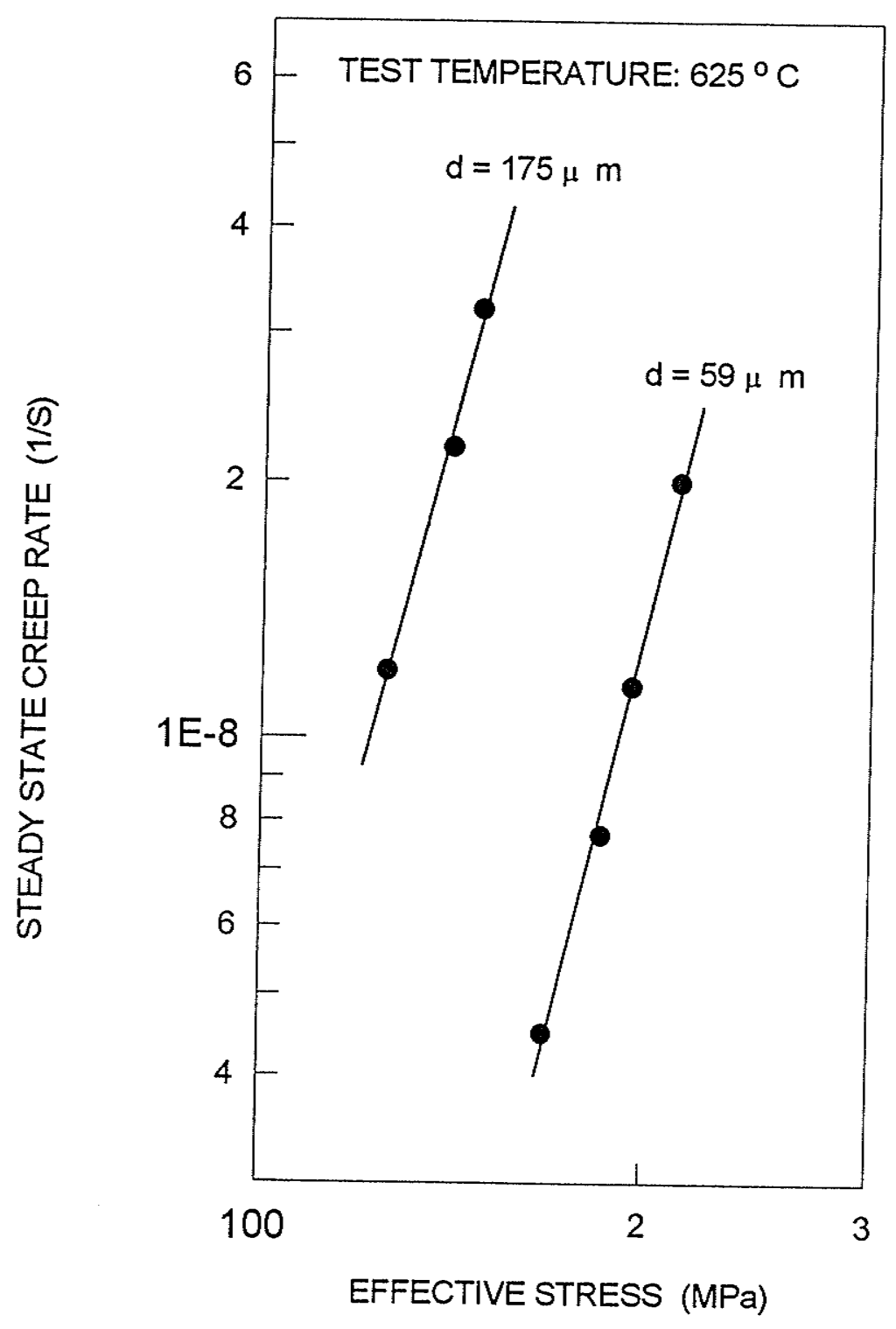

Fig. 4.35 Dependence of steady state creep rate on effective stress for material $B$ at two levels of grain size 


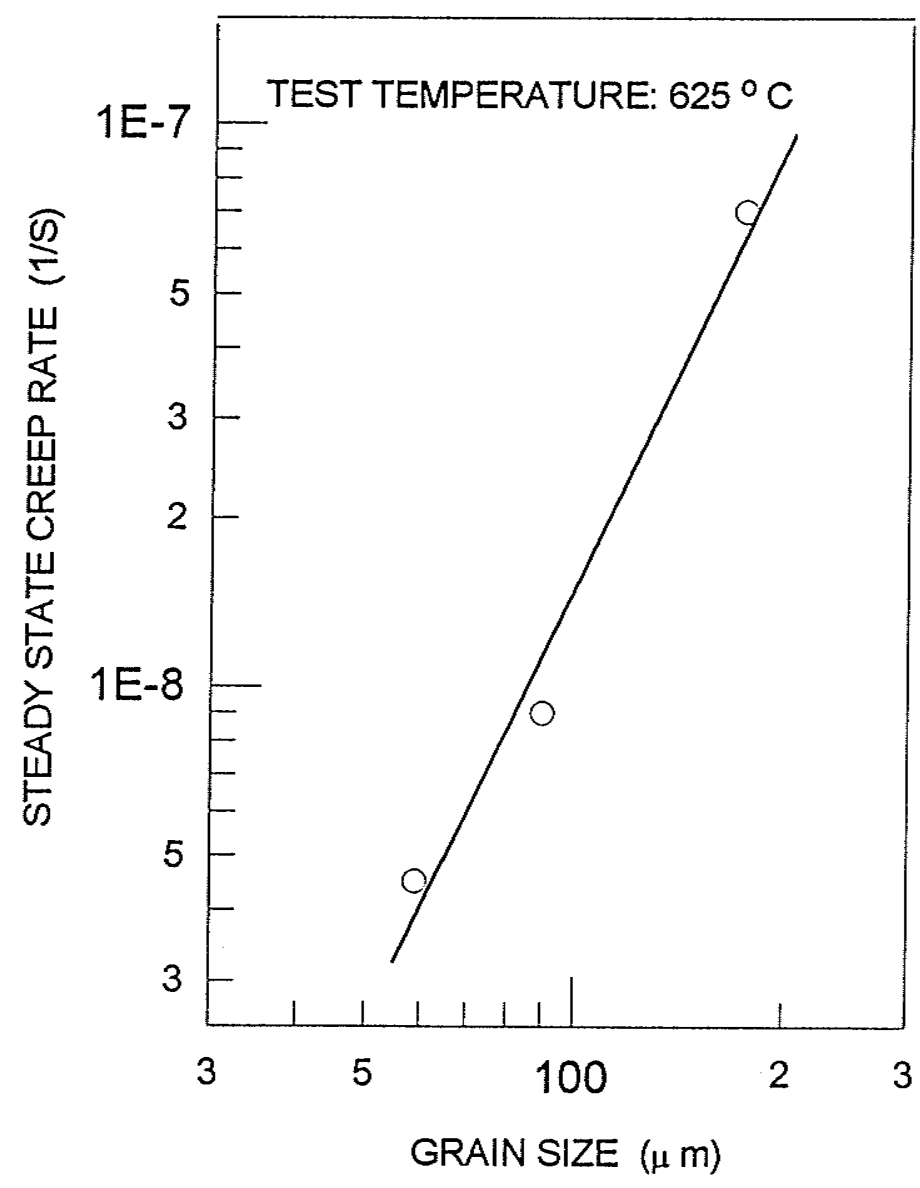

Fig. 4.36 Dependence of steady state creep rate on grain size for material $\mathrm{B}$ at a given effective stress of $168 \mathrm{MPa}$ 


\section{CHAPTER FIVE DISCUSSION}

\subsection{INTRODUCTION}

\subsubsection{CREEP MECHANISM IN MATERIAL A}

The experimental results obtained in the material with clean grain boundaries have shown that the creep behavior of the material is not influenced by grain size in the temperature and stress region in which tests were conducted. For example: (i) the effective stress exponent is observed to be within the range in which its value is found for most precipitate-strengthened materials. (ii) The minimum creep rate and the back stress are independent of grain size. These observations suggest that the microstructure of grain interior of the material is responsible for the creep behaviour observed in this study.

The grain interior of the material was precipitate-strengthened with $\gamma^{\prime \prime}$ precipitates. The interaction between a moving dislocation and precipitates has been studied by many researchers. Fig. 5.1 illustrates the variation in critical shear stress, required for the operation of a particular mechanism, with the size of precipitates $[90,204]$. It can be seen that, dislocations cut through precipitates when the size of precipitates is small. As the size of precipitates increases, cutting process becomes difficult and is replaced by Orowan bowing-out mechanism at a critical size of particles. When particles are larger than this size, a smaller critical stress may need for the deformation to occur. When the applied stress is so low that both cutting and Orowan bowing-out mechanism are not possible, deformation may occur by dislocations climbing over the particles. The operation of this mechanism, as reviewed in Chapter Two, requires the assistance of thermal activation, therefore, is often observed only at high temperatures. The critical particle size that delineates the cutting mechanism and Orowan bowing out mechanism at $625^{\circ} \mathrm{C}$ in Inconel 718 was experimentally determined to be $23.2 \mathrm{~nm}[200]$. In present studies most of the experiments on material A were conducted on specimens aged at $725^{\circ} \mathrm{C}$ for 25 hours. This treatment produced $\gamma^{\prime \prime}$ discs of $16.3 \mathrm{~nm}$ diameter. At this size of $\gamma^{\prime \prime}$, two type of 
interactions between a moving dislocation and particles may possibly occur, That is, dislocations cutting through precipitates at higher stress levels and dislocations climbing over the precipitates in the lower stress region.

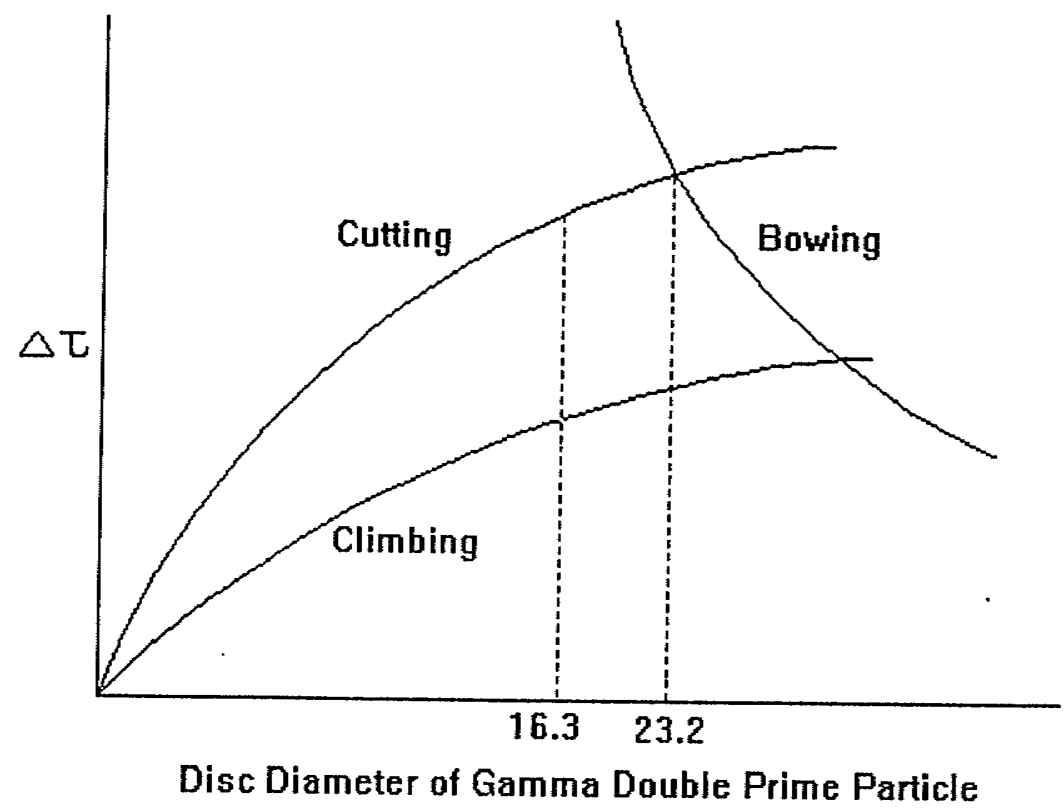

Fig. 5.I Schematic aging hardening curves illustrating the particle size of the optimum high temperature creep resistance and the particle size in the material used in present studies.

Many creep studies[205] on precipitate-strengthened alloys have shown that, irrespective of the volume fraction and average size of precipitates, the magnitude of the stress exponent decreases with decreasing applied stress, i.e. in all cases, the value of $n$ decreases from $\sim 12$ to $\sim 5$ over the stress range examined. This decrease in the value of $n$ is accompanied by a decrease in the measured activation energy for creep. From the examination of surface of specimens of copper-cobalt alloys after creep deformation, Whilsire and his co-workers ${ }^{[205]}$ suggested that at higher stresses where a higher value of 
$n$ is found, moving dislocations can either cut through or bow between the particles. While at lower stresses where a lower value of $\mathrm{n}$ is observed, dislocations move by climbing over the particles.

The above observations are quite similar to what has been observed during the creep deformation of material A. At higher stress levels, a stress exponent of about 11 at both the test temperatures was observed. At lower stresses, an exponent of 5 was observed when the material was tested at $600^{\circ} \mathrm{C}$. Therefore, it is believed that the dislocation cutting mechanism operates at higher stresses, and dislocation climbing is responsible for deformation at lower stresses.

\subsubsection{CREEP MECHANISM IN MATERIAL B}

Unlike material A, the creep behaviour of material B, as summarized below, has been observed to be very grain boundary dependent.

(i) There exists a range of size of $\gamma^{\prime \prime}$ particles, within which the secondary creep rate of the material does not vary with the size of $\gamma^{\prime \prime}$.

(ii) The values of back stress is observed to depend on the initial applied stress, and is also influenced by grain size and density of grain boundary precipitates. However, this was not the case in material A.

(iii) The secondary creep rate increases with an increase in grain size, Such a dependence contradicts the generally held belief that the secondary creep rate either decreases with an increase in grain size due to grain boundary sliding, or does not vary significantly with grain size as observed in material A.

(iv) Not only the secondary creep rate, but all the creep curves of material B are entirely different than those observed for material A

All these features observed during creep deformation in material B indicate that the creep deformation of this material may be also affected by the microstructure of the grain 
boundaries. Part of these effects is reflected in the nature of creep equation for the alloy, which is presented next.

The apparent dependence of steady state creep rate on applied stress can be written as follows,

$$
\dot{\varepsilon}_{s}=A\left(\frac{d}{b}\right)^{\frac{1}{2}}\left(\frac{\sigma}{G}\right)^{13} \exp \left(-\frac{Q_{a}}{R T}\right)
$$

where $A$ is a structural constant and $d$ is the grain size. By considering the dependence of back stress on applied stress and grain size, presented in Chapter Four, Eq. 5.1 can be rewritten as,

$$
\dot{\varepsilon}_{s}=A^{\prime}\left(\frac{d}{b}\right)^{2}\left(\frac{\sigma_{a}-\sigma_{b}}{G}\right)^{6.8} \exp \left(-\frac{Q_{e}}{R T}\right)
$$

The equation thus obtained does not resemble any of the creep equations reviewed in Chapter Two; except for the one proposed by Robinson and et al (refer to section 2.2.2.2). They suggested an equation of following form:

$$
\dot{\varepsilon}_{s}=S\left(\frac{D_{e f f}}{b^{2}}\right)\left(\frac{\lambda}{b}\right)^{p}\left(\frac{\sigma}{E}\right)^{N}
$$

where $S$ is a microstructural constant dependent upon the stacking fault energy and dislocation structure, $D_{e f f}$ is the effective diffusion coefficient, exponent $N$ and $p$ are constant, $\lambda$ is the subgrain size.

This suggests that, when grain boundaries of a material are decorated with particles, they can behave like sub boundaries developed during the creep of pure metals, and single phase alloys that exhibit Class II type of creep behaviour. 
To confirm the above hypothesis, two important aspects may have to be addressed.

(i) Characterization of grain boundary sliding in both the materials. This is because grain boundary sliding is believed to be a major deformation factor that may contribute to the total creep strain in the region of power-law dislocation creep (section 2.3.3).

(ii) The dependence of back stress on applied stress and grain size. The unusual behaviour in material $B$ was due to the unique dependence of back stress on applied stress as well as on grain size. Therefore, to determine the actual creep mechanism that governs the deformation of the material, the origin of the back stress in both the materials may have to be determined. 


\subsection{CHARACTERIZATION OF GRAIN BOUNDARY SLIDING}

\subsubsection{GRAIN BOUNDARY SLIDING PROCESS IN MATERIAL A AND MATERIAL B}

\subsubsection{INCUBATION TIME FOR GRAIN BOUNDARY SLIING}

As reviewed in Chapter Two, grain boundary sliding contributes to total creep strain to a significant extent only when the deformation at grain boundaries occurs at a rate that is faster than the deformation rate within the grain materials. Under these circumstances, the grain boundaries cannot transmit the full shear traction. The shear stress across the relaxed grain boundaries, then, would cause the boundaries to slide. In the situation where precipitates are present on the grain boundaries, the grain boundary sliding process is rather complicated.

Although an extraordinary amount of work has been reported $[126,206,207]$, the general understanding of the effect of precipitates on grain boundary sliding has not changed as noted in many reviews of the literature published from time to time. They indicate that (i) precipitates at grain boundaries do not inhibit grain boundary sliding (ii) The sliding rate is decreased after the formation of particles at the boundaries. (iii) In most cases, an incubation period for grain boundary sliding is observed whose magnitude increases with an increase in the size of grain boundary precipitates, (iv) The amount of grain boundary sliding depends on the volume fraction, size, shape and distribution of particles at the grain boundaries. For examples, platelet-type precipitates permit larger amounts of grain boundary sliding than do the rod-shaped particles.

The characterization of incubation time for grain boundary sliding may be particularly important in the present studies since it can define when grain boundary sliding starts to contribute to the total creep deformation. Although the existence of incubation 
time has been reported several time, a satisfactory explanation, especially quantitative description, is lacking. The only explanation has been provided by Ishida et al[208], who studied the siding behaviour in a two-phase aluminum 3\% copper alloy. They suggested that, the incubation period may represent the time taken by the grain boundaries to migrate into precipitate-depleted zones where sliding can take place. However, such suggestions contradict many experimental findings. An example is the experiments of Gittins on single phase brass, and two phase brass with an almost continuous distribution of $\gamma^{\prime}$ precipitates along the grain boundaries. He observed that sliding was possible without migration but it was considerably impeded by the precipitates, for although both creep and sliding rates were lower in the two-phase alloy, there was a proportionally greater reduction in the sliding rate. The mechanism provided by Ishida[208] may not be true in the present studies, since the migration of grain boundary was not observed in the materials heat treated either to have precipitate-free boundaries or have precipitates on the grain boundaries. In addition the precipitate-depleted zones along grain boundaries did not exist in material B. Therefore, other mechanism may be responsible for the grain boundary siding observed in this study.

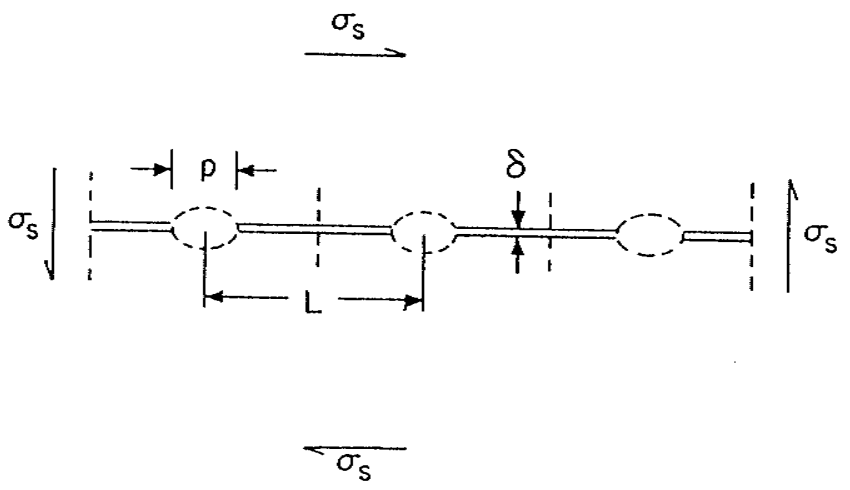

Fig. 5.2 Relaxation of shear stress along a sliding grain boundary between boundary particles by yiscous sliding of the boundary[210]. 
In order to define the conditions under which creep voids might develop at triple points of grain boundaries or around precipitates at the grain boundaries, Argon et al[210] have characterized the sliding process of grain boundary under the influence of grain boundary precipitates. The introduction of their concept may help explain the grain boundary sliding that was observed in the present studies.

Consider a set of relatively equiaxed grains containing grain boundary precipitates as shown in Fig. 5.2. It may be assumed that all boundaries and interphases are incoherent and can slide at the temperature under consideration, and that grains have isotropic elastic properties and plastic resistance. When a tensile stress $\sigma_{a}$ is applied at time $t=0$, a combination of homogeneous elastic, plastic, and creep deformation is initiated in all the grains. For a brief period traction of all types are transmitted across all grain boundaries and interfaces during which no stress concentration exists. Within a period $\tau_{B R}$ after the application of stress, however, the viscous sliding of all free segments of grain boundaries, not pinned by particles, will relax the shear stress acting across them. This produces a concentration of stress on all the particles on the sliding grain boundaries, which initiates accelerated power-law creep in the grain matrix around particles and diffusion flow along boundaries with particles. This tends to reduce the stress concentration. Thus, after a period $\tau_{B R}$, the stress distribution away from the boundaries in the polycrystalline sample will still be largely uniform. At these locations, however, the initially uniformly distributed shear traction will have been taken up by concentrated stress at particles. Within an additional increment of time $\Delta \tau_{P L}$ or $\Delta \tau_{D F}$, however, accelerated power-law creep or diffusional flow around the particles will begin to transfer matter around these grain boundary particles and will set up an initial steady state stress concentration around them as overall shear displacements across the boundary begin to occur. Such shear displacements along the boundaries, over the particles, will over a period of $\Delta \tau_{P L}{ }^{\prime}$ or $\Delta \tau_{D F}{ }^{\prime}$ gradually reduce the shear support offered by the grain boundary particles. This will 
relax even the average shear traction along the entire length of the sliding boundaries, and will build up stress concentrations at triple grain junctions. Thus, after initiation of creep, and as time goes on, stress redistribution occurs over a gradually increasing scale of characteristic dimension until a final steady state distribution gets established with a wave length on the scale of grain size.

On the basis of the above hypothesis, it may be accepted that the grain boundary sliding may start to contribute to total creep strain only when the shear support offered by the grain boundary particles is lost. That is, the incubation period may be assumed to be equal to $\tau=\tau_{B R}+\tau_{D F}+\tau_{D F}{ }^{\prime}$ and $\tau=\tau_{B R}+\tau_{P L}+\tau_{P L}{ }^{\prime}$, both of which correspond to the moment when the concentrated shear stress around particles is relaxed by the diffusion of matter and dislocation creep, respectively.

The characteristic time as described above was determined by Argon, Chen and Lau[210] by the following expressions:

$$
\begin{aligned}
& \tau_{B R}=B(L / b) \\
& \Delta \tau_{D F}=\frac{B}{8}\left(\frac{p^{3}}{\Omega}\right) \\
& \Delta \tau_{P L}=B \frac{\Lambda^{3}}{\Omega} \\
& \Delta \tau_{D F}{ }^{\prime}=\Delta \tau_{D F}\left(\frac{d}{L}\right) \frac{\beta(1 / 4)}{\beta(c)} \\
& \Delta \tau_{P L}{ }^{\prime}=\Delta \tau_{P L}\left(\frac{d}{L}\right) \frac{\beta(1 / 4)}{\beta(c)}
\end{aligned}
$$


where

$$
\begin{aligned}
& \beta\left(\frac{p}{L}=c\right)=\cos ^{-1}\left\{\frac{1}{\cos \frac{\pi}{2}\left(1-\frac{p}{L}\right)}\right\} \\
& B=\frac{1}{\pi}\left[\frac{k T}{\mu \delta D_{B}}\right] \beta\left(\frac{p}{L}\right) \\
& \Lambda=\left[\left(\frac{p}{L}\right)^{m-1} \frac{\Omega \delta D_{B} \sigma}{\dot{k} T}\right]^{1 / 3}
\end{aligned}
$$

In these expressions, $p$ is the particle size, $L$ the particle spacing; $\delta$ the thickness of grain boundaries; $D_{B}$ the grain boundary self-diffusion coefficient; $b$ the length of Burger's vector; $k$ the Boltzmann's constant; $\Omega$ the atomic volume; $d$ the grain size; $D_{V}$ the volume self diffusion coefficient; $m$ the stress exponent, and $\Lambda$ is a characteristic scaling dimension. As discussed above, within a time increment of approximately $\Delta \tau_{P L}$ or $\Delta \tau_{D F}$, an initial steady state of stress distribution gets established around the grain boundary particles as matter begins to be transported around them between oppositely stressed regions of the particle. This occurs either by diffusional flow along the particle interface or by accelerated power-law creep in the surrounding matrix. The former mechanism dominates for small particles with a size less than the characteristic scaling dimension $A$, while the latter mechanism is dominant for particles much larger than $\Lambda$.

\subsubsection{INCUBATION TIME OF GRAIN BOUNDARY SLIDING IN PRESENT MATERIALS}

Consider the situation in material $B$ where the material was heat treated to have various densities of precipitates at grain boundaries, and was creep tested at $795 \mathrm{MPa}$ and 
$625^{\circ} \mathrm{C}$. The values of various constants of the material are as follows: $G=64.9 \times 10^{9} \mathrm{~Pa}$; $b=2.5 \times 10^{-10} \mathrm{~m} ; \quad \Omega=2.3 \times 10^{-29} \mathrm{~m}^{3} ; \quad R=1.987 \mathrm{cal} /(\mathrm{mol} \mathrm{K}) ; \quad k=1.38 \times 10^{-23} \mathrm{~J} / \mathrm{K}$; $\delta D_{B}=2.8 \times 10^{-15} \exp \left(-27.4 \mathrm{kcal} \mathrm{mol}^{-1} / R T\right) \mathrm{m}^{3} \mathrm{~s}^{-1}$. Based on these data, the characteristic time and scaling dimension $\Lambda$ for material B were calculated, and are listed in Table 5.1.

Table 5.1 Characterization of grain boundary sliding in the material with grain boundary precipitates

\begin{tabular}{|c|c|c|c|c|c|}
\hline & $900^{\circ} \mathrm{C}$ & $925^{\circ} \mathrm{C}$ & $950^{\circ} \mathrm{C}$ & $975^{\circ} \mathrm{C}$ & $1000^{\circ} \mathrm{C}$ \\
\hline $\mathbf{p}(\mathbf{m})$ & $4.3 \times 10^{-7}$ & $5.2 \times 10^{-7}$ & $3.9 \times 10^{-7}$ & $3.4 \times 10^{-7}$ & $3.7 \times 10^{-7}$ \\
\hline $\mathbf{L}(\mathbf{m})$ & $7.1 \times 10^{-7}$ & $7.7 \times 10^{-7}$ & $7.7 \times 10^{-7}$ & $7.5 \times 10^{-7}$ & $16.9 \times 10^{-7}$ \\
\hline $\mathbf{c}$ & 0.606 & 0.675 & 0.506 & 0.453 & 0.219 \\
\hline$\dot{\varepsilon}_{s}\left(\mathbf{S}^{-1}\right)$ & $1.25 \times 10^{-8}$ & $1.28 \times 10^{-8}$ & $1.32 \times 10^{-8}$ & $9.9 \times 10^{-8}$ & $8.3 \times 10^{-8}$ \\
\hline$\Lambda(\mathbf{m})$ & $5.57 \times 10^{-6}$ & $8.52 \times 10^{-6}$ & $2.66 \times 10^{-6}$ & $1.88 \times 10^{-6}$ & $0.3 \times 10^{-6}$ \\
\hline$\tau_{B R}(\mathbf{S})$ & $1.92 \times 10^{-7}$ & $1.68 \times 10^{-7}$ & $2.72 \times 10^{-7}$ & $3.03 \times 10^{-7}$ & $12.06 \times 10^{-7}$ \\
\hline$\Delta \tau_{D F}(\mathbf{S})$ & $2.92 \times 10^{-2}$ & $4.16 \times 10^{-2}$ & $2.85 \times 10^{-2}$ & $2.15 \times 10^{-2}$ & $4.91 \times 10^{-2}$ \\
\hline$\Delta \tau_{D F}{ }^{\prime}(\mathbf{S})$ & 5.9 & 9.7 & 4.1 & 2.8 & 1.6 \\
\hline$\Delta \tau_{P L}(\mathbf{S})$ & 507.4 & 1463.9 & 72.4 & 29.1 & 69.8 \\
\hline$\Delta \tau_{P L}{ }^{\prime}(\mathrm{h})$ & 28.5 & 94.3 & 2.86 & 1.04 & 0.62 \\
\hline
\end{tabular}

Note: Applied stress is $795 \mathrm{MPa}$; test temperature is $625^{\circ} \mathrm{C}$; grain size is $59 \mu \mathrm{m}$.

It can be seen from Table 5.1 that, the relaxation of shear stress on the segment of grain boundary between two precipitates is rather rapid. When this relaxation is completed, the shear traction will be concentrated on the particles. This concentrated stress around particles, will be further relaxed either by the diffusion of matter around the particles when the characteristic scaling dimension $\Lambda$ is larger than the size of precipitates, or by power-law dislocation creep when $\Lambda<\mathrm{p}$. 
The calculated values of $\Lambda$ listed in Table 5.1 indicates that the size of precipitates is less than $\Lambda$ in all cases except for the material with a second solid solution treatment at $1000^{\circ} \mathrm{C}$. In this material, the grain boundaries were decorated with very low density of precipitates. This suggests that the relaxation will take place favourably by matter diffusion around the precipitates. Under this relaxation process, the stress concentrations are generally considered to be too low to initiate cavities around them( for the initiation of cavities around precipitates, stress concentration between 10-20 are needed).

Microstructural examination of crept sample of material B contradicts the above suggestions. As shown in Fig. 5.3, the creep voids were observed even in the steady state stage of creep, and had developed around almost all of the precipitates at grain boundaries in the latter stages of creep.

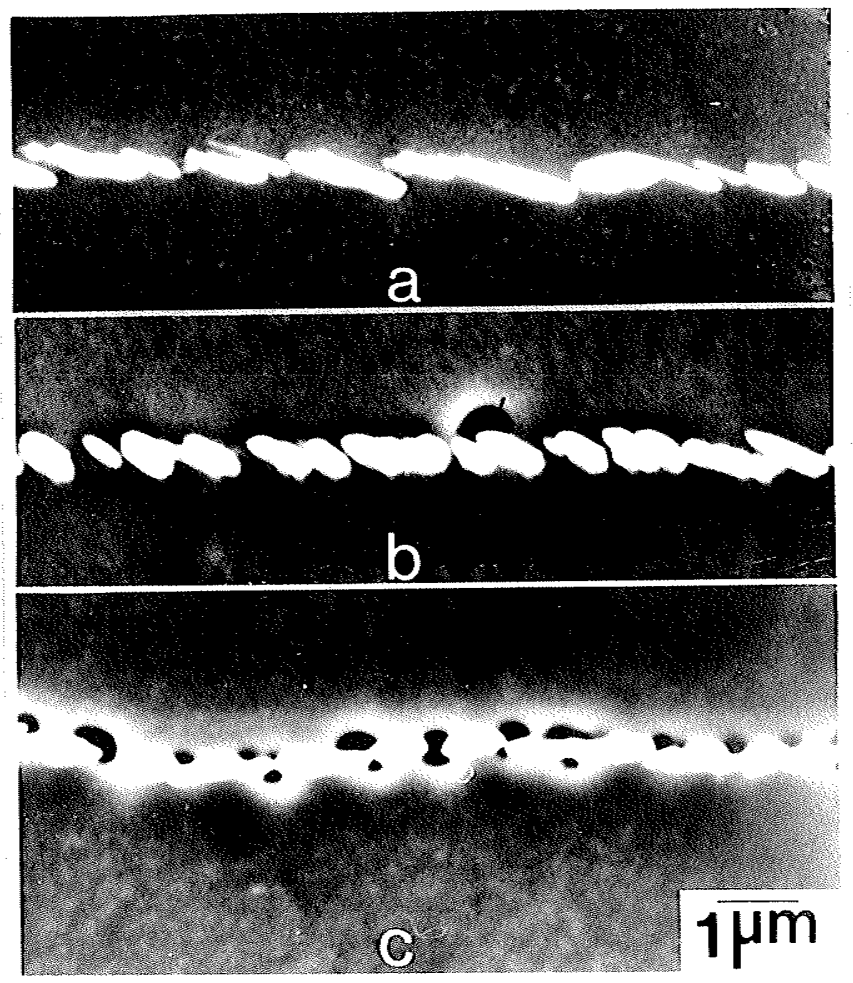

Fig. 5.3 Microstructures of grain boundaries in material B. The material has been tested and interrupted at a) position $A$, b) Position B, c) position $C$ as in Fig. 4.15 . 
The inconsistency between results of the calculations and the experimental observations probably can be bridged by the fact that the size of grain boundary particles is not constant, but varies over a wide range. An example of such a distribution is presented in Fig. 5.4, in which the material was given a second solid solution treatment at $975^{\circ} \mathrm{C}$ for one hour. Fig. 5.4 indicates that the grain boundaries of the material contain two major groups of precipitates: one with a size below the average diameter; another has a size above the average diameter. This broad difference in grain boundary particle size probably is caused by the heat treatment procedures used. The group of precipitates with a larger size would be introduced during furnace cooling and would be further coarsened during the subsequent partial solid solution heat treatment, while the group of precipitates with smaller size might be produced only in the course of the second solid solution heat treatment.

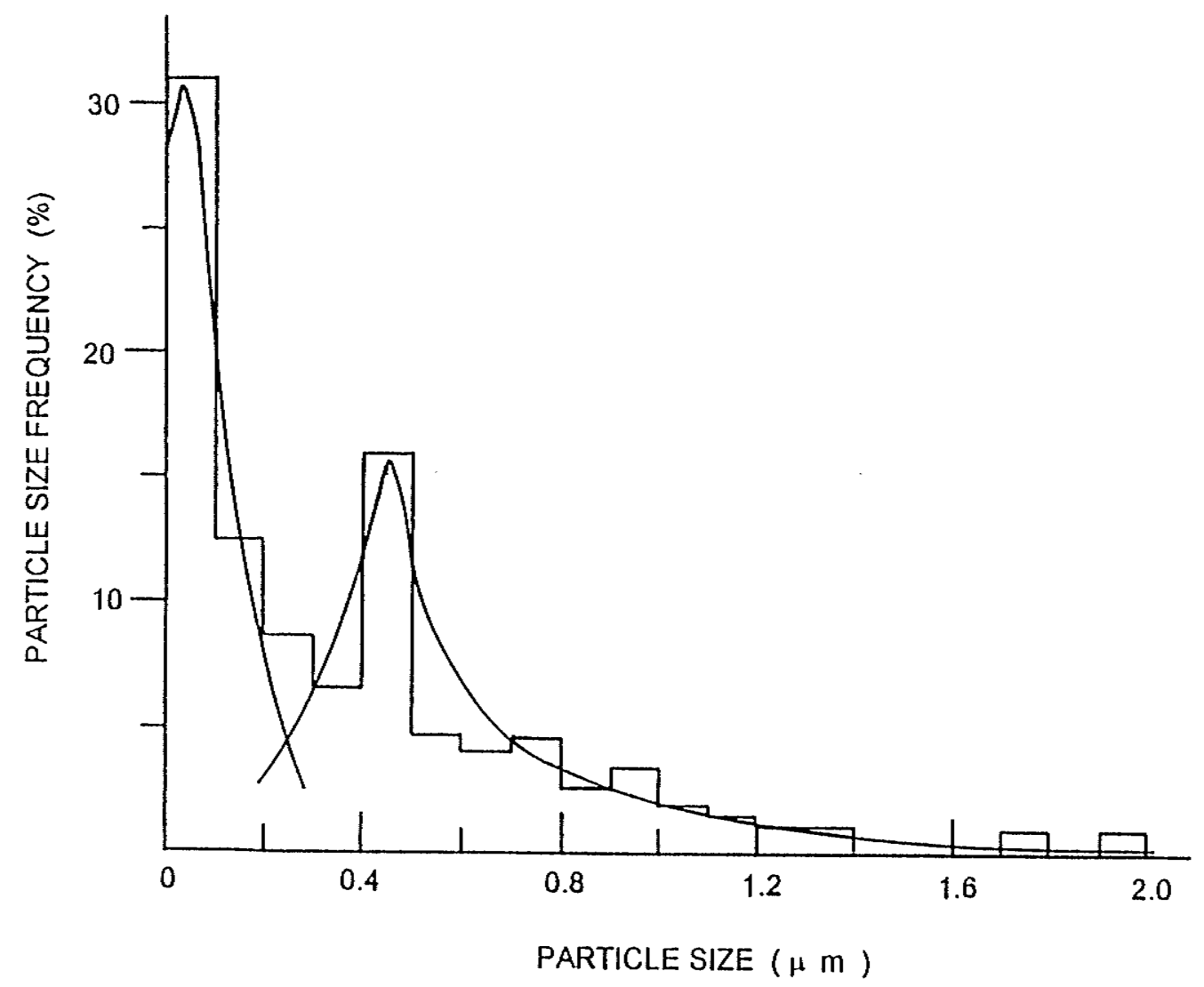

Fig. 5.4 Size distribution of grain boundary precipitates in the material with a second solid solution treatment at $975^{\circ} \mathrm{C}$ for one hour. 
If it is considered that $\Lambda$ is larger than $p$, then the time needed for the completion of relaxation of concentration around particles by matter diffusion will vary with the size of the individual particles ( refer to Eq. 5.5). For example, when the precipitate size is 0.1 $\mu \mathrm{m}, \Delta \tau_{D F}{ }^{\prime}$ is about 0.703 second, while when the size is $1.0 \mu \mathrm{m}, \Delta \tau_{D F}{ }^{\prime}$ is 703.1 seconds. The much sooner completion of relaxation around small particles may make the segment of the grain boundary containing them behave like the part of a grain boundary which is originally free of precipitates. Therefore, the actual density of grain boundary precipitates - the density of those bigger precipitates that are still undergoing relaxation by matterdiffusion around them, will be decreased. At the same time, the average size of these precipitates will be much bigger than the average size which were calculated with an inclusion of all particles on grain boundaries.

Consider the situation in the material that was given a second solid solution heat treatment at $975^{\circ} \mathrm{C}$, and assume that all the particles with a size equal to and below $0.3 \mu$ $\mathrm{m}$ belong to a group denoted $P_{S}$, and the rest of them belong to Group $P_{L}$. The particles in Group $P_{S}$ were found to have a fraction of $51.9 \%$ of the total precipitates, while the particles in Group $P_{L}$ have a fraction of $48.1 \%$ of total precipitates. The average particle size in Group $P_{S}$ and $P_{L}$ is about $0.11 \mu \mathrm{m}$ and $0.653 \mu \mathrm{m}$, respectively. The density of precipitates in Group $P_{L}$ is $0.653 \times 0.481 \div 0.75=0.419$. Based on this the characteristic scaling dimension was calculated to be $0.137 \mu \mathrm{m}$. This value of $\Lambda$ is smaller than the size of the particles in group $P_{L}$. Therefore, diffusion around particles will not be a favoured relaxation process; instead, power-law creep may take place to relax the concentrations.

The calculation above might be helpful in understanding the grain boundary sliding behaviour that occurred in material.B. Within a very short time of applying stress, relaxation of shear traction can occur on the segment of grain boundaries which are free of precipitates, and concentration of shear traction on particles can set up. The relaxation of concentrations around particles will occur either by mass diffusion around particles or by power-law dislocation creep. The calculations in Table 5.1 indicates that 
the diffusion of matter around particles will be favoured under the test conditions. However, because of the large differences in the size of precipitates on grain boundaries, the relaxation time will vary significantly with the size of particles on grain boundaries, the small particles will need much shorter time than bigger particles. The early completion of relaxation of small particles will reduce the number, and also increase the average size of the precipitates that are still undergoing relaxation by the matter diffusion process. This change will cause the characteristic scaling dimension to decrease to a value that might be less than the average size of those grain boundary precipitates around which relaxation by matter diffusion is not completed. As a result, the power-law creep relaxation will prevail the on-going relaxation by matter-diffusion around the precipitates. Therefore, the initiation of creep voids around particles will become possible. When the stress concentration around the bigger precipitates is completely relaxed, it may be also possible for the smaller particles to undergo the power-law creep relaxation. This is because when the bigger particles loose their pinning to the sliding boundaries, the part of grain boundaries surrounding them will resemble the segment which was originally free of any precipitates. In this situation, the density of small particles has to be considered, which may cause a characteristic scaling dimension smaller than their average size. When this is true, the concentration of stress around precipitate particles can be relaxed by power-law creep deformation. Therefore, it may be also possible to initiate void formation around them. For example, in the case of the material with a solid solution treatment at $975^{\circ} \mathrm{C}$, the density of small precipitates is about $0.11 \times 519 / 0.75=0.076 \mu \mathrm{m}$ which gives a value of $\Lambda$ of $0.00015 \mu \mathrm{m}$. This value of $\Lambda$ is much smaller than the average size of small particles $(0.11 \mu \mathrm{m})$, suggesting that power-law relaxation can take place.

The proposed mechanism can explain (i) why the creep voids can be initiated around precipitates at grain boundaries even though the matter diffusion around precipitates is a preferred mechanism; (ii) why creep voids can be observed sooner or latter around all the precipitates. The most important purpose of this discussion is to 
determine when is the relaxation of stress concentration around particles completed, i.e. when does the grain boundary sliding start to contribute significantly to the total creep strains?

Suppose that the stress concentration around particles is relaxed by power-law creep deformation, then, the starting time for grain boundary sliding can be calculated by, $\tau=\tau_{B R}+\Delta \tau_{P L}+\Delta \tau_{P L}$ '. The variation of $\tau$ with the average density of grain boundary precipitates is shown in Table 5.1. The value of $\tau$ has been found to be 94.3 hour for the material with a partial solid solution treatment at $925^{\circ} \mathrm{C}$. The actual time that the precipitates may pin the grain boundaries in this material may be slightly less than 94.3 hour. This is because the density of those precipitates that can undergo power-law creep relaxation should be slightly smaller than the density of precipitates which is obtained by an inclusion of all the particles at the grain boundaries. However, such a decrease in the value of $\Delta \tau_{P L}{ }^{\prime}$ should be minor since the smaller particles shares an insignificant fraction of total density, although they greatly influence the value of average size of precipitates. The secondary creep stage of material B tested at $625^{\circ} \mathrm{C}$ and $795 \mathrm{MPa}$ starts after about 15 hour and ends after about 40 hour( Fig. 4.14c). From Eqn. 5.8, it can be also noticed that, $\Delta \tau_{P L}{ }^{\prime}$ increases with an increase in grain size. This suggests that, with a same density of grain boundary precipitates, grain boundary sliding can be delayed to a later stage of creep if the material has a bigger grain size. Therefore, it may be safe to assume that grain boundary sliding does not make a significant contribution to total creep strain in the primary and secondary stage of creep at all grain size levels in the material with a second solid solution treatment at $925^{\circ} \mathrm{C}$.

This assumption can be verified by examining the profile of creep curves illustrated in Figs. 4.30 and 4.31. When grain boundary sliding occurs, a negative dependence of creep rate on grain size should be observed. In the material with clean grain boundaries, the creep rate in the primary stage does decrease with increase in grain size. However, in material B, the creep rate in the primary stage does not vary with grain size at all, 
indicating a non-occurrence of grain boundary sliding. In the secondary creep stage of the material, the creep rate increases with an increase in grain size. This dependence is opposite to the normally observed effect of grain size on creep rate due to grain boundary sliding.

\subsubsection{EFFECT OF INCUBATION TIME ON FRACTURE BEHAVIOUR}

The suggestion that the critical time to start grain boundary sliding depends on the precipitate parameters at grain boundaries can be also verified by the fracture characteristics of the material presented in section 4.5.2. The correlation between the calculated results and the experimental observations is given below in terms of crack initiation, propagation and complete rupture.

Crack Initiation: It was found that wedge cracks formed at the triple points of grain boundaries when a materials had either a very low precipitate density at grain boundaries or clean grain boundaries. However, creep-void formed cracks on normal boundaries were often observed in the material with high precipitate density at grain boundaries. These observations are consistent with the calculated values given in Table 5.1 , where it is seen that the time for which precipitates can effectively pin the sliding boundaries are sharply decreased with a decrease in the density of precipitates at the grain boundaries. Therefore, the concentration of shear stress at triple points of grain boundaries will occur much earlier in the material with a lower density of precipitates at grain boundaries than the material with a higher precipitate density at the grain boundaries. This implies that, an increase in the density of precipitates at grain boundaries will increase the incubation time for the initiation of a wedge crack at the triple points. This process is schematically illustrated by a straight line marked $t_{1-W}$ in Fig. 5.5. On the other hand, when precipitates act as a barrier to grain boundary sliding, the high concentration of stress may cause the formation of creep voids, as is observed in Fig. 5.3. These creep 
voids may also grow and link up to form an unstable crack size. With an increase in the precipitate density at grain boundaries, the time required for voids to become unstable cracks will also increase. This is because the higher the density, the value of the shear stress shared by each precipitate is reduced and a longer time is needed for the growth of such voids. This creep void-induced crack forming process is presented by a straight line denoted by $t_{I-V}$ in Fig. 5.5 .

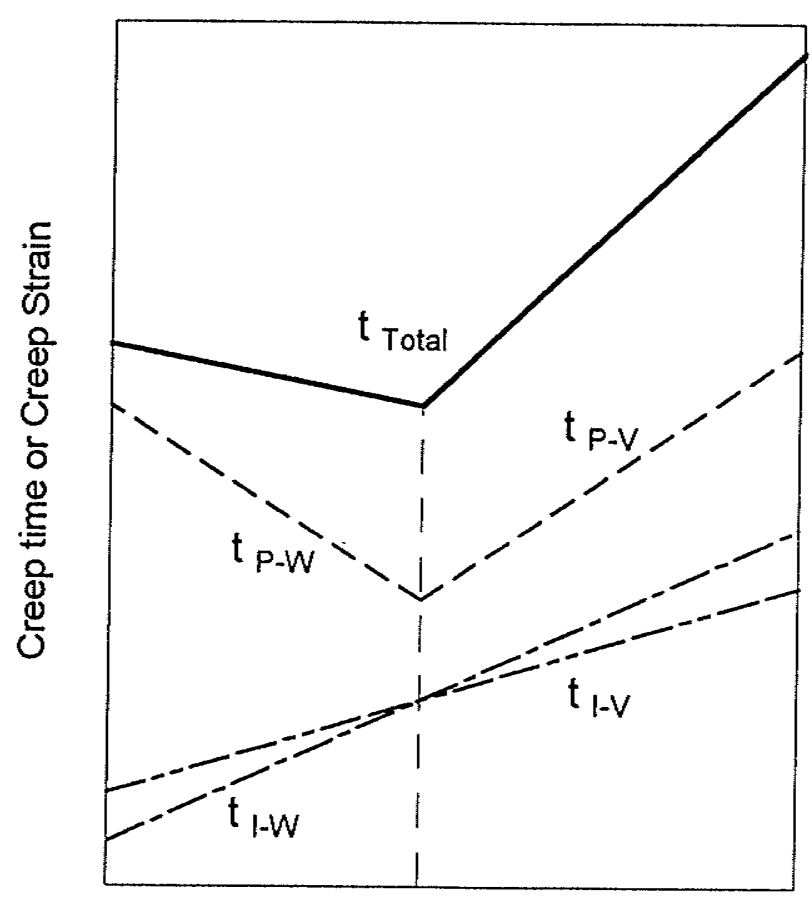

Particle Density at Grain Boundaries

Fig. 5.5 Schematic diagrams illustrating the dependence of creep time or creep strain on particle density at grain boundaries.

The $t_{t-W}$ line intercepts the $t_{I-V}$ line. The intercept delineates the process of wedge-crack initiation at a triple point of grain boundaries and that of void-crack development on normal grain boundaries, i.e. wedge cracks are dominant in the material with lower density of precipitates at grain boundaries, while void-formed cracks might be 
associated in the material with higher density of precipitates at grain boundaries. This is exactly what has been observed in Fig. 4.29.

Crack Propagation: After the crack has been initiated, its propagation will take place. The wedge cracks in the low density region will propagate in a way like a wedge chiseling into the openings. Therefore, the stress normal to the grain boundaries, and the bonding strength between the grains that may determine the propagation process. The presence of precipitates, which introduced creep voids around them, will actually weaken the bonding strength of the two grains in a direction perpendicular to the boundary. As a result, the propagation process can be accelerated with an increase in precipitate density at grain boundaries. This process is demonstrated by the $t_{P-W}$ line in Fig. 5.5 .

In contrast to the propagation of a wedge crack, the propagation of void-formed cracks on a normal boundary may depend on the magnitude of the shear stress acting on individual cracks and the resistance to the propagation in the sliding direction of a grain boundary. It is believed that, an increase in precipitate density at grain boundaries, will decrease the shear stress available to act on the propagating cracks, and may also increase the resistance for propagation. Both these factors will decelerate the propagation process, as indicated by $t_{P-V}$ line in Fig. 5.5 .

The above analysis of the manner in which the state of stress controls the crack propagation process, depending upon the nature of the crack can be verified by the examination of fracture surfaces shown in Fig. 4.28 and Fig. 5.6. For example, the material with the lowest rupture time has been identified to fracture by the propagation of wedge cracks. Its intergranular boundary facets are scattered with the precipitates and cavities with shapes similar to those of the precipitates that have been pulled out from the surface. Indications of deformation around the precipitates as well as on the grain boundary surface are not evident. This is also true for the material with clean grain boundaries, in which the trace of slip lines due to the deformation of grain material are well preserved. In contrast 
to this, the material which is suggested to have fractured by the propagation of voidformed cracks shows massive deformation on the grain boundaries, which must be by a stress acting in the plane of the grain boundary surface.

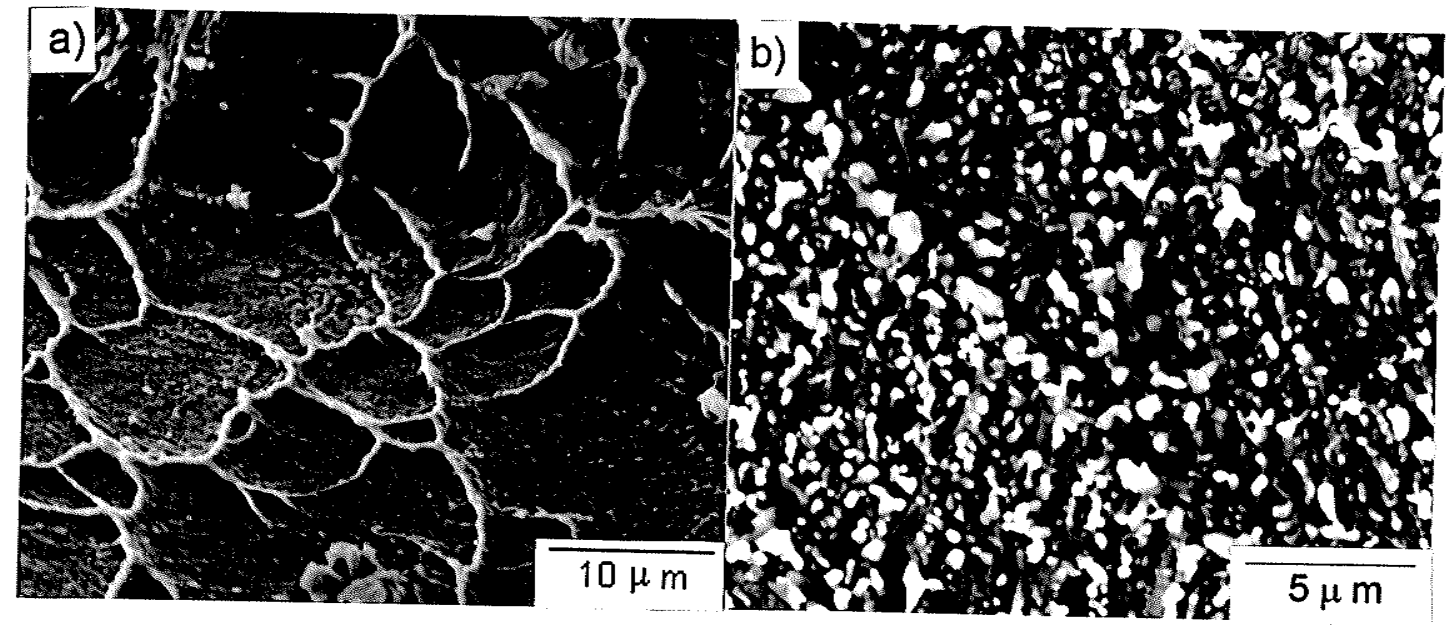

Fig. 5.6 SEM photos showing the microstructure on the intergramular surface of the material with a precipitate density at grain boundaries of $67 \%$ and $45 \%$, respectively

The Complete Rupture Process: The complete rupture process, as represented by a solid line in Fig. 5.5, includes both the initiation and propagation process. In the low precipitate density region, an increase in the precipitate density at grain boundaries may increase the time needed for wedge cracks to develop, but will shorten the propagation process. For example, the material with clean grain boundaries or with a small amount of precipitates on them may require a shorter time to initiate wedge cracks, but may need a longer time for them to propagate because of the smaller amount of damage caused by the smaller precipitates at the grain boundaries. This will reduce the total rupture time. When the grain boundary precipitate density is relatively high, the unstable cracks on normal boundaries can develop earlier than wedge cracks at triple points, and the propagation process will rely on the shear condition along the grain boundary and increase the overall rupture time as the particle density is increased further. 


\subsubsection{CONTRIBUTION OF GRAIN BOUNDARY SLIDING TO TOTAL CREEP STRAIN}

In material B, grain boundary sliding can be inhibited in the earlier stage of creep. However, this does not mean that grain boundary sliding can not occur at all during the whole course of creep deformation. In fact, grain boundary sliding will resume when the concentrated stress around precipitates is relaxed. However, the contribution of deformation by the sliding to the total creep strain might be smaller than in the material without any precipitates on grain boundaries. This is because the presence of precipitates will change grain boundary viscosity which is given by $[119,128]$

$$
\eta_{B}=\eta_{B O} V_{f}\left(\frac{p}{b}\right)^{2}
$$

where, $\eta_{B O}=k T / 8 b D_{b}$ is the intrinsic viscosity of a flat grain boundary, $\mathrm{b}$ is the atomic size, and $D_{B}$ is the grain boundary diffusion coefficient, $\mathrm{p}$ is the diameter of particles.

The grain boundary viscosity is related to the grain boundary sliding displacement $\dot{U}_{G B}$ through[128]

$$
\dot{U}_{G B}=\left(\frac{w}{\eta_{B}}\right)_{T}
$$

where $w$ is boundary thickness typically twice the atomic size.

The maximum contribution of grain boundary sliding to the total creep rate is [128]

$$
\dot{\varepsilon}_{g b s}\left(=\frac{\dot{U}_{G B}}{d}\right)=\frac{w}{d} \frac{\bar{\tau}}{\eta_{B}}
$$


Substituting Eq. 5.12 into Eq.5-14, gives

$$
\dot{\varepsilon}_{g b s}=\frac{w}{d} \frac{\bar{\tau}}{\eta_{B O}} \frac{1}{V_{f}}\left(\frac{b}{p}\right)^{2}
$$

Eq. 5.15 indicates that with an increase in particle size or volume fraction of particles, the maximum contribution of grain boundary sliding to total strain rate will decrease.

In the material with clean grain boundaries, grain boundary sliding should contribute significantly to the total creep strain during the course of all the various creep stages. From creep curves shown in Fig.4.30, it is seen that, the creep rate in primary stage increases with a decrease in grain size. The difference in creep rate in the material with different grain sizes is magnified in creep curves presented by creep rate versus creep strain plots as compared to creep rate versus creep time plots (Fig.4.30a).

Langdon[126] has indicated that the dependence of grain boundary sliding rate should be determined at the same condition at which the same grain deformation is obtained, since creep resistance of grain material does not vary with grain size. At the same applied stress, it might be appropriate to assume that approximately the grain matrix of the material A with different grain sizes has been subjected to the same amount of deformation after a given creep time and at the same applied stress. With this assumption, the creep rate in the primary stage of the material with different grain sizes is plotted against the grain size in Fig. 5.7. It is seen that the creep rate varies with grain size by an exponent of about 0.5 or less. This dependence of creep rate on grain size is smaller than that observed in most other cases.

In the secondary creep stage of material A, creep rate is observed to be nearly independent of grain size (Fig. 4.32). This might not be because the grain boundary sliding 
does not occur during this stage. Instead, an alternative process might be in effect. One possible process could be the positive dependence of minimum creep rate on grain size, which is observed in the material ( material B) in which grain boundary sliding does not occur during this stage. The negative grain boundary sliding rate with grain size may be balanced out by the positive dependence of creep rate of grain material on grain size. The net result is an insignificant influence of grain size on the total creep rate.

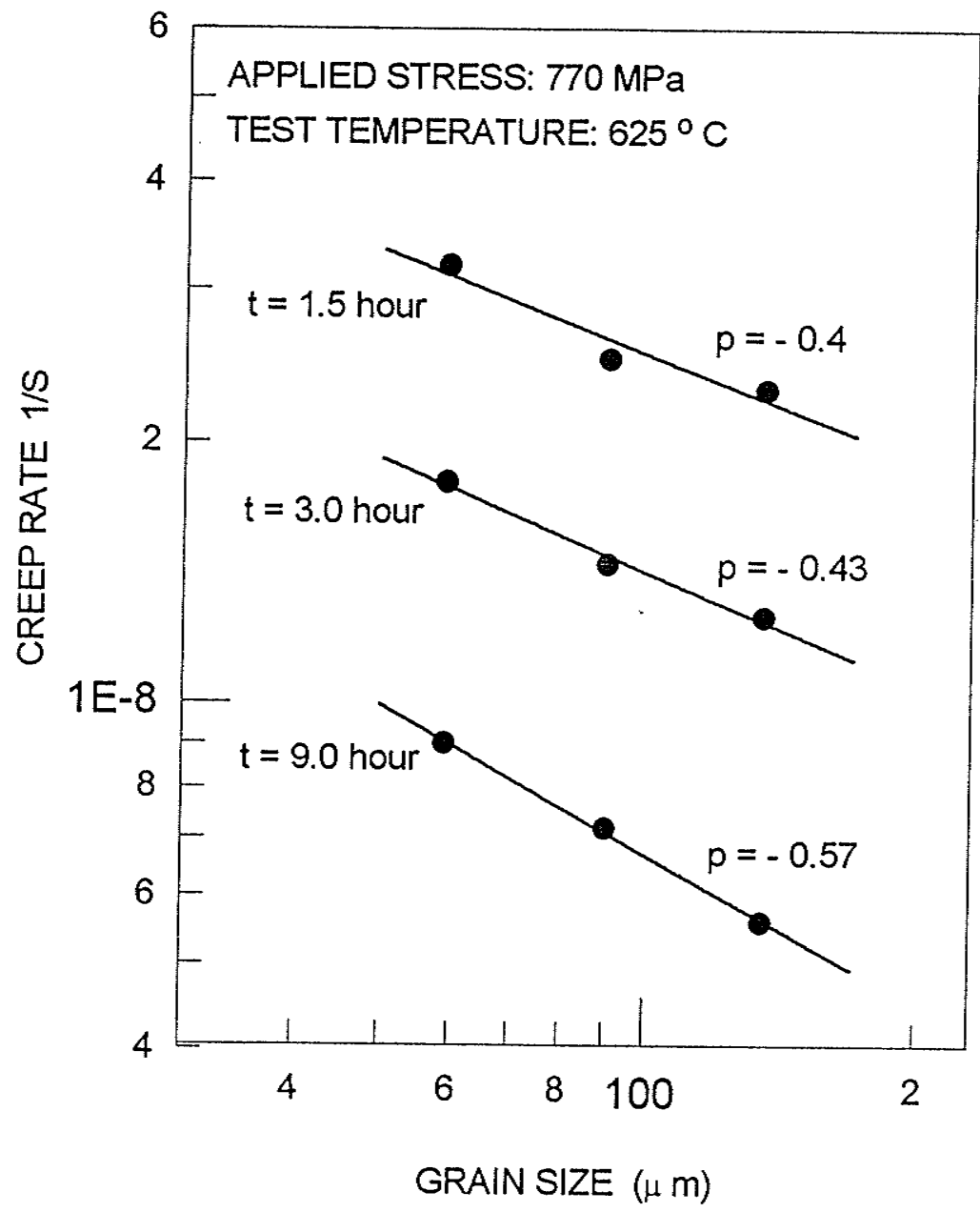

Fig. 5.7 Dependence of creep rate in primary stage on creep time in the material with clean grain boundaries 
The second possibility is that, cracks may initiate earlier in the material with larger grain size. The observed secondary creep rate of a material, then, may reflect the creep rate at the creep time (or strain) at which the further decrease in creep rate in primary stage with creep time or creep strain is interrupted by the occurrence of tertiary stage. The creep rate of material A in primary stage is observed to decrease with increase in grain size (Fig. 4.30). However, the tertiary stage does start earlier in the larger grained materials. Both factors, then, may result in an observed minimum creep rate virtually insensitive to grain size (Fig. 4.32).

However, if the tertiary stage does not start earlier in the material with larger grain size, the further decrease in creep rate in primary stage may be caused by either the increase in work-hardening of grain material or the decrease in the contribution of grain boundary sliding to total creep strain. The former may be impossible since the strain needed to reach the steady state stage for grain material is believed to be very low. Then the occurrence of the latter process suggests that the rate of grain boundary sliding continues to decrease even when the steady-state stage of creep in grain interiors is reached.

This analysis suggests the following which may be helpful in determining the actual dependence of grain boundary sliding rate on grain size.

(i) The amount of deformation by grain boundary sliding decreases with an increase in creep strain or creep time, even though a steady-state creep stage for grain interior is established. This means, the ratio, $\xi=\varepsilon_{g s s} / \varepsilon_{g}$, which is often used to determine the dependence of sliding rate on grain size and applied stress (refer to Chapter Two ), is not constant.

(ii) There is no evidence showing that there is a steady state stage for grain boundary sliding. This suggests that no unique equation exists to describe the grain boundary sliding in a material. 


\subsection{GRAIN BOUNDARY DEPENDENT CREEP BEHAVIOUR}

\subsubsection{THEORETICAL BASIS}

The above discussion suggests that grain boundary sliding may not occur in the earlier stages of creep in a material with precipitates at grain boundaries, However, significant differences exist in the two types of materials, with and without precipitates on the grain boundaries. These differences do not seem to be able to be bridged on the basis of the differences in the grain boundary sliding. In this respect, the following two points should be noted.

(i) Material with precipitates at grain boundaries shows a much higher creep rate than the material with clean grain boundaries. Firstly, this observations can not be caused by a reduction in grain strength due to the formation of grain boundary precipitates since it contradicts the results (Fig. 4.10) that the secondary creep rate does not vary with the strength of grain material in terms of the size of $\gamma^{\prime \prime}$ precipitates. It should also be noted that as the grain size increased, the total surface of the grain boundary is reduced in a larger grain material. Such a material will have fewer total number of precipitates, provided the density of the precipitate particles does not change. In such a situation, the amount of solute atoms available for the precipitates to form within the grains will increase. This will increase the strength of the grains of the material. This should reduce the creep rate, however, this is not observed in larger grain material. Secondly, this observation should not relate to grain boundary sliding, since creep rate of the material is increased with increase in grain size (Fig. 4.32).

(ii) The back stress of material B was observed to depend on the applied stress and grain size, which should not be influenced by grain boundary sliding. 
Besides the grain boundary sliding which depends on the size and interparticle spacing of grain boundary precipitates, it is clear that the deformation of grain boundaries in material B must also contribute to total creep rate through a mechanism which might be independent of grain boundary sliding. To determine this mechanism, it is better to distinguish the deformation due to grain boundary sliding from the deformation due to an unknown alternative grain boundary deformation mechanism. The characterization of grain boundary sliding in material B shows that, when this material was partially solid solution treated at $925^{\circ} \mathrm{C}$ for one hour, the precipitates that were introduced at grain boundaries could delay the grain boundary sliding to the end of the steady state creep stage. Therefore, in this material, grain boundary sliding may be ignored, and creep rate will be determined by the deformation of grain interior and by the deformation of grain boundaries which occurs by a mechanism that needs to be determined. Due to this reason, material B in the following section (except where specifically indicated), refers only to the material which was given a second solid solution treatment at $925^{\circ} \mathrm{C}$ for one hour.

\subsubsection{BASIC CONSIDERATION}

It is generally believed that in polycrystalline materials the applied stress is uniformly distributed throughout the grain material at a level equal to the macroscopic value of $\sigma_{a}$. When the deformation inhomogeneity is considered the concept of uniformly distributed stress may not hold true.

Mayers and Ashworth[211] proposed that the yield stress dependence of grain size is due to the elastic incompatibility stresses at the grain boundaries. They divided the process of yielding into three stages. In the first stage (prior to microyielding) (Fig.5.8a), the differences in elastic properties arising from the elastic anisotropy of adjacent grains establish localized stress concentration at the grain boundaries. In the second stage the stress concentration at the grain boundaries results in a localized plastic flow. This marks the onset of micro yielding. The dislocations do not propagate throughout the whole grain 
because of cross-slip induced by the difference in orientation between the maximum shear stress (due to the applied load) and the stress concentration caused by plastic incompatibility. The work hardened grain boundary layer has a flow stress $\sigma_{f C B}$, while the bulk has a flow stress $\sigma_{f B}\left(\sigma_{f G B}>\sigma_{f B}\right)$. The material behaves, at increasing applied loads, as a composite made out of a continuous network of grain -boundary film with flow stress $\sigma_{f G B}$ and of discontinuous ' island ' of bulk material with flow stress $\sigma_{f B}$. The increasing applied stress $\sigma_{a}$ does not produce plastic flow in the bulk, in spite of the fact that $\sigma_{a}>$ $\sigma_{f B}$, because the continuous grain boundary network provides the structure with rigidity (Fig.5.8b). The total strain in the continuous grain-boundary network does not exceed 0.005 , since it is elastic; hence plastic deformation in the bulk is inhibited. This situation is termed plastic incompatibility.
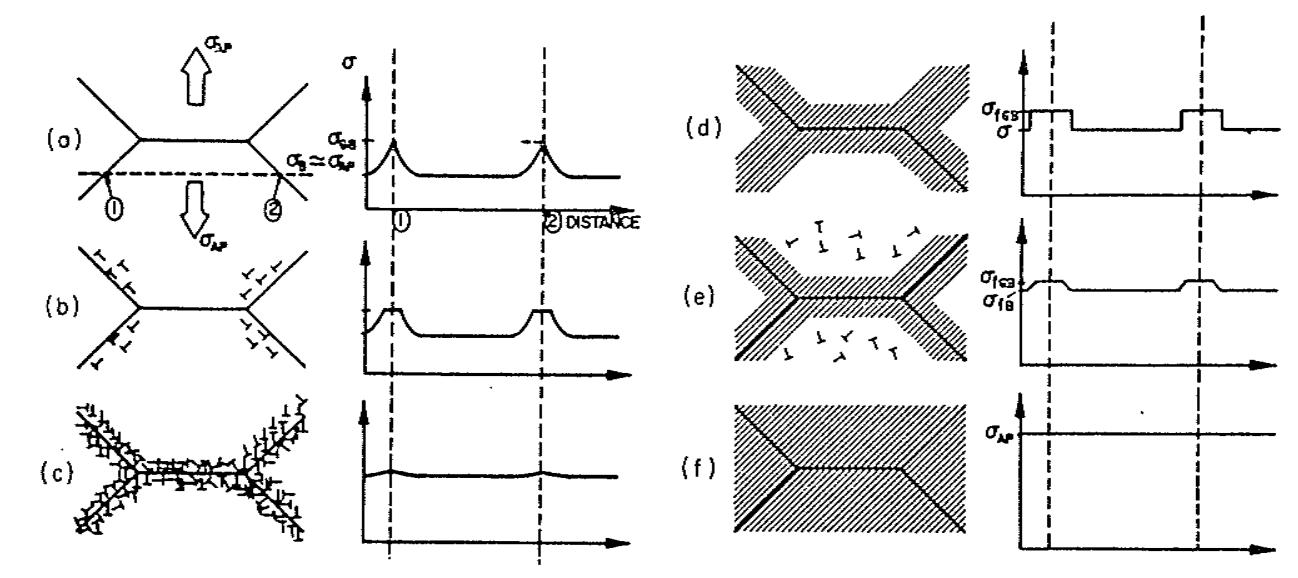

Fig. 5.8 Sequence of stages in polycrystalline deformation, starting with $(a, b)$ localized plastic flow in the grain-boundary regions (microyielding), forming a grain-boundary work-hardened layer $(c, d)$ that effectively reinforces the microstructure, and leading to $(e, f)$ macroyielding in which the bulk of the grains undergo plastic deformation[211]. 
In the third stage, when the applied stress is such that the stress in the grain boundary region becomes equal to $\sigma_{f G B}$, plastic deformation re-establishes itself in this region. The plastic deformation of the continuous matrix result in an increase in stress in the bulk with plastic flow (Fig. 5.8c). This marks the onset of macroyielding. After a certain amount of plastic flow, dislocation densities in the bulk and grain -boundary regions become the same. Since both regions have the same flow stress, plastic incompatibility disappears and $\sigma_{a}=\sigma_{g b}=\sigma_{b}$ (Fig 5.8f).

During creep deformation conditions, applied stress is usually less than the macroyielding stress. This means, the elastic and plastic incompatibility will exist in the grain boundary region when the load is fully applied. Since the applied stress is constant, the third stage as described by Mayers and Ashworth[211] will not appear. That is, the elastic and plastic incompatibility will remain in the grain boundary area unless some other process may take place to attenuate the stress concentrations in the grain boundary regions.
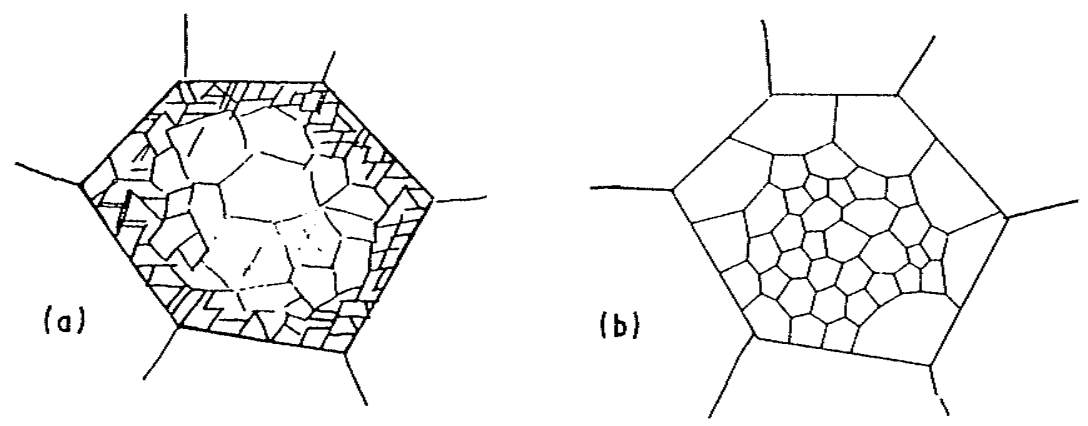

Fig, 5.9 Intergranular substructures developing: a) at high strain rates and/or low temperatures; b) at high temperatures and/or small flow rates where recovery processes are important [170]. 
During the creep deformation, the incompatibility can be attenuated by the diffusion controlled deformation processes, which might involve either the vacancy transportation or dislocation annihilation depending on the level of applied stress and testing temperature. When the test temperature or the applied stress is relative low, the developed incompatibility at the moment of the application of stress may exist for a quite long time. Opposite to this, the incompatibility may disappear very quickly after the stress is applied. An example of this is shown in Fig. 5.9[170]. Fig.5.9a corresponds to the intergranular substructures developed at high strain rates and/or low temperatures, while Fig. $5.9 \mathrm{~b}$ shows the intergranular substructures established at high temperatures and/or small flow rates where recovery process is important. Since the subgrain is a reverse function of applied stress, it can be seen that, the applied stress at grain boundaries in Fig.5.9a must be higher than in the grain interior. This will be opposite in Fig.5.9b.

When the incompatibility is relaxed, the applied stress can be uniformly distributed throughout the material. This will be similar to the third stage under tensile testing condition although the former was achieved by increasing the applied stress.

Even the type of incompatibility described by Mayers and Ashworth can be relaxed very quickly and very effectively. Similar incompatibility may be created in the course of creep around the grain boundary region or even in the grain interior: (i) when grain boundary has precipitate particles on it, the tendency of grain boundary sliding will produce stress concentration around these particles. If the precipitates at grain boundaries are so dense that concentrated stress field around each particle can overlap with that from its neighbours, the material may be considered to consist of a hard layer around grain boundaries and soft region in the grain interior. The applied stress will then be heterogeneously distributed. This might be true for material $\mathrm{B}$ since it has a very high density of grain boundary precipitates and the relaxation of concentrated stress occurs over an appreciable period of time; (ii) The incompatibility can be created in the material that can form subgrains. In these type of material, the concept of hard region of sub 
boundaries and soft region of subgrain interior was introduced by Nix and Ilshner[212] and was experimentally verified by Morris and Martin.also[213, 214].

\subsubsection{QUANTITATIVE DESCRIPTION OF HETEROGENEITY OF APPLIED STRESS}

\section{NIX AND ILSHNER'S CONSIDERATION}

Nix and Ilshner[212] believe that the existence of cellular or subgrain structure reflects a heterogeneity in dislocation distribution in the crystal. The regions of dislocation walls contain a high dislocation density $\rho_{w}$, while dislocation density inside the cells or subgrains, $\rho_{c}$ is relatively low. Thus, the local glide stresses $\tau_{w}$ and $\tau_{c}$ corresponding to these dislocation densities must also be different. A condition of compatibility of deformation in both regions under the applied (shear) stress requires that

$$
\tau_{w}=\tau+G f_{c}\left(\gamma_{p l . c}-\gamma_{p l . w}\right)
$$

and that

$$
\tau_{c}=\tau-G f_{w}\left(\gamma_{p l . c}-\gamma_{p l . w}\right),
$$

where $f_{w}$ and $f_{c}$ are the glide plane area fractions of walls and cell interior, respectively such that $\left(f_{w}+f_{c}=1\right)$; and $\gamma_{p l . c}-\gamma_{p l . w}$ is the plastic strain mismatch between the cells and the walls. As $\gamma_{p l . c}>\gamma_{p l . w}$, the local shear stress within the walls is higher than in the cell interior, i.e., $\tau_{w}>\tau_{s}$. This is why the walls are called hard regions and the cell interior soft regions. The stress $\tau_{w}$ acting in the hard regions is higher than the applied stress, and stress $\tau_{c}$ acting in the soft regions is smaller. The compatibility of deformation in the hard and soft regions is provided by dislocations generated at the interface between the regions. These dislocations accommodate the mismatch of the elastic strain and act as sources of long-range internal stresses. The sub-boundaries, forming during creep at homologous temperatures higher than about 0.4 , are frequently represented by planar dislocation networks near to the low-energy structure of ideal tilt and twist boundaries. In such 
substructure, the long-range internal stresses may appear due to elastic bending of subboundaries under the applied stress. Gibeling and $\mathrm{Nix}[215]$ approached this problem by computer simulation. Their results are shown schematically in Fig. 5.10. Again, the stress near the sub-boundaries ( hard regions ) is higher than the applied stress and it is lower in the subgrain interiors ( soft regions ).

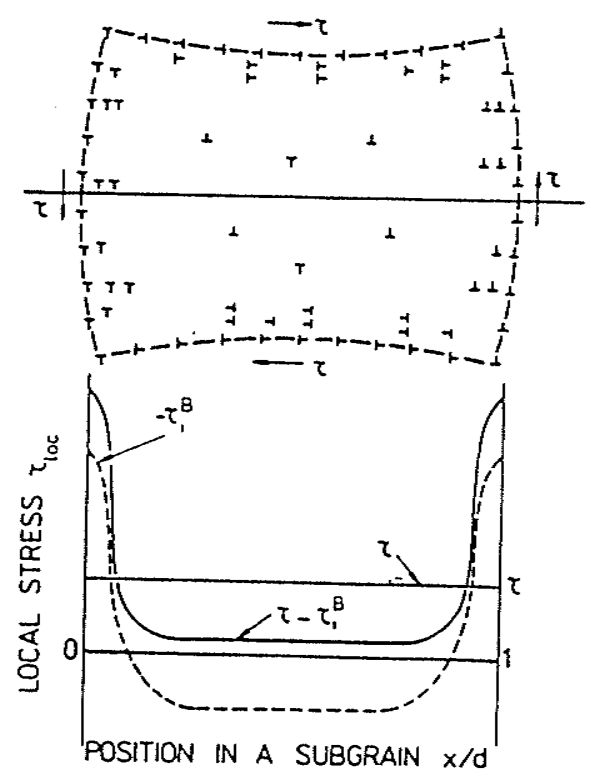

Fig. 5.10 A model of the internal stress due to elastic bending of sub-boundaries: $\tau_{i}^{B}$ is the internal stress field of sub-boundaries; because of $\tau_{i}^{B}$ the local stress $\tau-\tau_{i}^{B}$ is high at the sub-boundaries and low in the subgrain interior [215].

Morris and Martin[213, 214] measured the local stress in the vicinity of subboundaries and found it to increase with strain in primary creep ( Fig. 5.11). This supports the concept of the long-range internal stress resulting from the inhomogeneous distribution of dislocations in the hard and soft regions. The local stress is related to subboundary mesh size which depends on dislocation density stored in the sub-boundary and is a function of the applied stress and temperature. Morris and Martin also considered hard 
and soft subgrains in an effort to take into account further inhomogeneities in the dislocation density and microstructure within a specimen.

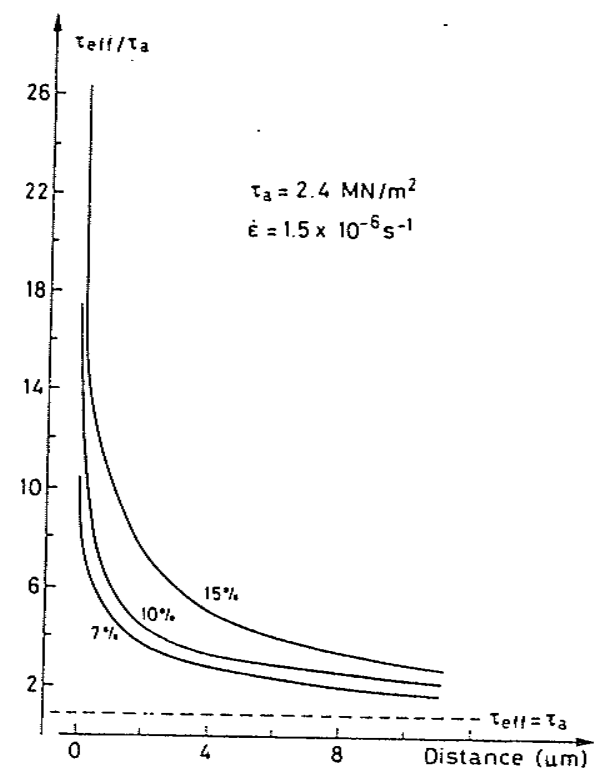

Fig. 5.11 Variation of the local stress with distance from a sub-boundary for different creep strains; Al-11Zn solid solution alloy crept at $523 \mathrm{~K}$ and $8 \mathrm{MPa}$ [213].

Although these investigators indicated the existence of heterogeneities in the applied stress, the actual partitioning of the applied stress to different regions has not been given. This will be the purpose of the following discussion.

\section{PARTITIONING OF APPLIED STRESS BETWEEN THE GRAIN}

\section{BOUNDARY AND THE GRAIN: BASED ON HALL-PETCH}

\section{RELATIONSHIP}

The Hall-petch relationship gives

$$
\sigma_{y}=\sigma_{o}+k / \sqrt{d}
$$


where $\sigma_{y}$ is the yield stress, $\sigma_{o}$ is a frictional stress required to move dislocations, $\mathrm{d}$ is the grain size, $k$ is a constant.

Let $\sigma_{b}=k / \sqrt{d}$, Eqn. 5.18 then becomes

$$
\sigma_{y}=\sigma_{o}+\sigma_{b}
$$

Eq. 5.19 indicates that the yield stress is due to the strength of grain material and the strength of grain boundaries. For a given microstructure of a material, the ratio $f$ between $\sigma_{o}$ and $\sigma_{b}$ is given by

$$
f=\frac{\sigma_{o}}{\sigma_{b}}=\frac{\sigma_{o}}{k} \sqrt{d}
$$

where $f$ can be considered as a microstructural constant although $\mathrm{k}$ varies with deformation strain.

When a stress $\sigma_{a}$ is applied to the very same material, the elastic and plastic incompatibility as proposed by Meyers and Ashworth[211] will cause the applied stress heterogeneity. Assume the applied stress shared by all the hard region of grain boundaries is $\sigma_{a b}$ and by all the soft region of grain interiors is $\sigma_{a o}$. The total applied stress can be expressed as

$$
\sigma_{a}=\sigma_{a o}+\sigma_{a b}
$$

It might be reasonable to believe that the ratio of $\sigma_{a o}$ and $\sigma_{a b}, f^{\prime}$, is similar to the ratio $f$ as defined in the tensile test conditions, that is, 


$$
f^{\prime}=\frac{\sigma_{a o}}{\sigma_{a b}}=f=\frac{\sigma_{o}}{k} \sqrt{d}
$$

For a given microstructure and at a given temperature, $\sigma_{o}$ and $\mathrm{k}$ are constant. These may define a new constant $R$

$$
\frac{\sigma_{o}}{k}=R=\frac{1}{\sqrt{d_{o}}}
$$

where $d_{O}$ is a constant which defines a special grain size aspect of the microstructure of a material. Substituting Eqs. 5.22 and 5.23 into Eq.5.21, results in

$$
\begin{aligned}
& \sigma_{a o}=\frac{1}{\frac{1}{R \sqrt{d}}+1} \sigma_{a} \\
& \sigma_{a b}=\frac{1}{R \sqrt{d}+1} \sigma_{a}
\end{aligned}
$$

The Hall-Petch relation can be also obtained from Eq.5.24. The macroyielding is observed when the applied stress within the grain interior is equal to the frictional stress experienced by a moving dislocation, $\sigma_{o}$, that is,

$$
\sigma_{a o}=\sigma_{o}=\frac{1}{\frac{1}{R \sqrt{d}}+1} \sigma_{a}
$$

In this situation, the total applied stress will be the yield stress. From Eqns. 5.26 and 5.23 , it is given by:

$$
\sigma_{y}=\sigma_{a}=\sigma_{o}+\frac{k}{\sqrt{d}}
$$


which is identical to the Hall-Petch relation given in Eq. 5.19.

Eqs.5.24 and 5. 25 indicate that the stress shared by all the grain interiors and by all the region of grain boundaries is only a fraction of the applied stress. It should be noted that $\sigma_{a o}$ and $\sigma_{a b}$ are not the actual applied stress acting in the region of the grain interior and in the region of grain boundaries, respectively. The actual stress acting in the individual region may have to consider the effect of area fraction of each region. According to the "law of mixture" for composite materials, the actual stress acting in each region can be given by:

$$
\sigma_{a}=A_{o} \sigma_{a o}{ }^{\prime}+A_{b} \sigma_{a b}{ }^{\prime}
$$

where $\sigma_{a o}{ }^{\prime}=\sigma_{a o} / A_{o}$ is the actual stress acting in the region of grain interior, and $\sigma_{a b}{ }^{\prime}=\sigma_{a b} / A_{b}$ is the actual stress acting in the hard region of grain boundaries. $A_{o}$ and $A_{b}$ are the area fraction of grain interior and the grain boundary, respectively. Both area fractions have been estimated by Meyers and Ashworth[211], and are given by:

$$
\begin{aligned}
& A_{o}=\frac{(d-2 t)^{2}}{d^{2}} \\
& A_{b}=\frac{d^{2}-(d-2 t)^{2}}{d^{2}}
\end{aligned}
$$

where $t$ is the thickness of grain boundary. Since $d>>t$, Eqs.5.29 and 5.30 can be simplified to:

$$
A_{0}=1
$$




$$
A_{b}=\frac{2 t}{d}
$$

Then, the actual stresses acted in each region can be written as:

$$
\begin{gathered}
\sigma_{a o}{ }^{\prime}=\sigma_{a o}=\frac{1}{\frac{1}{R \sqrt{d}}+1} \sigma_{a} \\
\sigma_{a b}{ }^{\prime}=\frac{d}{2 t} \frac{1}{R \sqrt{d}+1} \sigma_{a}
\end{gathered}
$$

\section{PARTITIONING OF APPLIED STRESS BETWEEN THE GRAIN} BOUNDARY AND THE GRAIN: BASED ON THE DEFORMATION BEHAVIOUR OF HARD AND SOFT REGION

Eq. 5.33 and 5.34 can also be developed based on the deformation behaviour of hard regions of grain boundaries and soft regions of grain interior.

Assume that a grain has a cubic shape( Fig. 5.12), it is subjected to a tensile stress, $\sigma_{a}$ and the grain boundary has a thickness of $t$. When stress is applied to the grain, it may have:

$$
F_{a}=2 F_{b}+F_{o}
$$

where $F_{a}$ is the force acting in the whole grain, $F_{b}$ and $F_{o}$ are the forces acting in the region of grain boundary and grain interior, respectively. The stress acting in each region can be written as

$$
\sigma_{a} d=2 \sigma_{a b}{ }^{\prime} t+\sigma_{a o}{ }^{\prime}(d-2 t)
$$

or 


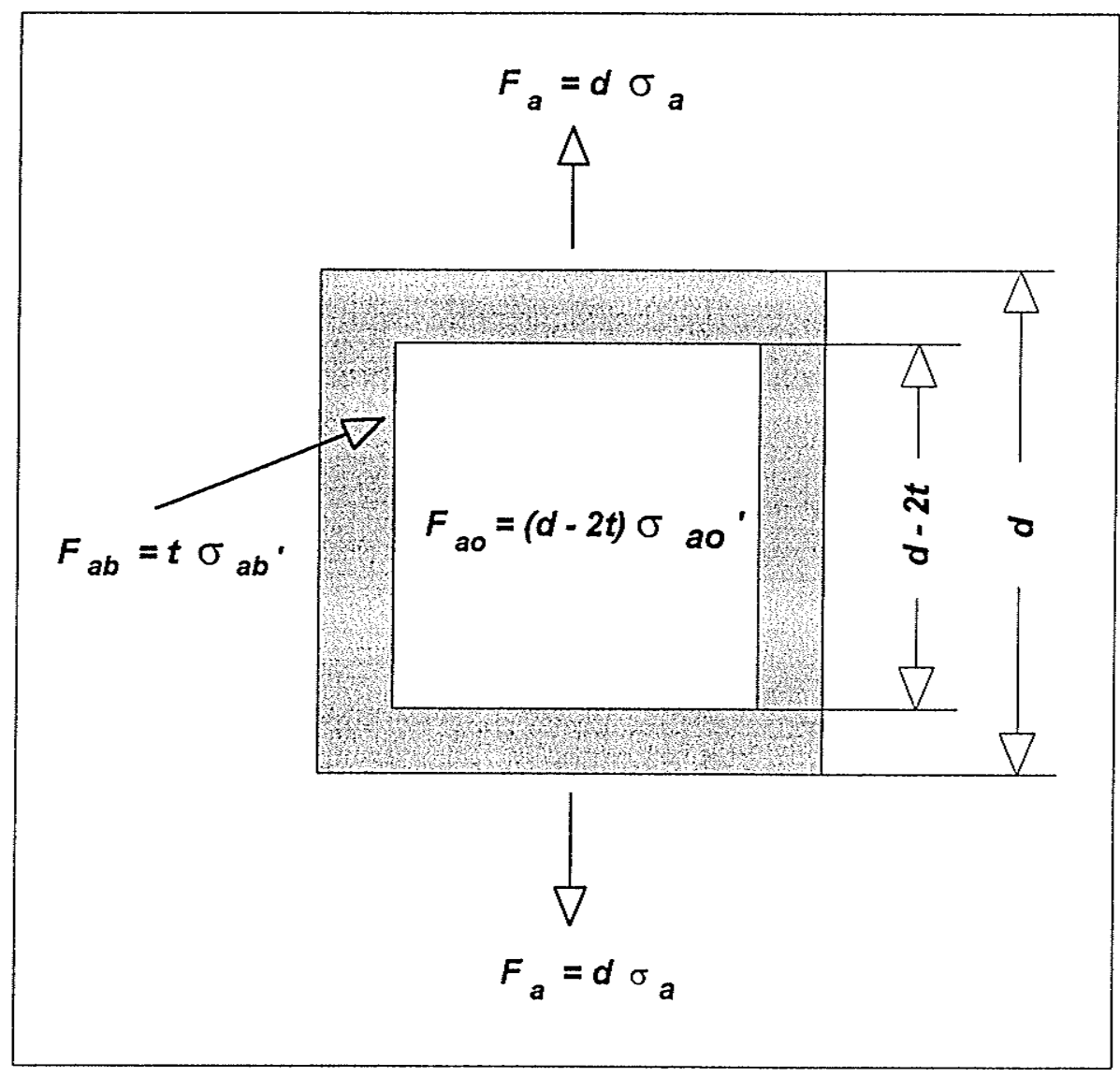

Fig. 5.12 Diagram showing a cubic grain with a diameter of d and grain boundary thickness of $2 t$ is applied with a stress $\sigma_{\text {a }}$ 


$$
\sigma_{a}=\frac{2 t}{d} \sigma_{a b}^{\prime}+\frac{d-2 t}{d} \sigma_{a o}^{\prime}
$$

Under creep conditions, the applied stress is less than the macroyielding stress. This means plastic deformation does not occur in the grain interior, therefore, the stress acting in the region can be given by

$$
\sigma_{a o}{ }^{\prime}=E\left(\frac{\Delta l}{d-2 t}\right)
$$

where $\mathrm{E}$ is Young' modulus of the grain interior, $\Delta l$ is the elongation of the grain material corresponding to stress $\sigma_{a o}{ }^{\prime}$. Unlike the situation in grain interior, plastic deformation has occurred at grain boundaries. The relation between the stress acting in the grain boundary region and the strain that occurs can be written as:

$$
\sigma_{a b}^{\prime}=K\left(\frac{\Delta l}{d}\right)^{\frac{1}{2}}
$$

where $\mathrm{K}$ is a constant which varies between $\mathrm{G} / 100$ and $\mathrm{G} / 1000$. Eq. $5.39[216]$ has been one of the most commonly used equation during the last few decades to describe the stress-strain curve of polycrystalline metals. $\Delta l / d$ is the total strain which includes the elastic and plastic deformation in the grain boundary region. In addition, $\Delta l / d$ should be equal to the total strain in the material. This is the condition required by Eq. 5.39.

The ratio between $\sigma_{a o}{ }^{\prime}$ and $\sigma_{a b}{ }^{\prime}$ can be written as

$$
f=\frac{\sigma_{a o}{ }^{\prime}}{\sigma_{a b}{ }^{\prime}}=\frac{E}{\frac{K}{\Delta l}}\left(\frac{1}{d}\right)^{1 / 2}
$$


Let $R^{\prime}=E /(K / \Delta l)$, then

$$
\frac{\sigma_{a a^{\prime}}}{\sigma_{a b}{ }^{\prime}}=R^{\prime}\left(\frac{1}{\sqrt{d}}\right)
$$

Substituting Eq. 5.41 into Eq. 5.37, gives

$$
\begin{gathered}
\sigma_{a o}{ }^{\prime}=\frac{1}{\frac{1}{\frac{R^{\prime}}{t} \sqrt{d}}+1} \sigma_{a} \\
\sigma_{a b}{ }^{\prime}=\left(\frac{d}{2 t}\right) \frac{1}{\frac{R^{\prime}}{t} \sqrt{d}+1} \sigma_{a}
\end{gathered}
$$

Let

$$
R=\frac{R^{\prime}}{t}=\frac{E \Delta l}{K t}=\frac{1}{\sqrt{d_{o}}}
$$

then, Eqs. 5.42 and 5.43 become

$$
\begin{aligned}
& \sigma_{a o^{\prime}}=\frac{1}{\frac{1}{R \sqrt{d}}+1} \sigma_{a} \\
& \sigma_{a b}{ }^{\prime}=\left(\frac{d}{2 t}\right) \frac{1}{R \sqrt{d}+1} \sigma_{a}
\end{aligned}
$$


Eqns. 5.45 and 5.46 are absolutely identical to Eqs 5.33 and 5.34, both of which were developed from Hall-Petch relation. By modifying the expression for $\mathrm{R}$, it is possible to obtain the Hall-Petch relationship from Eq. 5.45. Eq. 5.44 can be re-written as:

$$
R=\frac{E\left(\frac{\Delta l}{d}\right)}{K\left(\frac{\Delta l}{d}\right)^{1 / 2} \frac{t}{\sqrt{d}}}
$$

Macroyielding will begin when the stress within the grain interior is equal to the frictional stress experienced by a moving dislocations, $\sigma_{o}$, therefore,

$$
E\left(\frac{\Delta l}{d}\right)=\sigma_{o}=\sigma_{a o}^{\prime}
$$

At this stage, the macro-applied stress will be the yielding stress. Let $\Delta l / d=\varepsilon$ and if the assumption of Meyers and Ashworth that $t=\frac{1}{2 \alpha} \sqrt{d}$ is accepted, then Eq. 5.45, becomes

$$
\sigma_{y}=\sigma_{o}+k \frac{1}{\sqrt{d}}
$$

where

$$
k=\frac{1}{2 \alpha} K \varepsilon^{\frac{1}{2}}
$$

Eq. 5.49a) indicates that the value of $\mathrm{k}$ in the Hall-Petch relation depends on $\varepsilon^{1 / 2}$. This observation has been experimentally observed and theoretically verified by several researchers[174]. 


\subsubsection{CORRELATION BETWEEN PROPOSED MECHANISM AND EXPERIMENTAL RESULTS}

\subsubsection{ON THE CREEP RATE DEPENDENCE}

In material B, particularly when it was given a second solid solution treatment at $925^{\circ} \mathrm{C}$ for 1 hour, the distribution of precipitates at grain boundaries is such which can cause a continuous layer of concentration of stress for a long time. This will cause the material to have a situation which is similar to that described in the previous section, that is, a strong work-hardened grain boundary region, and a relatively soft grain interior(which is not hardened). As indicated by Eqns. 5.33 and 5.34, the total applied stress is divided into two parts. Therefore, it might be reasonable to assume that it is the applied stress that is actually acting in each region which will be responsible for its deformation.

\section{IN THE MATERIAL WITH CLEAN GRAIN BOUNDARIES}

As discussed earlier, when the stress is applied to a material, the elastic and plastic incompatibility could build around grain boundaries at the very beginning of creep deformation. However, this incompatibility could be eased quickly by the diffusioncontrolled deformation. When this happens, the applied stress would be distributed uniformly throughout the material, and the actual stress every where would be equal to the macro applied stress. Under these circumstances, the creep resistance of the material will be due to the microstructures of grain interior and the grain boundary could contribute an additional deformation to the total creep strain only by sliding along each other. 


\section{IN THE MATERIAL WITH PRECIPITATES AT GRAIN BOUNDARIES}

(1) Deformation Contribution By Grain Interior: The deformation of grain interior of material B may depend on two factors, i.e. its microstructure in terms of precipitate distribution parameters, and the actual stress applied to the grain interior.

\section{a) The Microstructures: In material $B$, precipitates at the grain boundaries} may consume some $\gamma^{\prime \prime}+\gamma^{\prime}$-forming elements, resulting in a reduced strength of the grain interior, therefore, causing a higher creep rate. This consideration, probably, can only partly explain why creep rate in material $B$ is always higher than that observed in material A. This is because when the material B was heat treated to have the same microstructure at grain boundaries but different within the grains, its steady-state creep rate still did not vary with the strength of the grain material (Fig. 4.10)

(b) The actual stress applied to the grain interiors: As presented in Eq. 5.33, the stress actually applied to the grain matrix of material $B$ is less than the macro applied stress by a factor of $[1 /(1 / R \sqrt{d}+1)]$. The results presented in Fig. 4.10 are from various specimens of the material which have the same grain boundary microstructure including precipitate parameters, and the same grain size. The only difference is the strengthening state of the grain interior. Therefore, the only variable that could influence the value of the factor $[1 /(1 / R \sqrt{d}+1)]$ is $\mathrm{R}$-the ratio between $\sigma_{o}$ and $\mathrm{k}$. With an increase in the strength of grain material, it is believed that the value of $\sigma_{o}$ will increase and the value of $\mathrm{k}$ will decrease. For example, with the same grain boundary microstructures, the Hall-Petch relationship is observed to be,

$$
\sigma_{y}=122.6+963.7\left(\frac{1}{d}\right)^{1 / 2}
$$

when the material interior is free of precipitates. However, when the same material was aged at $725^{\circ} \mathrm{C}$ for 25 hour, the Hall-Petch relationship became: 


$$
\sigma_{y}=726+689\left(\frac{1}{d}\right)^{1 / 2}
$$

Eq. 5.50 and 5.51 yield a value of $\mathrm{R}$ equal to $0.127 \mathrm{\mu m}^{-1 / 2}$ and $1.05 \mathrm{\mu m}^{-1 / 2}$, respectively, and the critical grain size corresponding to these values of $\mathrm{R}$ are about 61.8 $\mu \mathrm{m}$ and $0.9 \mu \mathrm{m}$, respectively. Therefore, the value of $\mathrm{R}$ will increase with an increase in strength of grain interior. The increase in R(or decrease of $d_{o}$ ) will increase the actual stress that is applied to the grain interior. This will cause a higher creep rate. Suppose that the critical grain size is decreased to about $0.1 \mu \mathrm{m}$ in the material with an ageing treatment at $725^{\circ} \mathrm{C}$ for 50 hours. The creep rate, caused by the change in $d_{o}$ can be estimated. This is shown in Table 5.2, in which the material with a grain size of $\mathrm{d}=59 \mu \mathrm{m}$ is supposed to be tested at $770 \mathrm{MPa}$. As listed in Table 5.2, it is found that a substantial increase in both the actual stress applied to the grain interior and the creep rate due to the grain interior occurs. This increased applied stress in the material with higher strength state causes the creep rate to be 2.7 time higher than that is observed in the material which was aged at $725^{\circ} \mathrm{C}$ for 25 hours. At the same macro applied stress, therefore, a decrease in creep rate due to an increase in strength of grain material may be balanced by the increase in creep rate due to an increase in actual stress applied to the grain material. As a result, the secondary creep rate of the material with a different grain interior strength can remain constant. As shown in Fig. 4.10, the secondary creep rate of material B is indeed not influenced by the size of $\gamma^{\prime \prime}$ when the material was heat treated to have a size of $\gamma^{\prime \prime}$ from about 17.3 to $26.2 \mathrm{~nm}$. Beyond this range of $\gamma^{\prime \prime}$-size, the creep rate was observed to either increase or decrease in a way similar to material A ( in which grain boundaries are free of precipitates ). This is because the applied stress in these regions is beyond the yield point of the material. When this happens, the third stage as proposed by Mayers and Ashworth[211] can be reached. In this stage the elastic and plastic incompatibility can 
disappear, which will lead to an uniform distribution of applied stress. As a result, the creep rate dependence of $\gamma^{\prime \prime}$-size similar to that observed in material A should be observed. The yield stress of material B is plotted against the size of $\gamma^{\prime \prime}$ in Fig. 5.13. It can be seen that when the size of $\gamma^{\prime \prime}$ is 14.6 and $29.5 \mathrm{~nm}$, the yield stress of both the materials is below or about the level of the applied stress (770 MPa).

Table 5.2 Variation in stress factor for grain material with $d_{o}$

\begin{tabular}{ccccc}
\hline$d_{o}$ & $\frac{1}{\frac{1}{\sqrt{d} / \sqrt{d_{o}}}+1}$ & $\frac{1}{\frac{1}{\sqrt{d} / \sqrt{d_{o}}}+1} \sigma_{a}$ & $\frac{1}{\frac{1}{\sqrt{d} / \sqrt{d_{o}}}+1}$ & $\begin{array}{c}\text { Increment in } \\
\text { creep rate }\end{array}$ \\
\hline $1 \mu \mathrm{m}$ & 0.89 & $685.4 \mathrm{MPa}$ & 0.22 & 1 \\
$0.1 \mu \mathrm{m}$ & 0.961 & $739.6 \mathrm{MPa}$ & 0.59 & 2.7 \\
\hline
\end{tabular}

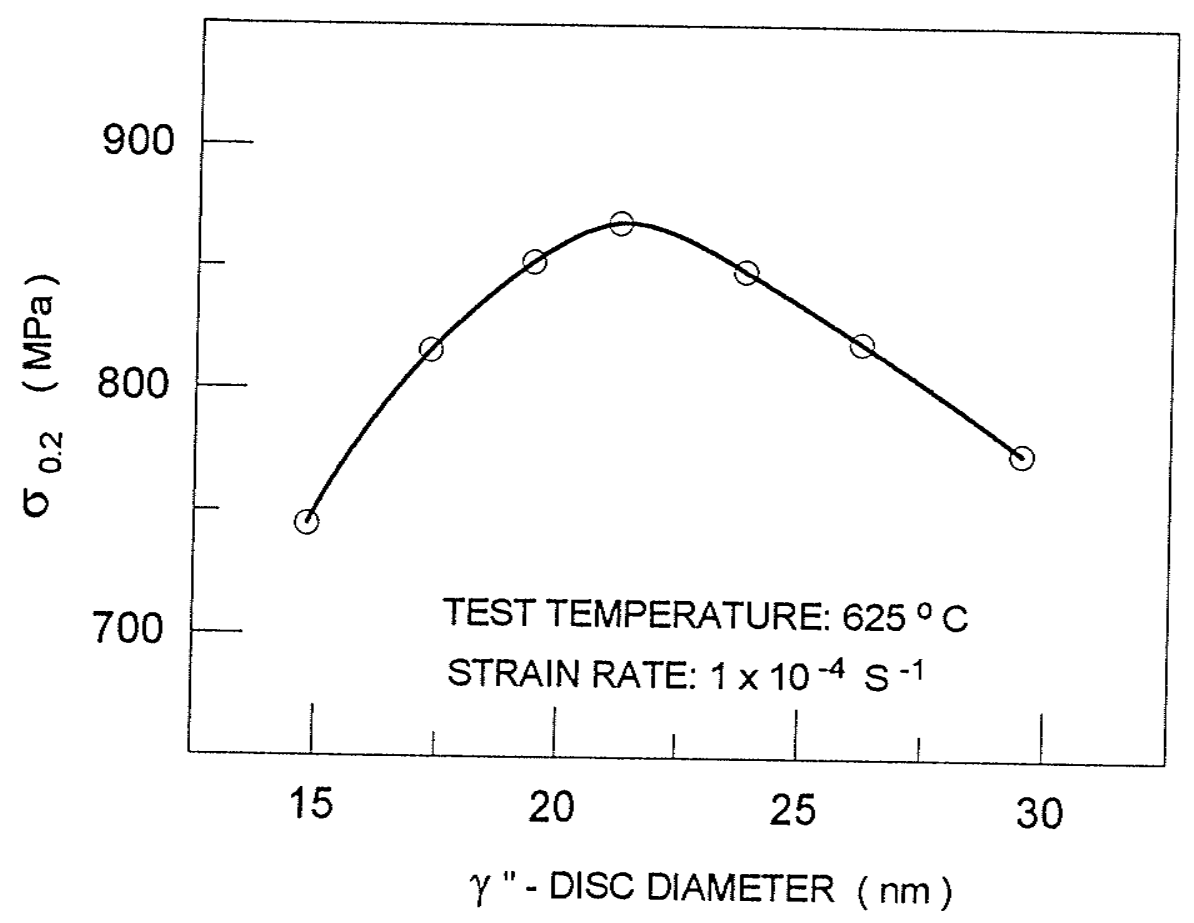

Fig. 5.13 Variation of yielding stress with $\gamma^{\prime \prime}$-disc diameter 
It should be also noted that, the creep rate of material B with a $\gamma^{\prime \prime}$-disc diameter less than $17.3 \mathrm{~nm}$ or bigger than $26.2 \mathrm{~nm}$ is also higher than that of material A which has a similar size of $\gamma^{\prime \prime}$. This probably is caused by a decrease in the strength of grain material, due to the formation of grain boundary precipitates. However, the increase in creep rate in material B due to this reason might be only minor. This can be seen by comparing the difference in creep rate in the region in which both materials show a same dependence of creep rate on $\gamma^{\prime \prime}$-size, with that in the region where creep rate is virtually independent of $\gamma^{\prime \prime}$-size

(2) Deformation from grain boundaries: In the previous discussion, it has been indicated that the actual stress applied to the grain interior of material B is less than the full amount of applied stress, which should give a creep rate much smaller than that of material $\mathrm{A}$, even if a reduced strength in the grain interior of material $\mathrm{B}$ due to the formation of grain boundary precipitates is considered. However, a much higher creep rate was always observed in material B. Therefore, the contribution to deformation from grain boundaries may have to be taken into consideration. According to Eq.5.34, the deformation at grain boundaries depends on two factors, (i) the strength of grain material and (2) the grain size. The thickness of grain boundary is assumed to be a function of grain size, therefore, it can be considered together with grain size.

Table 5.3 Variation in stress factor for grain boundaries with $d_{O}$

\begin{tabular}{cccc}
\hline$d_{o}$ & $\frac{1}{\sqrt{d} / \sqrt{d_{o}}+1}$ & $\frac{1}{\sqrt{d} / \sqrt{d_{o}}+1} \sigma_{a}$ & $\left(\frac{1}{\sqrt{d} / \sqrt{d_{o}}+1}\right)^{13}$ \\
\hline $0.9 \mu \mathrm{m}$ & 0.11 & $84.6 \mathrm{MPa}$ & $3.4 \times 10^{-13}$ \\
$0.1 \mu \mathrm{m}$ & 0.04 & $30.4 \mathrm{MPa}$ & $5.7 \times 10^{-19}$ \\
\hline
\end{tabular}


Effect of the strength of grain material: Similar to the analysis of stress acting in the grain interior, the actual stress acting at grain boundaries also depends on the value of $\mathrm{R}$. With an increase in grain material strength, the stress acting at grain boundaries should be smaller, which should contribute less to creep rate. This is opposite to the effect of grain interior strength on $\sigma_{a 0}$ '. However, due to $d>>d_{o}$, the stress factor $1 /(R \sqrt{d}+1)$ for $\sigma_{a b}$ 'is very small as compared to the stress factor for grain interior. This can be seen from the results of calculation presented in Table 5.3 in which the same common parameters were used as those used for calculations presented in Table 5.2. Even if the stress factor is magnified by $d / 2 t$ (Eq.5.34), the obtained stress is still much smaller than stress concentration, which is believed to be about 10-20 times the applied stress. Therefore, the local stress in grain boundary region is insignificantly influenced by the value of $R$. This means the grain boundaries contribute an amount of deformation which is irrespective of the strength of grain material ( this is true only in the situation where the total applied stress is less than the flow stress of a material).

Effect of grain size: The thickness of grain boundaries is assumed to be a function of grain size, which can be expressed by [211],

$$
t=\frac{1}{2 \alpha} \sqrt{d}
$$

Substituting Eq. 5.52 into Eq. 5.34 and accepting the fact that $R \sqrt{d}>>1$, Eq.5.34 can be re-written as:

$$
\sigma_{a b}{ }^{\prime}=\frac{\alpha \sigma_{a}}{R}
$$


which indicates that the contribution of grain boundary deformation to total creep strain is not influenced by grain size.

\section{(3) Dependence Of Creep Rate On Applied Stress: The previous} discussion simply indicates that the deformation of grain boundaries may contribute to the total creep strain. However, the amount of this contribution in the material used in this study is either influenced insignificantly by the strength of grain material, or is simply independent of the grain size. Therefore, the observed creep rate is suggested to be exclusively a function of the creep resistance of the grain material and the stress actually acting in the grain interior. The balance between these two factors results in the observations shown in Fig.4.10. When the effect of grain size is considered, the difference in the variation in creep rate with grain size, will be exclusively a result of the difference in the actual stress applied to grain interior, which is determined by Eq.5.33. It is found that when $d_{o}$ is assigned a value of about $0.37 \mu \mathrm{m}$, the creep rate obtained in the material B with different grain sizes can be represented by a single creep equation. Table 5.4 shows the applied stresses modified by the factor $1 /[(1 / R \sqrt{d})+1]$ : The creep rate is plotted against the modified applied $\sigma_{a o^{\prime}}$ in Fig. 5.14. It is seen that, the creep rate obtained at different stress levels in all the materials with different grain sizes is exclusively dependent on the actual applied stress $\sigma_{a o}$.

The critical grain size $d_{o}$ used in the calculations shown in Table 5.4 is a little smaller than the value experimentally determined ( refer to Eq. 5.51). Causes for this are suggested below:

(a) The value $\mathrm{k}$ is found to be a function of strain, as indicated by Eq. 5.49a). Under the creep conditions, the steady state creep stage normally starts before $0.2 \%$ strain. This means, the actual value of $k$ under creep conditions could be much smaller, which will result in a smaller value of $d_{o}$. 
Table 5.4 Modification of applied stress by the stress factor given in Eq. 5.33

\begin{tabular}{cccc}
\hline Grain Size $(\mu \mathrm{m})$ & $\sigma_{a}(\mathrm{MPa})$ & $\sigma_{a} /\left(\frac{\sqrt{d_{o}}}{\sqrt{d}}+1\right)(\mathrm{MPa})$ & $\dot{\varepsilon}_{s}\left(S^{-1}\right)$ \\
\hline 175 & 822.2 & 786.2 & $3.15 \times 10^{-8}$ \\
& 797 & 762.2 & $2.2 \times 10^{-8}$ \\
& 770 & 736.3 & $1.24 \times 10^{-8}$ \\
\hline 135 & 747.3 & 710.3 & $6.7 \times 10^{-9}$ \\
& 771.8 & 733.6 & $1.11 \times 10^{-8}$ \\
\hline 90 & 770.0 & 723.8 & $9.0 \times 10^{-9}$ \\
& 796.7 & 748.9 & $1.45 \times 10^{-8}$ \\
& 820.9 & 771.7 & $2.27 \times 10^{-8}$ \\
\hline \multirow{2}{*}{59} & 745 & 690.6 & $4.5 \times 10^{-9}$ \\
& 770.0 & 713.8 & $7.8 \times 10^{-9}$ \\
& 794.7 & 736.7 & $1.2 \times 10^{-8}$ \\
& 819.8 & 759.9 & $2.0 \times 10^{-8}$ \\
\hline
\end{tabular}

$* d_{o}=0.37 \mu \mathrm{m}$ 


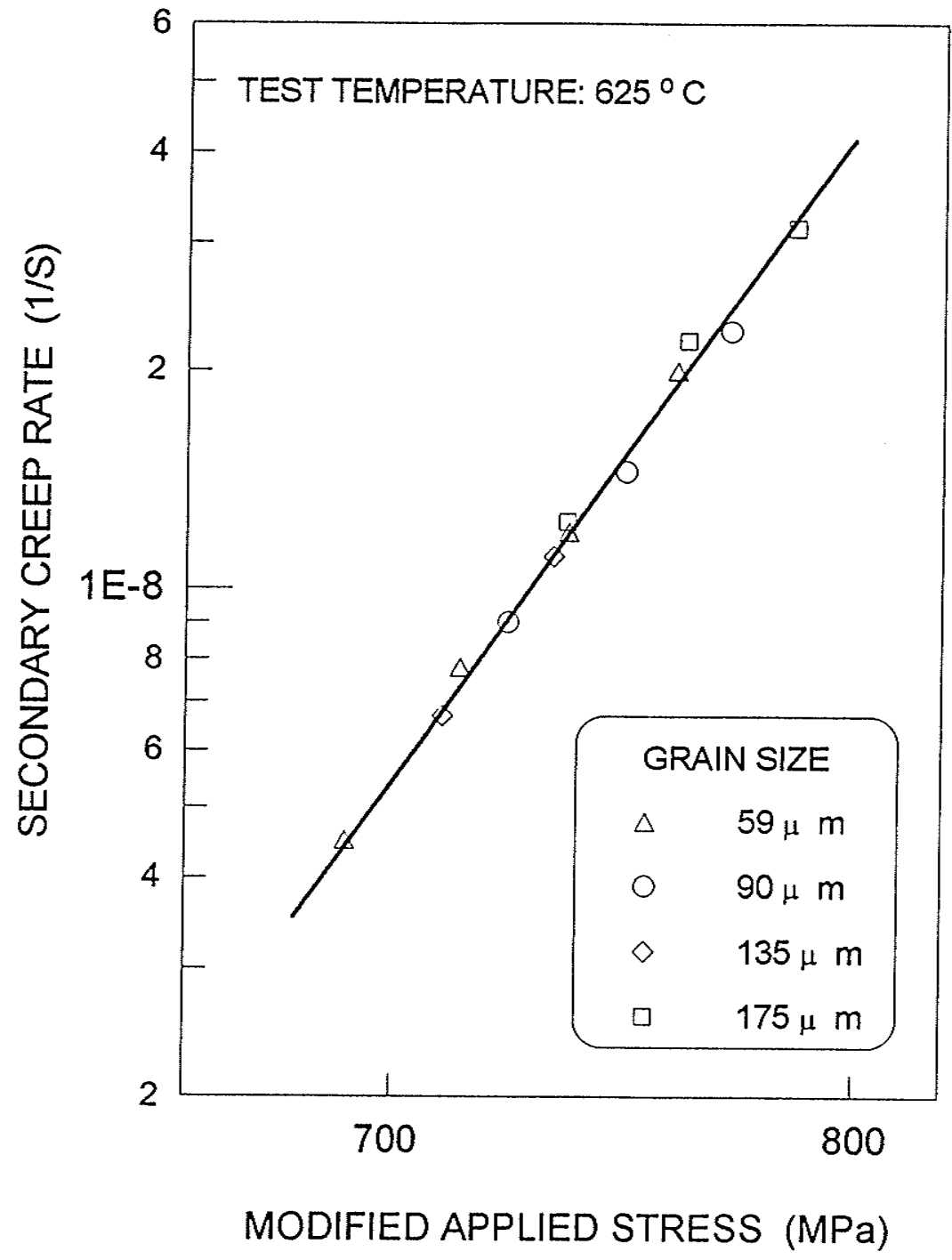

Fig. 5.14 Dependence of steady state creep rate on modified stress $\sigma$ ao', for material B with different grain size. 
(b) The creep rate is normally much smaller than the strain rates used in normal tensile testing. This slow rate will permit the hardened grain boundaries to undergo relaxation, which in turn, may reduce the degree of work-hardening. As a result, the critical yield stress of grain boundary material $\tau_{c}$, will be reduced. This will also reduce the value of $\mathrm{k}$, since it is found that it is proportional to $\tau_{c}^{1 / 2}$.

(4) Dependence Of Creep Rate On Grain Size: The change in creep rate with grain size under the same applied stress can be predicted from Eq. 5.33. As discussed earlier, the creep equation for material $\mathrm{B}$ can be written as:

$$
\dot{\varepsilon}=A\left(\frac{\sigma_{a o}{ }^{\prime}}{G}\right)^{13}
$$

That is,

$$
\dot{\varepsilon}=A\left(\frac{1}{1 / R \sqrt{d}+1}\right)^{13}\left(\frac{\sigma_{a}}{G}\right)^{13}
$$

The values of $[1 /(1 / R \sqrt{d}+1)]^{13}$ are calculated from Eqn. 5.55. These values are then plotted against the grain size as shown in Fig. 5.15. In this figure, the slope of the predicted curve is observed to be very close to the slope of the best fitting plot obtained from the experimental results

(5) Dependence Of Creep Rate On Creep Strain : In contrast to material A, the creep curve observed for material B is characterized by an extended steady state creep stages. These observations can also be related to the balance between a decreased creep rate due to an increase in the strength of grain material and the increased applied stress to the grain interior due to an increase in the value of $R$. The increase in the strength 


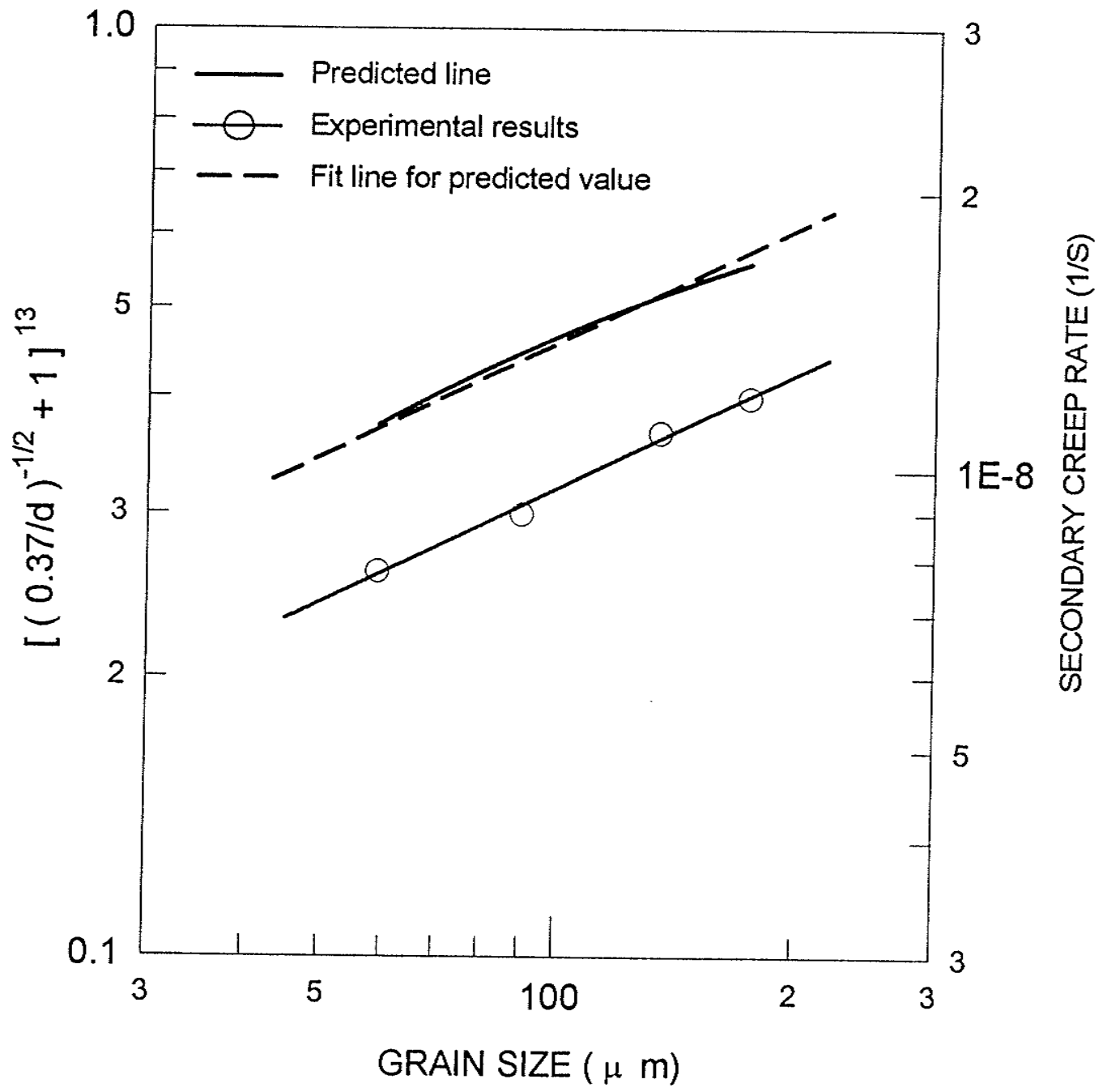

Fig. 5.15 Dependence of creep rate on grain size 
of grain material is due to an increase in work-hardening due to the deformation that occurred in the grain interior. Therefore, the steady state creep stage may start even when the maximum work-hardening of grain interior is not reached.

(6) Dependence Of Creep Rate On Density Of Grain Boundary Precipitates: A high density of grain boundary precipitates, will cause the formation of a continuous workhardened layer around the grain boundaries, which will prevent an uniform distribution of applied stress. Because of high local stress, grain boundaries will contribute a significant amount of deformation to total creep strain, which will be more than enough to compensate for the decrease in creep rate of grain interior due to the decreased applied stress in the grain interior. When the precipitate density is decreased, the material will behave more like the material with clean grain boundaries. This is because a) the precipitates may not form a continuous hardened layer in the region of grain boundaries, which will eliminate the heterogeneity in applied stress; b) the stress concentration can be relaxed more quickly and effectively, which will be able to contribute an extra amount of deformation to total creep strain.

\subsubsection{ON THE ORIGIN OF BACK STRESS}

By the consideration of the concept of hard and soft regions within a material, the origin of back stress can be also treated differently. In the material with clean grain boundaries, the stress acting on the grain material is equal to the applied stress, and the back stress is the applied stress at which the dislocations are just able to cut through the

precipitates in their glide planes. That is to say, the back stress is a function of the microstructure of the grain material.

In contrast to material $\mathrm{A}$, the back stress of material $\mathrm{B}$ with precipitates at grain boundaries could be influenced by two factors. That is, microstructure of the grain interior 
and microstructure of the grain boundaries. These two situations are considered separately next.

\section{THE ORIGIN OF THE BACK STRESS DUE TO THE MICROSTRUCTURE OF THE GRAIN INTERIOR}

Similar to the situation in material $\mathrm{A}$, if the back stress is considered to be the applied stress above which dislocations can cut through particles, then

$$
\sigma_{b o}=\sigma_{a o^{\prime}}=\frac{1}{\frac{1}{R \sqrt{d}}+1} \sigma_{a}
$$

Under these circumstances, the remaining applied stress will be the back stress for the material. That is:

$$
\sigma_{b}=\left(\frac{1}{R \sqrt{d}}+1\right) \sigma_{b o}
$$

Eq.5.57 indicates that, the back stress of material B will be always greater than that of material A, and the back stress will decrease with an increase in grain size. These two conclusions are obviously in contradiction to what has been observed in material B. Therefore, back stress of material B may have to be related to its microstructure at the grain boundaries.

\section{THE ORIGIN OF THE BACK STRESS DUE TO THE MICROSTRUCTURE OF THE GRAIN BOUNDARIES}

According to Nix and Ilshner( Fig. 5.10) $[212,215]$, the local stress is high at sub boundaries, and decreases to a negative value towards the center of the subgrains. The actual local stress at subboundaries is the sum of applied stress and internal stresses. The 
actual local stress in grain material, however, is the difference between the applied stress and local stress. Introducing this concept to material B, the internal stress at grain boundaries can be related to the concentrated stress around particles due to the tendency of grain boundaries to slide. The concentrated stress around particles on grain boundaries, as determined by Argon, Chen and Lau[210], was found to be a function of applied stress and distribution parameters of the precipitates. For a given grain boundary microstructure, the concentrated stress can be given by

$$
\sigma_{i b}=\beta \sigma_{a}
$$

where $\beta$ is a parameter dependent on morphology, distribution and volume fraction of precipitates.

Combining Eq. 5.34, 52 and 58, the total stress at grain boundary, $\sigma_{t b}$, can be given by,

$$
\sigma_{t b}=\sigma_{a b}{ }^{\prime}+\sigma_{i}=\frac{\sqrt{d}(\alpha+\beta R)+\beta}{R \sqrt{d}+1} \sigma_{a}
$$

Since $R \sqrt{d}>1$, Eq. 5.59 can be simplified to:

$$
\sigma_{t b}=\left[\frac{(\alpha+\beta R)}{R}+\frac{\beta}{R \sqrt{d}}\right] \sigma_{a}
$$

\section{(a) Dependence of back stress on grain size: Because of high stress at} grain boundaries, grain boundary deformation in terms of dislocation emission and absorption from and to grain boundaries may be likely, even when the applied stress is decreased to the level at which deformation within the grain interior is impossible. That is to say, material B could stop deforming only when the local stress at grain boundaries is 
decreased to the level below which the emission or absorption of dislocations can not occur. At that moment, the remaining applied stress will be the back stress of the material. Assuming that the critical stress required to initiate grain boundary deformation is $\sigma_{b b o}$, then

$$
\begin{aligned}
\sigma_{b b o} & =\sigma_{t b}=\left[\frac{(\alpha+\beta R)}{R}+\frac{\beta}{R \sqrt{d}}\right] \sigma_{b b}\left(=\sigma_{a}\right) \\
\text { or } \quad & \frac{1}{\sigma_{b b}}=\frac{1}{\sigma_{b b o}}\left[\frac{\alpha+\beta R}{R}+\frac{\beta}{R \sqrt{d}}\right]
\end{aligned}
$$

where $\sigma_{b b}$ is the back stress for material B.

Suppose that $\sigma_{b b o}$ is constant at the same applied stress and will not be influenced by grain size, then, Eq.5.62 indicates that the back stress will vary with $1 / \sqrt{d}$. In accordance with this, $1 / \sigma_{b}$ is plotted against $1 / \sqrt{d}$, and is seen to be a straight line in Fig. 5.16 .

(b) Effect of applied stress on back stress: Besides being dependent on the grain size, the back stress of material $B$ is also found to depend on the applied stress. This phenomenon may be related to the value of $\mathrm{R}$, as presented in Eq. 5.62, which can be rewritten as:

$$
\frac{1}{\sigma_{b b}}=\frac{1}{\sigma_{b b o}}\left[\beta+\frac{1}{R}\left(\alpha+\frac{\beta}{\sqrt{d}}\right)\right]
$$

With an increase in applied stress, the deformation at grain boundaries will be higher. According to Eq. 5.47, the value of $\mathrm{R}$ will increase accordingly. Therefore, a higher back stress can be expected ( refer to Eq. 5.63). 


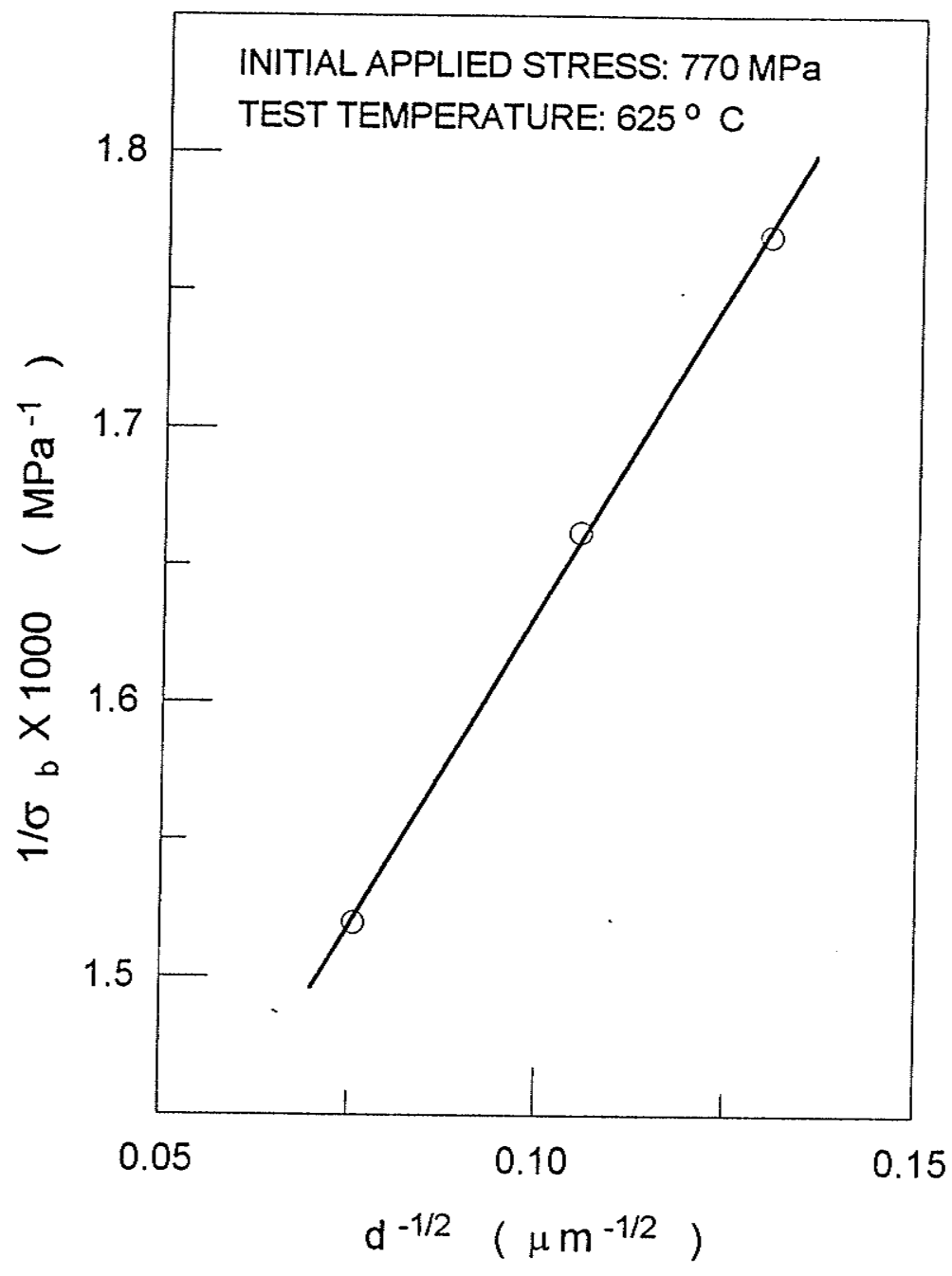

Fig. 5.16 Dependence of $1 / \sigma_{b}$ on $d^{-1 / 2}$ 
(iii) Dependence of back stress on the density of grain boundary particles: As shown in Fig. 4.25, the dependence of back stress on the density of grain boundary precipitates may have something to do with the value of $\beta$ given in Eq. 5.58. Argon, Chen and Lau[210] have found that $\beta$ varies inversely with the density of grain boundary precipitates. That is:

$$
\beta \propto c\left(\frac{1}{\rho}\right)
$$

where $\mathrm{c}$ is a constant and $\rho$ is the density of grain boundary precipitates. Eq. 5.64) indicates that with a decrease in $\rho$, the concentrated stress around precipitates will be higher.

It has been suggested that the concentrated stress around particles in all the material except the one with a solid solution treatment at $925^{\circ} \mathrm{C}$, can be relaxed very quickly ( Table 5.1). However, this suggestion may not be valid when the applied stress is reduced. As indicated in Eq. 5.11, the characteristic scaling dimension, $\Lambda$, increases with applied stress and decreases with an increase in creep rate. Because $\dot{\varepsilon}$ varies with applied stress much faster than the change in applied stress itself $\left(\dot{\varepsilon} \propto \sigma^{n}\right)$, the decrease in applied stress during the back stress measurement will cause a rapid decrease in the value of $\Lambda$. This should be able to produce a condition at which $\Lambda$ becomes smaller than the particle size. As a result, a layer of concentrated stress around grain boundary particles in these materials can be established, and their creep behaviour will also become similar to the material with a second solid solution treatment at $925^{\circ} \mathrm{C}$. Because the value of $\beta$ is inversely proportional to $\rho$, a decrease in density of precipitates at grain boundaries, according to Eq. 5.62, should cause a decrease in back stress

The above analysis may not be valid if the density of precipitates at grain boundaries is too low. This is because the isolated stress field around the widely separated 
particles can not form a continuous layer of stress field, and therefore, a heterogeneity in applied stress is not caused even if the reduced stress has caused a value of $\Lambda$ to be smaller than the particle size. The back stress obtained in this situation, then should be similar to that observed in the material with no precipitates at grain boundaries. 


\subsection{APPLICATION TO OTHER SITUATIONS-GRAIN SIZE DEPENDENCE OF CREEP RATE}

The literature review, present in chapter two, suggests that the steady state creep rate varies with grain size in two different ways: i). In the region of fine grain size, the creep rate decreases with an increase in grain size; ii). In the region of coarse grain size, creep rate increases with an increase in grain size. A satisfactory unified explanation for the two different types of dependence of creep rate on grain size is not available.

The mechanism proposed in section 5.3.1.2 can provide a new explanation for the effect of grain size on steady state creep rate. This mechanism considers the heterogeneity of applied stress distributed in grain interior and in the region of grain boundaries. This heterogeneity of applied stress is believed to be caused by grain size and the value of $R$. The latter reflects a balances between the stress acting in grain interior and in the region of grain boundaries.

Refer to the situation shown in Fig. 5.12, where the grain is considered to be a cubic box, outside of which is a hard shell and inside of which is a relatively soft pocket. To produce a deformation in the cubic grain, both the hard shell and the soft pocket have to deform compatibly. For example, when the hard region is driven by the stress $\sigma_{a b}$ ' to produce a deformation of $\Delta \varepsilon$, the soft region may have to deform nearly by the same amount before the "cubic box" can deform as a whole. That is to say, the force applied to the hard region is also supported by the soft region. The force applied to hard region is $F_{a b}{ }^{\prime}=(2 t) \sigma_{a b}{ }^{\prime}$, which is supported by the entire grain. The stress responsible for the deformation, then will be

$$
\sigma=\frac{F_{a b}^{\prime}}{d}=\frac{2 t}{d} \sigma_{a b}^{\prime}=\sigma_{a b}
$$


where $\sigma_{a b}$ is given in Eq. 5.25. Similarly, when the soft region is to deform $\Delta \varepsilon$, the force acting in this region may have to be supported by the hard region as well. The stress actually causing the deformation in this region will be $\sigma_{a o}$ (given in Eq. 5.24). instead of $\sigma_{a o}{ }^{\prime}$, although both of them are close to each other when $d>d_{o}$.

With the presence of both $\sigma_{a o}$ and $\sigma_{a b}$, the total deformation will consist of two parts. That is, deformation caused by $\sigma_{a o}$ and $\sigma_{a b}$, respectively. Particularly, when $d \leq d_{o}$, $\sigma_{a b}$ is much bigger than $\sigma_{a 0}$, deformation may be simply considered to be as a result of $\sigma_{a b}$. When $\mathrm{d} \geq \mathrm{do}, \sigma_{a o}$ becomes significant, deformation due to $\sigma_{a b}$ can be ignored. This analysis agrees with the discussion in Section 5.3.2, in which $\sigma_{a b} \ll \sigma_{a o}$, the extra deformation from grain boundaries is provided by the concentrated stress around particles.

By this consideration the effect of grain size on creep rate can be visualized. The creep rate has been often observed to decrease with increase in grain size up to a point and is then observed to increase with increase in grain size. That is, the creep rate equation can be written as:

$$
\begin{array}{ll}
\dot{\varepsilon}_{a b}=A_{a b}\left(\frac{\sigma_{a}}{\sqrt{d / d_{o}}+1}\right)^{n} & \text { at } d<d_{o} \\
\dot{\varepsilon}_{a o}=A_{a o}\left(\frac{\sigma_{a}}{\sqrt{d_{o} / d}+1}\right)^{n} & \text { at } d>d_{o}
\end{array}
$$

where $A_{a b}$ and $A_{a o}$ are constants and depend on the test temperature and microstructure of the material. Since $\sigma_{a o}$ and $\sigma_{a b}$ are two stresses that are responsible for the deformation of the material with the same microstructure, it may be assumed that,

$$
A_{a b}=A_{a o}=A
$$


The total creep rate can be written as

$$
\dot{\varepsilon}_{t o t}=A\left[\frac{d^{n / 2}+d_{o}^{n / 2}}{\left(d^{1 / 2}+d_{o}^{1 / 2}\right)^{n}}\right] \sigma_{a}^{n}
$$

The minimum creep rate can be obtained by setting

$$
\frac{\partial \varepsilon_{t o t}}{\partial d}=0
$$

By solving Eq. 5.70:

$$
d_{\min }=d_{0}
$$

where $d_{\min }$ is the grain size at which the creep rate is minimum. Eq. 5.71 indicates that the grain size corresponding to the minimum creep rate is equal to $d_{0}$ which is a variable defined in Eq. 5.23

Eqn 5.69 suggests that, i) For a material with the same microstructures (except grain size), the secondary creep rate will depend on the modified stress no matter which range the grain size belongs to; ii) Even for materials with different microstructures, the secondary creep rate will depend on the applied stress normalized by both grain size and the value of $R$. The latter variable should be able to represent the change in microstructure.

Under the same macro applied stress, the variation in total creep rate with grain size can be expressed as

$$
\dot{\varepsilon}_{t o t}=B \frac{d^{n / 2}+d_{o}^{n / 2}}{\left(d^{1 / 2}+d_{o}^{1 / 2}\right)^{n}}
$$


where

$$
B=A \sigma_{a}^{n}
$$

Assuming $\mathrm{B}=1$, the variation in $\dot{\varepsilon}_{t o t}$ with grain size at various values of $d_{o}$ and $n$ is shown in Figs. 5.17 and 5.18, respectively. The value of $n$ in Fig. 5.17 is chosen to be equal to 5 , the value of $d_{o}$ is chosen to be 1 and $100 \mu \mathrm{m}$. The following conclusions can be drawn from these two figures.

i). The slope in the curve of creep rate versus grain size is a function of grain size. In the region where $\mathrm{d}<<d_{o}$ or $\mathrm{d}>>d_{o}$, the dependence is rather weak. However, when the grain size is close to $d_{o}$, the dependence becomes stronger. In the region where $\mathrm{d}$ is very close to $d_{o}$, the dependence becomes weak again. These predictions are rather logical. For example, when $d>>d_{o}$, the effect of grain boundaries may be ignored and the creep rate will be more dependent of the microstructure of the grain material. When $d<<d_{o}$, the creep rate predicted in Eqn. 5.69 (which is not due to grain boundary sliding) will reach a limiting value as grain size is decreased. In this situation, the material can be considered to consist of grain boundaries and creep rate will depend on the deformation resistance provided by the grain boundaries. This is different from the mechanism of grain boundary sliding in which the creep rate will increase to an infinite value as grain size is decreased to an infinitesimal value.

ii). The dependence of creep rate on grain size is greatly influenced by the value of $d_{o}$. When $d_{o}$ is very small, a positive dependence of creep rate on grain size will be often observed when the grain size is in the range normally observed in real materials. Opposite to this, when $d_{o}$ is very large, a negative dependence of creep rate on grain size will be observed in normal materials. In addition, the value of $d_{o}$ is not randomly chosen, but depends on the microstructure of a material and the magnitude of applied stress which will affect the level to which grain boundaries are hardened. 


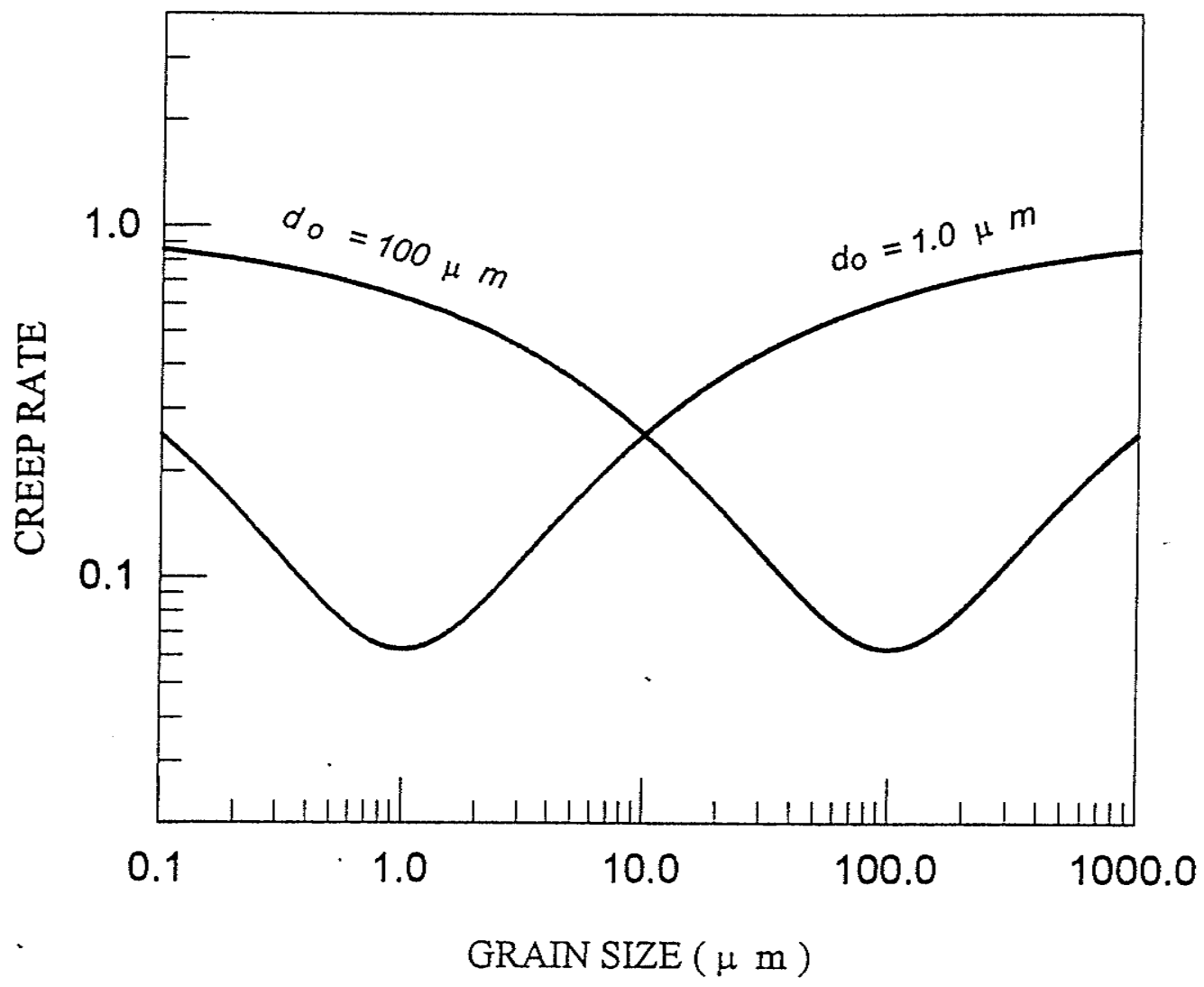

Fig. 5.17 Predicted variation in creep rate with grain size at two different levels of $d_{0}$. The stress exponent is assumed to be 5.0 


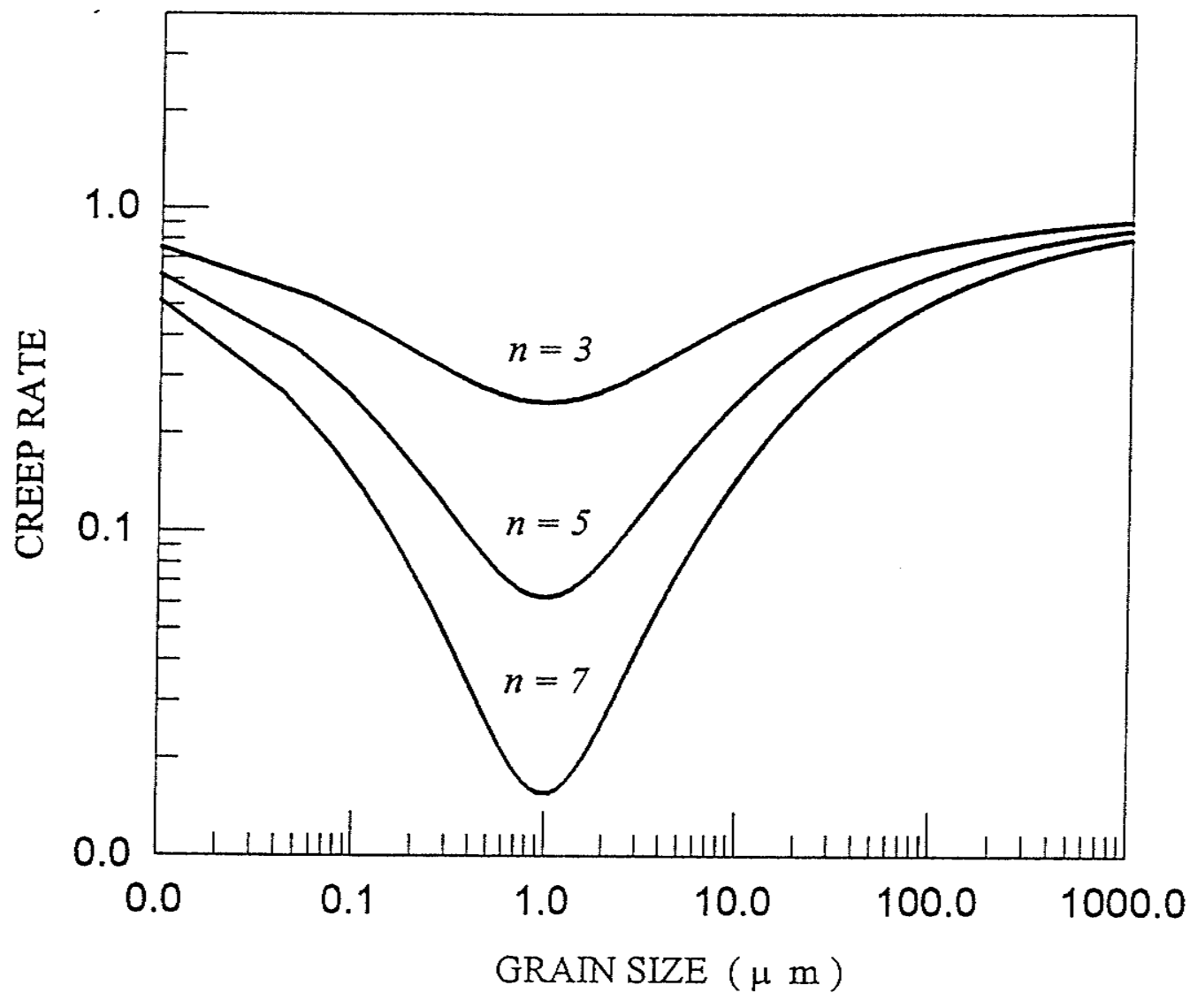

Fig. 5.18

The predicted variation in creep rate with grain size at different values of stress exponent. The value of $d_{o}$ is assumed to be $1 \mu \mathrm{m}$ 
iii). The slope in the curve of creep rate versus grain size is also a function of stress exponent. At a very low stress exponent, creep rate is influenced only to a minor extent by the grain size. With an increase in stress exponent, the slope of the creep rate-grain size curve increases (Fig. 5.18).

Finally, it should be noted that the above analysis is only suitable for a material in which incompatibility exists at the grain boundaries. For a material in which the incompatibility can be eased due to a diffusion process at grain boundaries, the creep rate may be found to be independent of grain size. This might be the case for the results reported in Fig. 2.19 in which the creep rate is observed to be insensitive to the change in grain size when $d$ is larger than about $100 \mu \mathrm{m}$ [158]. Fig. 2.19 also shows a negative dependence of creep rate on grain size when $d<d_{o}$. However, when the creep rate in this region is plotted against grain size on a double logarithm scales, it is found that the dependence of creep rate on grain size is rather weak ( the slope of the curve is less than F$0.5 \mid$ ). This weak dependence is not comparable with those results in which the slope is found to be as high as $|-2|$.

The following is an example which explains the dependence of creep rate on grain size by the mechanism proposed in this study.

Fig. 5.19, as reported by Garofalo[160], shows the dependence of creep rate on grain size of a $17 \mathrm{Cr}-14 \mathrm{Ni}$ austenitic stainless steel creep deformed at $704^{\circ} \mathrm{C}$. The results obtained by Garafalo have been analyzed by quite a few researchers $[161,162,164,217]$ ( refer to Chapter two ). The most recent analysis was provided by Fang and Murty[164]. They assumed that in the region where the steady state creep rate increases with a decrease in mean grain diameter $\mathrm{d}$, the following relationship holds

$$
\frac{\dot{\varepsilon}_{g b}}{D_{L}}=A_{G B} \frac{G b}{k T}\left(\frac{b}{d}\right)^{2}\left(\frac{\sigma}{G}\right)^{n-1}
$$




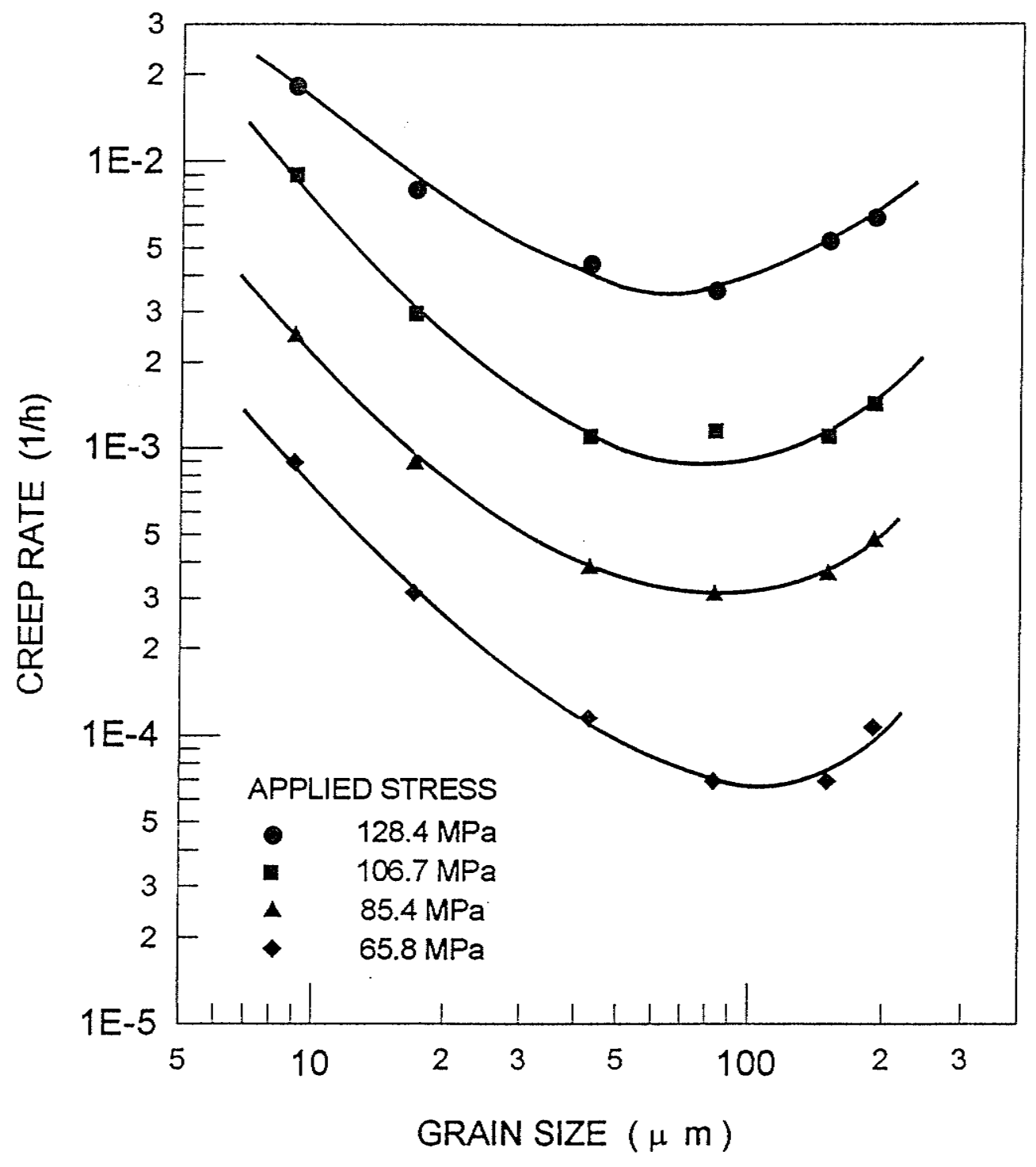

Fig. 5.19

Dependence of creep rate on grain size (Garafalo's work)[160] 
where, $A_{g b}$ is a constant and $\mathrm{n}=5.5$ is the stress exponent for steady-state creep rate in the region of mean grain diameter where creep rate does not depend on $d$. In this grain size region, creep rate is given by

$$
\frac{\dot{\varepsilon}_{g}}{D_{L}}=A_{G} \frac{G b}{k T}\left(\frac{\sigma}{G}\right)^{n}
$$

and the total creep rate will be given by:

$$
\dot{\varepsilon}_{\text {tot }}=\left\{A_{G}\left(\frac{\sigma}{G}\right)^{n}+A_{G B}\left(\frac{b}{d}\right)^{2}\left(\frac{\sigma}{G}\right)^{n-1}\right\} \frac{D_{L} G b}{k T}
$$

This equation has several fundamental shortcomings as indicated below:

i) It can predict only the negative dependence of creep rate with grain size. However, the creep rate indeed does increase with increase in grain size when grain size is greater than a certain critical value. Such positive dependence in the coarse grain size region has also been confirmed by many other investigators.

ii) The slope of the $\dot{\varepsilon}-d$ curve has been assumed to be 2 . This assumption is not reasonable. First of all, the actual slope in Fig. 5.19 is less than two and also varies with grain size. Secondly, Eq. 5.74 was developed based on the grain boundary sliding mechanism. The most convincing experimental results involving grain boundary sliding show that this slope is close to one[114].

iii) Eq. 5.74 assumes that the stress exponent in the region with fine grain size is $n-1$. This assumption contradicts the experimental results. As shown in Fig. 5.20, the actual stress exponent in Garafalo's work is observed to increase with the increase in grain size. 


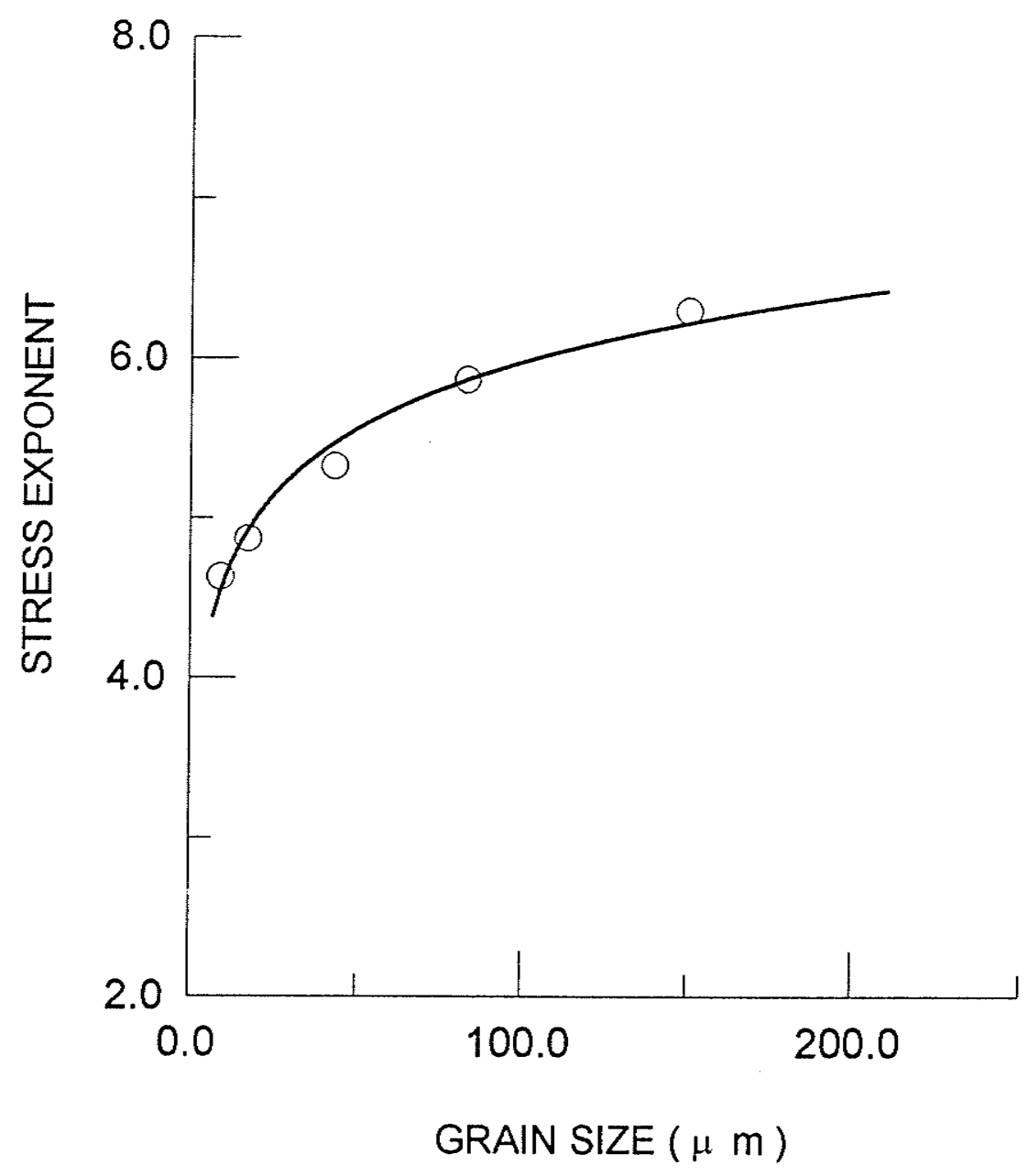

Fig. 5.20 Variation of stress exponent with grain size (Garafalo's work)

Using Eq. 5.69, the Garafalo's work can be re-analyzed. According to Eq. 5.47, $d_{o}$ ( or R ) should be also a function of applied stress. From the plots presented in Fig. 5.19 , the values of $d_{o}$ were determined and are listed in Table 5.5.

Table 5.5 Parameters used for calculations

\begin{tabular}{l|ccc}
\hline Applied stress (MPa) & 128.4 & 85.4 & 65.8 \\
\hline$d_{o}(\mu \mathrm{m})$ & 65 & 80 & 95 \\
B & 0.07759 & 0.0068 & 0.001649 \\
\hline
\end{tabular}


Together with the value of $d_{o}$, the value of $\mathrm{B}$ in Eq. 5.72 is also given in this table. Using the value of $d_{o}$ and $\mathrm{B}$, and assuming $n=5.5$ (which is the average value of stress exponent for the material), the creep equation at different levels of applied stress can be established, which is also depicted in Fig. 5.21 by the dotted line. The results obtained at 106.7 $\mathrm{MPa}$ are not presented in Fig. 5.21, since it does not provide a clear minimum value of creep rate. In Fig. 5.21, the experimental results obtained by Garafalo are also presented. As can be seen, the predicted equation fits the experimental results very well except at very small grain sizes where the experimentally obtained values are always higher than the predicted values. This deviation is quite reasonable because Eq. 5.69 does not predict the effect of grain size on creep rate on the basis of grain boundary sliding. As a matter of fact, grain boundary sliding does exist. However, it may only become significant when the grain size is very small. In addition, it is noticeable that the deviation between the experimentally obtained and the predicted value increases with decreasing applied stress. This observation is consistent with the theory of grain boundary sliding. As illustrated in Fig. 2.15 in detail, with a decrease in applied stress, the contribution of grain boundary sliding to the overall creep rate will be increased.

In Eq. 5.73, the value of B should depend on the applied stress with an exponent equal to about 5.5. To confirm this, the value of $B$ listed in Table 5.5, is plotted against $\sigma_{a}$. As shown in Fig. 5.22, a very good correlation is observed between the values of B and the applied stress. The slope of the straight line has been determined to be 5.6 by using curve fitting techniques, which is nearly the same as the average value of the stress exponent ( 5.5) determined from Garafalo's work.

The variation of $d_{O}$ with the applied stress is also plotted and is shown in Fig. 5.23. The curve yields the following equation:

$$
d_{o}=10^{6.9} \sigma_{a}^{-0.56}
$$




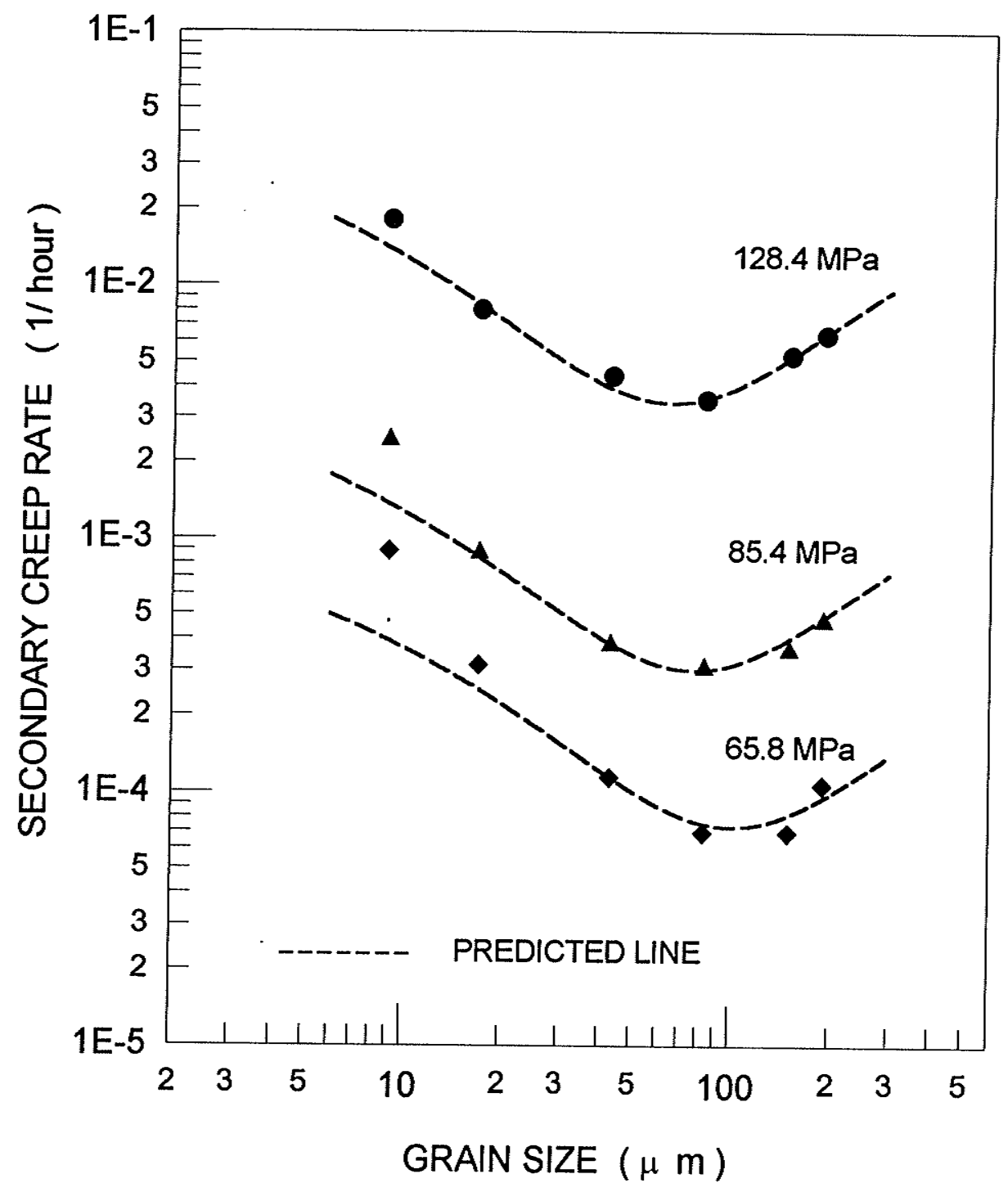

Fig. 5.21 Correlation between the predicted dependence of creep rate on grain size (dotted line) and experimental results. 


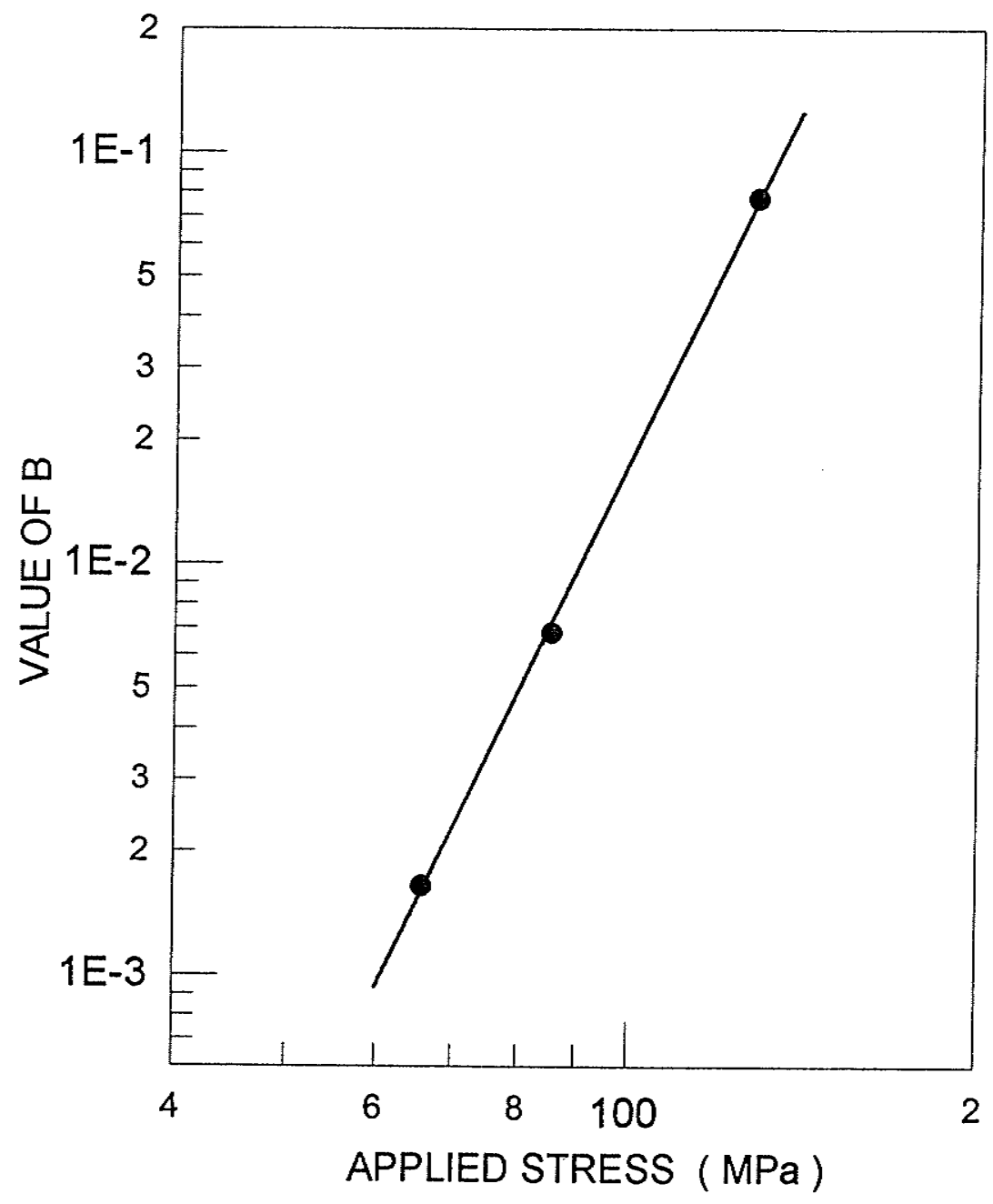

Fig. 5.22 Relationship between the applied stress and the value of $B$ 


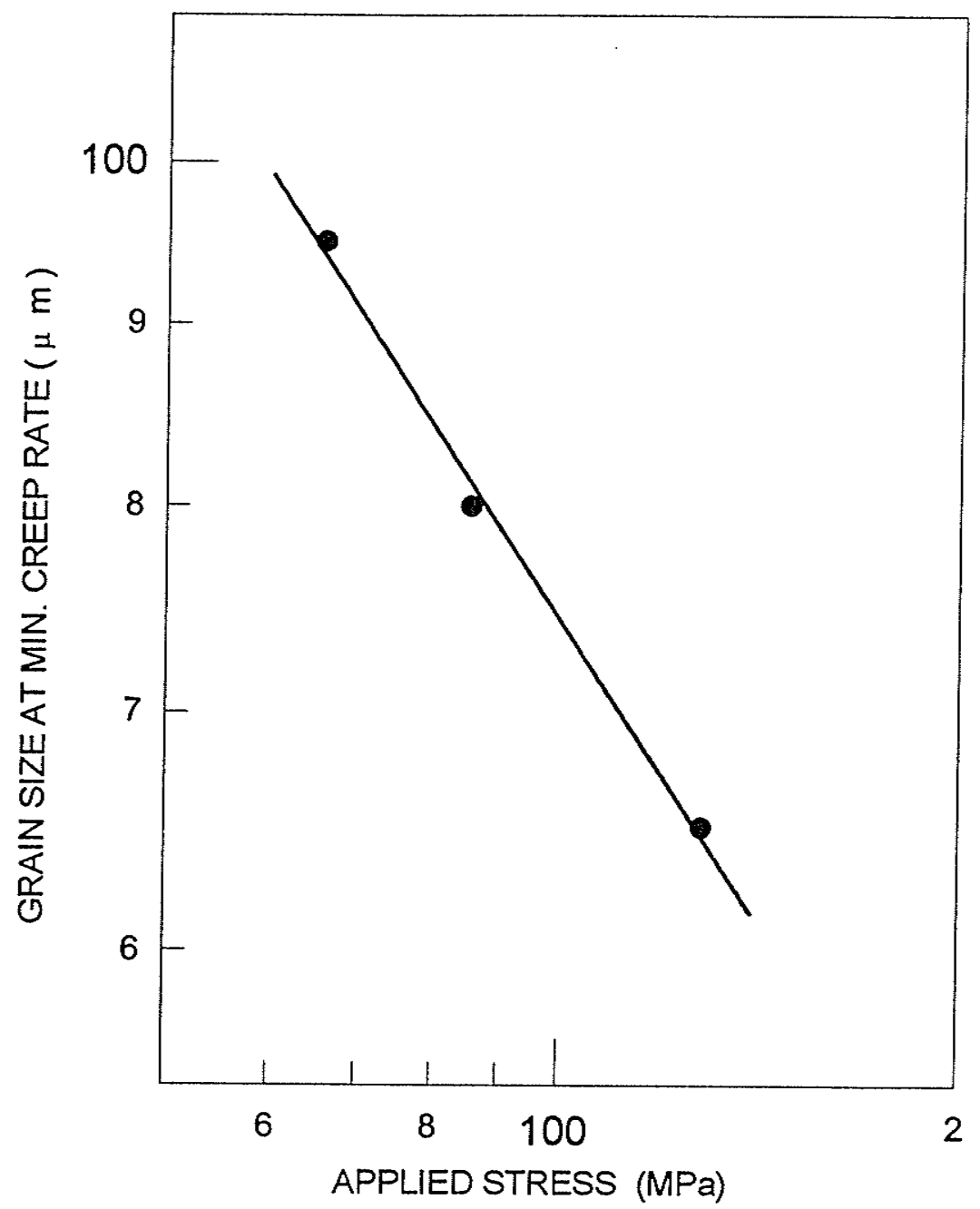

Fig. 5.23 Relation between the applied stress and the value of $d_{0}$ 
This dependence can be related to the definition of $d_{0}$. From Eqns. 5.23, 5.47 and 5.52, the following can be obtained:

$$
\frac{1}{\sqrt{d_{o}}}=2 \alpha \frac{E}{K} \varepsilon^{1 / 2}
$$

Accepting the fact that $\sigma_{a} \propto \varepsilon^{1 / 2}$, Eqn, 5.78 can be modified to

$$
\frac{1}{\sqrt{d_{o}}} \propto \sigma_{a} \text { or } d_{o} \propto \sigma_{a}^{-1 / 2}
$$

Eqn. 5.79 is consistent with Eqn. 5.77. This indicates that the critical grain size corresponding to the minimum creep rate should depend on the applied stress. 


\section{CONCLUSIONS}

Precipitation-strengthened nickel base Inconel 718 has been used in this study, The alloy was heat treated to produce two types of materials which are different only in the microstructures of their grain boundaries. The grain boundaries of one type were free of precipitates ( material $A$ ) and those of the second type were decorated with $\delta$-phase particles ( material B). Creep tests on specimens with these two microstructure were comparatively conducted at temperatures in the range of $600^{\circ} \mathrm{C}$ to $650^{\circ} \mathrm{C}$ and at constant applied stress in the range of $745 \mathrm{MPa}$ to $860 \mathrm{MPa}$. The following experimental results have been obtained:

1. For the materials with identical grain boundary precipitate conditions, the secondary creep rate was found to be independent of the size of strengthening precipitates within the grain interior. However, for the material with clean grain boundaries, the secondary creep rate was found to depend on the size of this precipitates within the grain interior, and the dependence was observed to be similar to those reported elsewhere.

2. The dependence of creep rate on applied stress was observed to be stronger in the material with precipitates at grain boundaries than the material with clean grain boundaries. The back stress was also found to be dependent on applied stress in the former material. However it was insensitive to applied stress in the latter material. When the effective stress was considered instead of applied stress, the effective stress exponent was determined to about 7 for material $\mathrm{B}$ and 3 for material $\mathrm{A}$.

3. The effective activation energy for creep of both the materials was similar to that of lattice diffusion. 
4. The creep behaviour of material B was found to depend on the grain boundary precipitate density, $\rho$, in the following ways:

(i) The secondary creep rate is observed to be insensitive to a change in $\rho$, when the value of $\rho$ is either very high or very low. The creep rate in the high $\rho$ value region is higher than that in the low $\rho$ region.

(ii) The same trend observed in the variation of creep rate, was also observed in the variation of back stress with $\rho$, except that the back stress is higher in the region with low values of $\rho$ than the region with high values of $\rho$.

(iii) The curve describing the variation in rupture time and total creep strain exhibited a V-shape with a minimum occurring at a value of $\rho$ of about $45 \%$. In addition, void-forming cracks on normal grain boundaries were observed only in the material with high grain boundary precipitate density, while wedge cracks at the triple points of grain boundaries were observed in the material with a low precipitate density at grain boundaries.

5. Both the creep rate and the back stress were found to increase with an increase in grain size in the material with precipitates at grain boundaries, however, they were insensitive to grain size in the material with clean grain boundaries.

The observed creep behaviour has been analyzed in the following two aspects:

1. Grain Boundary Sliding: It is proposed in this study that, the incubation time for grain boundary sliding can be determined by using the concept which was originally proposed by Argon et al to define the conditions under which creep voids might develop at triple points of grain boundaries or around precipitates at grain boundaries. The introduction of their concept has yielded the following conclusions: 
(i) By the consideration of the variation in the size of particies at grain boundaries, it is suggested that the stress relaxation process around particles can be changed from due to matter diffusion to power law dislocation relaxation. The latter process leads to a longer period for precipitates to pin the sliding grain boundaries, but can cause the formation of creep voids.

(ii) The length of time in which the grain boundary precipitates in present study can hold the grain boundaries from sliding increases with the increase in the density of grain boundary precipitates. This has caused an insignificant contribution of grain boundary sliding to total creep strain up to the tertiary stage in the material with a high grain boundary density of precipitates. This suggestion is supported by the observations that a) the creep rate in such a material increases with an increase in grain size, b) wedge cracks are only observed in the material with low precipitate density at grain boundaries.

\section{Partitioning of Applied Stress: It is suggested that the elastic and} plastic incompatibility around grain boundaries has caused heterogeneity distribution of applied stress. The incompatibility is described by a variable $R$, which considers the strengthening state of grain interior and of grain boundaries. The partitioning of the applied stress in both regions, then is quantitatively given by a factor which includes the effect of $R$ and the grain size. Based on these ideas, the following suggestions have been made:

(i) A heterogeneity in applied stress is suggested to occur in material B since the concentrated stress around grain boundary precipitate in the material has formed a workhardened layer along the grain boundaries. However, the incompatibility in material A can be eliminated by relaxation, which will permit a uniform distribution of applied stress.

(ii) It is found that the variable $\mathrm{R}$ increases with an increase in strengthening state of grain material. This will cause a larger share of applied stress in grain interior. Therefore, a decrease in creep rate due to the increase in the strength of grain interior is 
balanced by an increase in the creep rate due to an increase in the stress acting in the region. This mechanism explains why the creep rate is observed to be insensitive to the strength of grain interior in material B. Such a mechanism is also applicable during the entire course of creep of an individual sample.

(iii) The higher creep rate observed in material $B$ is a result of high internal stress around its grain boundaries. The high stress levels can provide extra deformation to total creep strain by dislocation emission and absorption to and from grain boundaries.

(iv) The back stress in material $B$ is the remaining applied stress at which the deformation at grain boundaries can not take place. However, in the material with clean grain boundaries, this back stress is the minimum applied stress required to initiate the deformation of grain interior. Due to these differences, the back stress in material B was observed to be a function of microstructure at grain boundaries and the stresses acting in the grain boundary region, while the back stress of material A was observed to be independent of grain size and applied stress.

(v) The above proposed mechanism has been also successfully applied for the explanation of the dependence of creep rate on grain size.

Finally it should be pointed out that the grain boundary dependent creep behaviour can be observed only when an incompatibility exists between the grain boundary and grain interior. This incompatibility always exists in the beginning of creep deformation. However, it may disappear towards the secondary creep stage. When this happens, the creep behaviour will depend on the microstructure of the grain interior. For creep deformation of the pure metals and Class II type alloys, where an incompatibility will occur at subboundaries, the mechanisms proposed in this study should be also applicable. This aspect needs to be studied in the future. 


\section{REFERENCES}

[1] J. Kennedy, Processes of Creep and Fatigue in Metals, Oliver and Boyd, Edinburgh 1962.

[2] F. Garofalo, Fundamentals of Creep and Creep-Rupture in Metals, McMillan, New York, 1965.

[3] M. F. Ashby and H. J. Frost, Constitutive Equations in Plasticity, A. S. Argon(Ed.), MIT, Cambridge, Mass, 1975, p.117.

[3a] A. Luhy, R. A. White and O.D. Sherby, Mater. Sci. Eng., 39(1979) 211

[4] F. R. N. Nabarro, in Report on Conference on strength of solids, Phys. Soc. London 1948, p.75.

[5] C. Herring, J. Appl. Phys. 21 (1950)437.

[6] R. L. Coble, J. Appl. Phys. 34(1963)1679.

[7] J. H. Weiner, in Mathematical Theory of Dislocations, T. Mura(Ed.), ASME, New York 1969, p.203.

[8] J. C. M. Li, in Dislocation Dynamics, A. R. Rozenfield, G. T. Hahn, A. L. Berment and R. J. Jaffee (Eds.), McGraw-Hill, New York 1968, p. 87.

[9] W. D. Nix, R. Gasca-Neri and J. P. Hirth, Philos. Mag. 23 (1973)1339.

[10] M. J. Turunen and V. K. Lindroos, Philos. Mag. 27 (1973) 81.

[11] J. Weertman, Trans ASM 61 (1968) 681.

[12] E. Orowan, J. West. Scotl. Iron Steel Inst. 54 (1946-47) 45.

[13] E. Orowan, in Symposium on Internal Stresses in Metals, Inst. Met., London 1948, p. 451.

[14] S. Takeuchi and A. S. Argon, J. Mater. Sci. 11(1976) 1542.

[15] R. W. Bailey, J. Inst. Met. 35(1926)27.

[16] J. Cadek, in "Creep in Metallic Materials", MSM48, Elsevier, 1988, pp73.

[17] J. Weertman, in Proc. J. E. Dorn Symp. Rate Processes in Plastic Deformation of materials, J. C. M. Li and A. K. Mukherjee (Eds.) ASM. Metals Park, OH 1975, p. 315.

[18] O. D. Sherby, Acta Metall. 10 (1962) 135.

[19] O. D. Sherby, and J. Weertman, Acta Metall, 27 (1979) 387.

[20] C. R. Barrett and O. D. Sherby, Trans. AIME 230 (1964 1322.

[21] S. L. Robinson and O. D. Sherby, Acta. Metall. 17 (1969) 109. 
[22] O. D. Sherby, and C. M. Young, in Proc. J. E. Dorn Symp. Rate Processes in Plastic Deformation of Materials, J. C. M. Li and A. K. Mukherjee (Eds.) ASM, Metals Park, OH, 1975, p. 497.

[23] O. D. Sherby, and M. T. Simnad, Trans. ASM 54 (1961) 227.

[24] O. D. Sherby, and P. M. Burke, Prog. Mater. Sci. 13 (1968) 325.

[25] J. P. Poirier, Plasticite a haute temperature des solides crystallines, Eyrolles, Paries 1976.

[26] G. Garofalo, Trans. AIME 227 (1963) 351.

[27] J. Weertman, J. Appl. Phys. 28 (1957) 362.

[28] C. R. Barrett and W. D. Nix Acta Metall. 13 (1965) 1247.

[29] S. Takeuchi and A. S. Argon, J. Mater. Sci. 11(1976) 1542.

[30] A. H. Clauer, B. A. Wilcox and J. P. Hirth, Acta Metall., 18(1970) 381.

[31] A. Orlova and J. Cadek, Philos Mag. 28 (1973) 891.

[32] J. Weertman, J. Appl. Phys. 26 (1955) 1213.

[33] A. K. Head, Philos Mag., 4 (1959) 295.

[34] J. M. C. Li, Discuss. Faraday Soc. 38 (1964) 138.

[35] L. I. Ivanov and V. A. Yanushkevich, Phys. Met. Metalloved, 17 (1964)102.

[36] W. Blum, Pyys. Stat. Solidi (b) 45 (1071) 561.

[37] A. S. Argon and S. Takeuchi, Acta Metall.29 (1981) 1877.

[38] J. Weertman, in Proc. Second Int. Conf. Creep and fracture in Engineering Materials and Structures, B. Wilshire and D. R. J. Owen (Eds.), Pineridge Press, Swansea, 1984. p. 1.

[39] A. Orlova, in Proc. 4th Nat. Seminar Creep and Creep Fracture, Valtice, Czecholovakia 1982, F. Dobes and J. Cadek (Eds.), Czech. Acad. Sci., Inst. Phys. Metall., Brno 1982, p. 200. (in Czech).

[40] D. Caillard and J. L. Martin, Acta Metall.30 (1982) 437.

[41] D. Caillard and J. L. Martin, Acta Metall.30 (1982) 791.

[42] D. Caillard and J. L. Martin, Acta Metall.31 (1983) 813.

[43] D. Mclean, Creep and Fracture of Metals at High Temperature, H. M. S. O., London (1976) 73.

[44] J. J. Jonas, C. M. Sellers and W. J. McG. Tegart, Metals Rev. 14, 1 (1969).

[45] M. M. Myshlyaev, Proc. 4th Int. Conf. Strength od Metals and alloys, Nancy France (1976), p. 1037.

[46] L. J. Cuddy, Metall. Trans. 395(1970)1.

[47] S. L. Robinson and O. D. Sherby, Acta Metall., 17, (1969) 109.

[48] C. M. Young, S. L. Robinson and O. D. Sherby, Acta Metall., 23 (1974) 633. 
[49] O. D. Sherby, R. H. Klundt and A. K. Miller, Metall. Trans., 8A, (1977) 843.

[50] I. Ferreira and R. G. Stang, Acta Metall., 31 (1983) 585.

[51] G. S. Makayama and J. C. Gibelling, Acta Metall. Mater., 38 (1990) 2023.

[52] F. Dobes, Scripta Metall. Matter. 27 (1992) 1435.

[53] K. Milicka, Acta Metall. Mater., Vol. 41, No.4, pp. 1163-1172, 1990.

[54] D. McLean, Trans., AIME 242 (1968) 1193.

[55] S. K. Mitra and D. McLean, Proc. R. Soc. London, A295 (1966) 288.

[56] H. E. Evans and K. R. Williams, Philos Mag., 28 (1973) 227.

[57] J. Gittus, Acta. Metall. 22 (1974) 789.

[58] R. Langeborg, Met. Sci. J, 3 (1969) 18.

[59] B. Burton, Philos. Mag. A45 (1982) 657.

[60] F. R. N. Nabarro, Philos. Mag. 16 (1967)231.

[61] N. F. Mott, in Creep and Fracture of Metals at High Temperatures, Proc. NPL Symp., HMSO London 1956, p. 21.

[62] L. Raymond and J. E. Dorn, Trans AIME, 230 (1964) 560.

[63] J. P. Hirth and J. Lothe, Theory of Dislocations, McGraw Hill, New York 1968.

[64] J. G. Harper and J. E. Dorn, Acta. Metall., 5 (1957) 654.

[65] P. Yavari, D. A. Miller and T. G. Langdon, Acta Metall., 30 (1982) 871.

[66] J. G. Harper, L. A. Shepard and J. E. Dorn, Acta Metall., 6 (19578) 509.

[67] T. G. Langdon and P. Yavari, Acta Metall., 30 (1982) 881.

[68] F. A. Mohamed and T. J. Ginter, Acta. Metall. 30(1982) 1869.

[69] C. R. Barrett, E. C. Mufhleisen and W. D. Nix, Mater. Sci. Eng. 10 (1972) 33.

[70] A. Mohamed, K. L. Murty and J. W. Morris, in Proc. J. E. Dorn Symp. Rate Processes in Plastic Deformation of Materials: J. M. C. Li and A. K. Mukherjee (Eds), ASM, Metals Park. OH 1975, p. 459.

[71] J. Friedel, dislocations, Pergamon Press, Oxford 1964.

[72] J. Cadek and J. Fiala, Acta Tech. CSAV, 33 (1988) 1.

[73] G. Malakondaiah and P. Rama Rao, Mater. Sci. Eng. 52 (1982) 207.

[74] J. Fiala, J. Novotny and J. Cadek, Mater. Sci. Eng. 60 (1983) 195.

[75] J. Novotny, J. Fiala and J. Cadek, Acta Metall. 33 (1985) 905.

[76] J. Novotny, J. Fiala and J. Cadek, Acta Metall. 31 (1983) 1697.

[77] J. Novotny, J. Fiala and J. Cadek, Scr Metall. 19 (1985) 867.

[78] S. Takeuchi and A. S. Argon, Acta Metall. 24 (1976) 883.

[79] J. Weertman, J. Appl. Phys 28 (1057) 1185.

[80] F. A. Mohamed and T. G. Langdon, Acta Metall. 22(1974) 779. 
[81] H.Laks, C. D. Wiseman, O. D. Sherby and J. E. Dorn, J. Appl. Mech. 24 (1957) 207.

[82] J. Weertman, Trans. AIME 218 (1960) 207

[83] K. J. Murty, Scr. Metall. 7 (1973) 899.

[84] K. Kucharova, I. Saxl and J. Cadek, Acta Metall. 22 (1974) 465.

[85] H. Oikawa, K. Sugawara and S. Karashima, Scr. Metall. 10 (1976) 885.

[86] F. A. Mohamed, Mater. Sci. Eng. 38 (1979) 73.

[87] S. S. Vagarali and T. G.Langdon, Acta Metall. 30 (1982) 1157.

[88] P. Yavari and T. G. Langdon, Acta Metall. 30 (1982) 2181.

[89] H. Oikawa, K. Honda and S. Ito, Mater. Sci. Eng. 64(1984) 237.

[90] L. M. Brown and R. K. Ham, in Strengthening Methods in Crystals, ed. by A. Kelly and R. B. Nicholson, Elsevier, Amsterdam (1971).

[91] M. Mclean, Acta Metall. Vol. 33, No. 4, pp 545 (1985).

[92] B. Reppich, Acta Metall. 30 (1982) 87.

[93] E. Orowan, Discussion in the Symposium on Internal Stresses in Metals and alloys, p.451 (Inst. Metals, London)

[94] G. S. Ansell and J. Weertman, Trans AIME 215 (1959) 838.

[95] W. Wickers and P. Greenfield, J. Nucl. Mater. 28(1968) 73.

[96] R. Lagneborg, J. Mater. Sci. 3 (1968) 586.

[97] J. D. Parker and B. Wilshire, Met. Sci. 12(1978) 453.

[98] K. R. Williams and B. Wilshire, Met. Sci. J. 7 (1973) 176.

[99] J. D. Parker and B. Wilshire, Met. Sci. J. 9(1975)248.

[100] H. Burt, J. P. Dennison and B. Wilshire, Met. Sci. 13 (1979) 285.

[101] I. R. McLauchlin, Met. Sci. 8 (1974) 247.

[102] W. J. Evans and G. F. Harrrison, Mat. Sci. 10(1976) 307.

[103] W. J. Evans and G. F. Harrrison, Mat. Sci. 13(1979) 346.

[104] B. D. Clay, Nucl. Energy 17 (1978) 115.

[105] R. S. W. Shewfelt and L. M. Brown, Philos Mag. 35 (1977) 945.

[106] R. Langeborg, Scr. Metall. 7 (1973) 605.

[107] R. W. Lund and W. d. Nix, acta Metall. 24 (1976) 469.

[108] G. M. Pharr and W. D. Nix, Scr. Metall. 10 (1976) 1007.

[109] L. M. Brown, in Proc. 3rd Riso Int. Symp. Metallurgy and Materials Science, Riso 1982.

[110] J. H. Hausset and W. D. Nix, Acta Metall. 25 (1977) 1491

[111] R. A. Stevens and P. E. J. Flewitt, Mater. Sci. Eng. 37 (1979) 237.

[112] H. E. Evans and G. Knowles, Met. Sci. 14 (1980) 262. 
[113] E. Arzt and M. F. Ashby, Scr. Metall. 16 (1982) 1285.

[114] T. G. Langdon, Mater. Sci. Eng., A166 (1993) 67.

[115] W. R. Cannon. Philos. Mag., 25 (1972) 1489.

[116] W.A. Rachinger, J. Inst. Met., 81 (1952 1953) 33.

[117] I. M. Lifshitz. Sov. Phys. Jetp, 17 (1981) 14.

[118] T. G. Langdon, Met. Forum, 4(1981)14.

[119] R. Raj and M.F. Ashby, Metall. Trans., Vol. 2, 1971, PP. 1113 1127.

[120] M. F. Ashby, R. Raj and R. C. Gifkins, Scripta Metallurgica, Vol. 4, (1970) 737.

[121] M. F. Ashby, Surface Science. Vol. 31,(1972) 498.

[122] R. S. Gates, Acta Metall., Vol. 21, (1973) 855.

[123] R. C. Pond, D. A. Smith and P. W. Southerden, in Proc. 4th International Conference on the Strength of Metals and Alloys,Nancy, France, 1976, Vol.1, 378.

[124] T. G. Langdon, Philos, Mag. Vol. 22,(1970) 689.

[125] A. S. Argon, in " Recent Advances in Creep and Fracture of Engineering Materials and Structures", B. Wilshire and D. R. Owen, eds., Prineridge Press, Swansea, 1982, pp. 1

[126] T. G. Langdon and R. B. Vastȧva, in Mechanical Testing For Deformation Model Development. (Rohde /Swearengen, Eds. ) (1980) 435.

[127] R. C. Gifkins, J. of the Australian Institute of Metals, Vol. 18, (1973) 137.

[128] F. W. Crossman and M. F. Ashby, Acta Metall., Vol.23, (1975) 425.

[129] M. V. Speight, Acta Metall. Vol. 24 (1976) 725

[130] R. C. Gifkins, Metall. Trans. A, Vol. 8A (1977).

[131] I-W. Chen and A. S. Argon, Acta Metall, Vol. 27, (1979) 749.

[132] A. Ball and M. M. Hutchison, Metal Science Journal, Vol. 3, (1969) 1.

[133] R. C. Gifkins, Metall. Trans. A. Vol. 7A (1976) 1225.

[134] M. Ronay and C. F. Aliotta, Philos. Mag. A, Vol.42 (1980) 161.

[135] P. R. Howell and G. L. Dunlop, in Proc. 1st Int. Conf. Creep and Fracture of Engineering Materials and Structures, B. Wilshire and D. R. J. Owen (Eds.), Pineridge Press, Swansea 1981, p. 127.

[136] R. C. Gifkins, J. Aust. Inst. Met. 18 (1973) 137.

[137] H. Gleiter, Acta Metall. 27(1979) 187.

[138] A. Ball and M. M. Hutchison, Met. Sci. J. 3 (1969) 1

[139] F. Ghahremani, Int. J. Solids Struct. 16 (1980) 847.

[141] J. H. Hensler and R. C. Gifkins, J. Inst. Metals, 92 (1963-1964) 340

[142] R. W. Evans and B. Wilshire, in Creep of Metals and Alloys, The Institute of Metals, 1985, p. 298. 
[143] V. Sklenicka, M. Pahutova, and J. Cadek, in The Microstructure and Design of Alloys: Proc. of the 3rd Int. Conf. on the Strength of Metals and Alloys, The Institute of Metals and The Iron and Steel Institute, London, 1973, Vol. 1, pp. $207-$ 211.

[144] I. Saxl, V. Sklenicka, and J. Cadek, Philos. Mag. Vol. 31, 1975, p. 233.

[145] T. G. Langdon, in The Microstructure and Design of Alloys: Proc. of the 3rd Int. Conf. on the Strength of Metals and Alloys, The Institute of Metals and The Iron and Steel Institute, London, 1973, Vol. 1, pp.222-226.

[146] V. M. Rozenberg, Fizika Metallov i Metallovedenie, Vol. 15, 1963, p. 397.

[147] C. A. P. Horton, in Grain Boundaries, The Institution of Metallurgists, London, 1976, p. E1.

[148] V. M. Rozenberg I. A. Epshtein, Fizika Metallov i Metallovedenie, Vol. 9, 1960, p. 124.

[149] I. Saxl, V. Sklenicka, and J. Cadek, Mater. Sci. Eng. Vol. 21 (1975) p. 49.

[150] V. Sklenicka, I. Saxl, J. Popule, and J. Cadek, Physica Status Solodi (a) Vol. 29 (1975) p. 315.

[151] K. Ciha, K. Milicka and J. Cadek, Kovove Materialy, Vol. 6 (1968) p. 313.

[152] R. S. Gates, Mater. Sci. Eng. Vol 27 (1977) p. 127.

[153] R. C. Gifkins, J. Austra. Inst. Met. Vol. 8 (1963) p. 148.

[154] R. S. Gates and C. A. P. Horton, Mater. Sci. Eng. Vol. 27 (1977) p. 105.

[155] T. G. Langdon, in Rate Processes in Plastic Deformation of Materials, J. C. M. Li and A. K. Mukherjee, Eds. American Society for Metals, Metal Park, OH, 1975,p. 410.

[156] T. G. Langdon, J. the Americam Ceramic Society, Vol. 58 (1975) p. 92.

[157] T. G. Langdon, Acta. Metall. Mater. Vol. 42 No. 7 (1994) 2437.

[158] O. D. Sherby and P. M. Burke, Prog. Mater. Sci. (B) (1967) 325.

[159] J. S. Zhang, P. E. Li, W. X. Chen and J. Z. Jin, Scripta Metall., 23(1989)547.

[160] F. Garofalo, Fundamentals of Creep and Creep Rupture in Metals, MacMillan, New York, 1965.

[161] H. E. Evans, Scr. Metall. 2(1968) 157.

[162] B. Burton, Scr. Metall. 3(1969) 247.

[163] O. A. Ruano, A. K. Miller and O. D. Sherby, Mater. Sci. Eng. 51(1981) 9.

[164] T-T Fang and K. L. Murty, Mater. Sci. eng. 61 (1983) L7.

[165] R. C. Gifkins, J. Aust. Inst. Met. 18 (1973) 137.

[166] R. Lagneborg, J. Iron Steel Inst. 207 (1969) 1503.

[167] T. G. Langdon, Scr. Metall. 4 (1970) 693. 
[168] S. L. Mannan and P. Rodriguez, Metal Sci. Vol. 17, Feb. (1983) 63.

[169] C. R. Barrett, J. L. Lytton and O. D. Sherby, Trans ATME 239 (1967) 170.

[170] D. McLean, in Proc. 4th Int. Conf. on Strength of Metals and Alloys, Nancy, France (1976) 958.

[171] R. W. Armstrong, in Dislocation Dynamics, ed. A. R. Rosenfield, G. T. Halm, A. L. Bement, and R. Z. Jaffee, 293, 1968.

[172] W. D. Bradley, J. S. August and O. K. Matlock, Mater. Sci. 11 (1977) 168.

[173] C. K. L. Davis, P. W. Davies and B. Wilshire, Philos Mag. 12 (1965) 827.

[174] A. Lasalmonie, J. L. Strudel, J. Mater. Sci. 21 (1986) 1837.

[175] F. T. Furillo, J. M. Pavidson and J. K. Tien, L. A. Jackman, Mater. Sci. Eng. B9 (1979) 267.

[176] J. Zhang, W. Chen, Z. Cao, Acta. Metall. Sincica, 2(5), (1989) 368.

[177] J. Zhang, W. Chen, Z. Cao, Acta and R. Tanaka, J. Iron \& Steel Inst. Jpn., $75(1989) 545$.

[178] K. Maruyama, Y. Watanabe and H. O. Kawa, Acta Metall. (34) 12 (1986) 2343.

[179] J. W. Brooks and P. J. Bridges, Superalloys 1988, ed. by S. Reichaman, D. N. Duhl, G. Maurer, S. Antolovich and C. Lund, The Metall. Soc. 1988, p. 33.

[180] A. K. Koul, P. Au, N. Bellinger, R. Thamburaj, et al, ibid p. 3.

[181] J. P. Collier, A. O. Selius and J. K. Tien, ibid, p. 43.

[182] E. Campo and C. Turco, Metall. Sci. Tech. 3(1), (1985) 17.

[182a]Y. Han, M. C. Chatervedi and J. R. Cahoon, Scripta Metall., 22(1988) 255

[183] D. R. Muzyka and G. N. Maniar, Source Book on Materials for Elevated Temperature Applications, ed. by E. F. Bradley, American Society for Metals, 1979 , p. 260.

[184] J. F. Radavich, J. of Metals, July (1988) 42.

[185] M. C. Chaturvedi and Y-F Han, Met. Sci. 17, March (1983) 145.

[186] E. A. Lorie, J. of Metals, July (1988) 36.

[187] J. P. Collier, S. H. Wong, J. C. Phillips, and J. K. Tien, Metall. Trans. 19A, July(1988) 1657.

[188] M. Sundararaman, P. Mukhopadhyay and S. Banerjee, Metall. Trans. (19A) March (1988) 1657.

[189] Y. C. Fayman, Mater. Sci. Eng. 92 (1987) 159.

[190] A. Orader-Basile and J. F. Radavich, in E. A. Loria (ed.), Proc. Int. Symp. on the Metallurgy and Applications of Superalloys 718, 625 and Various Derivatives, Pittsburgh, PA, June 23-26, 1991, pp.326.

[191] P. W. Davies, G. Nelines, K. B. Williams and B. Wilshire, J. Met. Sci., 7(1973)87. 
[192] J. D. Parker and B. Wilshire, J. Met. Sci., 12(1978)453.

[193] D. Sidey and B. Wilshire, J. Met. Sci., 3(1969)56.

[194] K. R. Williams and B. Wilshire, J. Met. Sci., 17(1983)145.

[195] J. C. Gibeling and W. D. Nix, Mater. Sci. Eng., 45(1980)123.

[196] J. F. Barker, Discussion of: Eiselstein, H. L., in Advances in the Technology of Stainless Steels and Related Alloys, STP 369, ASTM, Philadelphia, Pa., 1965, 78.

[197] P. S. Kotval, Trans. TMS_AIME, 242(1968)1764.

[198] Y-F. Han, P. Deb and M. C. Chaturvedi, Met. Sci., 16(1982)555.

[199] Y-F. Han and M. C. Chaturvedi, Mater. Sci. Eng., 89(1987)25.

[200] M. C. Chaturvedi and Y. Han, Mater. Sci. Eng., 89(1987)L7.

[201] P. L. Threadgill and B. Wilshire, Met. Sci., 8(1974)117.

[202] Y. Han and M. C. Chaturvedi, Mater. Sci. Eng., 85(1987)59.

[203] J. P. Dennison, R. J. Llewellyn and B. Wilshire, J. Inst. Metal., 95(1976)115.

[204] J. W. Martin: " Micromechanisms in Particle-hardened Alloys", Cambridge Univ. Press, 1980.

[205] R. W. Evans and B. Wilshire in " Creep of Metals and Alloys", The Institute of Metals, 1985, pp.104.

[206] H. Gleiter and B. Chalmers. Prog. Mater. Sci., 16(1972)179.

[207] J. Cadek: Creep in Metallic Materials", Elsevier, 1988, pp.252.

[208] Y. Ishida, A. W. Mullendore and N. J. Grant, Trans. AIME, 230(1964)1454.

[210] A. S. Argon, I-w. Chen and C-W Lau, in " Creep-Fatigue-Environment Interactions, ( R. M. Delloux and N. S. Stoloff, eds.) Conf. Proc. TMS-AIME, 1980, pp 46.

[211] M. A. Meyers and E. Ashworth, Philos. Mag. A., 46(1982)737

[212] W. D. Nix and B. Ilschner, in Proc. 5th Int. Conf. Strength of metals and Alloys, ICSMA5, P. Haasen, V. Gerold and G. Kostorz (Eds.), Pergamon Press, Oxford, 1979, Vol.3, p1503.

[213] M. A. Morris and J. L. Martin, Acta Metall., 32(1984)549.

[214] M. A. Morris and J. L. Martin, Acta Metall., 32(1984)1609.

[215] J. C. Gibeling and W. D. Nix, Acta Metall., 28(1980)1743.

[216] M. A. Meyers and K. K. Chawla, in "Mechanical Metallurgy", Prentice-Hall, Inc., New Jersey, 1984, pp.373.

[217] D. K. Matlock and W. D. Nix, Metall. Trans., 5(1974)961. 